\title{
Diagnostic value of brochoalveolar lavage in infectious disorders
}

Citation for published version (APA):

Linssen, C. F. M. (2007). Diagnostic value of brochoalveolar lavage in infectious disorders. [Doctoral Thesis, Maastricht University]. Datawyse / Universitaire Pers Maastricht. https://doi.org/10.26481/dis.20071122cl

Document status and date:

Published: 01/01/2007

DOI:

$10.26481 /$ dis.20071122cl

Document Version:

Publisher's PDF, also known as Version of record

\section{Please check the document version of this publication:}

- A submitted manuscript is the version of the article upon submission and before peer-review. There can be important differences between the submitted version and the official published version of record.

People interested in the research are advised to contact the author for the final version of the publication, or visit the DOI to the publisher's website.

- The final author version and the galley proof are versions of the publication after peer review.

- The final published version features the final layout of the paper including the volume, issue and page numbers.

Link to publication

\footnotetext{
General rights rights.

- You may freely distribute the URL identifying the publication in the public portal. please follow below link for the End User Agreement:

www.umlib.nl/taverne-license

Take down policy

If you believe that this document breaches copyright please contact us at:

repository@maastrichtuniversity.nl

providing details and we will investigate your claim.
}

Copyright and moral rights for the publications made accessible in the public portal are retained by the authors and/or other copyright owners and it is a condition of accessing publications that users recognise and abide by the legal requirements associated with these

- Users may download and print one copy of any publication from the public portal for the purpose of private study or research.

- You may not further distribute the material or use it for any profit-making activity or commercial gain

If the publication is distributed under the terms of Article $25 \mathrm{fa}$ of the Dutch Copyright Act, indicated by the "Taverne" license above, 
Diagnostic value of bronchoalveolar lavage in infectious disorders 
(c) Catharina Linssen, Maastricht 2007

ISBN: $978-90-5278-664-3$

Cover design: R.J.E. Zeelen

Layout: Tiny Wouters

Production: Datawyse | Universitaire Pers Maastricht

Financial support by Glaxo Smith Kline, Novartis Pharma B.V., Pfizer B.V., BD Diagnostic Systems, Carl Zeis N.V.-B.V., Biomerieux Benelux B.V., Clindia Benelux B.V., Schering-Plough B.V., GlaxoWellnessZeist, Bayer Schering Pharma, Grünenthal, Ild Care Foundation is gratefully acknowledged. 


\title{
Diagnostic value of bronchoalveolar lavage in infectious disorders
}

\author{
PROEFSCHRIFT \\ ter verkrijging van de graad van doctor \\ aan de Universiteit Maastricht, \\ op gezag van de Rector Magnificus, Prof. mr. G.P.M.F. Mols, \\ volgens het besluit van het College van Decanen, \\ in het openbaar te verdedigen \\ op donderdag 22 november 2007 om 16.00 uur
}

door

Catharina Linssen

Geboren op 19 mei 1974 te Roermond

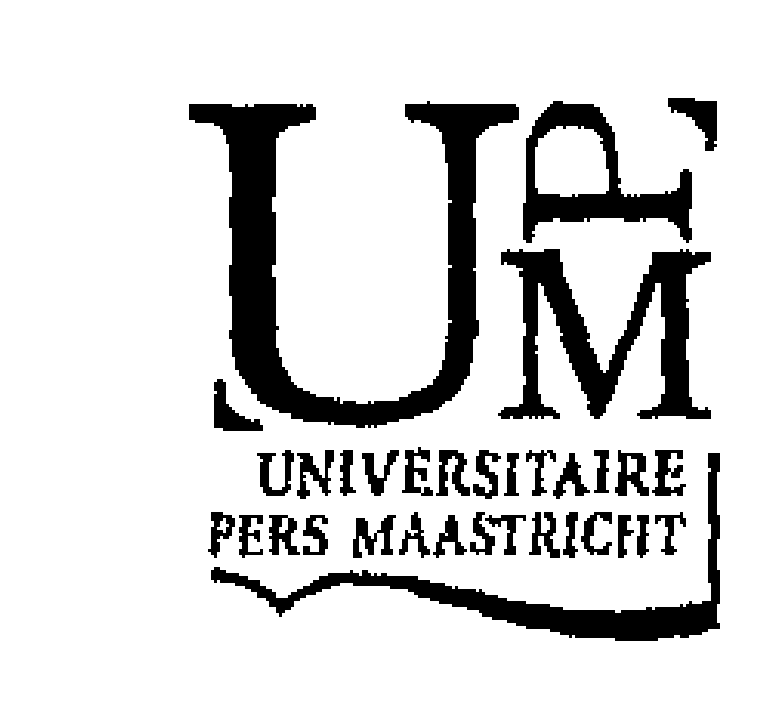




\section{Promotores}

Prof. Dr. C.A. Bruggeman

Prof. Dr. M. Drent

\section{Co-promotor}

Prof. Dr. J.A. Jacobs

\section{Beoordelingscommissie}

Prof. Dr. J.H. Zwaveling (voorzitter)

Prof. Dr. M.J. Bonten, UMC, Utrecht

Prof. Dr. A. de Bruïne

Prof. Dr. V.E. Poletti, Forli, Italy

Prof. Dr. H.C. Schouten 
Voor mijn ouders, Toosje en ome Wim 


\section{Contents}

Chapter 1 Introduction 9

Chapter 2 Use of Polylysine-coated slides in clinical bronchoalveolar $\quad 39$ lavage fluid samples

Chapter 3 Presence of reactive type II pneumocytes in bronchoalveolar lavage fluid

Chapter 4 Influence of antibiotic therapy on the cytological diagnosis of ventilator-associated pneumonia

Chapter 5 C-reactive protein and procalcitonin concentrations in broncho- 75 alveolar lavage fluid as a predictor of ventilator-associated pneumonia

Chapter 6 Inter-laboratory comparison of three different real-time PCR 89 assays for the detection of Pneumocystis jiroveci in bronchoalveolar lavage fluid samples

Chapter 7 High herpes simplex virus load in bronchoalveolar lavage fluid 103 is related to poor outcome in critically ill patients

Chapter 8 Summary and discussion

Samenvatting

List of abbreviations 159

List of publications 163

Dankwoord 167

Curriculum vitae 
Chapter

1

General introduction 


\section{History of bronchoalveolar lavage as a diagnostic and research tool}

Since the introduction of the rigid bronchoscope by Dr. Jackson in 1904 , bronchoalveolar lavage (BAL) had become an increasingly important tool in pulmonary diseases. Primary, BAL was used as a treatment for patients who suffered from diseases associated with accumulation of purulent secretions such as alveolar proteinosis, cystic fibrosis and bacterial pneumonia ${ }^{1}$. Large volumes of saline (15-30 I) were instilled over 2 to 3 hours to clear the lungs of excess secrete. This "large volume" BAL was commonly known as: bronchioloalveolar debridement ${ }^{2}$.

Between 1960 and 1970, the introduction of "small volume" (instillation of $300 \mathrm{ml}$ sterile saline) BAL followed. Tested on healthy volunteers, it was found to be a save method, providing extensive information on cellular components of normal BAL. fluid (BALF) ${ }^{3,4}$. After the introduction of the flexible scope in 1970, $a$ increase in implementation and use of BAL was seen. The increase in interest in BAL as a research tool was reflected by the increase in publications (40-fold) on BAL in the period 1970-1990. In recent years, research output dealing with BAL has reached a plateau at approximately 500 papers annually ${ }^{5}$.

\section{Description of bronchoalveolar lavage}

By definition BAL is a method for the recovery of cellular and non-cellular components from the lower respiratory tract (e.g. alveoli). It is a safe technique, with few major complications ${ }^{7}$. In many cases (e.g. pulmonary proteinosis, alveolar hemorrhage, eosinophilic pneumonia) BAL can replace lung biopsy ${ }^{8}$. Possible uses of BAL in diagnostics are summarized in Table 1.1.

\subsection{Technical aspects of bronchoalveolar lavage}

Guidelines and recommendations on the technical aspect of BAL have been published by the European Respiratory Society (ERS) Task Force in several reports $^{9,10}$. Premedication usually consists of a sedating compound (diazepam) with a compound that causes dilatation of the bronchi (atropine) and local anaesthesia by application of lidocaine. 
Table 1.1 Pulmonary diseases where BALF can be used to reach a diagnosis ${ }^{5,72,107}$.

\begin{tabular}{l} 
Non-infectious \\
Sarcoidosis \\
Hypersensitivity pneumonitis \\
Idiopatic lungfibrosis \\
Connective tissue disorders \\
Langerhanscell histiocytosis \\
Malignancies \\
Alveolar hemorrhage \\
Alveolar proteïnosis \\
Eosinofilic pneumonia \\
Bronchitis obliterans with organizing pneumonia \\
Asbestosis \\
Silicosis \\
\hline Infectious \\
(Ventilator-associated) pneumonia \\
Pneumocystis pneumonia \\
Mycobacterial infection \\
Aspergillus fumigatus infection \\
Viral pneumonia \\
Toxoplasma pneumonia \\
Legionella infection \\
Mycoplasma pneumoniae pneumonia \\
Chlamydia pneumoniae pneumonia \\
Cryptococcal infection \\
Histoplasma infection \\
Strongyloïdes infection \\
\hline
\end{tabular}

\subsection{Site of lavage}

The site of lavage depends on the localization of the abnormalities. In case of localized disease, for instance an infection with a radiographically apparent infiltrate or a malignancy, the involved segment should be sampled ${ }^{11}$. In patients with diffuse lung disease, the middle lobe or lingula is most commonly used site to be lavaged ${ }^{10}$ since anatomically this is the most accessible site and the fluid obtained at one site is representative of the whole lung in diffuse lung diseases (inflammation is not limited to one site) ${ }^{10}$. Using the method described, approximately $1.5-3 \%$ of the lung (approximately $1,000,000$ alveoli) are sampled ${ }^{6}$.

\subsection{Fluid used}

Usually, the lavage is performed using sterile saline $(0.9 \% \mathrm{NaCl})$. Preferable the saline is preheated to body-temperature $\left(37^{\circ} \mathrm{C}\right)$ to help prevent coughing and to, slightly, increase cellular yield ${ }^{12}$. However, this is not necessary and therefore many institutions use saline at room temperature ${ }^{13,14}$. 
The volume of sterile saline instilled differs between institutions, the volume varies between 100 and $300 \mathrm{ml}$ in aliquots of 20 to $50 \mathrm{ml}^{15}$, the ERS task force recommended the use of $200-240 \mathrm{ml}$ divided in four aliquots.

\subsection{Fluid instillation and recovery}

The fiberoptic bronchoscope is wedged into a subsegmental bronchus. The fluid is instilled through the bronchoscope and almost immediately recovered by applying suction $(25-100 \mathrm{mmHg})$. Each aliquot is aspired into a separate syringe or trap ${ }^{6}$. Recovered aliquots are consecutively numbered.

Usually $60-70 \%$ of the instilled volume is recovered in healthy volunteers ${ }^{16,17}$, in smokers, patients with underlying pulmonary disease and ventilated patients, the recovery rate is lower ${ }^{18,19}$.

\section{Laboratory processing of BALF}

BALF is processed immediately upon arrival at the laboratory. Since the first aliquot is usually poorly recovered and reflects a disproportionate amount of bronchial material ${ }^{20}$, this fraction is used it for mycobacterial investigation only. The other three fractions are pooled and processed. Complicated and timeconsuming procedures, such as filtration, lysation and resuspending of BALF can be avoided in order to sustain the cell morphology and to facilitate 24-hour service from the laboratory. Equal parts of fractions I, II and III are pooled and used for the further investigation, such as total cell count, cytospinpreparations, quantitative culture and determination of soluble factors. When indicated additional tests can be included such as: detection of fungi, Legionella pneumophila, viruses and detection of Mycoplasma pneumoniae and Chlamydia pneumoniae by means of polymerase chain reaction (PCR).

The total cell count is performed by using a Fuchs-Rosenthal hemocytometer, every nucleated cell is counted. A BALF sample retrieved from a healthy person contains 150.000 tot 300.000 cells per ml.

\subsection{Quality control of BALF}

To ensure that the obtained material represents the situation in the alveoli, a number of criteria have been established. A BALF is regarded nonrepresentative if it fulfills one of the following criteria: i) volume $<20 \mathrm{ml}$, ii) total cell count $<60.000$ cells $/ \mathrm{ml}$, iii) presence of $>1 \%$ squamous epithelial cells, iv) presence of $>5 \%$ bronchial epithelial cells, $v$ ) presence of extensive amounts of debris, vi) severely damaged cell morphology. 
$14 \mid$ Chapter 1

\subsection{Cytocentrifugation}

All preparations are made by cytocentrifugation using a Thermo-Shandon Cytospin 3 (Thermo Electron's Anatomical Pathology Group, Astmoor, England) following a standardised protocol ${ }^{21,22}$ using pre-cleaned slides. The amount of BALF (in drops) used is dependent on the number of cells per $\mathrm{ml}$ in the pooled fraction (Table 1.2). The program used follows a centrifugationspeed of $650 \mathrm{rpm}(\approx 40 \times g)$ with a low acceleration for 10 minutes. Using cytospinpreparations shows a few advantages over smear preparations. First of all, the cytospinpreparations are dry when they are taken out of the centrifuge, and can be fixed and stained immediately. Secondly, due to the monolayer, the preparation will stain equally and the contents of the cell and the nucleus are perfectly visible (Figure 1.1). The third advantage lies in the fact that a relatively small and easy-view preparation needs to be examined, making it easy to investigate the whole preparation. However, there is a small disadvantage, BALF differential cell counts on cytocentrifuged preparations can underestimate the proportion of lymphocytes ${ }^{23}$.

Table 1.2 Cytocentrifugation parameters of the Cytospin 3 in the work-up of BALF.

\begin{tabular}{lllll}
\hline Cells/ml & Number of drops & Acceleration & Speed & Time \\
\hline$<50.000$ & 7 & low & $650 \mathrm{rpm}$ & $20 \mathrm{~min}$ \\
$50.000-100.000$ & $5-4$ & low & $650 \mathrm{rpm}$ & $10 \mathrm{~min}$ \\
$10.000-200.000$ & $4-3$ & low & $650 \mathrm{rpm}$ & $10 \mathrm{~min}$ \\
$200.000-300.000$ & 3 & low & $650 \mathrm{rpm}$ & $10 \mathrm{~min}$ \\
$300.000-400.000$ & $3-2$ & low & $650 \mathrm{rpm}$ & $10 \mathrm{~min}$ \\
$400.000-500.000$ & 2 & low & $650 \mathrm{rpm}$ & $10 \mathrm{~min}$ \\
$>500.000$ & Dilute with NaCl 0.9\% to 3 drops final & low & $650 \mathrm{rpm}$ & $10 \mathrm{~min}$ \\
& volume & & & \\
BALF with excess & use 1 drop less than mentioned above & low & $650 \mathrm{rpm}$ & $10 \mathrm{~min}$ \\
amount of blood & & & & \\
\hline
\end{tabular}

( $\mathrm{rpm}=$ revolutions per minute)

\subsection{Stains performed on BALF}

Many stains can be used in the work-up of BALF. After extensive research the following stains were implemented in our hospital described below. A number of stains are routinely performed on each BALF sample. These include the Gram-stain (one preparation) and the May-Grünwald Giemsa (MGG) (three preparations) stain. Before Gram-stain is performed there is a two minute fixation step with absolute methanol. Unfixated preparations are used for the MGG stain. After staining, each preparation is sealed by using a drop of Shandon-mount (Thermo Electron's Anatomical Pathology Group) and a covering slip. This ensures that the quality of the preparation does not 
deteriorate by the oil used for the oil-immersion lens, and that no damage occurs during use so that they can be stored indefinitely. Besides the standard stains, a number of stains can be added to the work-up upon clinical indication. For example: Grocott (methenamine-silver)(fungi/Pneumocystis jirovecl), Auramine-Rhodamine, Ziehl-Neelsen (acid-fast bacteria), Legionella immuunfluorescence (Legionella spp), Acridine-orange (micro-organism in general) and the iron stain.

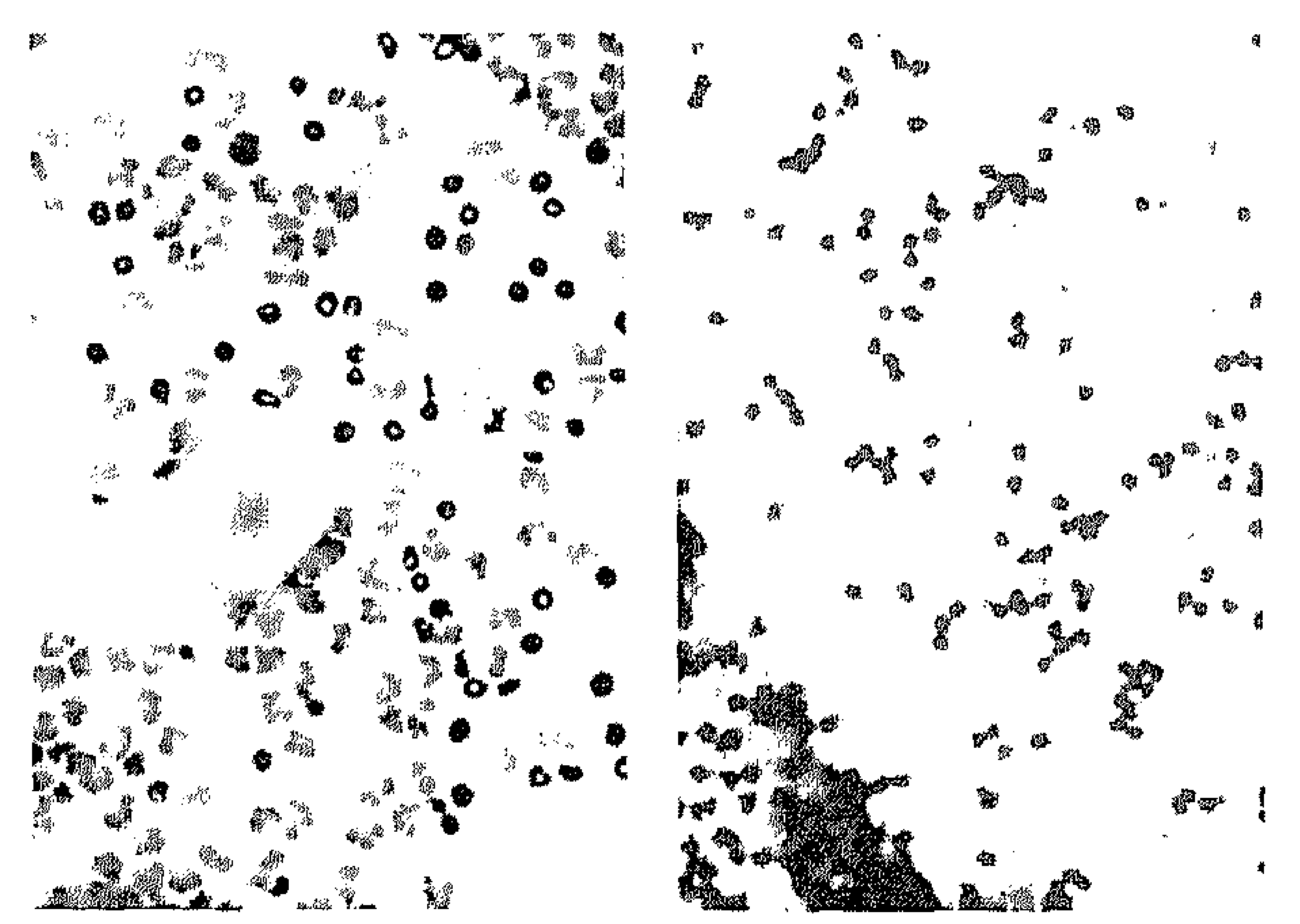

Figure 1.1 Gram stained preparations of a BALF sample, showing that by using cytospin preparations (left) the nucleus and the cell contents are better visualized compared to smear preparations (right). Magnification $400 x$.

\subsection{Cytological composition of BALF}

In a healthy individuals the cell population of BALF consists of 80 to $90 \%$ alveolar macrophages, 5 to $10 \%$ lymphocytes and the remaining 1 to $2 \%$ are polymorphonuclear granulocytes, eosinophils and mast cells.

\subsubsection{Alveolar macrophages}

Alveolar macrophages (AMs, Figure 1.2,1.3) are mononuclear cells with a diameter of $10 \mu \mathrm{m}$ to $40 \mu \mathrm{m}$. They have a large amount of light colored cytoplasm which is equally divided round the nucleus. The nucleus is round to oval. The cytoplasm can contain all sorts of phagotized material such as hemosiderine, carbon, micro-organisms and debris. In some diseases (for instance drug-induced pneumonitis) macrophages contain many small vacuoles in their cytoplasm, they are called "foamy" alveolar macrophages. 


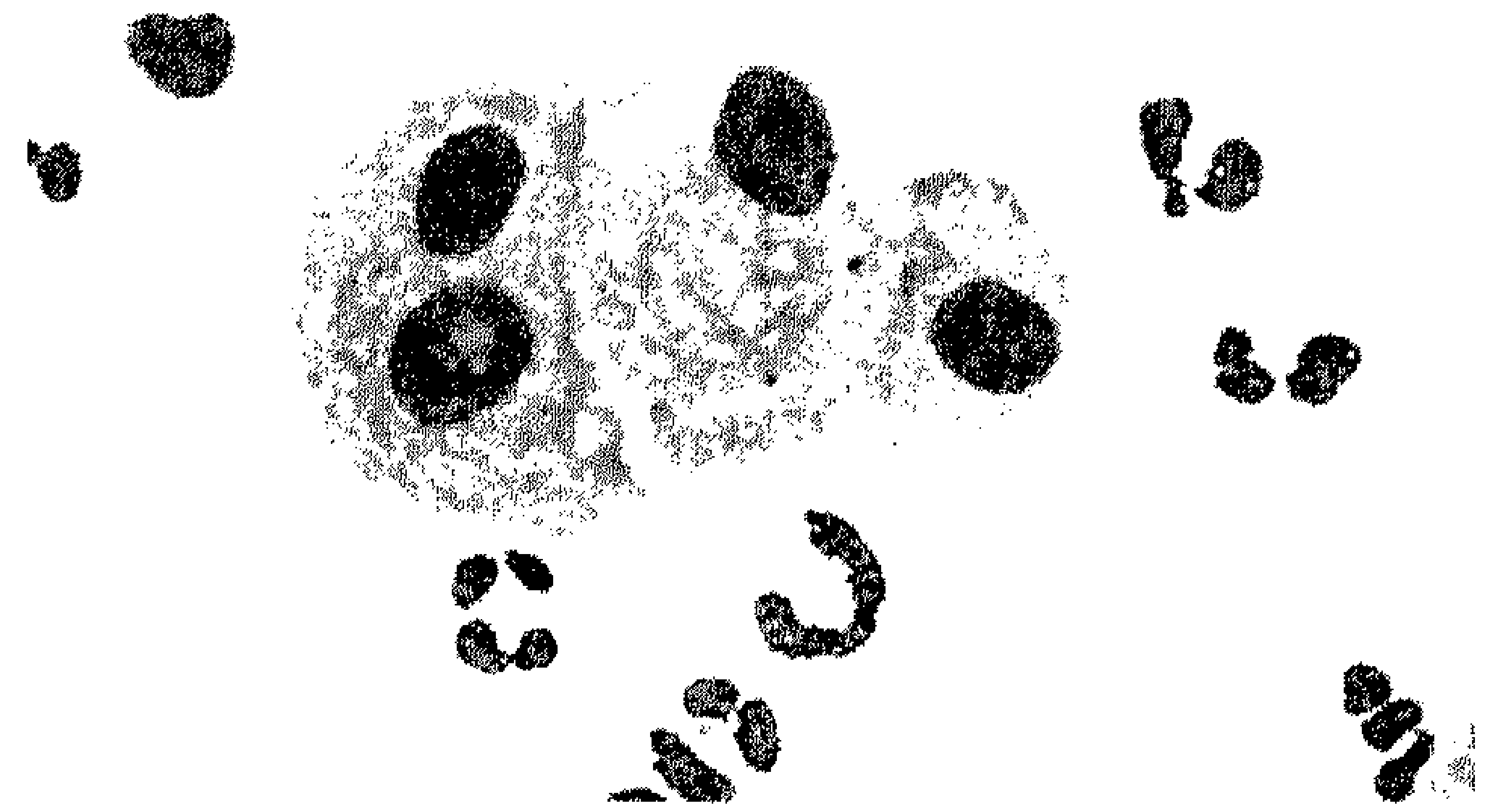

Figure 1.2 May-Grünwald Giemsa stain. Three alveolar macrophages (center) surrounded by polymorphonuclear neutrophils. One lymphocyte is present in the upper left corner. Magnification 1000x.
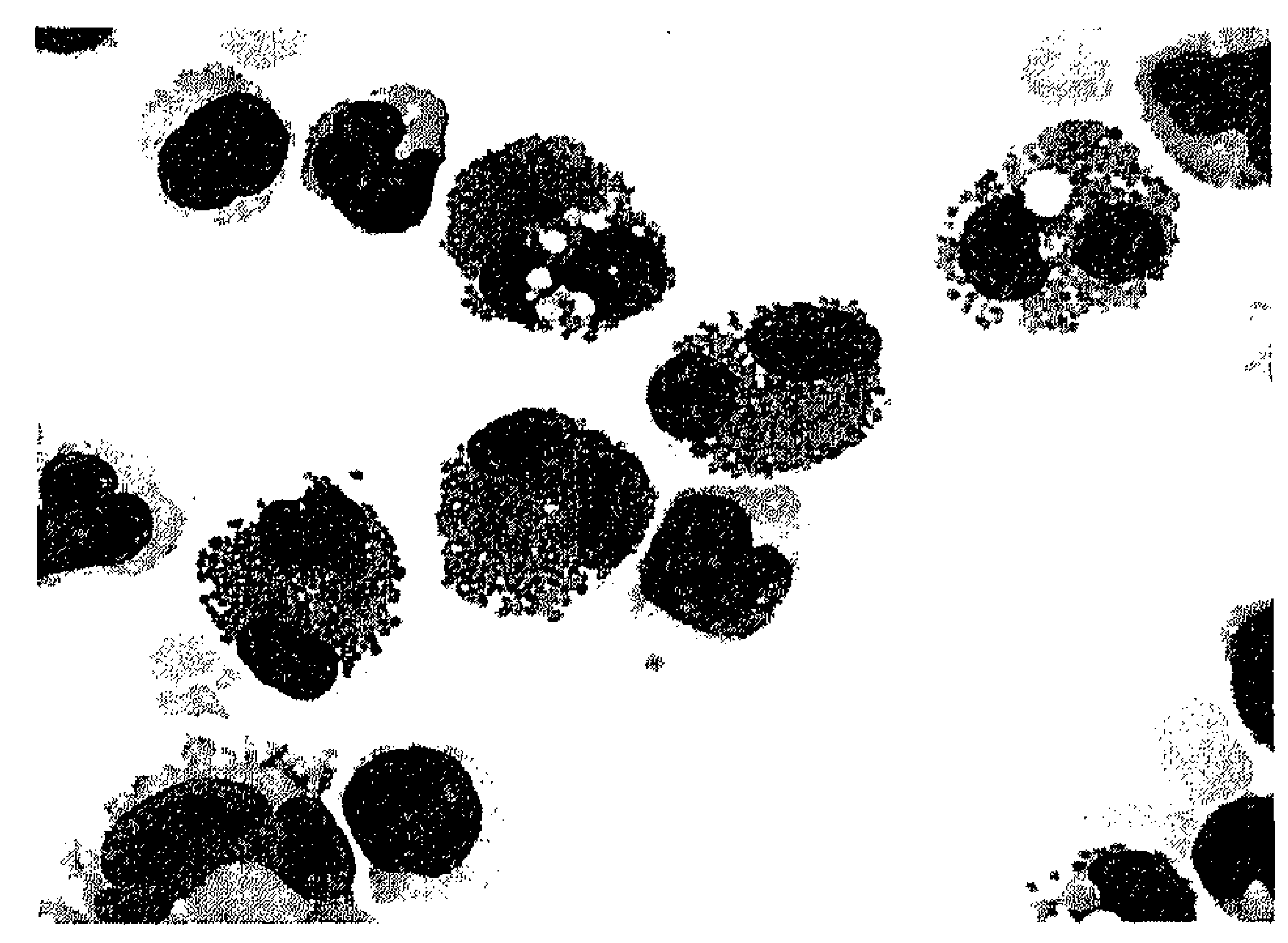

Figure 1.3 May-Grünwald Giemsa stain. Five eosinophils are present in the center. Eosinophils have a nucleus that usually consists of two lobes and their cytoplasm contains orange granulae. In the top left and right corner, lymphocytes are present. In the lower left corner part of an alveolar macrophage is visible. Magnification $1000 \times$.

\subsubsection{Lymphocytes}

Mature lymphocytes (Lyms, Figure 1.2, 1.3) are the smallest nucleated cells present in BALF. They contain a relatively large nucleus and little cytoplasm. The nucleus is round, sometimes with some indentations and has a dark purple color. Often only a small rim of light blue cytoplasm is visible. Activated Lyms are larger than mature Lyms and contain more cytoplasm which varies from 
pale blue (near the nucleus) to dark bleu (near the cell border). Often the cell border has a somewhat irregular appearance.

\section{4 .3 Polymorphonuclear neutrophils}

Polymorphonuclear neutrophils (PMNs, Figure 1.2) have an average diameter of 12 to $15 \mu \mathrm{m}$. Their nucleus has an irregular shape and consists of two to five lobes (average 3). The cytoplasm is slightly pink colored and contains numerous pink granules. An influx of PMNs can been seen in the lungs of patients after traumatic insertion of a bronchoscope, in ventilated patients an patients with infectious disorders.

Necrobiotic neutrophils are smaller than PMNs, with only one, compact dark colored nucleus. They are degenerated PMNs which can be seen in case of longstanding inflammation.

\subsubsection{Eosinophils}

Eosinophils (Eos, Figure 1.3) have approximately the same size as PMNs, but their nucleus usually consists of two, round, lobes. Their cytoplasm is colorless and contains orange granules which are larger than those seen in the PMNs. An increased number of Eos can be seen in patients with Pneumocystis jiroveci pneumonia, asthma, drug-induced pulmonary disease, eosinophilic pneumonia, extrinsic allergic alveolitis and idiopathic pulmonary fibrosis ${ }^{24}$.

\subsubsection{Mast cel/s}

Mast cells (MCs) are large cells with blue or purple-red granules in their cytoplasm which cover the nucleus completely. They are uncommon cells to be found in BALF. Increased number of MCs can be encountered in patients with asthma, bronchiolitis obliterans or farmer's lung disease $\mathrm{e}^{25,26}$.

\subsubsection{Bronchial epithelial cells}

The presence of bronchial epithelial cells indicates contamination from the higher bronchial tract. They can be divided into:

Ciliated epithelial cells (Figure 1.4):

The ciliated epithelial cells are easily noted columnar cells with a basal nucleus, a pale cytoplasm and a distinctive endplate with a bunch of cilia. Loose cilia can sometimes be confused with slim Gram-negative rods. 

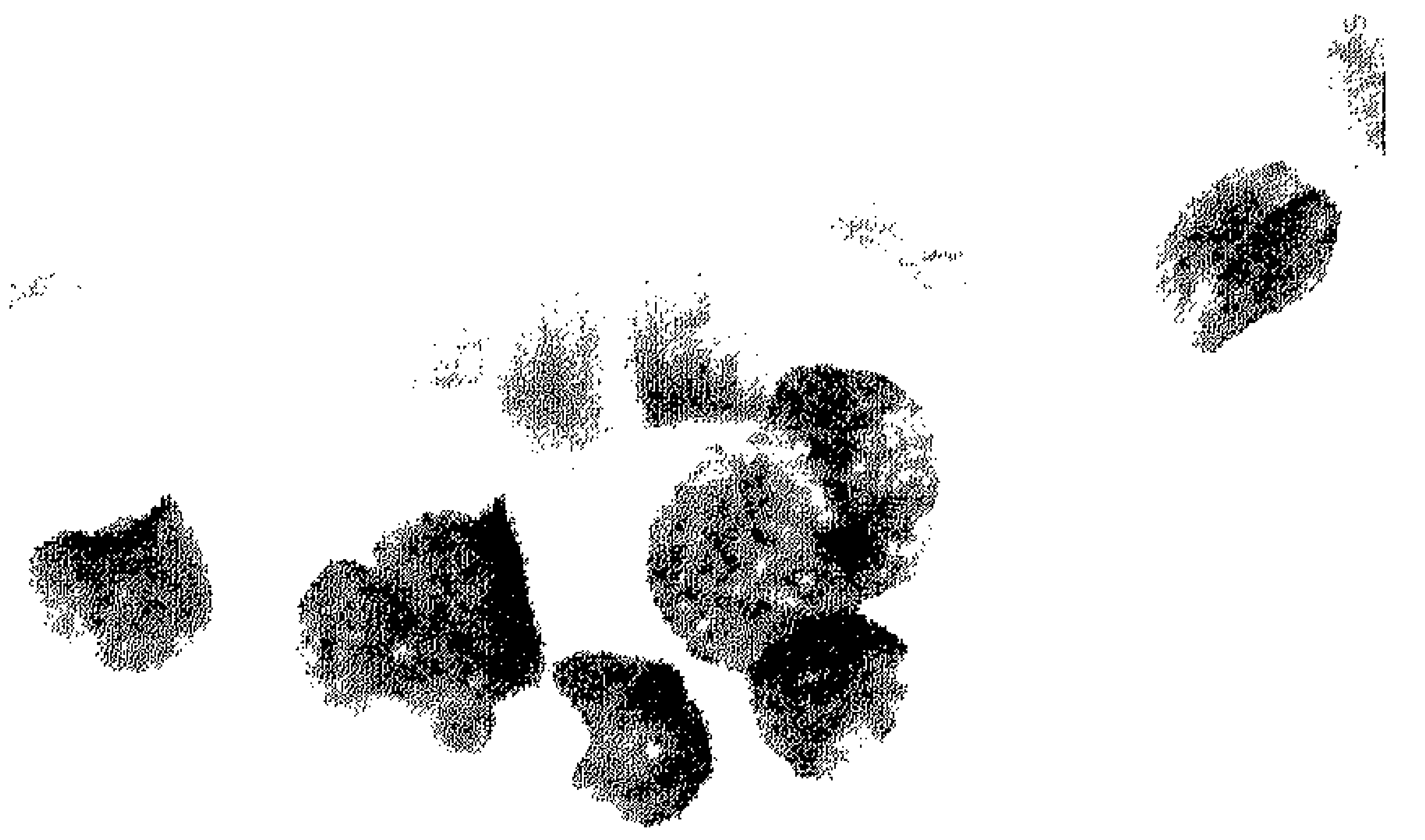

Figure 1.4 May-Grünwald Giemsa stain. A group of ciliated epithelial cells. These are columnar cells with a basely located nucleus and cilia at the apical end. Magnification Magnification 1000x.

Goblet cells:

The mucus secreting Goblet cells are more difficult to recognise. They are also pale, elongated cells with a nucleus at the base. The cytoplasm extends above the nucleus in a shape like that of a wine goblet.

\subsubsection{Squamous epithelial cells}

Presence of squamous epithelial cells in BALF points to oropharyngeal contamination of the BALF. They are large, square, flat, angular cells with a dark colored, relatively small nucleus. Often they are covered with bacteria and can therefore influence the specificity of the quantitative culture in a negative way.

\subsubsection{Reactive type // pneumocytes}

Type II pneumocytes are surfactant producing cells present at the inside of the alveoli (alveolar lining cells). In normal circumstances these cells are not seen in BALF, or are indistinguishable from alveolar macrophages. However, in case of serious pulmonary damage, they can be found in BALF as reactive type 11 pneumocytes (RPII, Figure 1.5.). RPII cells are large cells which can be easily spotted, even at a low magnification. They have a small, dark colored nucleus. Their cytoplasm has a dark color and contains large vacuoles. Often they cluster together giving them a glandlike appearance. Reactive type II pneumocytes resemble malignant cells. These cells can be seen in patients with, for instance, acute respiratory distress syndrome $(A R D S)^{27}$ or pneumocystis pneumonia ${ }^{28}$. 


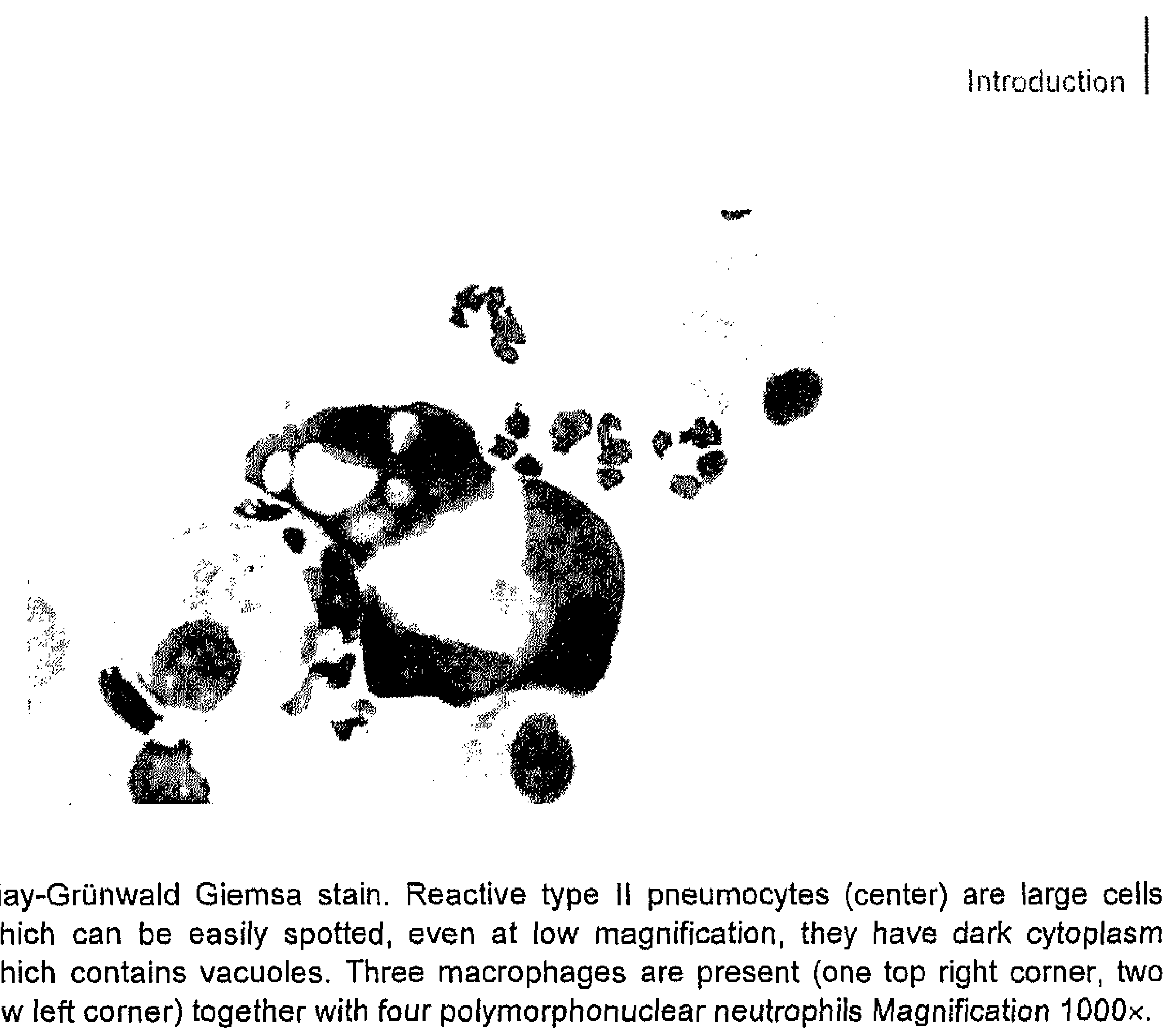

\subsubsection{Intracellular micro-organisms}

Infected cells or intracellular organisms (Infected cells, IC, Figure 1.6), are cells which have phagotized micro-organisms. The majority of these cells are PMNs, however in a small percentage of cases alveolar macrophages are also involved. Different stains can be used for the evaluation of the percentage of IC in BALF, the May-Grünwald Giemsa stain was found superior over the Gramstain and the acridine-orange stain, resulting in the highest reliability ${ }^{29}$. An additional advantage of the MGG stain is the fact that the percentage IC can be enumerated at the same time as performing the differential cell count. The presence of $\geq 2 \%$ IC per 500 nucleated cells in the MGG stain points to the diagnosis ventilator-associated pneumonia (VAP) in a patient on ventilation ${ }^{30}$.

\subsubsection{Plasma cells}

Plasma cells (PCs) are cells with a diameter of 8 to $20 \mu \mathrm{m}$, they have a similar appearance as Lyms, but with a round to oval nucleus which lies eccentric. Their cytoplasm is stained intense blue with a clear zone in the vicinity of the nucleus. Plasma cells can be seen in BALF of patients with pneumocystis pneumonia, drug-induced pulmonary disease, extrinsic allergic alveolitis and malignant lymphomas. 
20

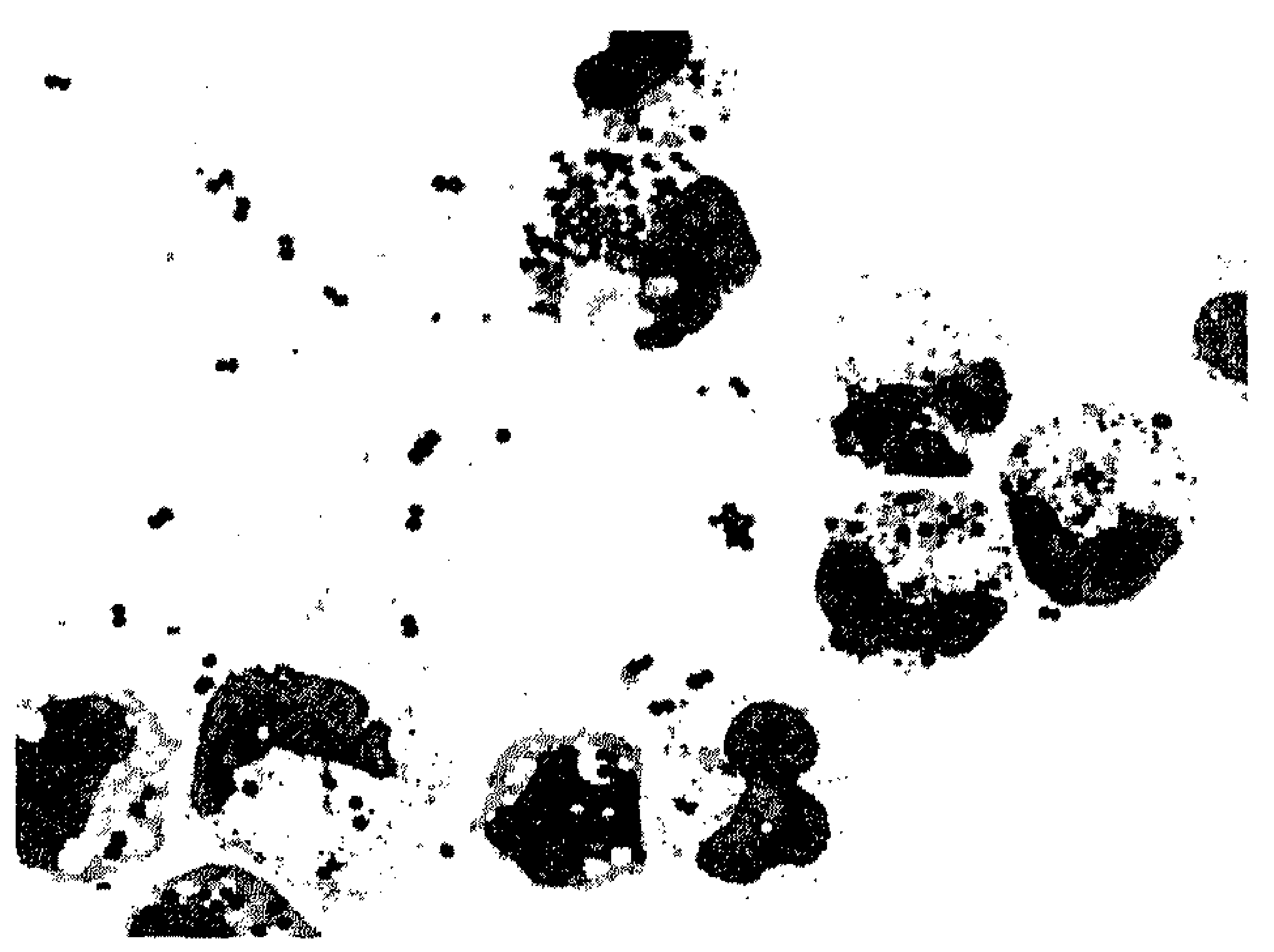

Figure 1.6 May-Grünwald Giemsa stain. In this figure infected cells are shown. Infected cells are cells that have phagotised micro-organisms. Magnification 1000x.

\subsection{The differential cell count}

The differential cell count is performed on MGG stained preparations. When screening at low magnification (magnification: 100x), the presence of squamous epithelial cells, clusters of RPll cells, large clusters of $P$. jiroveciand mucus plugs can be noted. The differential cell count is performed using a magnification of $1000 x$ and a standardised protocol ${ }^{31,32}$. A total of 500 nucleated cells are counted, including the $\mathrm{IC}$, and reported as a percentage of 500 cells. Specific morphological phenomena, such as foamy alveolar macrophages, activated Lyms, necrobiotic neutrophils and RPII cells, are reported separately. The differential cell count can be used as an instrument to limit the differential diagnosis in pulmonary diseases (Table 1.3)

\subsection{The quantitative culture}

The quantitative culture of BALF is the current "gold standard" for the diagnosis VAP. Since the alveoli are rinsed with approximately $200 \mathrm{ml}$ of fluid, the actual BALF sample is an approximately 10-100 times diluted representation of the situation in the alveoli. In case of a bacterial infection, the bacterial concentration in the alveoli is $10^{5}$ tot $10^{6}$ colony forming units $(\mathrm{cfu}) / \mathrm{ml}$. For the quantitative culture, this results in a cut-of value of $10^{4} \mathrm{cfu} / \mathrm{ml}^{33}$. 
Introduction 21

Table 1.3 The direction in which the elevation or the presence of certain cells in the differential cell count in BALF can point ${ }^{\mathrm{a}}$

\begin{tabular}{|c|c|c|c|c|c|c|c|}
\hline Associated diseases & AMs & Lyms & PMNs & Eos & PCs & MCs & RPII \\
\hline \multicolumn{8}{|l|}{ Non-infectious diseases } \\
\hline Sarcoidosis & & $\uparrow$ & $=$ & $=/ \uparrow$ & - & $=/ \uparrow$ & - \\
\hline Extrinsic allergic alveolitis & FAM & $\uparrow \uparrow$ & $\uparrow$ & $=/ \uparrow$ & $+/-$ & $\uparrow \uparrow$ & - \\
\hline Drug-induced pneumonitis & FAM & $\uparrow \uparrow$ & $\uparrow$ & $\uparrow$ & $+1-$ & $\uparrow \uparrow$ & - \\
\hline Idiopathic pulmonary fibrosis & & $\uparrow$ & $\uparrow / \uparrow \uparrow$ & $\uparrow$ & - & $\uparrow$ & $+1-$ \\
\hline$B O P^{*}$ & FAM & $\uparrow$ & $\uparrow$ & $\uparrow$ & $+/-$ & $=/ \uparrow$ & \\
\hline Eosinophilic pneumonia & & $\uparrow$ & $=$ & $\uparrow \uparrow$ & $+1-$ & $=/ \uparrow$ & \\
\hline Alveolar proteinosis & FAM & $\uparrow$ & $=$ & $=$ & - & $=$ & \\
\hline Diffuse alveolar hemorrhage & & $=l \uparrow$ & $\uparrow$ & $=/ \uparrow$ & - & $=$ & $+1-$ \\
\hline ARDS $^{\star \star}$ & & $\uparrow$ & $\uparrow \uparrow$ & $\uparrow$ & - & $=/ \uparrow$ & $+1-$ \\
\hline Hematologic malignancies & & $\uparrow$ & $\uparrow$ & $=/ \uparrow$ & - & $=/ \uparrow$ & \\
\hline Astma & & $=$ & $=$ & $\uparrow$ & - & $=$ & \\
\hline \multicolumn{8}{|l|}{ Infectious diseases } \\
\hline Ventilator-associated pneumonia & & $=$ & $\uparrow \uparrow$ & $=$ & - & $=$ & $+/-$ \\
\hline Pheumocystis pneumonia & & $=/ \uparrow$ & $\uparrow$ & $=/ \uparrow$ & $+1-$ & $=$ & $+1-$ \\
\hline Viral pneumonia & & $=$ & $\uparrow \uparrow$ & $=$ & - & $=$ & $+1-$ \\
\hline Aspiration pneumonia & FAM & $=$ & $\uparrow \uparrow$ & $=$ & - & $=$ & $+1-$ \\
\hline
\end{tabular}

${ }^{a}$ Adapted from Drent $e t a l^{8}$

AMs: alveolar macrophages, Lyms: lymphocytes, PMNs: polymorphonuclear neutrophils, Eos: eosinophils, PCs: plasma cells, MCs: mast cells, RPIl: reactive type II pneumocytes, FAM: foamy alveolar macrophages, +: present, -: not present, +/-: can be present

* BOOP: bronchiolitis obliterans with organising pneumonia

** Acute respiratory distress syndrome.

\section{Detection of soluble factors in BALF}

Unlike the different cellular components of BALF, soluble components are effected by the dilution of BALF since quantitative measurements per milliliter are mostly use to express measurements ${ }^{34}$. Four main problems prevent accurate quantification of soluble factors in BALF, namely: i) there is a unknown amount of dilution during lavage, ii) contamination from the epithelial lining fluid (ELF) sample with bronchial material can occur during BAL, iii) the sample can be inadequate by inadequate mixing and iv) permeability of the lung varies, this may lead to loss of introduced fluid into the tissues and increase leakage of soluble factors from the blood and tissues into the ELF ${ }^{34}$. Using a standardized protocol, like the one we use, helps reduce the above mentioned problems. As recommended by the ERS task force, a standard volume of $\mathrm{NaCl}$ is introduced $(200 \mathrm{ml})$ in four aliquots $(50 \mathrm{ml}$ each). In case of diffuse pulmonary disease, a standard lobe (lingula) is used for lavage. However, even if a standardized protocol for BAL is used, the volume of fluid recovered can not be controlled. Two possible solutions can be used to, largely, overcome this problem. The first is expressing the concentration of a 
22 Chapter 1

soluble factor as proportion of another factor, similar to the percentage of cells in the differential cell count. For example, expressing individual proteins as a proportion of the total protein ${ }^{34}$. The second possible solution is the use of the urea concentrations in BALF and serum. Since urea is a very small molecule, it can freely pass the barrier between blood and ELF. Therefore, at least in theory, the concentration of urea in ELF and serum should be the same. Wiedermann and co-workers described an easy to use formula for this purpose ${ }^{35}$ :

$$
[X] E L F=([X] B A L F \times \text { urea serum }) / \text { urea BALF concentrations }
$$

To assess permeability of the blood/ELF barrier, the concentration of albumin can be of use. Normally albumin is too large a molecule to pass the barrier. In case of leakage, high concentrations of albumin can be found in ELF and therefore in BALF ${ }^{36}$.

Several non-cellular components can be detected in BALF, among these are: immunoglobulins ${ }^{37}$, proteases and antiproteases ${ }^{38}$, angiotensin-converting enzyme $^{39}$, antioxidants, oxidants and oxidation products ${ }^{40}$, lipid mediators ${ }^{41}$, cytokines $^{42}$, soluble adhesion molecules ${ }^{43}$, markers of fibrosis ${ }^{44}$, granulocyte derived markers ${ }^{45}$, tumour markers ${ }^{46}$, markers of cell death and other components.

\subsection{Procalcitonin}

Procalcitonin (PCT) is a 116 amino acid protein with a molecular weight of approximately $13 \mathrm{kDalton}$, which undergoes posttranslational proteolysis to become the hormone calcitoni $\mathrm{n}^{47}$. In healthy patients calcitonin is produced and released by the C-cells of the thyroid gland after specific intracellular proteolysis of the prohormone. However, in severe bacterial infections and sepsis, procalcitonin is found in the blood and is produced extra thyroidal. Until now, it is not clear which cells are responsible for the production of PCT during infection. Several cells have been proposed: liver ${ }^{48,49}$, neuroendocrine cells of lungs or intestine, and peripheral blood-monocytes ${ }^{50}$. The indication for PCT lies primarily as a, supporting, diagnostic parameter for bacterial infections such as sepsis and septic shock ${ }^{49,51-54}$, which can be explained by the fact that bacterial lipopolysaccharid (LPS) is (in vitro) a major stimulus for the production of PCT. Furthermore, PCT could also be useful in other infections like yeast infection ${ }^{55}$ and parasitic infection ${ }^{56}$. Even though the clinical relevance of PCT has been shown in patients with sepsis, PCT can also be elevated in patients with nonseptic systemic inflammatory response syndrome (SIRS) ${ }^{57,58}$, trauma patients ${ }^{59}$ and immediately after surgery ${ }^{58}$ or trauma, without obvious infection. PCT concentration in both serum and BALF have been investigated as a 
diagnostic method in patients with VAP. Serum PCT, but not PCT determined in BALF, was indicated as a helpful parameter in early VAP diagnosis ${ }^{60}$. However, PCT in BALF was determined by a test designed for serum, with a detection-limit that may be to high for the detection of PCT in BALF ${ }^{60}$. PCT kinetics have been used to predict the outcome in patients with severe community-acquired pneumonia admitted to the intensive care unit (ICU). It appears that the increase of the PCT level in serum over the first three days of admittance to the ICU, is correlated with a poor prognosis ${ }^{61}$.

\subsection{C-reactive protein}

C-reactive protein was discovered in 1929 by Oswald Avery whilst studying patients with a Streptococcus pneumoniae infection. CRP is an inflammatory marker (protein), produced in the lever in response to interleukine-6 produced by macrophages and monocytes ${ }^{62}$. Healthy humans have peripheral blood CRP below $3 \mathrm{mg} / \mathrm{l}$. In case of infection or inflammation (caused by physical trauma) blood CRP levels can increase 1,000-fold or more. CRP is used as a marker in the diagnosis of infections and to monitor the efficiency of treatment. Recently, CRP has been discovered as a marker of atherosclerosis, probably because low-grade chronic inflammation plays a part in atherosclerosis ${ }^{63}$. CRP can be influenced by different factors, such as: age, hormones, diabetes, smoking, obesity, hypertension and some medication (e.g. aspirin) ${ }^{64}$. Several studies have been performed to determine the value of CRP levels in serum of patients with VAP. Measurement of CRP levels (and PCT levels) upon admittance and after four days can predict the survival of patients with VAP. A decrease in either CRP or PCT is correlated with an increased survival of patients with $\mathrm{VAP}^{65}$.

\section{$5 \quad$ Value of BAL in non-infectious pulmonary diseases mimicking ventilator-associated pneumonia}

Several non-infectious pulmonary diseases, such as ARDS, alveolar hemorrhage and drug-induced pneumonia, can mimic VAP ${ }^{66}$. Bronchoalveolar lavage with differential cell count can be a tool in differentiating between infection and non-infectious pulmonary disease (Table 1.1). For instance, a BALF with a high total cell count, a high percentage of PMNs, but no IC and a quantitative culture below $10^{4} \mathrm{cfu} / \mathrm{ml}$, suggests the presence of ARDS rather than VAP. 
$24 \mid$ Chapter 1

\section{Value of bronchoalveolar lavage in infectious pulmonary diseases}

BAL can be useful in many infectious pulmonary diseases (Table 1.1).

\subsection{Ventilator-associated pneumonia}

Ventilator-associated pneumonia (VAP) is defined as a pneumonia in patients receiving mechanical ventilation, occurring more than 48 hours after intubation. VAP can be divided in VAP occurring within the first five days of mechanical ventilation (early-onset VAP) and after five days (late-onset VAP) ${ }^{67}$. VAP is the most frequent hospital acquired infection in ICU patients, occurring in $9-27 \%$ of intubated patients ${ }^{68,69}$ VAP is associated with a high mortality, varying from 20 $70 \%$, depending on the micro-organism involved ${ }^{68}$. Besides the high mortality associated with VAP, it has been demonstrated that VAP prolongs both the duration of mechanical ventilation and ICU stay ${ }^{68,69}$.

The highest incidence of VAP is seen in patients after trauma or thermal injuries ${ }^{70}$.

Usually the upper airways in humans are colonised with bacteria, whilst the lower airways are sterile. In patients receiving mechanical ventilation, a series of factors facilitate bacteria to colonise and finally infect the lower airways ${ }^{71}$. First of all, due to the presence of a tube, the cough reflex is prohibited, the clearance by means of mucus transport by ciliated cells is reduced and the tracheal epithelium is injured. Secondly, underlying illness and malnutrition have a negative influence on the immune system, which in turn responds to the infection in a less than adequate way. Table 1.4 shows the different bacteria associated with VAP. Since the "normal" commensal flora changes during the course of admittance to the ICU, the causative organisms in early- and lateonset VAP differ ${ }^{67}$. The main causative organisms in early-onset VAP include Haemophilus influenzae, Streptococcus pneumoniae and Staphylococcus aureus whilst the organisms involved in late-onset VAP include Pseudomonas aeruginosa, Enterobacteriaceae and Staphylococcus aureus ${ }^{72}$. 
Table 1.4 Etiology of ventilator-associated pneumonia as documented by bronchoscopic techniques in 24 studies for a total of 1,689 episodes and 2,490 pathogens.

\begin{tabular}{lc}
\hline Pathogen & Frequency $(\%)$ \\
\hline Pseudomonas aeruginosa & 24.4 \\
Acinetobacter spp. & 7.9 \\
Stenotrophomonas malthophilia & 1.7 \\
Enterobacteriaceae* & 14.1 \\
Haemophilus spp. & 9.8 \\
Staphylococcus aureust & 20.4 \\
Streptococcus spp. & 8.0 \\
Streptococcus pneumoniae & 4.1 \\
Coagulase-negative staphylococci & 1.4 \\
Neisseria spp & 2.6 \\
Anaerobic bacteria & 0.9 \\
Fungi & 0.9 \\
Others (<1\% each)f & 3.8 \\
\hline
\end{tabular}

Adapted from Chastre et $a l^{68}$

* Distribution when specified: Klebsiella spp., 15.6\%; Escherichia coli, 24.1\%; Proteus spp., 22.3\%; Enterobacter spp., 18.8\%; Serratia spp., 12.1\%; Citrobacter spp., 5.0\%; Hafnia alvei, 2.1\%.

+ Distribution when specified: Methicillin-resistant $S$. aureus, $55.7 \%$, methicillin-sensitive $S$. aureus, $44.3 \%$.

₹ Including Corynebacterium spp., Moraxella spp., and Enterococcus spp.

The diagnosis VAP is difficult since a world-wide accepted gold-standard is lacking. Clinical parameters, shown in Table $1.5^{73}$, are highly sensitive but nonspecific $^{73}$. Most studies use quantitative culture of BALF as a "semigold"standard. The world-wide accepted cut-off value for the presence of VAP is established at $10^{4} \mathrm{cfu} / \mathrm{ml}$. Approximately $30-40 \%$ of patients clinically suspected of VAP, have microbiologically confirmed VAP using the quantitative culture method $^{33}$. Primarily, the cut-off value for quantitative culture was chosen to avoid underdiagnosis of VAP, consequently this cut-off value may be to sensitive and result in treatment of patients without VAP. One of the disadvantages of quantitative culture of BALF is the delay of 24-48 hours until results are known. Microscopic techniques (e.g. differential cell count including IC) have proven to be reliable and fast method in the differentiation between VAP and non-VAP ${ }^{30,74}$. One of the major advantages of using BALF in the diagnosis VAP is the fact that clinicians can be directed towards a cause outside the pulmonary tract, in case of negative microscopy and/or culture. Since VAP is associated with a high mortality, an early diagnosis is essential as is the initial choice of antibiotics. Studies have shown that delay in administration of effective treatment against VAP is associated with higher mortality, morbidity and hospital-costs ${ }^{75-77}$. Up to $50 \%$ of the empirically started antibiotic treatment regimes need to be altered due to the presence of resistant bacteria (either unexpected isolates or multi-drug resistant bacteria) ) $^{75,78}$ Unfortunately, the latter can only partly be prevented by the use of microscopy of BALF in the diagnosis VAP. 
26 Chapter 1

Table 1.5 Clinical parameters indicating suspected VAP. Clinical suspicion of VAP is made when both criteria 1 and II are met $^{73}$.



Adapted from Bonten et al. ${ }^{73}$

\subsection{Pneumocystis jiroveci}

The micro-organism was first described in 1909 by Chagas who discovered them in the lungs of guinea pigs. Thinking it was a type of trypanosome he called it, Schizotrypanum cruz ${ }^{79}$. In 1912 Delanoë demonstrated these cysts to be unrelated to trypanosomes and renamed them Pneumocystis carini ${ }^{\beta 0}$. In the period 1920-1960 an epidemic of pneumonia (interstitial plasma cell pneumonia) was identified in prematurely born infants, particularly in orphanages or foundling homes in Germany and nearby European countries ${ }^{81}$. In 1942, Pneumocystis was seen in the lungs of two Dutch infants who had died of interstitial pneumonia, however it was not attributed to the microorganism at the time ${ }^{81}$. It was not until 1951 when Jirovec demonstrated the etiologic agent to be Pneumocystis ${ }^{82}$. Until the 1980s, Pneumocystis was thought to be a protozoan, due to its life cycle, sensitivity to co-trimoxazol and the fact that it did not react to antifungal therapy with amphotericin B. However in 1988, investigation of ribosomal RNA demonstrated it to be closely related to fungi ${ }^{83}$. It has generally been accepted that pneumocystis organisms are species specific ${ }^{84}$. Recently, the human form, Pneumocystis carinii f. $\mathrm{sp}$. hominis, was renamed after Dr. Otto Jirovec: Pneumocystis jirovec ${ }^{85}$.

One of the major problems in researching $P$. jiroveci is that cultivation of the fungus in vitro is impossible. Some investigators were able to achieve replication of rat-derived $P$. carinii in different cell lines (limited to up to 10 cycli), cultivation of $P$. jiroveci has never succeeded yet. Studies dealing with the life cycle have been based on forms seen in microscopic images of limited cultures and infected pulmonary tissue.

Serologic studies have shown that $P$. jiroveci has a world-wide distribution and most children have already been into contact with the fungus at young age ${ }^{86}$.

$P$. jiroveci is an opportunist, causing pneumocystis pneumonia (PCP) in immunocompromised patients. In the 1980s, it used to be a disease found mainly in patients infected with the human immunodeficiency virus (HIV), however, since the introduction of Highly Active Anti Retroviral Therapy (HAART) and chemoprofylaxis for PCP, there has been a shift towards HIV- 
negative immunocompromised patients. The latter category includes patients using immunosuppressive medication or with an inherited or acquired immunodeficiency ${ }^{87}$. Clinical symptoms associated with PCP include: subtle onset of progressive dyspnea, non-productive cough and low-grade fever. Physical examination shows tachypneu and tachycardia whilst auscultation is often normal. Compared to HIV-negative patients, HIV-positive patients usually have a more subtle onset, symptoms develop over a longer period, $P$. jiroveci loads are higher but pulmonary damage is less severe. In HIV-positive patients, the influx of PMNs into the lung is decreased compared to HIV-negative patients, resulting in better oxygenation and survival in the HIV-positive group ${ }^{88}$.

For years, the diagnostic method of choice has been BAL with specific stains. Different stains can be used, most diagnostic centres always use a combination of two stains: one suitable to detect trophozoit forms (ie. Giemsa, monoclonal antibodies) and one to detect cyst forms (Methenamine silver (Figure 1.7), Calcofluor white, Toluidine blue 0 ). In the hands of an experienced microscopist each stain has a good sensitivity and specificity ${ }^{89}$. However, the microscopic evaluation of BALF samples for the presence of $P$. jiroveci is cumbersome and requires specialised microscopists. Especially in BALF samples containing a low burden of $P$. jiroveci, establishing the diagnosis is often difficult and time consuming. In this situation (i.e. HIV-negative patients) polymerase chain reaction (PCR) could prove its value.

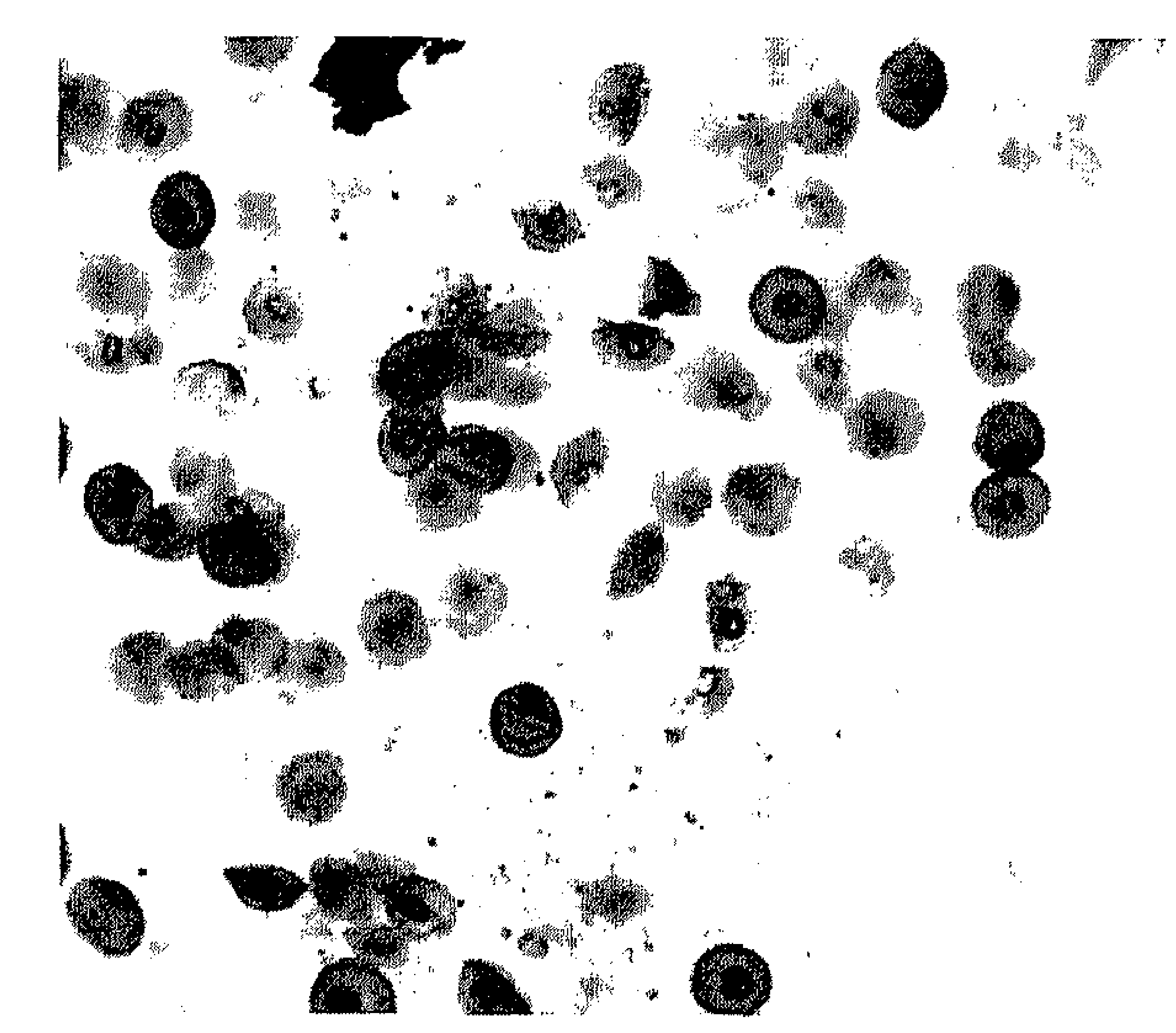

Figure 1.7 Methenamine silver stain (Grocott). This stains the chitine present in the fungal cellwall black. This figure shows a cluster of $P$. jiroveci cysts. Magnification $1000 \times$. 


\subsection{Herpes simplex virus}

Herpes simplex virus (HSV) belongs to the human herpesvirus group. It causes a wide variety of infections. There are two serotypes that infect humans, herpes simplex virus 1 (HSV-1) and herpes simplex virus 2 (HSV-2). HSV-1 is normally associated with orofacial infections and meningitis whereas HSV-2 is associated with genital infections. Both viruses remain in the bodies sensory neurons as latent infection and can reactivate causing lesions near their entry point in the body.

HSV-1 has been described as cause of pneumonia in immunocompromised patients (e.g. AIDS) $)^{90,91}$. However, the prevalence of and the risk-factors for developing a HSV-1 pneumonia are still unknown. In literature the estimated mortality of a Herpes simplex pneumonia is high, varying between 20 till $50 \%{ }^{92,93}$. HSV-1 is regularly cultured from respiratory samples, such as oropharyngeal swabs and BALF, from hospitalised patients ${ }^{94,95}$ with and without suspected pneumonia. Due to the introduction of more sensitive diagnostic procedures for the detection of respiratory pathogens, like real-time polymerase chain reactions, the percentage HSV-1 positive respiratory samples will only increase in the near future ${ }^{96}$. Since HSV can be found in up to $5 \%$ of respiratory specimens of the general population at any given time, the clinical relevance of HSV presence in the respiratory tract in hospitalised patients remains unclear.

\section{Nucleic acid amplification techniques in infectious diseases}

In recent years, the introduction of molecular methods in the diagnostic workup of respiratory infectious diseases has increased. Molecular techniques, such as polymerase chain reaction (PCR) offer some advantages over conventional techniques (culture, serology). First of all, the use of PCR leads to an increase in sensitivity, especially in micro-organisms that can not (easily) be cultured ${ }^{97,98}$ and in case of a low burden of micro-organisms. Furthermore it is a universal technique making it possible to identify every micro-organism, using unique primers and probes, making it very specific. Finally, PCR is a relatively rapid method for identification compared to culture and serology ${ }^{98}$. Several PCR methods can be useful in the identification of causative organisms in pulmonary infectious diseases. In case of a conventional PCR method, post-PCR products are analysed by means of gel-electrophoresis, enzyme immunoassay detection or dot-blot hybridisation. In recent years, the conventional PCR methods are increasingly replaced by real-time PCR reactions (Figure 1.8) which do not require separate post-PCR product analysis. This has led to results being 


\section{Introduction}

available earlier and with less chance of contamination since there is no need to open PCR tubes after amplification. An additional advantage of real-time PCR methods is the fact that this method measures the amount of amplified PCR product during each cycle. This makes it possible to obtain quantitative results, which is essential when identifying micro-organisms which can lead to either carrier state or infection (e.g. P. jiroveci, ${ }^{99}$ ). Combining diagnostic PCRs in order to identify different micro-organisms at the same time may be the future since respiratory pathogens can cause the same clinical symptoms. Using PCR assays which only detect one micro-organism may prove to be too expensive and require too much material. Multiplex PCR reactions permit the amplification and identification of multiple pathogens simultaneously, however in general, they are less sensitive compared to mono-specific PCRs ${ }^{100}$. PCR can be used for the identification of many causative organisms of pneumonia. Table 1.6 sums up the most prevalent, causative micro-organisms of pulmonary infection for which a PCRs is described in literature with their references.

Table 1.6 PCR assays described in literature for different micro-organism causing pulmonary infection.

\begin{tabular}{ll}
\hline Micro-organisme & PCR described $^{*}$ \\
\hline Bacteria: & $(108,109)$ \\
Streptococcus pneumoniae & $(108,109)$ \\
Haemophilus influenzae & $(100,108)$ \\
Mycoplasma pneumoniae & $(100,108)$ \\
Chlamydia pneumoniae & $(110,111)$ \\
Legionella pneumophila & \\
Fungi: & $(112-114)$ \\
Pneumocystis jiroveci & $(115,116)$ \\
Aspergillus fumigatus & \\
Viruses: & $(117,118)$ \\
HSV-1,2 & $(100,119)$ \\
RSV & $(120,121)$ \\
HMPV & $(100,119)$ \\
Influenza A,B & $(100,119)$ \\
Parainfluenza 1,2,3 & \\
\hline
\end{tabular}

* for detection in respiratory samples. 
$30 \mid$ Chapter 1

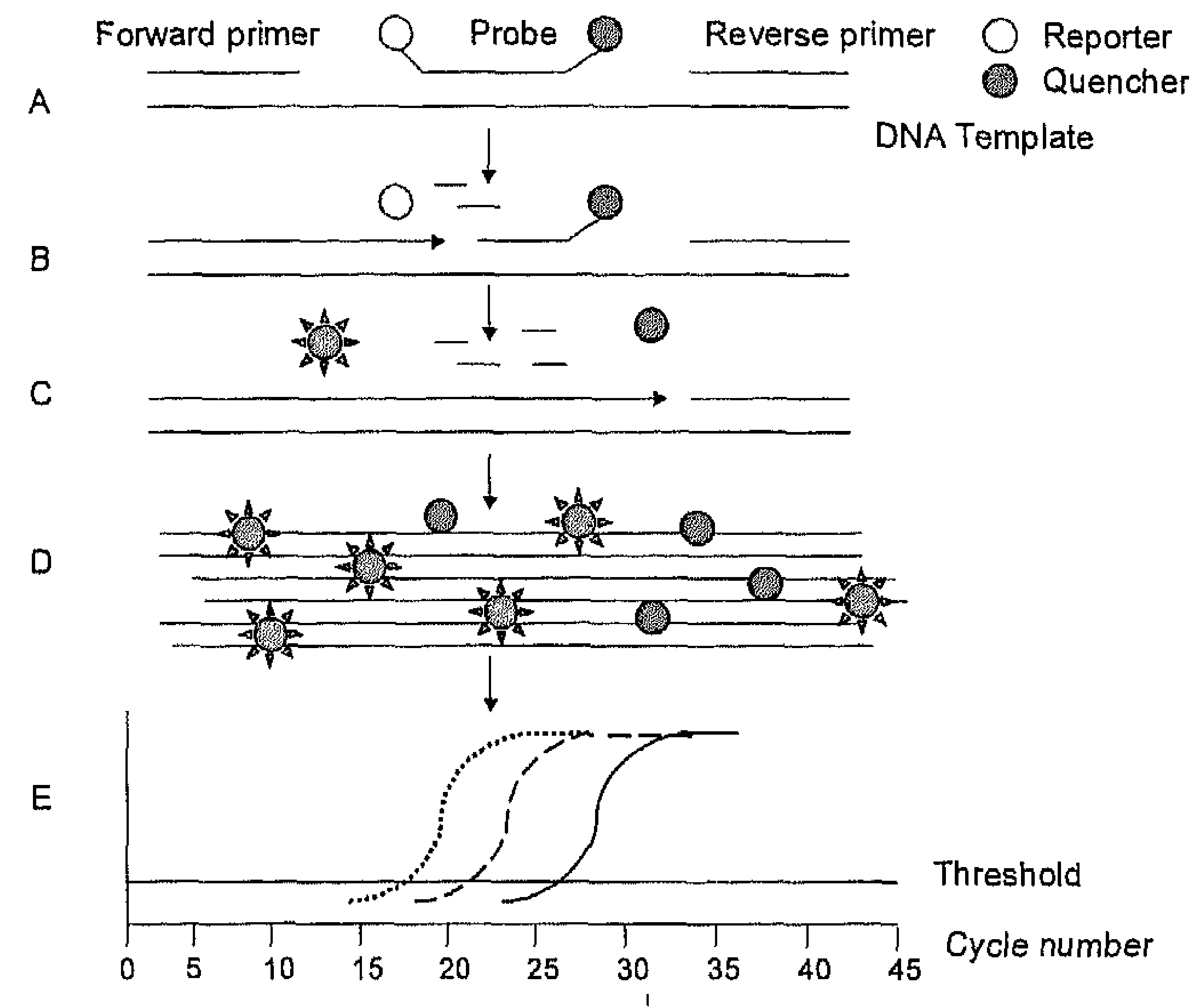

Figure 1.8 Theoretic background of real time PCR

A. After the DNA has been isolated from the sample, it is denaturated into two single strands. This single stranded DNA is used as a template. Forward and reverse primers are designed to bind to a conserved region of the target DNA. A nonextendable hybridization probe is designed to bind the target internal to the PCR product. The probe contains a reporter fluorescent dye on the $5^{\prime}$ end and a quencher dye to the 3 'end.

B. Taq polymerase extends the DNA from the forward primer until it encounters the probe. Since the probe is non-extendable the Taq polymerase removes the probe nucleotides

C. This results in the parting of the quencher dye and the reporter fluorescent dye, allowing the detection of the fluorescent dye.

$D$. At the end of the 40 cycles, the sample contains the extended DNA, and a concomitant amount of fluorescent dye.

E. Product analysis. The amount of fluorescence (y-axis) is measured at the end of each cycle ( $x$-axis). Relative quantification is possible by means of the $\mathrm{Ct}$ value (threshold cycle), referring to the cycle at the end of which the fluorescent signal crosses the threshold.

PCR: Polymerase Chain Reaction, DNA: Desoxyribo Nucleic Acid 


\section{Aims of the study}

The scope of the studies presented in this thesis was to improve the quality of BAL as a diagnostic tool in pulmonary infectious diseases and to shorten the time in which the diagnosis can be made. In combination with the patients history, physical examination, and imaging of the lungs, BALF cytology is a widely used additional tool in establishing or ruling out of pulmonary infections. Traditionally BALF work-up includes a total cell count, a differential cell count, additional stains, quantitative culture and additional cultures. The standardisation of BALF analysis is very important to ensure comparability between the different laboratories. In our laboratory BALF analysis (differential cell count as well as quantitative cultures) is well standardised using the protocol developed by de Brauwer and co-workers ${ }^{21,29,31,32,101}$. However microscopic analysis of BALF does not always reach the sensitivity required to make a definitive diagnosis, for instance due to the quality of the sample, use of antibiotics at the time of BAL or due to a low burden of the micro-organism in BALF. Furthermore, bacterial and viral cultures take time, up to 48 hours for bacterial and up to 7 days for viral culture and since an early diagnosis is essential in most infectious diseases, fast alternatives are investigated.

In the diagnostic approach of patients with diffuse interstitial lung diseases the differential cell count of BALF samples is helpful in guiding the clinician to a certain disease (Table 1.3). Therefore, the technical performance should be standardised and optimised. Previous reports ${ }^{23}$ indicated that using cytocentrifuge slides may influence the recovery of lymphocytes in particular. This prompted us to improve our recovery rate of cells. Two previously performed studies by de Brauwer et al. ${ }^{21,31}$ already showed that the differential cell count is influenced by the area counted ${ }^{31}$ and the protocol used for cytocentrifugation ${ }^{21}$. We hypothesised that the use of slides with a positively charged cell surface may provide superior cell adhesion when used for cytocentrifugation of BALF. Previously, the same principal has been shown in the cytology of buccal smears ${ }^{102}$, urine ${ }^{103}$ and cerebrospinal fluid samples ${ }^{104}$. In chapter 2, we evaluated Polylysine-coated slides in the diagnostic work-up of clinical BALF samples.

In chapter 3, the presence of reactive type II pneumocytes in BALF were investigated. RPII cells had been described in patients with adult respiratory distress syndrome (ARDS) ${ }^{27}$ and Pneumocystis jiroveci pneumonia ${ }^{28}$. It was hypothesised they may be present in specific pulmonary diseases and therefore could play a role in limiting the differential diagnosis in patients.

Antibiotic therapy at time of lavage has been shown to influence the quantitative culture results. Their influence on the percentage infected cells (\%IC) has resulted in conflicting data. Some studies show no influence of antibiotic therapy on $\% \mathrm{IC}^{105}$ whilst others show a decline in both sensitivity and 
$32 \mid$ Chapter 1

specificity of $\% \mathrm{IC}^{106}$ when patient are on antibiotic therapy at the time of lavage. Since ventilator-associated pneumonia has a high mortality, an early diagnosis is important, however many patients admitted to the intensive care unit already receive antibiotic therapy at the time of the lavage. In chapter 4 , therefore, the effect of antibiotic therapy on the reliability of cytological parameters in BALF in the prediction of VAP was assessed.

In most hospitals, facilities to perform BALF analysis on a 24-hour basis, are not present. Therefore a fast method for differentiating between VAP and nonVAP, present in all hospitals, was sought. PCT and CRP both are acute fase proteins associated with inflammation/infection and the since the diagnostic test is available in every hospital, they appeared ideal candidates. In chapter 5 high-sensitivity-C-reactive protein and -procalcitonin concentrations in both serum and BALF were measured. The hypothesis was that local production of either or both of the proteins in the event of pneumonia would result in an elevation of the protein concentration in BALF, making it a possible to differentiate between VAP and non-VAP.

In the past, PCP was an indication for HIV. However, since the introduction of HAART and chemoprophylaxis the number of HIV-positive patients diagnosed with PCP has decreased. Patients at risk have shifted from HIV-positive patients to patients otherwise immunocompromised (e.g. malignancy, corticosteroid use). The main difference this makes for the laboratory diagnosis is the fact that the $P$. jioveci burden in these patients is often very low. Since microscopy of BALF still remains the "gold standard" for the diagnosis PCP, two problems have emerged. First of all, since the incidence of PCP has declined it has become more difficult to ascertain the required level of expertise. Secondly, since the majority of patients at risk have a low $P$. jiroveci burden, microscopy, even in the hands of experts, is extremely time-consuming and may be not sensitive enough. Real-time PCR may be a solution for this problem, however commercial kits and quality control panels are not available making it difficult to evaluate and implement the PCR for $P$. jiroveci in the diagnostic work-up of BALF. In chapter 6 , the inter-laboratory comparison of three different real-time PCR assays for the detection of $P$. jiroveci in BALF is described, giving a starting point for the clinical validation of comparable PCRs. In a large percentage of patients suspected of a pneumonia in whom BAL is performed, no causative organism is found. The hypothesis was that viral infections may play a role in these patients. HSV is relatively often isolated from BALF, however clinical relevance remains unclear. In chapter 7, therefore we evaluated the HSV viral load in BALF in relationship with outcome in intensive care patients. Finally, chapter 8 contains a summary and the conclusions from the preceding chapters. 


\section{References}

1. Rogers RM, Braunstein MS, Shurman JF. Role of bronchopulmonary lavage in the treatment of respiratory failure: a review. Chest. 1972;62:Suppl:95S-106.

2. Ramirez J, Kieffer RF, Jr., Ball WC, Jr. Bronchopulmonary lavage in man. Ann Intern Med. 1965;63:819-28.

3. Pratt SA, Finley TN, Smith MH, Ladman AJ. A comparison of alveolar macrophages and pulmonary surfactant obtained from the lungs of human smokers and nonsmokers by endobronchial lavage. Anat Rec. 1969;163:497-507.

4. Finley TN, Swenson EW, Curran WS, Huber GL, Ladman AJ. Bronchopulmonary lavage in normal subjects and patients with obstructive lung disease. Ann Intern Med. 1967;66:651-8.

5. Reynolds HY. Use of bronchoalveolar lavage in humans--past necessity and future imperative. Lung 2000;178:271-93.

6. Goldstein RA, Rohatgi PK, Bergofsky EH, Block ER, Daniele RP, Dantzker DR, Davis GS, Hunninghake GW, King TE Jr, Metzger WJ, et al. Clinical role of bronchoalveolar lavage in adults with pulmonary disease. Am Rev Respir Dis. 1990;142:481-6.

7. Klech H, Hutter C. Side-effects and safety of BAL. Eur Respir J. 1990;3:939-40, 961-9.

8. Drent $M$, Baughman RP, Meyer $P$. Bronchoalveolar Lavage. In: Costabel U, DuBois R, Egan J, editors. Diffuse Parenchymal Lung Disease. Basel: Karger; 2007.

9. Clinical guidelines and indications for bronchoalveolar lavage (BAL): Report of the European Society of Pneumology Task Group on BAL. Eur Respir J. 1990;3:937-76.

10. Haslam PL, Baughman RP. ERS task force report on a-cellular components in BAL. Eur Respir Rev 1999;9:25-7.

11. Meduri GU, Chastre J. The standardization of bronchoscopic techniques for ventilatorassociated pneumonia. Chest 1992;102(5 Suppl 1):557S-64S.

12. Pingleton SK, Harrison GF, Stechschulte DJ, Wesselius LJ, Kerby GR, Ruth WE. Effect of location, $\mathrm{pH}$, and temperature of instillate in bronchoalveolar lavage in normal volunteers. Am Rev Respir Dis. 1983;128:1035-7.

13. Jacobs JA, Stobberingh EE, Cornelissen El, Drent M. Detection of Streptococcus pneumoniae antigen in bronchoalveolar lavage fluid samples by a rapid immuno-chromatographic membrane assay. J Clin Microbiol. 2005;43:4037-40.

14. Croce MA, Fabian TC, Mueller EW, Maish GO, 3rd, Cox JC, Bee TK, Boucher BA, Wood GC. The appropriate diagnostic threshold for ventilator-associated pneumonia using quantitative cultures. J Trauma. 2004;56:931-4; discussion 934-6.

15. Costabel U, Guzman J. Bronchoalveolar lavage in interstitial lung disease. Curr Opin Pulm Med. 2001;7:255-61.

16. Ettensohn DB, Jankowski MJ, Duncan PG, Lalor PA. Bronchoalveolar lavage in the normal volunteer subject. I. Technical aspects and intersubject variability. Chest. 1988;94:275-80.

17. Ettensohn DB, Jankowski MJ, Redondo AA, Duncan PG. Bronchoalveolar lavage in the normal volunteer subject. 2. Safety and results of repeated $B A L$, and use in the assessment of intrasubject variability. Chest. 1988;94:281-5.

18. Reynolds HY, Fulmer JD, Kazmierowski JA, Roberts WC, Frank MM, Crystal RG. Analysis of cellular and protein content of broncho-alveolar lavage fluid from patients with idiopathic pulmonary fibrosis and chronic hypersensitivity pneumonitis. J Clin Invest. 1977;59:165-75.

19. Low RB, Davis GS, Giancola MS. Biochemical analyses of bronchoalveolar lavage fluids of healthy human volunteer smokers and nonsmokers. Am Rev Respir Dis. 1978;118:863-75.

20. Crystal RG, Reynolds HY, Kalica AR. Bronchoalveolar lavage. The report of an international conference. Chest. 1986;90:122-31.

21. De Brauwer El, Jacobs JA, Nieman $F$, Bruggeman $C A$, Wagenaar SS, Drent $M$. Cytocentrifugation conditions affecting the differential cell count in bronchoalveolar lavage fluid. Anal Quant Cytol Histol. 2000;22:416-22.

22. Jacobs $J A$, De Brauwer $E$. BAL fluid cytology in the assessment of infectious lung disease. Hosp Med. 1999;60:550-5. 
$34 \mid$ Chapter 1

23. Saltini C, Hance AJ, Ferrans VJ, Bassef F, Bitterman PB, Crystal RG. Accurate quantification of cells recovered by bronchoalveolar lavage. Am Rev Respir Dis. 1984;130:650-8.

24. Allen JN, Davis WB, Pacht ER. Diagnostic significance of increased bronchoalveolar lavage fluid eosinophils. Am Rev Respir Dis. 1990;142:642-7.

25. Foresi A, Bertorelli G, Pesci A, Chetta A, Olivieri D. Inflammatory markers in bronchoalveolar lavage and in bronchial biopsy in asthma during remission. Chest. 1990;98:528-35.

26. Pesci A, Rossi GA, Bertorelli G, Aufiero A, Zanon P. Olivieri D. Mast cells in the airway lumen and bronchial mucosa of patients with chronic bronchitis. Am J Respir Crit Care Med. 1994;149:1311-6.

27. Grotte D, Stanley MW, Swanson PE, Henry-Stanley MJ, Davies S. Reactive type II pneumocytes in bronchoalveolar lavage fluid from adult respiratory distress syndrome can be mistaken for cells of adenocarcinoma. Diagn Cytopathol 1990;6:317-22.

28. Jacobs JA, Dieleman MM, Cornelissen EJ, Groen EA, Wagenaar SS, Drent M. Bronchoalveolar lavage fluid cytology in patients with Pneumocystis carinii pneumonia. Acta Cyto $2001 ; 45: 317-26$

29. De Brauwer $E_{1}$ Jacobs J, Nieman F, Bruggeman $C$, Drent $M$. Test characteristics of acridine orange, Gram, and May-Grunwald-Giemsa stains for enumeration of intracellular organisms in bronchoalveolar lavage fluid. J Clin Microbiol 1999;37;427-9.

30. Allaouchiche $B$, Jaumain $H$, Dumontet $C$, Motin J. Early diagnosis of ventilator-associated pneumonia. Is it possible to define a cutoff value of infected cells in BAL fluid? Chest 1996;110:1558-65.

31. De Brauwer EI, Drent M, Muider PG, Bruggeman CA, Wagenaar SS, Jacobs JA. Differential cell analysis of cytocentrifuged bronchoalveolar fluid samples affected by the area counted. Anal Quant Cytol Histol. 2000;22:143-9.

32. De Brauwer El, Jacobs JA, Nieman F, Bruggeman CA, Drent M. Bronchoalveolar lavage fluid differential cell count. How many cells should be counted? Anal Quant Cytol Histol. 2002;24:337-41.

33. Baselski V. Microbiologic diagnosis of ventilator-associated pneumonia. Infect Dis Clin North Am 1993; $7: 331-57$

34. Haslam PL, Baughman RP. Report of ERS Task Force: guidelines for measurement of acellular components and standardization of BAL. Eur Respir J. 1999;14:245-8.

35. Wiedermann FJ, Mayr AJ, Kaneider NC, Fuchs D, Mutz NJ, Schobersberger W. Alveolar granulocyte colony-stimulating factor and alpha-chemokines in relation to serum levels, pulmonary neutrophilia, and severity of lung injury in ARDS. Chest 2004;125:212-9.

36. Ratjen $F$, Havers $W$, Braun J. Intrapulmonary protein leakage in immunocompromised children and adults with pneumonia. Thorax. 1999;54:432-6.

37. Merrill WW, Out TA. Measurement of immunoglobulins in bronchoalveolar lavage fluid. Eur Respir Rev 1999;9:70-5.

38. Braun J, O'Connor $\mathrm{C}$. Measurement of proteases and antiproteases in bronchoalveolar lavage fluid. Eur Respir Rev 1999;9:76-85.

39. Juillerat-Jeanneret $L$, Soubrier $G$, Aubert JD, Leuenberger $P$. Measurement of angiotensin converting enzyme in bronchoalveolar lavage fluid. Eur Respir Rev 1999;9:86-92.

40. Kelly FJ, Buhl R, Sandstrom T. Measurement of antioxidants, oxidants and oxidation products in bronchoalveolar lavage fluid. Eur Respir Rev 1999;9:93-8.

41. Chavis C, Arnoux B, Bousquet J. Detection of lipid mediators in bronchoalveolar lavage fluid. Eur Respir Rev 1999;9:99-105.

42. Strieter RM, Miller EJ, Kurdowsa AK, Reid PT, Donelly SC. Measurement of cytokines in bronchoalveolar lavage fluid. Eur Respir Rev 1999;9:106-12.

43. Dentener MA, Bouma MG, Drent M, Wouters EF, Buurman WA. Measurement of soluble adhesion molecules (sICAM-I and sE-selectin) in bronchoalveolar lavage fluid. Eur Respir Rev 1999;9:113-7.

44. Pohl WR, Kummer F, Bjermer LH. Measurement of markers of fibrosis and extra-cellular matrix components in bronchoalveolar lavage fluid. Eur Respir Rev 1999;9:118-25.

45. Bjermer LH, Ahlstedt $S$, Braun J. Measurement of granulocyte derived markers in bronchoalveolar lavage fluid. Eur Respir Rev 1999;9:126-34. 
46. Pirozynski $M$, Spatafora $M$, Rennard SI. Measurement of tumour markers in bronchoalveolar lavage fluid. Eur Respir Rev 1999;9:135-40.

47. Le Moullec JM, Jullienne A, Chenais J, Lasmoles F, Guliana JM, Milhaud G, Moukhtar MS. The complete sequence of human preprocalcitonin. FEBS Lett 1984;167:93-7.

48. Nijsten MW, Olinga $P$, The TH, de Vries EG, Koops HS, Groothuis GM, Limburg PC, ten Duis $\mathrm{HJ}$, Moshage $H_{1}$. Hoekstra $H J$, Bijzet $J$, Zwaveling $J H$. Procalcitonin behaves as a fast responding acute phase protein in vivo and in vitro. Crit Care Med 2000;28:458-61.

49. Assicot M, Gendrel D, Carsin H, Raymond J, Guilbaud J, Bohuon C. High serum procalcitonin concentrations in patients with sepsis and infection. Lancet 1993;341:515-8.

50. Oberhoffer $M$, Stonans I, Russwurm S, Stonane $E$, Vogelsang $H$, Junker U, Jäger $L$, Reinhart K.. Procalcitonin expression in human peripheral blood mononuclear cells and its modulation by lipopolysaccharides and sepsis-related cytokines in vitro. J Lab Clin Med 1999;134:49-55.

51. Gendrel D, Assicot M, Raymond J, Moulin F, Francoual C, Badoual J, Bohuon C. Procalcitonin as a marker for the early diagnosis of neonatal infection. J Pediatr 1996;128:570-3.

52. Gendrel D, Raymond J, Assicot M, Moulin F, Iniguez JL, Lebon P, Bohuon C. Measurement of procalcitonin levels in children with bacterial or viral meningitis. Clin Infect Dis 1997;24: $1240-2$.

53. Ugarte $H$, Silva $E$, Mercan $D$, De Mendonca $A$, Vincent $J L$. Procalcitonin used as a marker of infection in the intensive care unit. Crit Care Med 1999;27:498-504.

54. Brunkhorst FM, Eberhard OK, Brunkhorst R. Discrimination of infectious and noninfectious causes of early acute respiratory distress syndrome by procalcitonin. Crit Care Med $1999 ; 27: 2172-6$

55. Gerard $Y$, Hober D, Petitjean S, Assicot $M$, Bohuon C, Mouton $Y$, Wattré P. High serum procalcitonin level in a 4-year-old liver transplant recipient with a disseminated candidiasis. Infection 1995;23:310-1.

56. Davis TM, Assicot $M$, Bohuon $C$, St John A, Li GQ, Anh TK. Serum procalcitonin concentrations in acute malaria. Trans R Soc Trop Med Hyg 1994;88:670-1.

57. Reinhart K, Karzai W, Meisner M. Procalcitonin as a marker of the systemic inflammatory response to infection. Intensive Care Med. 2000;26:1193-200.

58. Meisner $M$, Tschaikowsky $K$, Hutzler $A$, Schick $C$, Schuttler J. Postoperative plasma concentrations of procalcitonin after different types of surgery. Intensive Care Med 1998;24: 680-4.

59. Mimoz O, Benoist JF, Edouard AR, Assicot M, Bohuon C, Samii K. Procalcitonin and Creactive protein during the early posttraumatic systemic inflammatory response syndrome. Intensive Care Med. 1998;24:185-8.

60. Duflo F, Debon R, Goudable J, Chassard D, Allaouchiche B. Alveolar and serum oxidative stress in ventilator-associated pneumonia. $\mathrm{Br} J$ Anaesth 2002;89:231-6.

61. Boussekey N, Leroy O, Alfandari S, Devos P, Georges H, Guery B. Procalcitonin kinetics in the prognosis of severe community-acquired pneumonia. Intensive Care Med. 2006;32: 469-72.

62. Weinhold B, Bader A, Poli $V$, Ruther U. Interleukin-6 is necessary, but not sufficient, for induction of the humanC-reactive protein gene in vivo. Biochem J. 1997;325:617-21.

63. Paffen $E$, DeMaat MP. C-reactive protein in atherosclerosis: A causal factor? Cardiovasc Res. 2006;71:30-9.

64. Prasad K. C-reactive protein (CRP)-lowering agents. Cardiovasc Drug Rev. 2006;24:33-50.

65. Seligman R, Meisner M, Lisboa TC, Hertz FT, Filippin TB, Fachel JM, Teixeira PJ. Decreases in procalcitonin and C-reactive protein are strong predictors of survival in ventilatorassociated pneumonia. Crit Care. 2006;10:R125.

66. Jacobs JA, De Brauwer El, Ramsay G, Cobben NA, Wagenaar SS, van der Ven AJ, Bruggeman CA, Drent $M$. Detection of non-infectious conditions mimicking pneumonia in the intensive care setting: usefulness of bronchoalveolar fluid cytology. Respir Med 1999;93: $571-8$.

67. Trouillet $\mathrm{JL}$, Chastre J, Vuagnat $A$, Joly-Guillou ML, Combaux D, Dombret MC, Gibert C. Ventilator-associated pneumonia caused by potentially drug-resistant bacteria. Am J Respir Crit Care Med 1998;157:531-9. 
68. Chastre J, Fagon JY. Ventilator-associated pneumonia. Am J Respir Crit Care Med 2002; 165:867-903.

69. Rello J, Ollendorf DA, Oster $G$, Vera-Llonch $M$, Bellm $L$, Redman R, Kollef MH; VAP Outcomes Scientific Advisory Group. Epidemiology and outcomes of ventilator-associated pneumonia in a large US database. Chest. 2002;122:2115-21.

70. Richards MJ, Edwards JR, Culver DH, Gaynes RP. Nosocomial infections in medical intensive care units in the United States. National Nosocomial Infections Surveillance System. Crit Care Med 1999;27:887-92.

71. Ewig S, Torres A, El-Ebiary M, Fabregas N, Hernandez C, Gonzalez J, Nicolás JM, Soto L. Bacterial colonization patterns in mechanically ventilated patients with traumatic and medical head injury. Incidence, risk factors, and association with ventilator-associated pneumonia. Am J Respir Crit Care Med. 1999;159:188-98.

72. Park DR. The microbiology of ventilator-associated pneumonia. Respir Care. 2005;50(6):74263; discussion 763-5.

73. Bonten MJ, Bergmans DC, Stobberingh EE, van der Geest S, De Leeuw PW, van Tiel FH, Gaillard CA. Implementation of bronchoscopic techniques in the diagnosis of ventilatorassociated pneumonia to reduce antibiotic use. Am J Respir Crit Care Med 1997;156:1820-4.

74. Kirtland SH, Corley DE, Winterbauer RH, Springmeyer SC, Casey KR, Hampson NB, Dreis DF. The diagnosis of ventilator-associated pneumonia: a comparison of histologic, microbiologic, and clinical criteria. Chest 1997;112:445-57.

75. Rello J, Gallego M, Mariscal D, Sonora R, Valles J. The value of routine microbial investigation in ventilator-associated pneumonia. Am J Respir Crit Care Med. 1997;156:196-200.

76. Luna CM, Vujacich $P$, Niederman MS, Vay $C$, Gherardi $C$, Matera J, Jolly EC. Impact of BAL data on the therapy and outcome of ventilator-associated pneumonia. Chest. 1997;111: 676-85.

77. Kollef MH, Ward S. The influence of mini-BAL cultures on patient outcomes: implications for the antibiotic management of ventilator-associated pneumonia. Chest. 1998;113:412-20.

78. Alvarez-Lerma F. Modification of empiric antibiotic treatment in patients with pneumonia acquired in the intensive care unit. ICU-Acquired Pneumonia Study Group. Intensive Care Med. 1996;22:387-94.

79. Chagas C. Nova tripanosomiaze humana. Mem Istit Oswaldo Cruz 1909;1:159-218.

80. Delanoe $P$, Delanoe M. Sur les rapports des kystes de Carinii du poumon des rats avec le trypanosoma Lewisii. CR Acad Sci (Paris) 1912;155:658-60.

81. Goldman AS, Goldman LR, Goldman DA. What caused the epidemic of Pneumocystis pneumonia in European premature infants in the mid-20th century? Pediatrics. 2005:115: e725-36.

82. Vanek J, Jirovec O. Parasitic pneumonia. Interstitial plasma cell pneumonia of premature, caused by pneumocystis Carinii. Zentralbl Bakteriol Parasitenkd Infektionskr Hyg. 1952;158:120-7.

83. Edman JC, Kovacs JA, Masur H, Santi DV, Elwood HJ, Sogin ML. Ribosomal RNA sequence shows Pneumocystis carinii to be a member of the fungi. Nature 1988;334:519-22.

84. Gigliotti $F$, Harmsen AG, Haidaris, $C G$, Haidaris PJ. Pneumocystis carinii is not universally transmissible between mammalian species. Infect Immun. 1993;61:2886-90.

85. Stringer $J R$, Beard $C B$, Miller RF, Wakefield $A E$. A new name (Pneumocystis jiroveci) for Pneumocystis from humans. Emerg Infect Dis 2002;8:891-6.

86. Peglow SL, Smulian $A G$, Linke MJ, Pogue $C L$, Nurre $S$, Crisler J, Phair J, Gold JW, Armstrong $D$, Walzer PD. Serologic responses to Pneumocystis carinii antigens in health and disease. J Infect Dis. 1990;161:296-306.

87. Kovacs JA, Gill VJ, Meshnick S, Masur $\mathrm{H}$. New insights into transmission, diagnosis, and drug treatment of Pneumocystis carinii pneumonia. Jama 2001;286:2450-60.

88. Limper $A H$, Offord KP, Smith TF, Martin WJ, 2nd. Pneumocystis carinii pneumonia. Differences in lung parasite number and inflammation in patients with and without AIDS. Am Rev Respir Dis 1989;140:1204-9.

89. Baughman RP. Current Methods of Diagnosis. In: Walzer PD, editor. Pneumocystis carinii pneumonia. New York: Marcel Dekker, Inc; 1994:381-401. 
90. Wallace JM. Pulmonary infection in human immunodeficiency disease: viral pulmonary infections. Semin Respir Infect 1989;4:147-54.

91. Kim EA, Lee KS, Primack SL, Yoon HK, Byun HS, Kim TS, Suh GY, Kwon OJ, Han J. Viral pneumonias in adults: radiologic and pathologic findings. Radiographics 2002;22:S137-49.

92. Camps $K$, Jorens PG, Demey HE, Pattyn SR, leven M. Clinical significance of herpes simplex virus in the lower respiratory tract of critically ill patients. Eur J Clin Microbiol Infect Dis 2002;21:758-9..

93. Cook $\mathrm{CH}$, Martin LC, Yenchar JK, Lahm MC, McGuinness B, Davies EA, Ferguson RM. Occult herpes family viral infections are endemic in critically ill surgical patients. Crit Care Med 2003:31:1923-9.

94. Bruynseels $P$, Jorens PG, Demey HE, Goossens H, Pattyn SR, Elseviers MM, Weyler J, Bossaert $L L$, Mentens $Y$, leven $M$. Herpes simplex virus in the respiratory tract of critical care patients: a prospective study. Lancet 2003;362:1536-41.

95. van den Brink JW, Simoons-Smit AM, Beishuizen A, Girbes AR, Strack van Schijndel RJ, Groeneveld $A B$. Respiratory herpes simplex virus type 1 infection/colonisation in the critically ill: marker or mediator? J Clin Virol 2004;30:68-72.

96. Oosterheert JJ, van Loon AM, Schuurman R, Hoepelman Al, Hak E, Thijsen S, Nossent G, Schneider MM, Hustinx WM, Bonten MJ. Impact of rapid detection of viral and atypical bacterial pathogens by real-time polymerase chain reaction for patients with lower respiratory tract infection. Clin Infect Dis 2005;41:1438-44.

97. Olsson $\mathrm{M}$, Stralin $\mathrm{K}$, Holmberg $\mathrm{H}$. Clinical significance of nested polymerase chain reaction and immunofluorescence for detection of Pneumocystis carinii pneumonia. Clin Microbiol infect 2001;7:492-7.

98. Templeton KE, Scheltinga SA, Graffelman AW, Van Schie JM, Crielaard JW, Sillekens $P$, Van Den Broek PJ, Goossens H, Beersma MF, Claas EC. Comparison and evaluation of real-time $P C R$, real-time nucleic acid sequence-based amplification, conventional PCR, and serology for diagnosis of Mycoplasma pneumoniae. J Clin Microbiol 2003;41:4366-71.

99. Sing A, Trebesius $K$, Roggenkamp A, Russmann $H$, Tybus $K$, Pfaff $F$, Bogner JR, Emminger $C$, Heesemann J. Evaluation of diagnostic value and epidemiological implications of $P C R$ for Pneumocystis carinii in different immunosuppressed and immunocompetent patient groups. J Clin Microbiol 2000;38:1461-7.

100. Grondahl B, Puppe W, Hoppe A, Kuhne I, Weigl JA, Schmitt HJ. Rapid identification of nine microorganisms causing acute respiratory tract infections by single-tube multiplex reverse transcription-PCR: feasibility study. J Clin Microbiol. 1999;37:1-7.

101. Jacobs JA, De Brauwer El, Cornelissen EI, Drent M. Accuracy and precision of quantitative calibrated loops in transfer of bronchoalveolar lavage fluid. J Clin Microbiol 2000;38:2117-21.

102. Mazia D, Schatten G, Sale W. Adhesion of cells to surfaces coated with polylysine. Applications to electron microscopy. J Cell Biol. 1975;66:198-200.

103. Husain $O A$, Millett JA, Grainger JM. Use of polylysine-coated slides in preparation of cell samples for diagnostic cytology with special reference to urine sample. J Clin Pathol. 1980;33:309-11.

104. van Oostenbrugge RJ, Arends JW, Buchholtz R, Twijnstra A. Cytology of cerebrospinal fluid. Are polylysine-coated slides useful? Acta Cytol. 1997;41:1510-2

105. Timsit JF, Cheval C, Gachot B, Bruneel F, Wolff M, Carlet J, Regnier B. Usefulness of a strategy based on bronchoscopy with direct examination of bronchoalveolar lavage fluid in the initial antibiotic therapy of suspected ventilator-associated pneumonia. Intensive Care Med 2001;27:640-7.

106. Sirvent JM, Vidaur L, Gonzalez S, Castro P, de Batlle J, Castro A, Bonet A. Microscopic examination of intracellular organisms in protected bronchoalveolar mini-lavage fluid for the diagnosis of ventilator-associated pneumonia. Chest. 2003;123:518-23.

107. Reynolds HY. Bronchoalveolar lavage. Am Rev Respir Dis. 1987;135:250-63.

108. Stralin K, Korsgaard J, Olcen P. Evaluation of a multiplex PCR for bacterial pathogens applied to bronchoalveolar lavage. Eur Respir J. 2006;28:568-75. 
$30 \mid$ Chapter 1

109. Kais $M$, Spindler $C$, Kalin M, Ortqvist A, Giske CG. Quantitative detection of Streptococcus pneumoniae, Haemophilus influenzae, and Moraxella catarrhalis in lower respiratory tract samples by real-time PCR. Diagn Microbiol Infect Dis. 2006;55:169-78.

110. Templeton KE, Scheltinga SA, Sillekens P, Crielaard JW, van Dam AP, Goossens H, Claas EC. Development and clinical evaluation of an internally controlled, single-tube multiplex realtime PCR assay for detection of Legionella pneumophila and other Legionella species. $\mathrm{J}$ Clin Microbiol. 2003;41:4016-21.

111. Rantakokko-Jalava $K$, Jalava J. Development of conventional and real-time PCR assays for detection of Legionella DNA in respiratory specimens. J Clin Microbiol. 2001;39:2904-10.

112. Helweg-Larsen J, Jensen JS, Benfield T, Svendsen UG, Lundgren JD, Lundgren $B$. Diagnostic use of PCR for detection of Pneumocystis carinii in oral wash samples. J Clin Microbiol 1998;36:2068-72.

113. Larsen $H H$, Kovacs JA, Stock $F$, Vestereng VH, Lundgren $B$, Fischer SH, Gill VJ. Development of a rapid real-time PCR assay for quantitation of Pneumocystis carinii $f . s p$. carinii. J Clin Microbiol 2002;40:2989-93.

114. Wakefield AE, Pixley FJ, Banerji S, Sinclair K, Miller RF, Moxon ER, Hopkin JM. Detection of Pneumocystis carinii with DNA amplification. Lancet 1990;336:451-3.

115. Rantakokko-Jalava K, Laaksonen S, Issakainen J, Vauras J, Nikoskelainen J, Viljanen MK, Salonen J. Semiquantitative detection by real-time PCR of Aspergillus fumigatus in bronchoalveolar lavage fluids and tissue biopsy specimens from patients with invasive aspergillosis. J Clin Microbiol. 2003;41:4304-11.

116. Spiess B, Buchheidt D, Baust $C$, Skladny $H$, Seifarth $W$, Zeilfelder $U$, Leib-Mösch $C, M o ̈ r z ~ H$, Hehlmann R. Development of a LightCycler PCR assay for detection and quantification of Aspergillus fumigatus DNA in clinical samples from neutropenic patients. $J$ Clin Microbiol. 2003;41:1811-8.

117. O'Neill HJ, Wyatt DE, Coyle PV, McCaughey C, Mitchell F. Real-time nested multiplex PCR for the detection of herpes simplex virus types 1 and 2 and varicella zoster virus. J Med Virol. 2003;71:557 60 .

118. van Doornum GJ, Guldemeester J, Osterhaus AD, Niesters HG. Diagnosing herpesvirus infections by real-time amplification and rapid culture. J Clin Microbiol. 2003;41:576-80.

119. Templeton KE, Scheltinga SA, Beersma MF, Kroes AC, Claas EC. Rapid and sensitive method using multiplex real-time PCR for diagnosis of infections by influenza a and influenza $B$ viruses, respiratory syncytial virus, and parainfluenza viruses $1,2,3$, and 4 . J Clin Microbiol. 2004;42:1564-9.

120. Scheltinga SA, Templeton KE, Beersma MF, Claas EC. Diagnosis of human metapneumovirus and rhinovirus in patients with respiratory tract infections by an internally controlled multiplex real-time RNA PCR. J Clin Virol. 2005;33:306-11.

121. Cote $S$, Abed $Y$, Boivin $G$. Comparative evaluation of real-time PCR assays for detection of the human metapneumovirus. J Clin Microbiol 2003;41:3631-5. 
Chapter

Use of Polylysine-coated slides in clinical

bronchoalveolar lavage fluid samples

CFM Linssen, JA Jacobs, FHM Nieman, EIM Cornelissen, M. Drent Analytical and Quantitative Cytology and Histology 2003;25:281-284 


\section{Abstract}

\section{Objective}

Polylysine coating of microscope slides provides superior cell adhesion. We compared polylysinecoated (PLC) slides to conventional slides in cyto-centrifuged bronchoalveolar lavage (BAL) fluid samples.

\section{Study design}

Twenty BAL fluid (BALF) samples with representative numbers of alveolar macrohages (Ams); lymphocytes (Lyms) and polymorphonuclear neutrophils (PMNs) were cytocentrifuged on uncoated slides and on PLC slides (2 slides each). Cell density, differential cell counts and cytomorphology were assessed on May-Grünwald-Giemsa-stained preparations. Reliability of cell differentiation was expressed as a $\Phi$ value, which measures combined reproducibility and agreement. Statistical significance of differences between slides was calculated with ANOVA. Clinical relevance was assessed using a validated computer program predicting the most probable diagnosis.

\section{Results}

Although not statistically significant, cell recovery was lower on PLC slides as compared to uncoated slides. PLC slides held significantly fewer Lyms as compared to uncoated slides. (mean value \pm SD: $25.89 \% \pm 28.26$ versus $28.34 \% \pm 29.96$, respectively). Counts of AMs, 4lLyms and PMNs displayed excellent $\Phi$ values for both uncoated and PLC slides. No discrepancies in the computer-generated diagnoses were found.

\section{Conclusion}

For BALF cytology on cytocentrifuged preparations, PLC slides are not superior to conventional slides. 


\section{Introduction}

The differential cell count obtained by bronchoalveolar lavage (BAL) gives valuable information in the assessment of interstitial lung diseases and pneumonia ${ }^{1}$. Easy-to-read monolayer preparations that reveal well-preserved cell morphology can be obtained by cytocentrifugation. The cytocentrifugation process involves low-speed centrifugation of BAL fluid (BALF), during which the cells are deposited on the microscope slide and the cell-free fluid is absorbed into a filter path.

BALF differential cell counts on cytocentrifuged preparations, however, underestimate the proportion of lymphocytes (Lyms) ${ }^{2}$. In a previous study, we demonstrated that this difference was influenced by the operating conditions of the cytocentrifuge ${ }^{3}$. In the present study, we evaluated the recovery of different BALF cell types when cytocentrifuged on polylysine-coated (PLC) slides. PLC slides have a positively charged surface that provides superior cell adhesion. They have been used in the cytology of buccal smears and of urine and cerebrospinal fluid samples ${ }^{4-6}$ but have never been evaluated for cytocentrifugation of BALF samples. We compared PLC slides to conventional glass slides with respect to cell recovery, differential cell count and cytomorphology and assessed the clinical relevance of the differences.

\section{Materials and methods}

BALF samples were obtained from patients suspected of having pneumonia or interstitial lung diseases. Bronchoscopy with BAL and laboratory processing of the recovered BALF have been described previously ${ }^{7}$. Cytocentrifugation was performed with a Shandon Cytospin 3 (Shandon Scientific Ltd., Astmoor, England) using white filter cards (Shandon). In order to obtain monolayer preparations, the number of drops was adjusted to the BALF total cell count ${ }^{8}$. Cytocentrifugation conditions were as follows: speed, 650 revolutions per minute; duration, 10 minutes; acceleration rate, low. Each sample was cytocentrifuged on uncoated, cleaned glass slides (Menzel-Gläser, Braunschweig, Germany) and on PLC slides (Menzel-Gläser) (2 slides each).

\section{Cell density, differential cell counts and cytomorphology}

Cell density on the cytocentrifuge spot was assessed by counting the number of nucleated cells on 4 prefixed focal areas in each quadrant of the cytocentrifuge spot using a 10:1 objective. The sum of the areas counted represented a surface of $0.59 \mathrm{~mm} 2$, and the number of cells counted was multiplied by 47.84 to express cell density per square millimetre on the cytocentrifuge spot. BALF samples with representative numbers of alveolar 
42 Chapter2

macrophages (Ams), lymphocytes (Lyms) and polymorphonuclear neutrophils (PMNs) were selected for analysis. Freshly spun BALF samples were air dried, and slides were simultaneously stained according to May-Grünwald-Giemsa. Differential cell counts were made on both PLC and uncoated slides (2 each) by 1 observer counting 500 nucleated cells in a circular pattern round the cytocentrifuge spot ${ }^{7}$. Counts were recorded after 100, 200,300, 400 and 500 cells were enumerated. Apart from AMs, Lyms and PMNs, cell types included were eosinophils (Eos) and mast cells (MCs). Cytomorphology was assessed by a trained observer scoring blindly, on a 500-cell count, the number of free and pyknotic nuclei and the number of cells with vacuolization of the cytoplasm and tearing or stretching of the cell borders.

\section{Statistical analysis}

To assess the reproducibility of counting each cell type, variance components were estimated to be used in calculating intraclass correlation coefficients for reproducibility. For each type of slide and cell, "hundreds of cells counted" and "try" were seen as random factors with, respectively, five and two categories. Formulas were based upon Norman's quasiclassical R coefficients, which are very closely related to the $\rho^{2}$-coefficients in generalizability theory ${ }^{9,10}$. From these components the $\Phi$ value was calculated. This $\Phi$ value can vary from 0 (no reliability at all) to 1 (perfect reliability) and can be used as a reproducibility measure. $A \Phi$ value of $\geq 0.95$ in counting was considered acceptable ${ }^{11}$. Interslide differences in differential cell counting, cell density and cytomorphology were analyzed by repeated measurements mixed model ANOVA. To overcome problems with negative sums of variance components in Quasi F ratio denominators, Saterthwaite's and Cockran's formulas were used to test for statistical significance ${ }^{12}$. All data were analyzed by SPSS-PC, version 10.0.5 (Chicago, Illinois, U.S.A.), and also by GENOVA (University of Massachusetts, Boston, Massachusetts, U.S.A.), a program for generalized analysis of variance ${ }^{13}$. A p-value $<0.05$ was considered statistically significant.

\section{Assessing clinical relevance}

In order to assess clinical relevance, a validated computer program was used to predict the diagnosis in all patients included in the study. The computer program is based on a polychotomous regression model ${ }^{1}$ and predicts the patient's diagnosis using several variables: volume of recovered BALF, total cell count, percentages of AMs, Lyms, PMNs and Eos, and demographic data. The predicted diagnoses generated by the computer program include idiophathic pulmonary fibrosis, sarcoidosis and extrinsic allergic alveolitis. 
Polylysine-coated slides in clinical BALF samples $\mid 43$

\section{Results}

A total of 20 BALF samples were included for analysis. Although not statistically significant, the cell density on the cytocentrifuge spot was lower on PLC slides as compared to uncoated slides (mean value \pm SD: $918.7 \pm 595.4$ versus $939.9 \pm 557.9$ cells $/ \mathrm{mm}^{2}$, respectively).

Table 2.1 lists the differential cell counts of PLC slides versus uncoated slides. The PLC slides tended to hold more AMs and significantly fewer Lyms and MCs as compared to the uncoated slides. In 17 of 20 samples, fewer Lyms were counted on the PLC slides as compared to the uncoated slides. The mean value \pm SD difference in lymphocyte counts between PLC and uncoated slides was $2.99 \% \pm 3.38 \%$ (range $0.10-12.10$ ); in 6 samples, differences $>5 \%$ were observed. Ams, Lyms, PMNs and Eos counting displayed excellent $\Phi$ values on both PLC and uncoated slides. MCs did not achieve the acceptable $\Phi$ value on either type of slide ( $\Phi$ values 0.82 and 0.85 for PLC and uncoated slides, respectively).

Table 2.1 Differential cell counts obtained in 20 BALF samples.

\begin{tabular}{lccc}
\hline Cell type & PLC slides & Uncoated slides & p-value \\
\hline Alveolar macrophages & $59.43 \pm 33.25$ & $57.04 \pm 34.10$ & 0.0554 \\
Polymorphonuclear neutrophils & $10.89 \pm 20.36$ & $10.84 \pm 20.92$ & N.S. \\
Lymphocytes & $25.89 \pm 28.26$ & $28.34 \pm 29.96$ & 0.0388 \\
Eosinophils & $3.38 \pm 6.7$ & $3.37 \pm 6.54$ & N.S. \\
Mast cells & $2.03 \pm 2.47$ & $2.08 \pm 2.47$ & 0.0031 \\
\hline
\end{tabular}

A differential cell count was done by one observer on two slides of both PLC and uncoated slides. For each cell type, mean values $\pm S D$ are expressed as a percentage of the $2 \times 500$ cells counted.

Table 2.2 summarizes the cytomorphologic characteristics. Free nuclei were ore frequently observed on uncoated slides, whereas tearing and stretching of the cell borders were seen more frequently on PLC slides; however, these differences were not statistically significant. The most probable diagnoses predicted by the computer program were as follows: sarcoidosis $(n=8)$, idiopathic pulmonary fibrosis $(n=8)$, extrinsic allergic alveolitis $(n=3)$ and bacterial infection $(n=1)$. There was no difference in the predicted diagnosis between PLC and uncoated slides. 
44 Chapter 2

Table 2.2 Cytomorphology of cytocentrifuged BALF samples for both type of slides.

\begin{tabular}{lccc}
\hline Cell type & PLC slides & Uncoated slides & P value \\
\hline Free nuclei & $13.15 \pm 9.39$ & $17.25 \pm 14.07$ & N.S. \\
Necrobiotic PMNs & $2.85( \pm 7.21)$ & $3.05( \pm 7.13)$ & N.S. \\
Tearing and stretching & $74.35( \pm 76.26)$ & $51.25( \pm 57.01)$ & N.S. \\
Vacuolated cytoplasma & $10.70( \pm 12.27)$ & $11.6( \pm 14.93)$ & N.S. \\
\hline
\end{tabular}

Mean \pm SD numbers of free nuclei, necrobiotic PMNs, torn of stretched cell borders and vacuolated cytoplasm are expressed as percentages of 500-cell count.

\section{Discussion}

In the present study, we demonstrated that BALF specimens cytocentrifuged on PLC slides tended to hold fewer cells as compared to uncoated slides. In addition, samples cytocentrifuged on PLC slides contained more AMs and significantly fewer Lyms and MCs than those cytocentrifuged on uncoated slides. Concerning cytomorphology, no significant differences were found between samples cytocentrifuged on PLC versus uncoated slides.

As the adhesion of cells to standard microscope slides is low, coating of slide surfaces has been used to enable cells to become more firmly attached and to increase cell yield. Apart from such proteins as albumin and gelatin, various polycations have been evaluated ${ }^{14}$. Polycationic molecules, such as polylysine, are absorbed strongly by solid surfaces, leaving cationic sites that combine with the anionic sites on cell surfaces ${ }^{4}$.

With regard to cell adhesion rates, PLC slides have been demonstrated to be superior not only to uncoated slides but also to albumin- and gelatin-coated slides $^{5,6}$. For this reason, our finding of a lower adhesion rate for PLC slides was unexpected. From Table I it is clear that this difference is attributable to the lower recovery rate of Lyms on PLC slides. The mean numbers of AMs were higher on PLC slides than on uncoated slides, and BALF samples with an excess of AMs showed higher total cell recovery on PLC slides (results not shown). AMs are large cells that are known to be more sticky, especially at lower cytocentrifugation speeds ${ }^{3,15}$. By contrast, Lyms in BALF are the cell type most vulnerable to various procedures, including centrifugation and washing of the BALF sample, as well as to the cytocentrifugation process itself ${ }^{2,16,17}$. Indeed, Lyms have been shown to disappear in the filter card during cytocentrifugation ${ }^{18}$. Therefore, we hypothesize that AMs, due to their larger surface as compared to that of Lyms, are relatively more attracted by the cationic surface charges on PLC slides. Lyms, with a smaller surface, are less attracted and, due to their small volume, are prone to disappear into the filter card. The net result is an increase in AMs and relative decrease in Lyms on PLC slides. As, in this study, we used unprocessed BALF samples, we hypothesize that centrifugal and capillary forces during cytocentrifugation 
exceed the electrostatic surface charges. This is in line with the finding of previous studies, in which much greater differences in total cell recovery between PLC and uncoated slides were observed when samples were prepared by sedimentation ${ }^{5}$ than when they were obtained by cytocentrifugation ${ }^{6}$. With regard to cytomorphology, no significant differences were observed between PLC and uncoated slides. This is in line with the findings of van Oosterbrugge and coworkers ${ }^{6}$, who did not find morphologic differences in cytocentrifuged cerebrospinal preparations. In addition, the $\Phi$ values for the different cell types were in agreement with previous findings ${ }^{19}$. Although statistically significant, the differences in Lyms counts between PLC and uncoated slides were not clinically relevant in this study. Even in cases of discrepancies $>5 \%$, the diagnoses predicted by the computer program were identical for both type of slides.

In conclusion, when compared to that on uncoated slides, the total cell count of BALF samples cytocentrifuged on PLC slides tended to be lower, and PLC slides held fewer Lyms. The present findings do not warrant the routine use of PLC slides for cytocentrifugation of BALF samples. 


\section{References}

1. Drent $M$, Jacobs JA, Cobben NA, Costabel U, Wouters EF, Mulder PG. Computer program supporting the diagnostic accuracy of cellular BALF analysis: a new release. Respir Med 2001:95:781-6.

2. Saltini C, Hance AJ, Ferrans VJ, Basset F, Bitterman PB, Crystal RG. Accurate quantification of cells recovered by bronchoalveolar lavage. Am Rev Respir Dis. 1984;130:650-8.

3. De Brauwer El, Jacobs JA, Nieman F, Bruggeman CA, Wagenaar SS, Drent $M$. Cytocentrifugation conditions affecting the differential cell count in bronchoalveolar lavage fluid. Anal Quant Cytol Histol. 2000;22:416-22.

4. Mazia D, Schatten G, Sale W. Adhesion of cells to surfaces coated with polylysine. Applications to electron microscopy. J Cell Biol. 1975;66:198-200.

5. Husain OA, Millett JA, Grainger JM. Use of polylysine-coated slides in preparation of cell samples for diagnostic cytology with special reference to urine sample. J Clin Pathol. 1980;33:309-11.

6. van Oostenbrugge RJ, Arends JW, Buchholtz R, Twijnstra A. Cytology of cerebrospinal fluid. Are polylysine-coated slides useful? Acta Cytol. 1997;41:1510-2.

7. De Brauwer EI, Drent M, Mulder PG, Bruggeman CA, Wagenaar SS, Jacobs JA. Differential cell analysis of cytocentrifuged bronchoalveolar fluid samples affected by the area counted. Anal Quant Cytol Histol. 2000;22:143-9.

8. Jacobs JA, De Brauwer E. BAL fluid cytology in the assessment of infectious lung disease. Hosp Med 1999;60:550-5.

9. Shavelson RJ, Webb NM. Generalizability Theroy: A primer. Newbury Park, California: Sage Publications; 1991.

10. Streiner DL, Norman GR. Health measurement scales: a practical guide to their development and use. Oxford: Oxford University Press; 1991.

11. De Brauwer $E$, Jacobs J, Nieman F, Bruggeman $C$, Drent $M$. Test characteristics of acridine orange, Gram, and May-Grunwald-Giemsa stains for enumeration of intracellular organisms in bronchoalveolar lavage fluid. J Clin Microbiol 1999;37:427-9.

12. Kirk RE. Experimental design. Pacific Grove, California: Brooks/Cole Publishing Company; 1982.

13. Crick GE, Brennan RL. GENOVA:a generalized analysis of variance system: Fortran IV computer program and manual. Dorchester, Massachusetts: University of Massachusetts at Boston Computer Facilities; 1982.

14. Seyfert $S$, Voigt $A$, Kabbeck-Kupijai D. Adhesion of leucocytes to microscope slides as influenced by electrostatic interaction. Biomaterials. 1995;16:201-7.

15. Willcox M, Kervitsky A, Watters LC, King TE, Jr. Quantification of cells recovered by bronchoalveolar lavage. Comparison of cytocentrifuge preparations with the filter method. Am Rev Respir Dis. 1988;138:74-80.

16. Lam S, LeRiche JC, Kijek K. Effect of filtration and concentration on the composition of bronchoalveolar lavage fluid. Chest. 1985;87:740-2.

17. Mordelet-Dambrine M, Arnoux A, Stanislas-Leguern $G$, Sandron D, Chretien J, Huchon $G$. Processing of lung lavage fluid causes variability in bronchoalveolar cell count. Am Rev Respir Dis. 1984;130:305-6.

18. Laviolette $M$, Carreau $M$, Coulombe R. Bronchoalveolar lavage cell differential on microscope glass cover. A simple and accurate technique. Am Rev Respir Dis. 1988;138:451-7.

19. De Brauwer El, Jacobs JA, Nieman F, Bruggeman CA, Drent M. Bronchoalveolar lavage fluid differential cell count. How many cells should be counted? Anal Quant Cytol Histol. 2002; $24: 337-41$. 


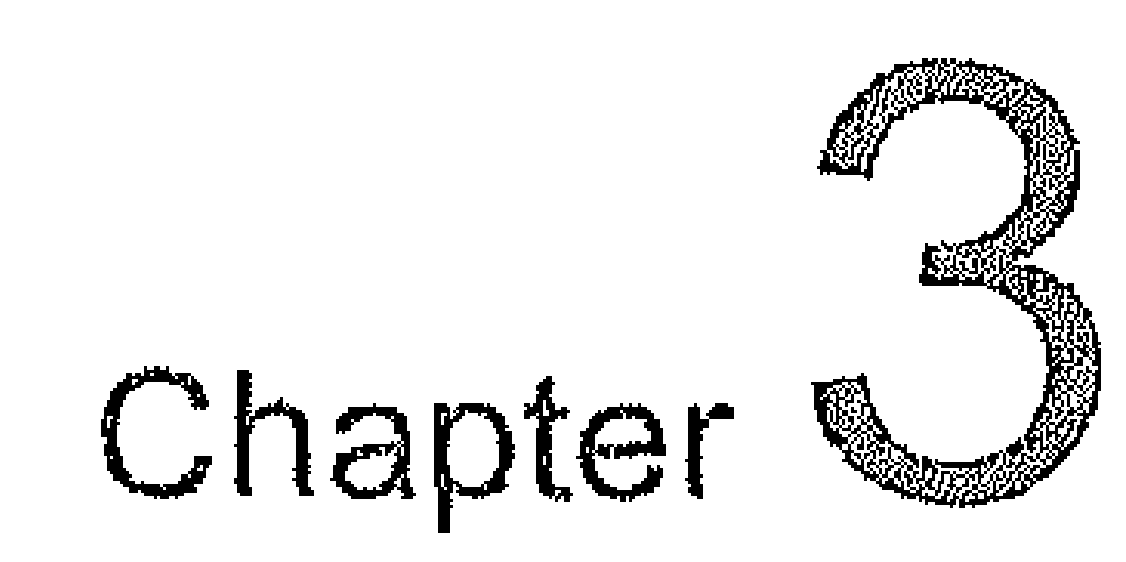

Presence of reactive type II pneumocytes in bronchoalveolar lavage fluid

CFM Linssen, JA Jacobs, VE Poletti, WNKA van Mook, EIM Cornelissen, M Drent

Acta Cytologica 2004; 48:497-504 


\section{Abstract}

Objective

To evaluate the prevalence of reactive type II pneumocytes (RPII) in bronchoalveolar lavage fluid (BALF) samples obtained in patients with various pulmonary disorders.

\section{Study design}

Consecutive BALF samples were screened for the presence of RPII on May-Grünwald Giemsa stained cytocentrifuged preparations. BALF samples with and without RPII were compared with regard to prevalence, associated clinical diagnoses and cytological findings.

Results

RPII were generally large cells with a high N/C ratio and a deeply blue stained vacuolated cytoplasm. Most RPIl occurred in cohesive cell groups, and the vacuoles tended to confluent. Cytological findings associated with RPII were the presence of foamy alveolar macrophages, activated lymphocytes and plasma cells. RPIl were present in $94(21.7 \%)$ out of 433 included BALF samples. Highest prevalences were noted in patients with systemic inflammatory response syndrome and alveolar hemorraghe. In addition, RPll tended to occur more frequently in ventilatorassociated pneumonia, pneumocystis pneumonia, extrinsic allergic alveolitis and drug-induced pulmonary disorders. In contrast, RPII were not observed in BALF samples obtained from patients with sarcoidosis.

Conclusion

RPII were prevalent in about one-fifth of BALF specimens. They were mainly associated with conditions of acute lung injury and not observed in sarcoidosis. 


\section{Introduction}

The microscopic examination of bronchoalveolar lavage fluid (BALF) is appreciated for various clinical applications. In our hospital, bronchoscopy with bronchoalveolar lavage (BAL) is routinely used in the assessment of interstitial lung diseases (ILD), ventilator-associated pneumonia (VAP) and opportunistic lung infections. For this purpose, a standardised protocol for laboratory work-up including a differential cell count on cytocentrifuged preparations has been implemented ${ }^{1,2}$.

Type II pneumocytes are normally not present in BALF specimens, except when they are hyperplastic and shed into the alveolar space ${ }^{3}$. These so-called hyperplastic or reactive type II pneumocytes (RPII) were first observed in BALF samples obtained from patients with the acute respiratory distress syndrome (ARDS) ${ }^{4,5}$. Recently, we observed these cells in BALF samples of patients with drug-induced pulmonary toxicity ${ }^{2}$ and pneumocystis pneumonia ${ }^{6}$.

In the present study, we assessed the prevalence, the associated clinical conditions and the accompanying cytological findings of RPII in a series of consecutive clinical BALF specimens routinely submitted for analysis.

\section{Materials and methods}

\section{Sampling technique}

During a 36-month period (January 2000 - January 2003), all BALF samples obtained were considered. Bronchoscopy with BAL was performed with a fiberoptic bronchoscope (Pentax FB-15H/FB-15X, Pentax Medicals, Tokyo, Japan) and "wedged" into the right middle lobe or lingula (in the assessment of interstitial lung diseases) or the affected segmental or subsegmental bronchus (when pneumonia was suspected). The fluid was instilled into the subsegment through the biopsy channel of the bronchoscope in four aliquots of $50 \mathrm{ml}$ sterile saline $(0.9 \% \mathrm{NaCl}$, room temperature) and immediately aspirated and recovered. The BALF samples were transported to the laboratory within 15 minutes after collection and analysed within one hour upon arrival in the laboratory.

\section{Laboratory processing}

The volume of the recovered BALF was recorded. The first fraction, representing the bronchial fraction, was separated for mycobacterial culture and the remaining fractions were pooled for further analysis. The total cell count was performed in a Fuchs Rosenthal hemocytometer chamber. All BALF 
samples were quantitatively cultured for bacteria and yeasts using 2- and $10-\mu \mathrm{l}$ volumes transferred by pipettes ${ }^{7}$. They were also cultured for filamentous fungi and mycobacteria and, if clinically indicated, for Legionella spp. In addition, stains for detection of Pneumocystis jiroveci and filamentous fungi (Methenamine-silver stain), Legionella pneumophila (immunofluorescent antibody stain), acid-fast bacteria (auramine-rhodamine stain) and hemosiderin visualisation (Perls'stain) were performed on cytocentrifuged preparations. When community-acquired pneumonia was suspected, culture and serology for the detection of viral pathogens were done, and polymerase chain reactions for the detection of Chlamydia pneumoniae and Mycoplasma pneumoniae were performed.

Cytocentrifugation was done with the Cytospin 3 apparatus (Shandon Scientific, Ltd, Astmoor, U.K.) using uncoated precleaned slides (MenzelGläser, Emergo, Landsmeer, The Netherlands). The number of drops per cytospin chamber was adjusted to the total cell count ${ }^{\dagger}$. Cytocentrifugation conditions were as follows: speed: 650 revolutions per minute, duration: 10 minutes, and acceleration rate: low. After drying, three preparations of each sample were May-Grünwald Giemsa (MGG) stained and subsequently sealed with a coverslip and mounting medium (Histomount, Shandon Scientific Ltd.). Six additional unstained slides were stored at $-30^{\circ} \mathrm{C}$ for further analysis.

Differential cell counts were made by examining 500 nucleated cells excluding squamous and bronchial epithelial cells. Cells were screened for the presence of intracellular organisms, and the number of cells with phagocytised organisms was expressed as a percentage of the 500-cell aliquot. All three preparations per BALF were screened for the presence of RPII cells, activated lymphocytes, plasma cells and foamy alveolar macrophages. RPII cells were identified by the descriptions reported by previous investigators ${ }^{3,4}$.

\section{Exclusion criteria}

BALF samples were excluded if the retrieved volume was less than $20 \mathrm{ml}$, if the total cell count was less than $60.000 / \mathrm{ml}$, or if the preparations showed excessive amounts of red blood cells, intercellular debris or damaged red blood cells.

\section{Additional stains}

From all samples in which RPII were observed as well as from 10 control samples, unstained cytocentrifuged slides stored at $-30^{\circ} \mathrm{C}$ were retrieved and stained by the alkaline phosphatase stain (Leucognost-alpa, Merck KGaA, Darmstadt, Germany) according to the instructions of the manufacturer. Ten 
samples with RPII were stained with a peroxidase-antiperoxidase method using monoclonal antibodies against cytokeratin 7 and $\mathrm{Ki}-67$ a monoclonal antibody that reacts with a nuclear antigen expressed in proliferating cells but not in quiescent cells (Dako, Glostrup, Denmark).

\section{Clinical diagnoses - definitions}

Diagnoses were based upon review of the patients' clinical records. Pneumonia was microbiologically defined as (1) recovery of an obligatory respiratory pathogen including Legionella pneumophila, Mycobacterium tuberculosis, Influenza virus, Respiratory Syncytial Virus (RSV), Adenovirus and $P$. jiroveci, (2) recovery of bacteria other than $L$. pneumophila and $M$. tuberculosis in quantities $\geq 10^{4}$ colony forming units $/ \mathrm{ml}$ (except when only oral flora was recovered) and/or the presence of $\geq 2 \%$ cells with phagocytised organisms ${ }^{8}$. Infectious pneumonia was further categorised as community-acquired pneumonia, hospital acquired pneumonia (onset of pneumonia after $\geq 2$ days of hospitalisation), or ventilator-associated pneumonia. All patients hospitalised at the Intensive Care Unit met the criteria for systemic inflammatory response syndrome (SIRS) ${ }^{9}$, Diagnoses of interstitial lung diseases were made on pathological, radiographic and clinical findings. If these data were not available, the probable diagnosis as generated by means of a validated computer program was recorded ${ }^{10}$. This program uses demographic variables and BALF variables including the differential cell count in a polychotomous logistic regression model to predict the diagnosis of either infection, sarcoidosis, extrinsic allergic alveolitis and drug induced pulmonary toxicity, or idiopathic pulmonary fibrosis. The predicted diagnoses were considered if they displayed a $\geq 70 \%$ probability level. Further, a number of $\geq 20 \%$ hemosiderin loaden macrophages was considered as diagnostic for alveolar hemorrhage ${ }^{11}$ Acute eosinophilic pneumonia was defined according to the criteria of Allen et al. which include also a BALF eosinophil count of at least $25 \%{ }^{12}$.

\section{Statistical analysis}

Comparisons of proportions between groups were analysed for statistical significance by means of the $x^{2}$ test and differences in means were assessed by the student's t-test.

\section{Results}

During the study period, a total number of 489 BALF samples were submitted. Fifty-six samples were excluded from analysis, resulting in 433 samples obtained from 372 patients. The mean ( $\pm S D$ ) age of the patients was $56 \pm 16$ years (range 12-94 years), and the male-to-female ratio was 1.9: 1. 
52 Chapter 3

In $94(21.7 \%)$ samples obtained from 87 (23.4\%) patients, RPII were observed. Table 3.1 lists the clinical diagnoses corresponding to the BALF samples. From this table, it is clear that RPII were seen in a variety of pulmonary conditions. High prevalences of RPII were noted in patients hospitalised at the intensive care unit and suffering from SIRS and/or ventilator-associated pneumonia. Likewise, RPII were prevalent in nearly one third of BALF samples showing alveolar hemorrhage and also occurred in samples with (suspected) extrinsic allergic alveolitis and drug induced pulmonary toxicity. Although the total numbers per diagnosis were small, RPII were also observed in patients with pneumocystis pneumonia and eosinophilic pneumonia. In the group of intensive care unit patients with SIRS and in the group of alveolar hemorrhage, the differences reached statistical significance. In contrast, RPII were not observed in BALF samples obtained from patients with verified or suspected sarcoidosis $(p<0.05)$ nor in patients with pulmonary tuberculosis.

Table 3.1 Occurrence of reactive type If pneumocytes in BALF samples obtained in patients with various pulmonary disorders ${ }^{2}$.

\begin{tabular}{|c|c|c|c|c|}
\hline Disorder & $\sum n^{b}$ & $\underline{n}$ & $\%$ & p-value \\
\hline \multicolumn{5}{|l|}{ Infectious disorder } \\
\hline Community-acquired pneumonia (CAP) & 38 & 6 & 15.8 & N.S. \\
\hline Hospital-acquired pneumonia (HAP) & 22 & 3 & 13.6 & N.S. \\
\hline $\begin{array}{l}\text { Intensive Care Unit (ICU) patients with systemic } \\
\text { inflammatory response syndrome (SIRS) and ventilator } \\
\text { associated pneumonia (VAP) }\end{array}$ & 66 & 16 & 24.2 & N.S. \\
\hline ICU patients with SIRS, VAP not confirmed & 77 & 26 & 33.8 & 0.007 \\
\hline Pneumocystis pneumonia & 11 & 3 & 27.3 & N.S. \\
\hline Mycobacterium tuberculosis, pulmonary infection & 6 & 0 & 0 & N.S. \\
\hline \multicolumn{5}{|l|}{ Interstitial lung diseases } \\
\hline Sarcoidosis & 23 & 0 & 0.0 & 0.020 \\
\hline Suspected of sarcoidosis & 18 & 0 & 0.0 & 0.047 \\
\hline $\begin{array}{l}\text { Drug induced pulmonary toxicity and/or extrinsic allergic } \\
\text { alveolitis }\end{array}$ & 20 & 6 & 23.1 & N.S. \\
\hline $\begin{array}{l}\text { Suspected of drug induced pulmonary toxicity and/or } \\
\text { extrinsic allergic alveolitis }\end{array}$ & 8 & 3 & 37.5 & N.S. \\
\hline Idiopathic pulmonary fibrosis & 15 & 2 & 13.3 & N.S. \\
\hline Suspected of idiopathic pulmonary fibrosis & 22 & 1 & 4.3 & N.S. \\
\hline \multicolumn{5}{|l|}{ Other pulmonary diagnoses } \\
\hline Acute eosinophilic pneumonia & 4 & 2 & 50.0 & N.S. \\
\hline Alveolar hemorrhage & 77 & 24 & 31.2 & 0.039 \\
\hline No final diagnosis & 49 & 11 & 22.4 & N.S. \\
\hline Total ${ }^{\mathrm{B}}$ & 433 & 94 & 21.7 & \\
\hline
\end{tabular}

a Total number of diagnoses $(n=456)$ outnumber the number of BALF samples $(n=433)$, as combined diagnoses occurred: alveolar hemorhage included cases of CAP, HAP and VAP (5 cases each), drug induced pulmonary toxicity $(n=3)$, SIRS $(n=2)$, tuberculosis $(n=1)$ and idiopathic pulmonary fibrosis ( $n=1) ;{ }^{b} \sum n=$ total number of cases; $n=$ number of cases with RPII cells in BALF, $\%=n / \Sigma n \times 100$. 
In most MGG-stained samples, RPII were already discerned at the low power field by their tendency to appear as cohesive cell groups. RPII were generally larger than the surrounding alveolar macrophages and their cytoplasm was more deeply blue stained. Intercytoplasmic connections were observed between the RPII in the cell groups. The volume of cytoplasm varied, but most RPII had a high nuclear/cytoplasmic ratio. Many RPII contained large vacuoles, that tended to confluent. Sometimes the vacuolated cytoplasm pushed the nucleus eccentrically towards the cell border. Nuclei were large and sometimes irregularly shaped. Although the majority of RPII occurred in aggregates, singly lying cells with corresponding morphologic features were occasionally observed. In some of these singly lying RPII, the cytoplasmatic vacuoles were smaller and more numerous (Figure 3.1, A-F). The various morphologic presentations of RPII were not linked to any particular clinical diagnosis (results not shown). From 86 samples, unstained slides were available for alkaline phosphatase staining, $75(87.2 \%)$ samples with RPII showed positive cells clearly fitting the RPII morphology, no such cells were observed in the control samples without RPII cells. In the remaining RPII positive samples ( $n=11)$, very few RPII were seen on the MGG stained slides. The colour intensity of the positively stained cells ranged from faint to strong. All ten samples stained positive with both cytokeratin and Ki-67 markers.

With respect to the differential cell count, no differences were seen between BALF samples with and without RPII cells (Table 3.2). However, BALF samples with RPII cells displayed more frequently foamy alveolar macrophages, activated lymphocytes and plasma cells.

Table 3.2 Associated cytologic findings in BALF samples with reactive type II pneumocytes.

\begin{tabular}{|c|c|c|c|}
\hline & \multicolumn{2}{|c|}{ Reactive type II pneumocytes } & \multirow[t]{2}{*}{$p$-value } \\
\hline & present & not present & \\
\hline Differential cell count (mean $\% \pm S D$ ) & $(n=95)$ & $(n=338)$ & \\
\hline Alveolar macrophages & $42.8 \pm 30.5$ & $44.0 \pm 34.7$ & N.S. \\
\hline Lymphocytes & $15.6 \pm 19.9$ & $16.4 \pm 23.1$ & N.S. \\
\hline Polymorphonuclear neutrophils & $39.1 \pm 33.2$ & $38.1 \pm 38.5$ & N.S. \\
\hline Eosinophils & $1.7 \pm 5.3$ & $1.3 \pm 4.7$ & N.S. \\
\hline Mast cells & $0.5 \pm 1.3$ & $0.2 \pm 0.7$ & 0.096 \\
\hline \multicolumn{4}{|c|}{$\begin{array}{l}\text { Cytological findings (presence in numbers of BALF } \\
\text { samples) }\end{array}$} \\
\hline Foamy alveolar macrophages & 59 & 118 & $p<0.001$ \\
\hline Activated lymphocytes & 33 & 51 & $p<0.001$ \\
\hline Plasma cells & 11 & 16 & $p<0.05$ \\
\hline
\end{tabular}


$54 \mid$ Chapter 3



Figure 3.1 Reactive type II pneumocytes (RPII) in May-Grünwald Giemsa stained cytocentrifuged BALF samples. RPIl showed a tendency to appear as cohesive cell groups. They were generally larger than the surrounding alveolar macrophages and their cytoplasm was more deeply blue stained. Groups of cohesive RPII cells were recognisable at the low power field (A and B). Intercytoplasmic connections were observed, and many RPII contained large vacuoles, that tended to confluent $(C, D, E)$. The volume of cytoplasm varied, but most RPII had a high nuclear/cytoplasmic ratio. Sometimes the vacuolated cytoplasm pushed the nucleus eccentrically towards the cell border (A). Nuclei were large and sometimes irregularly shaped. Although the majority of RPII occurred in aggregates, singly lying cells with small vacuoles were occasionally observed $(F)$. Scale bar represents $10 \mu \mathrm{m}$. 


\section{Discussion}

In the present study, we observed RPII cells in $21.7 \%$ of a series of consecutive BALF samples. The alveolar epithelium is composed of squamous type I cells and cuboidal type II cells. Type II cells synthesise, secrete, and recycle all components of the surfactant that regulates surface tension in the lungs ${ }^{13}$. In addition, they contribute to epithelial repair by their ability to proliferate and differentiate into type I cells and into Clara cells, which are nonciliated cells in the terminal bronchioles ${ }^{14}$. Further, they play a role in alveolar fluid balance, coagulation and fibrinolysis ${ }^{14}$.

Till now, only a few studies reported data on the prevalence of RPII in BALF samples. Stanley and coworkers observed RPII in $12(31.6 \%)$ out of 38 samples obtained from patients with ARDS, while Ohori et al. reported RPII in only 10 out of 4880 samples recovered from lung transplant patients ${ }^{5,15}$. In the latter study however, most bronchoscopies with BAL were performed as part of routine follow-up in patients who were not presenting symptoms of rejection nor infection. In the present study, the samples obtained in patients with SIRS and/or alveolar hemorrhage (which may comprise patients with ARDS) showed prevalences comparable to those in the former study. The overall high prevalence of RPII in the present series may in part be explained by our microscopy protocol, which asks for screening of three MGG stained preparations at the low power field in order to detect squamous epithelial cells (to rule out oropharyngeal contamination in suspected pneumonia) and/or foamy alveolar casts (pointing to pneumocystis pneumonia) ${ }^{1,6}$. Indeed, screening of the cytocentrifuged specimens at the low power field allowed fast and easy recognition of RPII, especially when they occur in groups or clusters, and in some of the BALF samples RPII were observed only in one out of three cytocentrifuged preparations (results not shown).

In the present study, cells morphologically classified as RPII reacted with the alkaline phosphatase stain, which stains Clara cells and RPII cells ${ }^{16}$. The morphological appearance of RPII on the MGG stained slides varied, in line with previous descriptions $s^{4,5,15,17}$. This variation in morphology may reflect intermediate stages in the differentiation of RPII to type I epithelial cell ${ }^{13}$ and may explain for the different intensities of the alkaline phosphatase stain in the present series. Further, the epithelial origin of the RPII cells was confirmed by reaction with monoclonal antibodies against cytokeratin 7 (a quite specific phenotype of type II epithelial alveolar cells) and they were demonstrated to be in the proliferative phase (being marked by Ki-67 monoclonal antibodies), as previously demonstrated on histological preparations obtained from patients with diffuse alveolar damage ${ }^{18}$. 
The observation of RPII in BALF samples was originally studied in patients with ARDS $S^{4,5}$. Maximum shedding of RPII occurred during the exudative phase at 4 to 10 days after the onset of ARDS, and their presence persisted through the organizing stage 5 . The presence of RPII along with extracellular amorphous material as observed in Papanicoulaou-stained BALF samples has been reported as the cytologic hallmark of diffuse alveolar damage for which the clinical entity includes acute interstitial pneumonia and acute eosinophilic pneumonia $^{19-21}$.

Apart from these conditions, we found high prevalences of RPII in BALF samples of patients with extrinsic allergic alveolitis and drug-induced pulmonary disorders, pneumocystis pneumonia and ventilator-associated pneumonia. These findings support the suggestion that atypical cells, previously reported in various other lung cytology preparations and obtained from patients with pneumonia, pulmonary infarction, radiation, cytotoxic chemotherapy and bronchiectasis, are in fact RPII ${ }^{4}$. We observed no RPII in BALF samples of patients with pulmonary tuberculosis or sarcoidosis and, to our knowledge, RPII have not been reported in these conditions. This may be explained by the intensity and localisation of the pathologic process, i.e. granulomatous diseases such as in sarcoidosis and tuberculosis have a more chronical course and the alveolar epithelium may be not so severely altered as in cases of acute lung injury due to the previously mentioned conditions. The absence of RPII in sarcoidosis may be added to the other BALF cytological characteristics of this disease ${ }^{22}$.

The pathophysiological role of RPII remains unclear. In methotrexate-induced pulmonary toxicity, RPII were demonstrated to modulate inflammatory cell recruitment by releasing neutrophil, eosinophil and monocyte chemotactic activities $^{23}$. Further, RPII produce profibrotic factors such TGF- $\beta_{1}$, plateletderived growth factor and TNF- $\alpha$, but it is not clear whether they contribute to pulmonary fibrosis ${ }^{13}$.

Several authors emphasize malignancy as an important differential diagnosis of $\mathrm{RPII}^{4,5,22,24}$. In particular, bronchoalveolar carcinoma must be differentiated. Subtle morphologic cytologic characteristics in favour of either RPII or carcinoma have been listed ${ }^{4,22,24}$, but these features have a considerable overlap ${ }^{15}$ and are better evaluated on Papanicoulaou-stained preparations than on MGG-stained preparations ${ }^{25}$. Further, no single immunohistochemic marker accurately discriminates between both cell types, e.g. RPII may react with monoclonal antibodies against CEA and B72.3 (a marker for the tumorassociated TAG-72 antigen) $)^{4,17}$. Careful clinicopathologic evaluation is necessary to ensure accurate diagnosis ${ }^{4,5,15}$. With regard to the present study, 
several arguments apart from the high prevalence argue for the nonneoplastic nature of observed cells. None of the patients with RPIl presented with localised mass lesions suspected for primary or metastatic carcinoma, but in stead they presented with a rapid clinical course and a clinical picture of acute pulmonary damage. Further, all patients with interstitial lung diseases have been followed up for periods extending to one year (results not shown).

Although not specific, the presence of associated cytological findings such as foamy alveolar macrophages, activated lymphocytes and plasma cells was in line with our previous findings and may point to either extrinsic allergic alveolitis, drug induces pulmonary toxicity or pneumocystis pneumonia $a^{2,6,26}$. When combined to these and other cytologic findings ${ }^{22}$, the presence of RPII may be of additional diagnostic value in the assessment of interstitial lung diseases. 


\section{References}

1. Jacobs JA, De Brauwer E. BAL fluid cytology in the assessment of infectious lung disease. Hosp Med. 1999;60:550-5.

2. Jacobs JA, De Brauwer El, Ramsay G, Cobben NA, Wagenaar SS, van der Ven AJ, Bruggeman CA, Drent M. Detection of non-infectious conditions mimicking pneumonia in the intensive care setting: usefulness of bronchoalveolar fluid cytology. Respir Med. 1999;93: 571-8.

3. Stanley M. Quanlitative and quantitative cytology in control subjects. In: Stanley M, HenryStanley M, Iber C, editors. Bronchoalveolar Lavage: Cytology and Clinical Applications. New York: Igaku-Shoin; 1991:27-65.

4. Grotte D, Stanley MW, Swanson PE, Henry-Stanley MJ, Davies S. Reactive type II pneumocytes in bronchoalveolar lavage fluid from adult respiratory distress syndrome can be mistaken for cells of adenocarcinoma. Diagn Cytopathol. 1990;6:317-22.

5. Stanley MW, Henry-Stanley MJ, Gajl-Peczalska KJ, Bitterman PB. Hyperplasia of type II pneumocytes in acute lung injury. Cytologic findings of sequential bronchoalveolar lavage. Am J Clin Pathol. 1992;97:669-77.

6. Jacobs JA, Dieleman MM, Cornelissen El, Groen EA, Wagenaar SS, Drent $M$. Bronchoalveolar lavage fluid cytology in patients with Pneumocystis carinii pneumonia. Acta Cytol. 2001;45:317-26.

7. Jacobs JA, De Brauwer El, Cornelissen El, Drent M. Accuracy and precision of quantitative calibrated loops in transfer of bronchoalveolar lavage fluid. J Clin Microbiol. 2000;38:2117-21.

8. Allaouchiche B, Jaumain $H$, Dumontet $C$, Motin J. Early diagnosis of ventilator-associated pneumonia. is it possible to define a cutoff value of infected cells in BAL fluid? Chest. 1996;110:1558-65.

9. Committee MotACoCPSoCCMCC. Definitions for sepsis and organ failure and guidelines for the use of innovative therapies in sepsis. Crit Care Med. 1992;20:864-74.

10. Drent $M$, Jacobs JA, Cobben NA, Costabel U, Wouters EF, Mulder PG. Computer program supporting the diagnostic accuracy of cellular BALF analysis: a new release. Respir Med. 2001;95:781-6.

11. De Lassence A, Fleury-Feith J, Escudier E, Beaune J, Bernaudin JF, Cordonnier C. Alveolar hemorrhage. Diagnostic criteria and results in 194 immunocompromised hosts. Am J Respir Crit Care Med. 1995;151:157-63.

12. Allen JN, Davis WB. Eosinophilic lung diseases. Am J Respir Crit Care Med. 1994;150: 1423-38.

13. Fehrenbach $\mathrm{H}$. Alveolar epithelial type II cell: defender of the alveolus revisited. Respir Res. 2001;2:33-46.

14. Mason RJ, Shannon JM. Alveolar type II cells. In: Crystal RG, West JB, editors. The lung: Scientific Foundations. Second ed. Philadelphia: Lippencott-Raven; 1997.

15. Ohori NP. Epithelial cell atypia in bronchoalveolar lavage specimens from lung transplant recipients. Am J Clin Pathol. 1999;112:204-10.

16. Edelson JD, Shannon JM, Mason RJ. Alkaline phosphatase: a marker of alveolar type II cell differentiation. Am Rev Respir Dis. 1988;138:1268-75.

17. Biyoudi-Vouenze R, Tazi A, Hance AJ, Chastre J, Basset F, Soler P. Abnormal epithelial cells recovered by bronchoalveolar lavage: are they malignant? Am Rev Respir Dis. 1990; 142:686-90.

18. Katzenstein AL, Myers JL, Mazur MT. Acute interstitial pneumonia. A clinicopathologic, ultrastructural, and cell kinetic study. Am J Surg Pathol. 1986;10:256-67.

19. Beskow CO, Drachenberg CB, Bourquin PM, Britt EJ, Simsir A, Gunev I, Papadimitriou JC. Diffuse alveolar damage. Morphologic features in bronchoalveolar lavage fluid. Acta Cytol. 2000;44:640-6.

20. Trisolini $R$, Cancellieri A, Bonaccorsi A, Poletti V. Bronchoalveolar lavage suggesting diffuse alveolar damage in a patient with acute eosinophilic pneumonia. Sarcoidosis Vasc Diffuse Lung Dis. 2001;18:311-2. 
21. Bonaccorsi A, Cancellieri A, Chilosi $M$, Trisolini R, Boaron $M$, Crimi N, Poletti V. Acute interstitial pneumonia: report of a series. Eur Respir J. 2003;21:187-91.

22. Zaman SS, Elshami A, Gupta PK. Bronchoalveolar lavage cytology in pulmonary sarcoidosis. Acta Cytol. 1995;39:1117-23.

23. Koyama $S$, Sato E, Takamizawa A, Tsukadaira A, Haniuda M, Kurai M, Numanami H, Nagai $S$, Izumi T. Methotrexate stimulates lung epithelial cells to release inflammatory cell chemotactic activities. Exp Lung Res. 2003;29:91-111.

24. Fiorella RM, Gurley SD, Dubey S. Cytologic distinction between bronchioalveolar carcinoma and reactive/reparative respiratory epithelium: a cytomorphometric analysis. Diagn Cytopathol. 1998;19:270-3.

25. Linder J, Radio SJ, Robbins RA, Ghafouri M, Rennard SI. Bronchoalveolar lavage in the cytologic diagnosis of carcinoma of the lung. Acta Cytol. 1987;31:796-801.

26. Drent $M$, van Velzen-Blad $H$, Diamant $M$, Wagenaar $S S$, Donckerwolck-Bogaert $M$, van den Bosch JM. Differential diagnostic value of plasma cells in bronchoalveolar lavage fluid. Chest. 1993;103:1720-4. 


\section{Chapter}

Influence of antibiotic therapy on the cytological diagnosis of ventilator-associated pneumonia

CFM Linssen, JA Jacobs, JSAG Schouten, WNKA van Mook, G Ramsay, M Drent

\section{Submitted}




\section{Abstract}

\section{Objective}

To assess the influence of antibiotics on the value of various cytological parameters, and their combinations in diagnosing ventilator-associated pneumonia.

\section{Study design}

This prospective study was conducted at the general intensive care unit (17 beds) of the University Hospital Maastricht. A total of 335 episodes of clinically suspected ventilator-associated pneumonia (VAP) (defined by the clinical and radiological criteria previously described by Bonten et al.) in 282 patients were studied.

\section{Results}

Bronchoalveolar lavage fluid (BALF) cytology included a total cell count/ml, differential cell count and the percentage of infected cells ( $\mathrm{C}$, cells containing phagocytised organisms). Antibiotic therapy from 72 hours prior to lavage was recorded. Areas under the Curve (AUC) of Receiver Operating Characteristic curves were calculated for various cytological parameters and their combinations, in patients with and without antibiotic therapy. In 126 (37.6\%) episodes in 106 patients VAP was confirmed. There was no difference in AUCs in patients with or without antibiotic therapy for any parameter studied. Most prominent AUCs were (for patient groups with and without antibiotics combined): total cell count: 0.65 , percentage polymorphonuclear neutrophils: 0.71 and percentage IC: 0.90 . The combination of percentage IC with any other cytological parameter did not increase the AUC. At a threshold of $2 \%$, the percentage infected cells had an $86.2 \%$ positive and an $88.1 \%$ negative predictive value for VAP.

\section{Conclusion}

Antibiotic therapy did not influence the predictive value of the percentage infected cells in BALF in diagnosing VAP. 


\section{Introduction}

Ventilator-associated pneumonia (VAP) is a common complication in intensive care (ICU) patients, represents up to $80 \%$ of the nosocomial infections in the $\mathrm{ICU}^{1,2}$ and is associated with high mortality rates ${ }^{3,4}$.

Bronchoalveolar lavage (BAL) with quantitative culture is currently regarded as the reference method for the diagnosis $V A P^{5}$ since clinical presentation, radiology and laboratory parameters are non-specific. However, results of $B A L$ fluid (BALF) cultures can take up to 48 hours. Because microscopic examination of BALF can be achieved within two hours ${ }^{6,7}$, the diagnostic value of cytological parameters has been explored. These parameters include the total cell count $(T C C)^{8-10}$, the percentage of polymorphonuclear neutrophils $(\mathrm{PMNs})^{9,11}$ and the percentage of cells containing phagocytised organisms, also known as infected cells or cells with intracellular organisms (IC) $)^{7,9,12,13}$. However, the influence of antibiotic therapy on the percentage of IC has not been studied thoroughly. The previously performed studies used a relatively small study population ${ }^{14}$, used different techniques for calculation of the percentage IC and resulted in conflicting results ${ }^{14-16}$. Therefore, we evaluated the influence of antibiotic therapy on the predictive value of combinations of cytological parameters of BALF in diagnosing VAP. In addition, we established the most accurate cut-off values of these parameters for the diagnosis of VAP.

\section{Materials and methods}

\section{BALF inclusion and laboratory processing}

This prospective study was conducted at the University Hospital Maastricht during a 61-month period (January 1999 until February 2004). The hospital has a general ICU of 17 beds. In this period all consecutive BALF samples of ICUpatients with clinical suspicion of VAP, were included. Clinical suspicion of VAP was defined by the clinical and radiological criteria previously described by Bonten et al.: i.e. rectal temperature $>38^{\circ} \mathrm{C}$ or $<35.5^{\circ} \mathrm{C}$, blood leukocytosis $\left(>10 \times 10^{3} / \mathrm{mm}^{3}\right)$ and $/$ or left shift or blood leukopenia $\left(<3 \times 10^{3} / \mathrm{mm}^{3}\right)$, more than ten leukocytes in Gram-stain of tracheal aspirate (in high-power field), positive culture of tracheal aspirate and a new, persistent, or progressive infiltrate on chest radiograph ${ }^{17}$.

\section{Sampling technique}

A fiberoptic bronchoscope (Pentax FB-15H/FB-15X, Pentax Medicals, Tokyo, Japan) was introduced and "wedged" into the affected segmental or 
64 $\mid$ Chapter 4

subsegmental bronchus. Sterile saline $(0.9 \% \mathrm{NaCl}$, room temperature) was instilled in four aliquots of $50 \mathrm{ml}$, immediately aspirated and recovered. BALF samples were transported to the laboratory within 15 minutes after collection and processed immediately upon arrival at the laboratory.

\section{Laboratory processing}

The first fraction of BALF (bronchial fraction) was processed separately for mycobacterial analysis and the three remaining fractions were pooled for further analysis. BALF work-up was conducted as previously described ${ }^{6}$ and included a total cell count, differential cell count and quantitative culture. BALF samples were quantitatively cultured for bacteria and yeast using 2 and $10 \mu \mathrm{l}$ pipettes $^{18}$. After 48 hours, bacterial colonies were counted and identified according to standard methods and minimal inhibitory concentration (MIC) values for most commonly used antimicrobial agents were determined. Cytocentrifuged preparations were made using Cytospin 3 apparatus (Thermo Electron's Anatomical Pathology Group, Astmoor, England) using a standardised protocol ${ }^{6}$. A differential cell count was done on May-Grünwald Giemsa (MGG) stained preparations by counting 500 nucleated cells and identifying; alveolar macrophages (AMs), lymphocytes (Lyms), polymorphonuclear neutrophils (PMNs), eosinophils (Eos) and mast cells (MCs). IC were expressed as a percentage of 500 nucleated cells counted ${ }^{19}$. The percentages of squamous epithelial cells and ciliated epithelial cells were counted on 500 nucleated cells and separately noted.

\section{Rejection criteria}

BALF samples were rejected if they fitted one of the following criteria: i) recovered volume less than $20 \mathrm{ml}$, ii) total cell count less than 60.000 cells $/ \mathrm{ml}^{10}$, ii) presence of excessive amounts of intercellular debris or damaged nucleated cells ${ }^{6}$ iv) presence of more than $1 \%$ squamous epithelial cells ${ }^{20,21}$.

\section{Definitions}

BALF samples were defined as VAP if the culture yielded organisms in quantities $\geq 10^{4}$ colony forming units (cfu) $/ \mathrm{ml}$. The remaining samples were categorised as non-VAP. An episode was defined as the period starting at the time of BAL until 14 days thereafter.

\section{Antibiotic use}

Antibiotic use was recorded for each episode, starting 72 hours before BAL and including the day of BAL. We divided patients into two groups (1) patients with 
antibiotic therapy and (2) patients without antibiotic therapy. The first group included patients on antibiotic therapy for more than 24 hours prior to bronchoscopy. The second group included patients with no antibiotic therapy in the 72 hours prior to bronchoscopy, those who were on antibiotic therapy for less than 24 hours and those who received antibiotics that were not active against the isolated pathogen.

\section{Statistical analysis}

To compare the different cytological parameters for the VAP-group versus the non-VAP group, $p$-values were calculated using a student t-test. To ascertain the value of different cells in diagnosing VAP, in both groups, Receiver Operation Characteristic (ROC) curves were plotted for prediction VAP using the different cell types and their combinations ${ }^{22}$. In addition, the most reliable cut-off value for the diagnosis of VAP of these parameters was determined.

\section{Results}

Numbers of samples, demographic data and microbiologic findings

During the study period, 394 consecutive BALF samples were obtained from 394 episodes of suspected VAP in 316 patients. Fifty-nine (14.9\%) samples were rejected, leaving 335 samples obtained from 282 patients for inclusion. Table 4.1 shows the baseline characteristics of the study patients. The median age of the patients was 60 years (range 15-87 years), and the male-to-female ratio was 2.2:1. A total of $185(55.2 \%)$ episodes were included from 166 patients using antibiotics at the time of bronchoscopy, the remaining 150 $(44.8 \%)$ episodes were from 138 patients who were not using antibiotics at the time of bronchoscopy. In 23 patients with multiple episodes of suspected VAP at least one episode of suspected VAP was whilst the patient was receiving antibiotic therapy and at least one without. VAP was microbiologically confirmed using culture as a reference test in 126 (37.6\%) episodes in 106 patients. In $40.5 \%(51 / 126)$ of these episodes, the patient was already receiving antibiotics at the time of the BAL. Table 4.2 gives an overview of the antibiotics used and whether mono-therapy or combination therapy was given up to 72 hours before BAL. 
Table 4.1 Baseline characteristics of study patients.

\begin{tabular}{lcc}
\hline & VAP $(n=106)$ & Non-VAP $(n=176)$ \\
\hline Characteristics & & \\
Age $( \pm$ SD) & $61( \pm 18)$ & $60( \pm 16)$ \\
Gender (\%) & $79(74.5)$ & $112(63.6)$ \\
$\quad$ Male & $27(25.5)$ & $64(36.4))$ \\
Female & & \\
Diagnosis on admittance ICU (\%) & $8(7.5)$ & $19(10.8)$ \\
Cardiac disease & $19(18.0)$ & $43(24.4)$ \\
Pulmonary disease & $5(4.7)$ & $18(10.2)$ \\
Underlying malignancy & $18(17.0)$ & $14(8.0)$ \\
Trauma & $14(13.2)$ & $25(14.2)$ \\
Surgery & $18(17.0)$ & $21(12.0)$ \\
Vascular surgery & $16(15.1)$ & $13(7.4)$ \\
Neurological & $8(7.5)$ & $23(13.0)$ \\
Other & & \\
\hline
\end{tabular}

Table 4.2 Antimicrobial treatment within 3 days prior to bronchoscopy with BAL, for 335 episodes of suspected VAP.

\begin{tabular}{lrrr}
\hline & VAP & Non-VAP & Total \\
\hline No antibiotics & 75 & 75 & 150 \\
Single antibiotic $(n=134)$ & & & \\
$\quad$-lactam antibiotics & 33 & 77 & 110 \\
Carbapenem & 1 & 1 & 2 \\
Fluoquinolones & 1 & 4 & 5 \\
Glycopeptides & 0 & 4 & 4 \\
Macrolides & 2 & 3 & 5 \\
$\quad$ Trimethroprim-Sulfa & 3 & 5 & 8 \\
Combination antibiotics $(n=51)$ & & & \\
B-lactam antibiotic + aminoglycoside & 4 & 12 & 16 \\
B-lactam antibiotic + macrolide & 4 & 1 & 5 \\
B-lactam antibiotic + fluochinolon & 1 & 7 & 8 \\
Other & 3 & 19 & 22 \\
\hline
\end{tabular}

a Combinations of two or more of the following antibiotics: trimethroprim-sulfa, clindamycin, metronidazol, rifampicin, glycopeptides, fluochinolones and macrolides. BAL=bronchoalveolar lavage, $V A P=$ ventilator-associated pneumonia.

\section{Cytological data}

The TCC, the percentages of PMNs, IC in PMNs, IC in AMs and IC(total) were significantly higher in the VAP-group, whilst the percentages of AMs, Lyms and Eos were significantly higher in the non-VAP group. In 186 samples, IC were observed: in 151 (81.2\%) samples only PMNs with phagocytised microorganisms were found, in $2(1.0 \%)$ samples only AMs with micro-organisms, and in $33(17.8 \%)$ the $\mathrm{IC}$ comprised both PMNs and AMs. 


\section{Predictive value of cytological parameters}

Table 4.3 shows the predictive value of the various cytological parameters for the diagnosis of VAP, expressed as the AUC of their ROC curves. The total cell count, the percentage PMNs and the percentage $I C$ reached the highest AUCvalues. Combinations of these parameters however did not result in an improvement of $A U C$, nor did any combination of other cytological parameters (Table 4.3). Antibiotic therapy in 72 hours prior to performance of BAL did not influence the predictive value of the $I C$ for the diagnosis VAP (Table 4.3). The highest AUC was reached by the percentage IC (PMNs and AMs combined) as a single parameter. Antibiotic therapy in 72 hours prior to performance of BAL did not influence the predictive value of the $I C$ for the diagnosis VAP. The best cut-off value for the diagnosis of VAP was obtained at $2 \%$, resulting in a sensitivity of $79.4 \%$ (95\% confidence interval (C.I): $75.4-83.4 \%)$ and a specificity of $92.3 \%$ (95\% C.I.: $88.0-96.6 \%)$. With a VAP prevalence of $37.6 \%$ this amounted to a positive predictive value of $86.2 \%$ and a negative predictive value of $88.1 \%$.

Table 4.3 Predictive value of cytologic parameters for the prediction of VAP, expressed as area under the curve (AUC) of their ROC curve.

\begin{tabular}{lccc}
\hline Cytologic parameter & $\begin{array}{c}\text { Total } \\
(n=335)\end{array}$ & $\begin{array}{c}\text { With antibiotics } \\
(n=185)\end{array}$ & $\begin{array}{c}\text { Without antibiotics } \\
(n=150)\end{array}$ \\
\hline Total cell count & 0.647 & 0.655 & 0.611 \\
Differential cell count (\%) & & & \\
$\quad$ Alveolar macrophages & 0.313 & 0.349 & 0.257 \\
Lymphocytes & 0.381 & 0.380 & 0.353 \\
Polymorphonuclear neutrophils & 0.705 & 0.675 & 0.756 \\
Eosinophils & 0.589 & 0.439 & 0.372 \\
$\quad$ Mast cells & 0.557 & 0.444 & 0.444 \\
Infected cells ${ }^{\text {a }}(\%)$ & 0.904 & 0.905 & 0.900 \\
Combination of cytologic parameters & & & \\
Infected cells $(\%)+$ PMNs (\%) & 0.892 & 0.901 & 0.893 \\
Infected cells $(\%)+$ Total cell count & 0.890 & 0.900 & 0.890 \\
\hline
\end{tabular}

${ }^{a}$ Polymorphonuclear neutrophils and alveolar macrophages combined. PMNs=polymorphonuclear neutrophils, $V A P=$ ventilator-associated pneumonia, $R O C=$ Receiver Operation Characteristic.

\section{Additional data on false-negative and false-positive results}

Based on an $1 \mathrm{C}$ count below the $2 \%$ cut-off value, $26(20.6 \%)$ BALF samples of the VAP group were incorrectly assigned to the non-VAP group. In fifty percent of these patients (13/26), BAL was performed whilst the patient was already receiving antibiotic treatment. Most $(17 / 26,65.4 \%)$ of these false negative samples showed culture results around the $10^{4} \mathrm{cfu} / \mathrm{ml}$ threshold. The microorganisms involved did not differ from those recovered in the true positive group (Table 4.4), and 6 out of 7 micro-organisms recovered were susceptible 


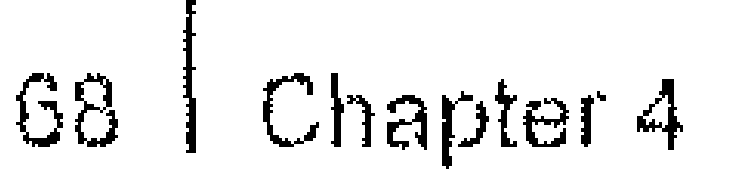

to the antibiotic the patients was receiving at the time of the BAL. In $17(65.4 \%)$ of these false negative samples, the MGG stained preparations revealed mucus plugs compiled of PMNs and micro-organisms. The mucus plugs were irregularly distributed over the cytospin spot, and in seven samples, infected cells were observed within these plugs. Bacteria cultured most often from samples containing these plugs were Pseudomonas aeruginosa $(8 / 17,47.1 \%)$ and Staphylococcus aureus (2/17, 11.8\%). There was no significant difference in the percentages of squamous epithelial cells and bronchial epithelial cells between the false negative samples and the true negative samples.

Table 4.4 Micro-organisms recovered in episodes of VAP (quantitative cultures $\geq 10^{4} \mathrm{cfu} / \mathrm{ml}$ ) matched by the numbers of infected cells $(<2 \%$ or $\geq 2 \%)$.

\begin{tabular}{lccc}
\hline Quantitative culture $\geq 10^{4} \mathrm{cfu} / \mathrm{ml}$ & & & \\
\hline Micro-organism & IC<2\% & $\mid \mathrm{C} \geq 2 \%$ & Total $^{{ }^{\mathrm{a}}}$ \\
\hline Pseudomonas aeruginosa & 7 & 30 & 37 \\
Staphylococcus aureus & 2 & 27 & 29 \\
Enterobacteriaceae $^{b}$ & 4 & 22 & 26 \\
Oral flora & 4 & 17 & 21 \\
Haemophilus influenzae & 4 & 12 & 16 \\
Streptococcus pneumoniae & 0 & 6 & 6 \\
Other streptococci $^{c}$ & 2 & 6 & 8 \\
Other $^{c}$ & 6 & 21 & 27 \\
\hline
\end{tabular}

a Numbers outreach total of BALF samples because in $31 / 126$ samples, multiple organisms were recovered in quantities $\geq 10^{4} \mathrm{cfu} / \mathrm{ml}$; ${ }^{b}$ Including Escherichia coli, Proteus mirabilis, Klebsiella pneumoniae; "Including Acinetobacter baumanii, Stenotrophomonas maltophilia and Moraxella catharrhalis.

A total of $209(62.4 \%)$ BALF samples had a quantitative culture below $10^{4} \mathrm{cfu} / \mathrm{ml}$. Of these samples $16(7.7 \%)$ showed $\geq 2 \%$ infected cells and were therefore considered as false positive results. Their median percentage IC was $3.4 \%$ (range $2.0-35.0 \%$ ) and in six samples, it exceeded $5 \%$ (range $6.4-35.0 \%$ ). In half of the patients $(8 / 16)$ with false positive results, antibiotic therapy was started before BAL was performed. In four out of eight samples from patients already on antibiotic therapy, BALF yielded a micro-organism susceptible to the given antibiotic therapy. One sample yielded no growth and the remaining three samples yielded bacteria resistant to the antibiotic therapy. Thirteen (13/16, $81.3 \%$ ), of the false positive samples reached a quantitative culture result just below the cut-off value of $10^{4} \mathrm{cfu} / \mathrm{ml}$.

\section{Borderline culture results}

Out of the 335 BALF samples obtained, $225(67 \%)$ yielded one or more microorganisms. A large percentage $(138 / 225,61.3 \%)$ showed quantitative culture results approaching the cut-off value: quantitative culture results of $10^{3} \mathrm{cfu} / \mathrm{ml}$ 
influence of antibiotic therapy on the cytological diagnosis of VAP $\mid 69$

and $10^{4} \mathrm{cfu} / \mathrm{ml}$ were found in respectively 83 and 55 samples. There was an equal distribution over episodes with and without antibiotic therapy (83/185, $39.5 \%$ versus $65 / 150,43.4 \%$ ). Lowering the cut-off value for the quantitative culture from $10^{4} \mathrm{cfu} / \mathrm{ml}$ to $10^{3} \mathrm{cfu} / \mathrm{ml}$ for episodes with antibiotic therapy, resulted in a large increase of false negative infective cell counts. The sensitivity decreased from $79.4 \%$ (95\% C.I: $75.4-83.4 \%$ ) to $60.6 \%$ (95\% C.I: $57.1-64.1 \%$ ) with a slight increase in specificity from $92.3 \%$ (95\% C.I.: 88.0 $96.6 \%$ ) to 93.8 (95\% C.l: $89.4-98.1 \%)$.

\section{Discussion}

The main, and clinically relevant finding of the present study is that, antibiotic therapy in 72 hours prior to performance of BAL under suspicion of VAP, did not influence the reliability of the infected cell count in BALF in the prediction of VAP. Among the cytological parameters of BALF cytocentrifuged preparations, the percentage IC most accurately predicted the presence of VAP. Moreover, combining percentage IC with any other cytological parameters did not increase the predictive value for VAP.

Several cytological parameters have been investigated in order to achieve a fast and reliable tool in the diagnosis of VAP. Both the TCC and the percentage of PMNs have demonstrated to be significantly higher in BALF samples from patients with VAP as compared to non-VAP $8,9,23,24$. Due to the overlap between the two groups however a clear distinction on the basis of both TCC and percentage PMNs was not possible, as confirmed in the present study.

The microscopic evaluation of the percentage of $I C$ in BALF has proven to be a reliable diagnostic tool in the diagnosing $V A P^{7,9,10,12-15}$. However, there are large differences in the methodology and in the cut-off values used in these different studies, making comparison of the study results difficult. Furthermore, conflicting results have been published concerning antibiotic influence on this parameter. The method used in this study was highly standardised ${ }^{19}$. Three parameters (TCC, percentage PMNs and percentage IC) were found to be significantly higher in patients with VAP, compared to non-VAP. Out of these, the AUC for percentage IC appeared to be the highest. Combining the different cytological parameters however did not improve the predictive value in diagnosing VAP. This can be explained by the high AUC of the percentage IC on its own, as well as by the number of other clinical conditions that cause elevations of the percentage PMNs in ventilated patients ${ }^{25}$. The best combination of sensitivity and specificity was reached at a cut-off value of $2 \%$ IC, which is in agreement with previous studies ${ }^{9,10}$.

No difference was found in the predictive value of cytological parameters between patients with and without antibiotic therapy at the time of the BAL 
(started up to 72 hours before). This is in contrast with previous studies ${ }^{14,15}$. Dotson et al. ${ }^{14}$ found both current antibiotic use as well as a recent history of antibiotic use to negatively influence the recovery of IC. In their group of seven patients with VAP already on antibiotic therapy before bronchoscopy, they found only two $(28 \%)$ patients with IC in BALF. Furthermore, the microorganisms recovered from these two patients were resistant to the antibiotic regime administered to these patients. In our study, $74.5 \%$ (38/51) of VAPs were correctly predicted by IC in the group receiving antibiotics. This significant difference could in part be explained by the size of the research group. Dotson et al. investigated 49 episodes (31 without antibiotic therapy, 18 with recent antibiotic therapy), whereas our study included 335 episodes of VAP. A second possible explanation is the cut-off value they used for IC, namely seven percent. In the present study two percent IC yielded the best predictive value, and when using higher cut-off values the sensitivity declines while increasing specificity. Sirvent et al. ${ }^{15}$ evaluated protected bronchoalveolar mini-lavage fluid and found a decline in sensitivity and specificity of $I C$ for the prediction of VAP in patients receiving antibiotic therapy up to 72 hours before BAL. However, they also found a percentage of $2 \% \mathrm{IC}$ or more to be the best cut-off value for both patients with and without antibiotic therapy at time of BAL. Moreover, Sirvent et $a l^{15}$ found a high percentage $(16 / 65,22.2 \%)$ of Haemophilus influenzae as causative organisms in their patients with VAP compared to $12.6 \%(16 / 126)$ in the present study. Since $H$. influenzae, due to its small size and fragile appearance, can easily be missed in both MGG- and Gram-stained preparations we hypothesized that this could attribute to the difference in sensitivity between both studies. However, the authors did not mention the organisms involved in the false negative results ${ }^{15}$. The findings of the present study are in line with Timsit et al. ${ }^{16}$ who found no difference in sensitivity and specificity of the IC count in patients with and without antibiotic therapy in the 48 hours before BAL.

The presence of plugs containing numerous bacteria may explain in part for the false negative samples. As these samples did not contain high numbers of squamous and/or bronchial epithelial cells, these plugs did not represent bronchial or oropharyngeal contamination. In histological studies, it has been shown that early stages of pneumonia are associated with focal accumulation of PMNs in the smaller bronchi, with spreading of PMNs throughout the lung in advanced pneumonia ${ }^{26}$. Hence, we hypothesised the observed plugs to be initial foci of pneumonia and they should be actively looked for in the low power field setting (magnification 100x). An alternative explanation may be the quantitative culture threshold used for defining VAP: the cut-off value of $10^{4} \mathrm{cfu} / \mathrm{ml}$ has been chosen in order to prevent undiagnosed VAPs and consequently may overestimate the number of $\mathrm{VAPs}^{27}$. In this way, it is interesting that nearly two thirds of false negative samples had quantitative 
cultures close to the $10^{4} \mathrm{cfu} / \mathrm{ml}$ threshold. It is possible that some of the culture positive samples with less that $2 \% \mathrm{IC}$ actually are to be considered as nonVAPs. Some authors suggested to decrease the cut-off value to $10^{3}$ in case of antibiotic therapy in the preceding $72-24$ hours of lavage ${ }^{28,29}$. The present study does not subscribe this view since no significant difference was found in the distribution of quantitative culture results (excluding the episodes which did not yield any bacteria in BALF) between patients with and without antibiotic therapy. Furthermore, the sensitivity for IC in predicting VAP decreased from almost $80 \%$ to $60 \%$, with only a slight increase in specificity.

No apparent clarification was present to explain for the $7.7 \%$ false positive results. Irrespective of the use of antibiotics, the high number of percentage IC in many the false-positive samples however gives concern with regard to the exclusion of the diagnosis VAP when the culture threshold is not reached. In this respect, it is interesting that recent studies define VAP not only by using the $10^{4} \mathrm{cfu} / \mathrm{ml}$ culture threshold but also by incorporating the $2 \%$ cut-off value of IC independently of the culture threshold as a criterion. This approach has also been implemented in daily practice in our intensive care ${ }^{13,30-34}$. Supportive of this approach is the fact that more than $80 \%$ of the false positives reached a quantitative culture result just below the cut-off value. Using the above cited combination of criteria to define VAP (thus combining the $10^{4} \mathrm{cfu} / \mathrm{ml}$ culture threshold and the $2 \%$ IC value), the number of VAP episodes in the present study would have increased from $126 / 335(37.6 \%)$ to $137 / 335(41.0 \%)$.

In the present study neither the occurrence of other conditions associated with PMNs influx in the ICU population, nor the episodes with borderline quantitative culture results were studied. Therefore, an additional study is required to address the presence of qualitative cytological parameters suggesting noninfectious conditions such as eosinophils, foamy alveolar macrophages, activated lymphocytes, plasma cells and reactive type 11 pneumocytes ${ }^{35}$. The presence of RPII cells has been associated with severe alveolar damage. A prospective evaluation of cytological parameters in different non-infectious conditions should be established to enable the construction of a predictive computer model in line with that constructed for use in the assessment of interstitial lung diseases ${ }^{23}$.

Present findings are relevant for ICUs in other hospitals, since the study population represents a heterogeneous group of intensive care patients comparable to that seen in general ICUs in many other hospitals. The presently used stains and techniques are within reach of all microbiology laboratory. If the MGG stain is not available, laboratories may also rely upon the Gram-stain as an alternative, as this latter stain also enables reliable detection of the percentage IC in BALF samples ${ }^{19}$. Since the percentage IC encompasses both PMNs and AMs, no distinction between these cell types is required and this 
precludes the need for more specialised cytological expertise of the laboratory staff.

In conclusion, antibiotic therapy in the 72 hours preceding the BAL did not influence the predictive value of cytological BALF parameters in the microscopic diagnosis VAP. The percentage of IC appears to be the most important parameter for distinguishing VAP from a non-VAP condition. A cut-off value of $2 \%$ could be ascertained using a standardised method. Combining the percentage IC with any other cytological parameter did not revealed better predictive values. 


\section{References}

1. Vincent $\mathrm{JL}$, Bihari DJ, Suter PM, Bruining HA, White J, Nicolas-Chanoin MH, Wolf $M$, Spencer $\mathrm{RC}$, Hemmer M. The prevalence of nosocomial infection in intensive care units in Europe. Results of the European Prevalence of Infection in Intensive Care (EPIC) Study. EPIC International Advisory Committee. Jama. 1995;274:639-44.

2. Richards MJ, Edwards JR, Culver DH, Gaynes RP. Nosocomial infections in medical intensive care units in the United States. National Nosocomial Infections Surveillance System. Crit Care Med. 1999;27:887-92.

3. Fagon JY, Chastre J, Hance AJ, Montravers P, Novara A, Gibert C. Nosocomial pneumonia in ventilated patients: a cohort study evaluating attributable mortality and hospital stay. Am $\mathrm{J}$ Med. 1993;94:281-8.

4. Rello J, Sonora R, Jubert $P$, Artigas $A$, Rue $M$, Valles J. Pneumonia in intubated patients: role of respiratory airway care. Am J Respir Crit Care Med. 1996;154:111-5.

5. Baselski VS, el-Torky M, Coalson JJ, Griffin JP. The standardization of criteria for processing and interpreting laboratory specimens in patients with suspected ventilator-associated pneumonia. Chest. 1992;102(5 Suppl 1):571S-579S.

6. Jacobs JA, De Brauwer E. BAL fluid cytology in the assessment of infectious lung disease. Hosp Med. 1999;60:550-5.

7. Timsit JF, Cheval C, Gachot B, Bruneel F, Wolff M, Carlet J, Regnier B. Usefulness of a strategy based on bronchoscopy with direct examination of bronchoalveolar lavage fluid in the initial antibiotic therapy of suspected ventilator-associated pneumonia. Intensive Care Med. 2001;27:640-7.

8. Pugin J, Auckenthaler $R$, Mili $N$, Janssens JP, Lew PD, Suter PM. Diagnosis of ventilatorassociated pneumonia by bacteriologic analysis of bronchoscopic and nonbronchoscopic "blind" bronchoalveolar lavage fluid. Am Rev Respir Dis. 1991;143:1121-9.

9. Allaouchiche B, Jaumain $H$, Dumontet $C$, Motin J. Early diagnosis of ventilator-associated pneumonia. Is it possible to define a cutoff value of infected cells in BAL fluid? Chest. 1996;110:1558-65.

10. Timsit JF, Misset B, Goldstein FW, Vaury P, Carlet J. Reappraisal of distal diagnostic testing in the diagnosis of ICU-acquired pneumonia. Chest. 1995;108:1632-9.

11. Sole-Violan J, Rodriguez de Castro F, Rey A, Martin-Gonzalez JC, Cabrera-Navarro P. Usefulness of microscopic examination of intracellular organisms in lavage fluid in ventilatorassociated pneumonia. Chest. 1994;106:889-94.

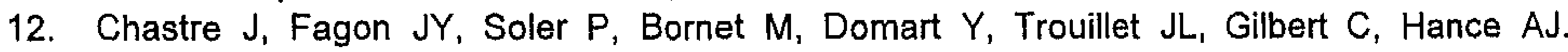
Diagnosis of nosocomial bacterial pneumonia in intubated patients undergoing ventilation: comparison of the usefulness of bronchoalveolar lavage and the protected specimen brush. Am J Med. 1988;85:499-506.

13. Chastre J, Trouillet $\mathrm{JL}$, Vuagnat $A$, Joly-Guillou ML, Clavier $H$, Dombret MC, Gilbert C. Nosocomial pneumonia in patients with acute respiratory distress syndrome. Am J Respir Crit Care Med. 1998;157:1165-72.

14. Dotson RG, Pingleton SK. The effect of antibiotic therapy on recovery of intracellular bacteria from bronchoalveolar lavage in suspected ventilator-associated nosocomial pneumonia. Chest. 1993;103:541-6.

15. Sivent JM, Vidaur L, Gonzalez S, Castro $P$, de Batlle J, Castro A, Bonet A. Microscopic examination of intracellular organisms in protected bronchoalveolar mini-lavage fluid for the diagnosis of ventilator-associated pneumonia. Chest. 2003;123:518-23.

16. Timsit JF, Misset B, Renaud B, Goldstein FW, Carlet J. Effect of previous antimicrobial therapy on the accuracy of the main procedures used to diagnose nosocomial pneumonia in patients who are using ventilation. Chest. 1995;108:1036-40.

17. Bonten MJ, Bergmans DC, Stobberingh EE, van der Geest S, De Leeuw PW, van Tiel FH, Gaillard CA. Implementation of bronchoscopic techniques in the diagnosis of ventilatorassociated pneumonia to reduce antibiotic use. Am J Respir Crit Care Med. 1997;156: $1820-4$. 
74 Chapter 4

18. Jacobs JA, De Brauwer El, Cornelissen EI, Drent M. Accuracy and precision of quantitative calibrated loops in transfer of bronchoalveolar lavage fluid. J Clin Microbiol. 2000;38:2117-21.

19. De Brauwer $E$, Jacobs J, Nieman F, Bruggeman $C$, Drent M. Test characteristics of acridine orange, Gram, and May-Grunwald-Giemsa stains for enumeration of intracellular organisms in bronchoalveolar lavage fluid. J Clin Microbiol. 1999;37:427-9.

20. Aubas S, Aubas P, Capdevila X, Darbas H, Roustan JP, Du Cailar J. Bronchoalveolar lavage for diagnosing bacterial pneumonia in mechanically ventilated patients. Am J Respir Crit Care Med. 1994;149:860-6.

21. Gerbeaux P, Ledoray V, Boussuges A, Molenat $F$, Jean P, Sainty JM. Diagnosis of nosocomial pneumonia in mechanically ventilated patients: repeatability of the bronchoalveolar lavage. Am J Respir Crit Care Med. 1998;157:76-80.

22. Obuchowski NA, Lieber ML, Wians FH, Jr. ROC curves in clinical chemistry: uses, misuses, and possible solutions. Clin Chem. 2004;50:1118-25

23. Drent $M$, Jacobs JA, Cobben NA, Costabel U, Wouters EF, Mulder PG. Computer program supporting the diagnostic accuracy of cellular BALF analysis: a new release. Respir Med. 2001;95:781-6.

24. Reynolds HY. Use of bronchoalveolar lavage in humans--past necessity and future imperative. Lung. 2000;178:271-93.

25. Jacobs JA, De Brauwer El, Ramsay G, Cobben NA, Wagenaar SS, van der Ven AJ, Bruggeman CA, Drent $M$. Detection of non-infectious conditions mimicking pneumonia in the intensive care setting: usefulness of bronchoalveolar fluid cytology. Respir Med. 1999;93 $571-8$.

26. Corley DE, Kirtland SH, Winterbauer RH, Hammar SP, Dail DH, Bauermeister DE, Bolen JW. Reproducibility of the histologic diagnosis of pneumonia among a panel of four pathologists: analysis of a gold standard. Chest. 1997;112:458-65.

27. Meduri GU, Chastre J. The standardization of bronchoscopic techniques for ventilatorassociated pneumonia. Chest. 1992;102(5 Suppl 1):557S-64S.

28. Wermert D, Marquette $C H$, Copin MC, Wallet $F$, Fraticelli $A$, Ramon $P$, Tonnel $A B$. Influence of pulmonary bacteriology and histology on the yield of diagnostic procedures in ventilatoracquired pneumonia. Am J Respir Crit Care Med. 1998;158:139-47.

29. Baker AM, Bowton DL, Haponik EF. Decision making in nosocomial pneumonia. An analytic approach to the interpretation of quantitative bronchoscopic cultures. Chest. 1995;107:85-95.

30. Trouillet JL, Chastre J, Vuagnat A, Joly-Guillou ML, Combaux D, Dombret MC, Gilbert C. Ventilator-associated pneumonia caused by potentially drug-resistant bacteria. Am J Respir Crit Care Med. 1998;157:531-9.

31. Combes A, Figliolini C, Trouillet JL, Kassis N, Wolff M, Gibert C, Chastre J. Incidence and outcome of polymicrobial ventilator-associated pneumonia. Chest. 2002;121:1618-23.

32. Hayon J, Figliolini C, Combes A, Trouillet JL, Kassis N, Dombret MC, Gilbert C, Chastre J. Role of serial routine microbiologic culture results in the initial management of ventilatorassociated pneumonia. Am J Respir Crit Care Med. 2002;165:41-6.

33. Delclaux C, Roupie E, Blot F, Brochard L, Lemaire F, Brun-Buisson C. Lower respiratory tract colonization and infection during severe acute respiratory distress syndrome: incidence and diagnosis. Am J Respir Crit Care Med. 1997;156:1092-8.

34. Marquette $\mathrm{CH}$, Copin MC, Wallet F, Neviere R, Saulnier F, Mathieu D, Durocher A, Ramon $P$, Tonnel AB. Diagnostic tests for pneumonia in ventilated patients: prospective evaluation of diagnostic accuracy using histology as a diagnostic gold standard. Am $J$ Respir Crit Care Med. 1995;151:1878-88.

35. Jacobs JA, Dieleman MM, Cornelissen El, Groen EA, Wagenaar SS, Drent $M$. Bronchoalveolar lavage fluid cytology in patients with Pneumocystis carinii pneumonia. Acta Cytol. 2001;45:317-26. 
chapter

C-reactive protein and procalcitonin concentrations." bronchoalveolar lavage fluid as a predictor of ventintes. associated pneumonia

CFM Linssen, O Bekers, M Drent, JA Jacobs

Submitted 


\section{Abstract}

\section{Objective}

Diagnosis of ventilator-associated pneumonia (VAP) is difficult. The usefulness of high-sensitivity PCT (ProCa-S) and - CRP (CRPH) in bronchoalveolar lavage fluid (BALF) and serum in the prediction of VAP was determined.

\section{Study design}

The study was conducted over a 28-month period (November 1999 - June 2002) at the University Hospital Maastricht. BALF samples were collected from patients admitted to the intensive care unit. Differential cell-count and quantitative culture of BALF were performed. CRP and PCT on BALF were determined by means of two high sensitivity kits (CRPH and ProCa-S respectively). Since both kits were designed for use on serum, validation for use on BALF was performed.

Results

117 patients were included. $43.6 \%$ (51/117) had microbiologically confirmed VAP. Both CRPH as ProCa-S showed good matrix effect, linearity and intra- and interassay variation. No significant differences in PCT and CRP levels in serum and BALF were found between the VAP and the nonVAP group.

\section{Conclusions}

Both the ProCa-S as the CRPH kit can be used for assessing the concentration of respectively PCT and CRP in BALF. PCT and CRP levels in BALF appeared to be of no additional value in the diagnosis of VAP. 


\section{Introduction}

Ventilator associated pneumonia (VAP) is a common complication in intensive care patients. The clinical diagnosis is difficult and a definite microbiological diagnosis is based on quantitative culture of bronchoalveolar lavage fluid (BALF) exceeding $10^{4}$ colony forming units (cfu) per $\mathrm{ml}$ and/or the presence of $\geq 2 \%$ cells with phagocytised organisms (infected cells, IC) ) $^{1,2}$. Routine application of BALF analysis is limited by the fact that this procedure is expensive and time-consuming, and relies upon specialised technicians. In most hospitals facilities for BALF cytology are not available on a 24-hour base, therefore we were interested in a fast method, present in most hospitals, to predict VAP. Several markers to differentiate between inflammation and infection have been described in literature ${ }^{3,4}$. Determination of C-reactive protein (CRP) in serum is a valuable marker of infection in serum ${ }^{5,6}$. Procalcitonin (PCT) has shown great potential as a marker in serum in recent years ${ }^{7.8}$. The value of PCT in serious bacterial infection, mainly sepsis, has been shown ${ }^{9-15}$. and it could also be useful in the diagnosis of other infections like yeast ${ }^{16}$ and parasitic infection ${ }^{17} \mathrm{Few}$ studies have investigated the value of PCT in patients with pneumonia. The studies that are available show discrepant results ${ }^{15,18,19}$ and all focused on detection of parameters in serum from patients with a community acquired pneumonia. One of the drawbacks of detecting any parameter in BALF is the dilution (approximately 10-100 times) of the original fluid present in the alveoli. In a preliminary study, we found the commercially available LUMltest unsuitable for the determination of PCT in BALF. Approximately $70 \%$ of BALF samples generated a concentration below the detection-limit of the LUMltest. ProCa-S is a novel kit, currently only available for research purposes, which may have a indication in the infectious work-up of BALF due to its low detection limit. Neither ProCa-S nor the high sensitivity CRP have been validated for BALF until now. The aim of the present study is to determine the usefulness of high-sensitivity PCT (ProCa-S) and CRP (CRPH) in BALF and serum in the prediction of VAP.

\section{Materials and methods}

\section{Patients included}

This study was conducted at the Intensive Care unit of the University Hospital Maastricht, a 700-bed teaching hospital, during a 28-month period (November 1999 until June 2002). The Intensive Care unit is a 17 bed, mixed surgical/medical unit. Patients suspected of VAP were included. Criteria were those described by Bonten et al. ${ }^{20}$ i.e. rectal temperature $>38^{\circ} \mathrm{C}$ or $<35.5^{\circ} \mathrm{C}$, 
Blood leukocytosis $\left(>10 \times 10^{3} / \mathrm{mm}^{3}\right)$ and/or left shift or blood leukopenia $\left(<3 \times 10^{3} / \mathrm{mm}^{3}\right)$, more than ten leukocytes in Gram stain of tracheal aspirate (in high-power field), positive culture of tracheal aspirate and a new, persistent, or progressive infiltrate on chest radiograph.

\section{Samples and sample preparation}

Patients suspected of VAP underwent bronchoscopy with BAL as part of the routine diagnostic work-up. Briefly, a fiberoptic bronchoscope (Pentax FB15H/FB-15X, Pentax Medicals, Tokyo, Japan) was introduced and "wedged" into the affected segmental or subsegmental bronchus. Sterile saline $(0.9 \%$ $\mathrm{NaCl}$, room temperature) was instilled in four aliquots of $50 \mathrm{ml}$, immediately aspirated and recovered. BALF samples were transported to the laboratory within 15 minutes after collection and processed immediately upon arrival. In addition, blood samples were collected immediately after the bronchoscopy.

\section{Microbiologic and cytologic processing of the BALF}

Each BALF was processed as previously described, including a total cell count, differential cell count and quantitative culture ${ }^{21,22}$. The percentage of polymorphonuclear neutrophils (PMNs) in BALF was assessed as a marker of inflammation. Bacterial burden of BALF was considered as the logaritmic value of the quantitative culture, i.e. expressed as $10^{2}, 10^{3} 10^{4}, 10^{5}$ and $>10^{5} \mathrm{cfu} / \mathrm{ml}$.

\section{Blood cultures}

Blood culture results at the time of BAL (1 day before bronchoscopy until 2 days after) were reviewed.

\section{Clinical chemistry}

The following components were measured in BALF: high-sensitivity CRP, highsensitivity PCT, albumin (as a marker of capillary leak), and urea (as a marker of dilution). In addition, albumin, urea, CRP and PCT levels were determined in serum. Albumin and urea levels were assessed upon arrival at the laboratory, CRP and PCT levels were assessed on serum and on BALF supernatans (centrifugation at $250 \mathrm{~g}$ for 10 minutes) that had been stored at $-80^{\circ} \mathrm{C}$ until the processing date.

BALF CRP was assessed as high-sensitivity CRP with a commercially available kit (CRPH, Beckman Coulter, Fullerton, California, USA). Serum CRP was determined using a commercially available kit (CRP, Beckman Coulter, Fullerton, California, USA). Serum PCT was assessed with the commercially 
available LUMltest (Brahms Diagnostica, Norcross, Georgia, USA) (results expressed as $\mu \mathrm{g} / \mathrm{l}$ ). BALF PCT levels were assessed with a high-sensitivity kit (ProCa-S test PCT, Brahms Diagnostics, Norcross, Georgia, USA), a kit designed for experimental purposes, expressing the results in the highsensitive $\mathrm{ng} / \mathrm{l}$ range. Serum albumin and serum and BALF urea levels were assessed using commercially available kits (Albumin (Bromcresol Purple method), Beckman Coulter, Fullerton, California, USA and Urea (Urease method), Beckman Coulter, Fullerton, California, USA). The Bromcresol Purple method for the detection of albumin has a detection limit of $8 \mathrm{~g} / \mathrm{l}$ which is below the average albumin concentration in BALF ${ }^{23}$, therefore BALF albumin levels were detected by means of the BN ProSpec (Dade Behring, Liederbach, Germany) based on particle-enhanched immunonephelometry with a detection limit of $2 \mathrm{mg} / \mathrm{l}$. All PCT measurements were performed in duplicate, and the mean of these duplicate results was considered. CRP and urea in both serum and BALF were measured on a Synchron LX20 analyser (Beckman Coulter, Fullerton, California, USA). Both BALF and serum PCT levels were determined on a Magic Lite Analyzer Il (Ciba Corning, Medfield, Massachusetts, USA).

In order to validate the ProCa-S and the CRPH for the use in BALF samples, matrix effect, detection limit, linearity and imprecision were determined for both tests.

\section{Definition of VAP}

VAP was defined as presence of $\geq 2 \%$ cells containing phagocitised organisms (infected cells, IC) ${ }^{2}$ and/or a quantitative culture result of BALF $\geq 10^{4} \mathrm{cfu} / \mathrm{ml}{ }^{1}$

\section{Rejection criteria}

BALF samples were rejected if the recovered volume was less than $20 \mathrm{ml}$, if the total cell count was less than $60.000 \mathrm{cells} / \mathrm{ml}$, if preparations showed excessive amounts of intercellular debris or damaged nucleated cells or more than $1 \%$ squamous epithelial cells.

\section{Statistical analysis}

In order to compare the ProCa-S and CRPH concentrations between recovered BALF samples, the levels were converted to concentrations in epithelial lining fluid (ELF) using the concentrations of urea in serum and BALF. The following formula described by Wiedermann and $c 0-$ workers ${ }^{24}$ was used:

$$
[\mathrm{X}] \mathrm{ELF}=\langle(\mathrm{X}] \mathrm{BALF} \times \text { urea serum }) / \text { urea BALF concentrations }
$$


$80 \mid$ Chapter 5

For convenience, we refer to the "concentrations in ELF" as concentrations in BALF in the text.

A Mann-Whitney $U$ test was performed to evaluate differences in ProCa-S, CRPH and cellular composition of BALF between the VAP and the non-VAP group (significance was set at 0.05). Correlations between PCT and CRP concentrations in BAL and serum were evaluated using Pearsons correlationcoefficient ( $r$ ). In order to ascertain the value of ProCa-S and CRPH concentrations in BALF for the diagnosis VAP, Receiver Operation Characteristic (ROC) curves were plotted ${ }^{25}$.

\section{Results}

In the period November 1999 until June 2002, 133 BALF samples with paired serum samples were obtained from intensive care patients suspected of VAP. A total of 16 BALF samples met the rejection criteria. This amounts to a total of 117 BALF samples, obtained from 117 patients, to be included. Out of these 117 BALF samples, 51 (43.6\%) were microbiologically confirmed VAP. Out of these microbiologically confirmed VAP, $28(54.9 \%)$ were caused by Grampositive micro-organisms, $22(43.1 \%)$ were caused by Gram-negative microorganisms and one $(2.0 \%)$ was caused by a yeast. Table 5.1 shows the cellular characteristics of the VAP and the non-VAP group.

Table 5.1 Cellular characteristics of BALF in the VAP group versus the non-VAP group.

\begin{tabular}{|c|c|c|c|c|c|}
\hline & \multicolumn{2}{|c|}{ VAP } & \multicolumn{2}{|c|}{ non-VAP } & \multirow[b]{2}{*}{ p-value } \\
\hline & Median & Range & Median & Range & \\
\hline Total cell count ${ }^{*} 10^{4}$, in cells $/ \mathrm{ml}$ & 57.0 & $8.0-5479.0$ & 28.0 & $7.0-728.0$ & $<0.01$ \\
\hline$\%$ PMNs & 89.4 & $9.6-99.8$ & 49.4 & $0.2-99.6$ & $<0.01$ \\
\hline$\%$ Ams & 6.8 & $0.0-87$ & 38.6 & $0.0-99.2$ & $<0.01$ \\
\hline$\%$ Lyms & 2.4 & $0-81.2$ & 3.2 & $0.0-90.2$ & N.S. ${ }^{a}$ \\
\hline$\%$ EoS & 0.0 & $0.0-1.0$ & 0.0 & $0.0-9.0$ & N.S. ${ }^{a}$ \\
\hline$\%$ MCs & 0.0 & $0.0-0.4$ & 0.0 & $0.0-1.0$ & N.S. ${ }^{a}$ \\
\hline$\%$ IC & 8.0 & $0.0-68.0$ & 0.0 & $0.0-1.2$ & $<0.01$ \\
\hline
\end{tabular}

${ }^{a}$ N.S.: not significant PMNs=polymorphonuclear neutrophil, AMs=alveolar macrophages, Lyms= lymphocytes, EOS=eosinophils, MCs=mast cells, $I C=$ infected cells, $B A L=$ bronchoalveolar lavage, $V A P=$ ventilator-associated pneumonia

\section{Abumin in BALF}

Albumin concentrations in BALF varied between $3 \mathrm{mg} / \mathrm{l}$ and $4150 \mathrm{mg} / \mathrm{l}$ with a mean of $74 \mathrm{mg} / \mathrm{l}$. 


\section{Validation of CRPH and ProCa-S determination in BALF}

\section{Matrix effect}

Since both the CRPH and ProCa-S are designed to use in serum, the effect of measuring in BALF was studied. To a BALF sample with no detectable PCT or CRP, various serum samples with high PCT and CRP concentrations were added and the recoveries were measured. The maximum dilution ratio of serum:BALF was 1:5. Recovery rates varied between 77 and $100 \%$ (Table $5.2)$.

Table 5.2 Matrix effects of CRPH and ProCa-S in BALF.

\begin{tabular}{cccccc}
\hline & CRPH & & & ProCa-S & \\
\hline $\begin{array}{c}\text { Calculated } \\
\text { [CRP] mg/l }\end{array}$ & $\begin{array}{c}\text { Measured } \\
\text { [CRP] mg/l }\end{array}$ & $\begin{array}{c}\text { Recovery } \\
(\%)\end{array}$ & $\begin{array}{c}\text { Calculated } \\
\text { [PCT] (ng/l) }\end{array}$ & $\begin{array}{c}\text { Measured } \\
\text { [PCT] (ng/l) }\end{array}$ & $\begin{array}{c}\text { Recovery } \\
(\%)\end{array}$ \\
\hline 0.41 & 0.40 & 97 & 1928 & 1482 & 77 \\
3.50 & 3.50 & 100 & 2108 & 1696 & 80 \\
6.00 & 5.70 & 95 & 2245 & 2292 & 102 \\
17.9 & 17.9 & 100 & 2300 & 2016 & 88 \\
\hline
\end{tabular}

$\mathrm{CRP}=\mathrm{C}$-reactive protein, $\mathrm{CRPH}=$ high-sensitivity $\mathrm{CRP}, \mathrm{PCT}=$ procalcitonin, ProCaS: highsensitivity PCT, BALF=bronchoalveolar lavage.

\section{Detection limit}

We determined the detection limit in BALF, which was $0.18 \mathrm{mg} / \mathrm{l}$ and $12 \mathrm{ng} / \mathrm{l}$ for $\mathrm{CRPH}$ and ProCa-S respectively (data not shown).

\section{Linearity}

Both CRPH as the ProCa-S tests showed good linearity in BALF in the investigated ranges. (Slope: 1.05 and 1.00 respectively)

Intra- and interassay variation

To determine the imprecision BALF samples were spiked with either high or low concentrations of CRP or PCT. Table 5.3 summarises the intra- and interassay variation for the CRPH as well as for the ProCa-S in BALF. The results of the inter-assay imprecision were obtained during a two week period. As can be concluded from Table 5.2, the results were within acceptable ranges (coefficient of variation $<10 \%$ ). 
$82 \mid$ Chapter 5

Table 5.3 Intra- and inter assay variation of the CRPH and the ProCa-S in BALF, determined on a sample with a low concentration and a sample with a high concentration of respectively CRP and PCT.

\begin{tabular}{lccccccccc}
\hline & \multicolumn{4}{c}{ CRPH (mg/l) } & \multicolumn{3}{c}{ ProCa-S (ng/l) } \\
\hline & \multicolumn{3}{c}{ Intra assay } & \multicolumn{2}{c}{ Inter assay } & \multicolumn{3}{c}{ Intra assay } & \multicolumn{2}{c}{ Inter assay } \\
& Sample & Sample & Sample & Sample & Sample & Sample & Sample & Sample \\
& low & high & low & high & low & high & low & high \\
\hline $\mathrm{X}^{\mathrm{a}}$ & 4.20 & 11.30 & 3.50 & 10.05 & 44.50 & 950.0 & 46.10 & 975.5 \\
$\mathrm{SD}^{\mathrm{b}}$ & 0.11 & 0.24 & 0.07 & 0.29 & 0.43 & 8.60 & 3.80 & 36.80 \\
$\mathrm{CV}^{\mathrm{c}}(\%)$ & 2.60 & 2.12 & 2.05 & 2.76 & 0.97 & 0.90 & 7.70 & 3.80 \\
\hline
\end{tabular}

${ }^{a} \mathrm{x}$ is the mean of seven determinations; ${ }^{\mathrm{b}} \mathrm{SD}$ is the standard deviation; ${ }^{\mathrm{c}} \mathrm{CV}$ is the coefficient of variation; $\mathrm{CRP}=\mathrm{C}$-reactive protein, $\mathrm{CRPH}=$ high-sensitivity $\mathrm{CRP}, \mathrm{PCT}=$ procalcitonin, ProCaS: highsensitivity PCT, BALF=bronchoalveolar lavage fluid.

\section{CRP and PCT concentrations in BALF and serum samples as a prediction of VAP}

Table 5.4 shows the mean, standard deviation (SD), median, range and $p$ values for PCT and CRP in BALF samples obtained from patients with and without VAP. No significant differences were found between both groups. From this table, it is clear that there was a large overlap between the VAP and the non-VAP group for both serum and BALF concentrations. ProCa-S and CRPH levels in BALF samples tended to be higher in the non-VAP group. For PCT and CRP in serum the opposite was seen. However, none of the differences reached statistical significance.

With regard to the CRPH concentrations in BALF, one outlier was identified (concentration $204.4 \mathrm{mg} / \mathrm{l}$ ), this belonged to the non-VAP group and also had a high CRP value in the serum together with a slightly increased PCT concentration in serum (124 mg/l and $5.6 \mu \mathrm{g} / /$ respectively). Both ProCa-S and albumin were low in the BALF of this patient. With regard to ProCa-S concentrations in BALF, four outliers were noted (values $>1.0 \mu \mathrm{g} / \mathrm{l}$ ), one in the VAP group and three in the non-VAP group. Three of them also had elevated concentrations of PCT in serum and albumin $(307,831$ and $4150 \mathrm{mg} / \mathrm{l})$ in BALF (all non-VAP group). The remaining patient had an elevated serum PCT concentration but a BALF albumin level within normal limits.

\section{BALF and serum CRP and PCT in the prediction of VAP}

Table 5.5 lists the ROC curves of CRP and PCT in BALF and serum. The AUC of both CRP and PCT in BALF and serum did not exceed 0.5 indicating that both CRP and PCT were not suitable for discriminating between patients with and without VAP in BALF as well as in serum. 
Table 5.4 Mean, standard deviation (SD), median and range for PCT and CRP in BALF and serum. None of the differences was statistically significant $(p>0.05)$

\begin{tabular}{lcc}
\hline & VAP $(n=51)$ & $n o n-V A P(n=66)$ \\
\hline CRP BALF (CRPH, mg/l) & 13.9 & 59.3 \\
Mean & 36.0 & 243.9 \\
SD & 4.1 & 4.4 \\
Median & $1.0-204.4$ & $0.0-2223.0$ \\
Range & & \\
PCT BALF (ProCa-S, $\mu \mathrm{g} / \mathrm{l})$ & 0.3 & 1.2 \\
Mean & 0.7 & 4.9 \\
SD & 0.1 & 0.1 \\
Median & $0.0-4.1$ & $0.0-33.9$ \\
Range & & \\
CRP serum (CRP, mg/l) & 155.4 & 160.8 \\
Mean & 98.9 & 87.8 \\
SD & 127.0 & 165.0 \\
Median & $9.8-363.0$ & $0.9-373.0$ \\
Range & & \\
PCT serum (LUMltest, $\mu \mathrm{g} / \mathrm{l})$ & 6.4 & 5.0 \\
Mean & 17.1 & 8.8 \\
SD & 1.0 & 1.6 \\
Median & $0.1-98.5$ & $0.1-48.1$ \\
Range &
\end{tabular}

$C R P=C$-reactive protein, $C R P H=h i g h$-sensitivity $C R P, P C T=$ procalcitonin, ProCaS: high-sensitivity $P C T, B A L F=$ bronchoalveolar lavage fluid.

Table 5.5 AUC for CRP and PCT in BALF and serum.

\begin{tabular}{ll}
\hline Parameter & AUC \\
\hline CRP in BALF & 0.477 \\
CRP in serum & 0.453 \\
PCT in BALF & 0.448 \\
PCT in serum & 0.373 \\
\hline
\end{tabular}

$C R P=C$-reactive protein, $C R P H=h i g h-s e n s i t i v i t y ~ C R P, P C T=$ procalcitonin, ProCaS: high-sensitivity $P C T, B A L F=$ bronchoalveolar lavage fluid, $A U C=a r e a$ under the curve.

\section{Correlations between blood and BALF}

There was no correlation between BALF CRPH and serum CRP concentrations $(r=0.27)$ There was a correlation between concentration of ProCa-S in BALF and PCT in serum ( $r=0.63)$. No correlation was found between BALF albumin levels and either ProCa-S and CRPH in BALF. However, there was a tendency towards higher albumin levels in BALF samples with either high ProCa-S or $\mathrm{CRPH}$ in BALF. 


\section{Correlations with PMNs and bacterial load}

No correlation $(r<0.1, p>0.1)$ was found between the percentage of polymorphonuclear neutrophils (\%PMNs) and PCT or CRP levels in BALF and serum. No correlation was found between the quantity of micro-organisms cultured in the BALF and the concentration of ProCa-S in BALF. When the bacterial burden in the BALF was considered, a large overlap was noted between the different categories (results not shown). No significant difference was found in the concentrations of BALF ProCa-S in samples from patients with pneumonia caused by Gram-positive micro-organisms versus patients with pneumonia caused by Gram-negative micro-organisms. One outlier (very high concentration of ProCa-S) was identified, this was a sample with Gram-positive bacteria (Staphylococcus aureus) present in a quantity of $>10^{5} \mathrm{cfu} / \mathrm{ml}$.

\section{Presence of bacteremia}

In all 117 patients, blood cultures were drawn at time of BAL. Micro-organisms were recovered in $10(8.5 \%)$ patients: Escherichia coli, Enterobacter cloacae, Streptococcus pneumoniae, Salmonella enteritidis, Serratia marsescens (1 isolate each), Staphylococcus epidermidis $(\mathrm{n}=2)$ and Candida albicans $(\mathrm{n}=3)$. The focus of the bacteremia could be established in $8 / 10$ patients, most frequent were intravenous catheter related bacteremia $(n=6)$, followed by urinary tract infection $(n=1)$ and gastroenteritis $(n=1)$ In $4 / 10$ patients VAP was present, however the bacteria recovered in BALF were not the same as recovered in the blood culture, making it unlikely that the pneumonia was the focus of the bacteremia. No significant differences were found, in PCT or CRP levels in BALF and serum, between the group of patients with and without proven bacteremia.

\section{Discussion}

In this study, ProCa S kit and the CRPH kit were validated for BALF. Both tests performed good when assessed for matrix-effect, linearity and reproducibility. There was a large overlap in ProCa-S and CRPH concentrations in BALF samples between patients with and without VAP. Both ProCa-S and $\mathrm{CRPH}$ concentrations in BALF resulted in a small AUC indicating both parameters to be unsuitable as a predictor for VAP.

In the diagnosis VAP, quantitative culture exceeding $10^{4} \mathrm{cfu} / \mathrm{ml}$, is regarded as a definite microbiological diagnosis ${ }^{1,2}$. In earlier studies ${ }^{26}$, we found that PMNs and lactate dehydrogenase activity, particularly its isoenzymes, in BALF appeared to be of important practical value in distinguishing between infection and non-infectious pulmonary disorders. 
Most other studies dealing with the subject of determining parameters in BALF do not take into consideration the 10-100 times dilution of BALF compared to the alveolar lining fluid ${ }^{24}$. This makes it difficult to compare those data with ours.

In this study, a reasonable correlation was found between serum PCT levels and ProCa-S in BALF. This is in line with Stiletto and co-workers ${ }^{27}$ who also found a correlation between PCT in BALF and serum in patients with severe pulmonary contusion.

Our findings indicate PCT in both serum and BALF to be unreliable in the diagnosis VAP. This is in contradiction with the results found by Oppert and coworkers ${ }^{8}$. They found elevations in serum PCT in patients with VAP after cardiopulmonary resuscitation. However they defined their diagnosis VAP according to the presence of radiographic signs and a micro-organism isolated from either blood or bronchial aspirate. Our diagnosis VAP relies upon a quantitative culture result of BALF $\geq 10^{4} \mathrm{cfu} / \mathrm{ml}$ making the diagnosis infection more evident. Since Oppert et al. may have included patients who do not reach our criteria for VAP, these groups might not be comparable.

Our study results are partly in line with the results of Duflo et $a l^{28}$ who found an increase in serum PCT in patients with VAP, but no increase in alveolar PCT. The difference between both studies lies in the fact that we used the highsensitivity kit (ProCa-S) which enabled us to detect even the slightest increase in PCT levels. In $72.6 \%$ (85/117) of cases PCT concentration in BALF were below the detection-limit of the LUMitest, this could explain the findings of Duflo et al.

The literature on PCT in patients with VAP is limited, however a few studies have been published concerning the use of PCT in patients with pneumonia. Werra et $a 1 .{ }^{15}$ investigated patients with septic or cardiogenic shock or severe pneumonia and found a significant increase in the concentration of PCT in blood in patients with septic shock only. Karzai et al. ${ }^{18}$ investigated patients with community acquired pneumonia and did not find an increase in the PCT level in the serum of these patients. Luyt et al..$^{29}$ evaluated PCT kinetics as a prognostic marker in VAP and found a high PCT level to be associated with a more severe disease. They also used ROC curves to illustrate the usefulness of serum PCT in the prediction of the outcome of VAP and found AUCs exceeding 0.8 .

The cellular origin of PCT in infection is not clear yet, however some evidence shows an important role for peripheral blood-monocytes ${ }^{30}$. We found the concentration range of PCT in BALF to be narrower than the concentration range of $\mathrm{PCT}$ in serum. Since there was no correlation between ProCa-S and/or CRPH and \%PMNs in BALF we believe that there is no local production of PCT within the alveoli. All BALF samples with extreme high concentrations of PCT were from patients who also had high concentrations of PCT in their 
serum, and the majority also had high albumin in their BALF. This could indicate alveolar leakage and therefore diffusion of PCT and CRP from the serum to the alveolar space.

No significant difference was found in ProCa-S levels in BALF and serum of patients with VAP versus patients with non-VAP. This may be because ICU patients are prone to several (nosocomial) infections such as bacteremia, which can account for the elevation of PCT in these patients.

No correlation was found between the organism causing the pneumonia and the concentration of ProCa-S in BALF, even though lipopolysaccherid (LPS) is recognised as the major stimulus of PCT production. This may be due to the fact that PCT is not locally produced, the presence of LPS from Gram-negative bacteria in the lung therefore do not stimulate PCT production, in contrast to (Gram-negative) bacteria in blood ${ }^{14,30}$.

Since the study was conducted retrospectively we were unable to follow PCT levels in serum (and/or BAL). Boussekey et al. investigated PCT kinetics in patients with severe community-acquired pneumonia admitted to the intensive care unit and found PCT to be an independent risk factor of mortality. ${ }^{31}$ Therefore it would be interesting to see if this can also be applied to patients with VAP. Due to the retrospective nature of the study, the amount of clinical data was limited. Blood cultures at the time of lavage were available and yielded a micro-organism in 10 out of 117 patients. No significant differences in PCT and CRP levels were found between the patients with and without bacteremia. On the other hand, the retrospective analysis did not allow to assess localised infections other than VAP, which could have influenced PCT and CRP values.

The aim of our study was to evaluate the value of PCT and/or CRP levels in serum and BALF samples in the discrimination between VAP and non-VAP. Unfortunately neither PCT nor CRP, in both serum as BALF, could be used to predict the presence of VAP.

Since the literature on PCT in BALF and serum as a predictor of VAP is contradicting, a large prospective study should be conducted to further assess the value of this parameter, taking into account the dilution of BALF compared to epithelial lining fluid.

In conclusion, the ProCa-S kit and the CRPH kit are useful in assessing the concentration of respectively PCT and CRP in BALF. As the PCT and CRP levels in BALF did not discriminate between patients with and without VAP, they appeared to be of no additional value in the diagnosis of VAP. Therefore, we stress that BALF analysis should at least include depicting the infected cells and a differential cell count to establish a VAP and distinguish it from other diagnoses like drug-induced pneumonitis, acute interstitial pneumonia or diffuse alveolar damage. 


\section{References}

1. Baselski V. Microbiologic diagnosis of ventilator-associated pneumonia. Infect Dis Clin North Am. 1993;7:331-57.

2. Allaouchiche $B$, Jaumain $H$, Dumontet $C$, Motin J. Early diagnosis of ventilator-associated pneumonia. Is it possible to define a cutoff value of infected cells in BAL fluid? Chest. 1996;110:1558-65.

3. Rothenburger M, Markewitz A, Lenz T, Kaulbach HG, Marohl K, Kuhlmann WD, Weinhold C. Detection of acute phase response and infection. The role of procalcitonin and C-reactive protein. Clin Chem Lab Med. 1999;37: 275-9.

4. Delevaux 1, Andre $M$, Colombier $M$, Albuisson $E$, Meylheuc CF, Begue RJ, Piette JC, Aumaitre $\mathrm{O}$. Can procalcitonin measurement help in differentiating between bacterial infection and other kinds of inflammatory processes? Ann Rheum Dis. 2003:62:337-40.

5. Almirall J, Bolibar I, Toran P, Pera G, Boquet X, Balanzo X, Sauca G. Contribution of Creactive protein to the diagnosis and assessment of severity of community-acquired pneumonia. Chest. 2004;125:1335-42.

6. Povoa P, Coelho L, Almeida E, Fernandes A, Mealha R, Moreira P, Sabino H. C-reactive protein as a marker of ventilator-associated pneumonia resolution: a pilot study. Eur Respir J. 2005:25:804-12.

7. Boussekey $N$, Leroy $O$, Georges $H$, Devos $P$, d'Escrivan $T$, Guery B. Diagnostic and prognostic values of admission procalcitonin levels in community-acquired pneumonia in an intensive care unit. Infection. 2005;33:257-63.

8. Oppert $M$, Reinicke A, Muller $C$, Barckow D, Frei U, Eckardt KU. Elevations in procalcitonin but not $\mathrm{C}$-reactive protein are associated with pneumonia after cardiopulmonary resuscitation. Resuscitation. 2002;53:167-70.

9. Assicot $M$, Gendrel D, Carsin H, Raymond J, Guilbaud J, Bohuon C. High serum procalcitonin concentrations in patients with sepsis and infection. Lancet. 1993;341:515-8.

10. Gendrel D, Assicot M, Raymond J, Moulin F. Francoual C, Badoual J, Bohuan C. Procalcitonin as a marker for the early diagnosis of neonatal infection. J Pediatr. 1996;128:570-3.

11. Gendrel D, Raymond J, Assicot M, Moulin F, Iniguez JL, Lebon P, Bohuan C. Measurement of procalcitonin levels in children with bacterial or viral meningitis. Clin Infect Dis. 1997;24:1240-2.

12. Ugarte $H$, Silva $E$, Mercan D, De Mendonca A, Vincent JL. Procalcitonin used as a marker of infection in the intensive care unit. Crit Care Med. 1999;27:498-504.

13. Brunkhorst FM, Eberhard OK, Brunkhorst R. Discrimination of infectious and noninfectious causes of early acute respiratory distress syndrome by procalcitonin. Crit Care Med. 1999;27:2172-6.

14. Al-Nawas B, Krammer I, Shah PM. Procalcitonin in diagnosis of severe infections. Eur J Med Res. 1996;1:331-3.

15. de Werra I, Jaccard C, Corradin SB, Chiolero R, Yersin B, Gallati H, Assicot M, Bohuan C, Baumgartner JD, Glauser MP, Heumann D. Cytokines, nitrite/nitrate, soluble tumor necrosis factor receptors, and procalcitonin concentrations: comparisons in patients with septic shock, cardiogenic shock, and bacterial pneumonia. Crit Care Med. 1997;25:607-13.

16. Gerard $Y$, Hober D, Petitjean $S$, Assicot $M$, Bohuon $C$, Mouton $Y$, Wattre $P$. High serum procalcitonin level in a 4-year-old liver transplant recipient with a disseminated candidjasis. Infection. 1995;23:310-1.

17. Davis TM, Assicot M, Bohuon C, St John A, Li GQ, Anh TK. Serum procalcitonin concentrations in acute malaria. Trans R Soc Trop Med Hyg. 1994;88:670-1.

18. Karzai W, Oberhoffer M, Meier-Hellmann A, Reinhart K. Procalcitonin--a new indicator of the systemic response to severe infections. Infection. 1997;25:329-34

19. Smith MD, Suputtamongkol $Y$, Chaowagul W, Assicot M, Bohuon C, Petitjean S, White NJ. Elevated serum procalcitonin levels in patients with melioidosis. Clin Infect Dis. 1995;20: $641-5$. 
$88 \mid$ Chapter 5

20. Bonten MJ, Bergmans DC, Stobberingh EE, van der Geest S, De Leeuw PW, van Tiel FH, Gaillard CA. Implementation of bronchoscopic techniques in the diagnosis of ventilatorassociated pneumonia to reduce antibiotic use. Am J Respir Crit Care Med. 1997;156: 1820-4.

21. Jacobs JA, De Brauwer E. BAL fluid cytology in the assessment of infectious lung disease. Hosp Med. 1999;60:550-5.

22. Jacobs JA, De Brauwer El, Cornelissen El, Drent M. Accuracy and precision of quantitative calibrated loops in transfer of bronchoalveolar lavage fluid. J Clin Microbiol. 2000;38:2117-21.

23. Schildge J, Nagel C, Grun C. Bronchoalveolar lavage in interstitial lung diseases: does the recovery rate affect the results? Respiration 2007;74:553-7.

24. Wiedermann FJ, Mayr AJ, Kaneider NC, Fuchs D, Mutz NJ, Schobersberger W. Alveolar granulocyte colony-stimulating factor and alpha-chemokines in relation to serum levels, pulmonary neutrophilia, and severity of lung injury in ARDS. Chest. 2004;125:212-9.

25. Obuchowski NA, Lieber ML, Wians FH, Jr. ROC curves in clinical chemistry: uses, misuses, and possible solutions. Clin Chem. 2004;50:1118-25.

26. Cobben NA, Jacobs JA, van Dieijen-Visser MP, Mulder PG, Wouters EF, Drent M. Diagnostic value of BAL fluid cellular profile and enzymes in infectious pulmonary disorders. Eur Respir J. 1999;14:496-502.

27. Stiletto RJ, Baacke M, Gotzen L, Lefering R, Renz H. Procalcitonin versus interleukin- 6 levels in bronchoalveolar lavage fluids of trauma victims with severe lung contusion. Crit Care Med. 2001;29:1690-3.

28. Duflo F, Debon R, Monneret G, Bienvenu J, Chassard D, Allaouchiche B. Alveolar and serum procalcitonin: diagnostic and prognostic value in ventilator-associated pneumonia. Anesthesiology. 2002;96:74-9.

29. Luyt CE, Guerin V, Combes A, Trouillet JL, Ayed SB, Bernard H, Gilbert C, Chastre J. Procalcitonin kinetics as a prognostic marker of ventilator-associated pneumonia. Am $\mathrm{J}$ Respir Crit Care Med. 2005;171:48-53.

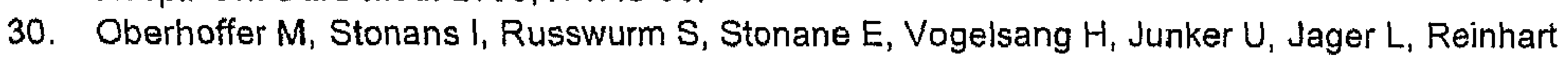
$K$. Procalcitonin expression in human peripheral blood mononuclear cells and its modulation by lipopolysaccharides and sepsis-related cytokines in vitro. J Lab Clin Med. 1999;134:49-55.

31. Boussekey N, Leroy O, Alfandari S, Devos P, Georges $H$, Guery B. Procalcitonin kinetics in the prognosis of severe community-acquired pneumonia. Intensive Care Med. 2006;32: 469-72. 
Chapter

Inter-laboratory comparison of three different real-time PCR assays for the detection of Pneumocystis jiroveci in bronchoalveolar lavage fluid samples

CFM Linssen, JA Jacobs, P Beckers, KE Templeton, J Bakkers, EJ Kuijper, WJG Melchers, M Drent, C Vink 
90 Chapter 6

\section{Abstract}

\section{Objective}

Pneumocystis jiroveci pneumonia (PCP) is an opportunistic infection affecting immunocompromised patients. While conventional diagnosis of $P C P$ by microscopy is cumbersome, the use of polymerase chain reaction (PCR) to diagnose PCP has great potential. Nevertheless, inter-laboratory validation and standardization of PCR assays is lacking. The aim of this study was to evaluate the inter-laboratory agreement of three independently developed realtime PCR assays for the detection of $P$. jiroveci in bronchoalveolar lavage fluid (BALF) samples.

Study design

A total of 124 samples were collected in three tertiary care laboratories (LUMC, MINC and RUNMC) and were tested by both microscopy and real-time PCR.

\section{Results}

Out of 41 samples positive for $P$. jiroveci by microscopy, 40 were positive in all three PCR assays.

The remaining sample was positive in a single assay only. Out of 83 microscopy-negative samples, 69 were negative in all three PCR assays. The other 14 samples were found positive, either in all three assays $(n=5)$, in two $(n=2)$ or in one of the assays $(n=7)$.

\section{Conclusion}

Our data demonstrate high inter-laboratory agreement between (real-time) PCR assays for the detection of $P$. jiroveci. 
Inter-laboratory comparison for the detection of P. jiroveciin BALF sarnples 91

\section{Introduction}

Pneumocystis carinii is an opportunistic pathogen that was classified as a fungus in $1988^{1}$. Although human-derived Pneumocystis carinii (P. carinii f.sp. hominis) has recently been renamed Pneumocystis jiroveci, the abbreviation PCP (now referring to Pneumocystis pneumonia) remains in use ${ }^{2}$. Patients at risk for $P$. jiroveci pneumonia can be divided into two categories: HIV-positive and -negative patients. Several risk factors have been identified in the HIVnegative group, such as immunosuppressive medication or an inherited or acquired immunodeficiency ${ }^{3}$. Since untreated PCP is associated with a high morbidity and mortality, ${ }^{4,5}$ especially in HIV-negative patients, a rapid and reliable diagnosis is mandatory. Current diagnosis of PCP relies on tinctorial and/or immunofluorescent staining of induced sputum or bronchoalveolar lavage fluid (BALF) samples ${ }^{6,7}$. Using these methods, sensitivity and specificity rates are reached which exceed $95 \%^{8-11}$. Major drawbacks of microscopy are, however, that it is cumbersome and requires trained microscopists. The latter makes it essential that positive samples are encountered regularly in order to ascertain an expertise in microscopy. In recent years, the incidence of PCP has declined significantly, especially in HIV-positive patients. Due to the introduction of highly active anti-retroviral therapy, PCP chemoprophylaxis, and an increase of patients receiving chemotherapy, the future trend will be towards samples with relatively low $P$. jiroveci burdens, making the diagnosis of PCP even more difficult ${ }^{12,13}$. Therefore, a rapid diagnostic technique, which can identify the presence of a low number of cysts, is needed.

Nucleic acid amplification tests, such as the polymerase chain reaction (PCR), play an increasing role in the detection of $P$. jirovec ${ }^{14,15}$. In particular, real-time PCR is highly suitable in the diagnosis of PCP, since this technique allows the generation of quantitative results. This is crucial, as $P$. jiroveci may be present in low quantities in some asymptomatic individuals ${ }^{16,17}$. Consequently, it is of utmost importance to be able to discriminate between asymptomatic carrier ship and clinically relevant infection. In recent years, molecular tests for detecting $P$. jiroveci have shifted from research to diagnostic applications ${ }^{18-20}$. Nevertheless, quality control panels for validation and standardization of such tests are currently lacking. Therefore, a study was initiated to compare the performance of three independently developed real-time PCR assays for the detection of $P$. jiroveci in three different tertiary care centers in The Netherlands. This retrospective study assessed the routine diagnostic performance of these assays on a collection of BALF samples of which the microscopic evaluation for the presence of $P$. jiroveci had already been performed. 
$92 \mid$ Chapter 6

\title{
Materials and methods
}

\author{
Design of the study
}

Three diagnostic medical microbiology laboratories participated in this study, i.e. Maastricht infection Center (MINC), Radboud University Nijmegen Medical Center (RUNMC) and Leiden University Medical Center (LUMC). All three laboratories are university tertiary care centers located in The Netherlands. Each of these laboratories supplied $P$. jirovecipositive and -negative samples. Diagnosis was based on microscopy. The materials were collected by one of us (C.F.M.L), encoded, and distributed to the other laboratories. Each laboratory received a set of samples and performed its own real-time PCR in a blinded fashion.

\section{BALF sampling and conventional diagnosis of PCP}

Samples obtained from patients suspected of PCP were collected over a period from August 1999 until April 2004. Bronchoscopy with BAL was performed with sterile saline, in four aliquots of $50 \mathrm{ml}$ (MINC), three aliquots of $20 \mathrm{ml}$ (LUMC) and three aliquots of $50 \mathrm{ml}$ (RUNMC). Samples were immediately transported to the laboratory and processed upon arrival. At the LUMC and RUNMC, aliquots of $10 \mathrm{ml}$ were centrifuged at $3000 \times \mathrm{g}$ and smears were made from the sediment. At the MINC, cytocentrifuged monolayer preparations were made as previously described ${ }^{21}$. Subsequently, slides were subjected to either Giemsa and methenamine silver staining (LUMC), Giemsa and direct immunofluorescence staining (PneumoCel, CeLLabs, Brookvale, Australia) (RUNMC) or May-Grünwald Giemsa and methenamine silver staining (MINC).

\section{Nucleic acid extraction and real-time PCR analysis}

At the MINC, $200 \mu$ l BALF was used for DNA isolation using the Wizard ${ }^{(B)}$ Genomic DNA Purification Kit (Promega, Madison, USA). Purified DNA was resuspended in a final volume of $120 \mu \mathrm{l}$. A real-time PCR was designed that targets the major surface glycoprotein (MSG) gene ${ }^{15}$. Assays were performed in 96-well Optical Reaction plates (Applied Biosystems [ABI], Foster City, California) in a volume of $50 \mu \mathrm{l}$ containing $0.6 \mu \mathrm{M}$ of each primer PCPFor and PCPRev (Table 6.1), $0.15 \mu \mathrm{M}$ of probe PCPProbe, $1 \times$ TaqMan $^{\circledR}$ Universal Master Mix (ABI) and $20 \mu \mathrm{l}$ of purified DNA. Thermal cycling was carried out on an $A B I$ PRISM 7000 Sequence Detection System (ABI) as follows: two minutes at $50^{\circ} \mathrm{C}, 10$ minutes at $95^{\circ} \mathrm{C}$, followed by 42 cycles of 15 seconds at $95^{\circ} \mathrm{C}$ and one minute at $60^{\circ} \mathrm{C}$. Quantification was performed using the $A B I$ PRISM software and is based on extrapolation of data to standard curves, which were 
Inter-laboratory comparison for the detection of P. jirovecin BALF samples $\mid 93$

generated by amplification of quantified dilutions of plasmid PPCP, which contains the $P$. jiroveciPCR fragment.

Table 6.1 Description of primers and probes used by the three laboratories.

\begin{tabular}{|c|c|c|c|c|c|}
\hline Laboratory & Target & & Primer $\left[5^{\prime}-3^{\prime}\right]$ (Name) & $\begin{array}{l}\text { GenBank } \\
\text { accession } \\
\text { no. }\end{array}$ & $\begin{array}{l}\text { Position } \\
\text { on gene }\end{array}$ \\
\hline$\overline{\text { MINC }}$ & MSG & $\begin{array}{l}\mathrm{F}^{\mathrm{a}} \\
\mathrm{P}^{\mathrm{b}} \\
\mathrm{R}^{\mathrm{c}}\end{array}$ & $\begin{array}{l}\text { CAAAAATAACAYTSACATCAACRAGG (PCPFor) } \\
\text { FAM-TGCAAACCAACCAAGTGTACGACAGG- } \\
\text { TAMRA (PCPProbe) } \\
\text { AAATCATGAACGAAATAACCATTGC (PCPRev) }\end{array}$ & $\mathrm{AF} 372980$ & $\begin{array}{l}223-248 \\
252-277 \\
378-354\end{array}$ \\
\hline LUMC & DHPS & $\begin{array}{l}\mathrm{F}^{\mathrm{a}} \\
\mathrm{P}^{\mathrm{b}}\end{array}$ & $\begin{array}{l}\text { ATGATTCTATATTAATGGATGTGGAG (PJIRs) } \\
\text { MB- } \\
\text { CGCGCTGGGCGACGATAATTGATATTGGTGGA } \\
\text { GCGCG-FAM (578PJIR) } \\
\text { AGATATTTTATAGCAGGAATAACTCG (PJIRas) }\end{array}$ & AJ586567 & $\begin{array}{l}148-173 \\
190-214\end{array}$ \\
\hline RUNMC & MSG & $\begin{array}{l}\mathrm{F}^{\mathrm{a}} \\
\mathrm{P} 1^{\mathrm{b}} \\
\mathrm{P} 2^{\mathrm{b}} \\
\mathrm{R}^{\mathrm{c}}\end{array}$ & $\begin{array}{l}\text { GAATGCAAATCYTTACAGACAACA (JKK114/15) } \\
\text { CAAAAATAACAYTSACATCAACRAGGC } \\
\text { (PCMSGFRET1U) } \\
\text { TGCAAACCAACCAAGTGTACGACAGG } \\
\text { (PCMSGFRT1D) } \\
\text { AAATCATGAACGAAATAACCATTGC (JKK17) }\end{array}$ & AF37298 & $\begin{array}{r}135-158 \\
223-248 \\
252-277 \\
378-354 \\
\end{array}$ \\
\hline
\end{tabular}

a Forward primer, ${ }^{b}$ Probe, ${ }^{c}$ Reverse primer. MSG: Major surface glycoprotein, DHPS: dihydroperoate synthase gene. The sequences from primers and probes used by MINC and RUNMC were obtained from reference ${ }^{15}$.

At the RUNMC, the MagnaPure LC Isolation station (Roche Applied Science, Mannheim, Germany) was used for nucleic acid isolation. A 100- $\mu$ l aliquot was isolated using the Total Nucleic Acid isolation kit (Roche Applied Science). Nucleic acids were resuspended in $50 \mu \mathrm{l}$ of $\mathrm{H}_{2} \mathrm{O}$. Real-time PCR for $P$. jiroveci was performed as described by Larsen et al., using the MSG gene as target ${ }^{15}$. All reactions were performed in $20 \mu \mathrm{l}$, consisting of $1 \times$ LightCycler FastStart DNA Master Hybridization Probes reaction mixture (Roche), $4 \mathrm{mM} \mathrm{MgCl}$, $1.0 \mu \mathrm{M}$ of each primer JKK14/15 and JKK17 (Table 6.1), $0.2 \mu \mathrm{M}$ of each probe PCMSGFRET1U and PCMSGFRET1D, and $5 \mu$ template. The PCR thermal profile consisted of an initial incubation at $95^{\circ} \mathrm{C}$ for 10 minutes, followed by a touch-down procedure, consisting of 11 cycles of 5 seconds at $95^{\circ} \mathrm{C}$ and 10 seconds at temperatures decreasing from $65^{\circ} \mathrm{C}$ to $50^{\circ} \mathrm{C}$. This was followed by 35 cycles of 5 seconds at $95^{\circ} \mathrm{C}$ and 10 seconds at $50^{\circ} \mathrm{C}$, and a final step of 15 seconds at $72^{\circ} \mathrm{C}$. Amplification, detection and data analysis was executed using the LightCycler v2.0 system (Roche). 
At the LUMC, nucleic acids were extracted from $200 \mu$-samples using the Qiagen whole blood DNA extraction kit (Qiagen, Hilden, Germany). Each sample was eluted using $200 \mu$ of elution buffer. Real-time PCR for $P$. jiroveci was targeted at the dihydroperoate synthase gene (DHPS), and was performed in $50 \mu \mathrm{l}$ reaction mixtures, consisting of $1 \times$ HotstarTaq $^{\mathrm{TM}}$ mastermix (Qiagen, Hilden, Germany), $3.5 \mathrm{mM} \mathrm{MgCl}_{2}, 0.4 \mu \mathrm{M}$ of each primer, $0.34 \mu \mathrm{M}$ of molecular beacon probe and $10 \mu \mathrm{l}$ of purified DNA. The PCR thermal profile consisted of 15 minutes at $95^{\circ} \mathrm{C}$, followed by 50 cycles of 30 seconds at $95^{\circ} \mathrm{C}, 30$ seconds at $55^{\circ} \mathrm{C}$ and 30 seconds at $72^{\circ} \mathrm{C}$. Amplification, detection and data analysis were performed with an iCycler $1 Q$ Real-Time Detection System (Bio-Rad, Veenendaal, The Netherlands).

\section{Additional analyses}

Since two of the three PCR assays were based on a multicopy target (MSG) and one assay on a single copy target (DHPS), comparison of quantification was performed on the basis threshold cycle $\left(C_{t}\right)$ values rather than absolute quantifications. In 26 samples (positive samples from the MINC), the $P$. jiroveci burden was also microscopically quantified ${ }^{21}$. For these samples, microscopic quantification was compared to PCR quantification using the MINC assay (described above).

\section{Statistical analysis}

Qualitative inter-assay agreement was assessed by pair wise comparisons of test results from the three laboratories by calculating the crude percent agreement and the kappa statistic. For this comparison, the results obtained on the initial run for each sample were taken and any $C_{t}$ value obtained was considered as a positive result. Further, pair wise correlations between the different laboratories' $C_{t}$ values for each sample were calculated using Pearson correlation coefficient. Correlation between microscopy quantification and realtime PCR quantification was also expressed as a correlation coefficient.

\section{Results}

\section{Origin of BALF samples}

A total of 124 BALF samples collected during the period August 1999-April 2004 were included. They were recovered from either HIV-positive or HIVnegative patients with a known risk factor for PCP, such as (hematological) malignancy, bone marrow or organ transplantation, Wegener's granulomatosis, and immunosuppressive or corticosteroid therapy ${ }^{7,12}$. In addition, a number of 
BALF samples obtained from patients with no known risk factor for PCP were included (Table 6.2). These samples were obtained from patients with newly diagnosed sarcoidosis or ventilator-associated pneumonia. The samples were obtained form the LUMC $(n=20)$, RUNMC $(n=18)$ and MINC $(n=86)$. As shown in Table 6.2, 41 samples (33.1\%) were found to be positive for $P$. jiroveci by microscopy.

Table 6.2 Origin of BALF samples included in this study.

\begin{tabular}{lccccc}
\hline & \multicolumn{2}{c}{ Patients at risk $^{\mathrm{a}}$} & \multicolumn{2}{c}{ Patients not at risk } \\
\hline $\begin{array}{l}\text { Microscopy result } \\
\text { for } P \text {.jiroveci }\end{array}$ & HIV-positive & HIV-negative & $\begin{array}{c}\text { Ventilator-associated } \\
\text { pneumonia }\end{array}$ & Sarcoidosis ${ }^{\mathrm{b}}$ & Total $^{-}$ \\
\hline Positive & 21 & 20 & 0 & 0 & 41 \\
Negative & 10 & 33 & 20 & 20 & 83 \\
\hline
\end{tabular}

a HIV-infected patients, or patients with a known risk factor for PCP, such as hematological malignancy, bone marrow or organ transplantation, Wegener's granulomatosis, and immunosuppressive or corticosteroid therapy; $b$ Sarcoidosis patients were not receiving immunosuppressive therapy or corticosteroids.

\section{Qualitative agreement between the three $P$. jiroveci real-time PCR assays}

All 124 samples were subjected to real-time PCR at each of the three participating laboratories. For $114(91.9 \%)$ of the 124 samples, the three laboratories obtained identical qualitative results (Table 6.3). Forty out of 41 (97.6\%) microscopy-positive samples were found positive in all three PCR assays. The remaining microscopy-positive sample was only positive in a single assay, but showed a relatively high $C_{t}$ value $\left(C_{t}=36.6\right)$. This sample was obtained from a patient with a low parasite burden (one cyst in one out of three investigated microscopic slides). This patient was diagnosed with PCP a week earlier and had been treated with cotrimoxazole during the week previous to the bronchoscopy.

Table 6.3 Comparison of the three real-time PCR assays for the detection of $P$. jiroveci.

\begin{tabular}{lccc}
\hline & \multicolumn{3}{c}{ Real-time PCR positive $(+)$ or negative $(-)$} \\
Number of samples & MINC & LUMC & RUNMC \\
\hline Microcopy-positive samples $(n=41)$ & + & + & + \\
40 & + & - & - \\
1 & & - & - \\
Microscopy-negative samples $(n=83)$ & - & + & + \\
69 & + & - & + \\
5 & - & - & - \\
4 & + & + & - \\
2 & + & - & + \\
1 & + & + & - \\
1
\end{tabular}


96

Chapter 6

Of the 83 microscopy-negative samples, $69(83.1 \%)$ were found negative in all three PCR assays (Table 6.3). The remaining 14 samples were PCR-positive in at least one of the three assays. Five of these were positive in all three assays, two samples were positive in two of the assays, and seven samples were positive in a single assay only. The majority $(12 / 14)$ of the patients with microscopy-negative/PCR-positive results were HIV-negative patients with one or more risk factors for PCP (data not shown). An additional patient was HIVpositive and the remaining patient did not have any known risk factors. The most likely explanation for the microscopy-negative/PCR-positive results is the higher sensitivity of PCR as opposed to microscopy.

The agreement between the three $P$. jiroveci real-time PCR assays was assessed by pair wise comparisons of the qualitative test results. Highest agreement was found between the MINC and LUMC assays, with a percentage of agreement of $96.8 \%$ and a Kappa value of 0.93 . The agreement between the other assays was also excellent, with a percentage of agreement of $94.4 \%$ and a Kappa value of 0.88 , between both the MINC and RUNMC assays and the RUNMC and LUMC assays.

\section{Quantitative comparison between the three real-time PCR assays}

To compare the quantitative performance of the three real-time PCR assays, pair wise correlations between $C_{t}$ values generated on samples that were scored positive in all three assays ( $n=45$; Table 6.3 ) were calculated. As shown in Figure 6.1, there was a good correlation between the $C_{t}$ values produced by each of the three assays. The correlation coefficients were $0.84,0.90$ and 0.99 between the LUMC and MINC assays, the MINC and RUNMC assays, and the LUMC and RUNMC assays, respectively. While the RUNMC and LUMC assays generated similar $C_{t}$ values (Figure $6.1 \mathrm{~A}$ ), the $C_{t}$ values produced by the MINC assay were somewhat lower than those produced by the other assays (Figure 6.1B and $\mathrm{C}$ ).

\section{Quantitative comparison between microscopy and real-time PCR}

To examine the correlation between microscopy and real-time PCR in quantitative detection, the results from these assays were compared for a selection of positive samples $(n=26)$. Since a comparison to $C_{t}$ values may be difficult to interpret, these values were first converted to copy number equivalents of a plasmid ( $\mathrm{pPCP}$ ) containing the P. jiroveci amplicon. This was achieved in the MINC real-time PCR assay by generating a standard curve using this plasmid (Figure 6.2A en B). Subsequently, the copy number equivalents of the $26 P$. jirovecipositive samples were plotted against the microscopically quantified $P$. jiroveci burden (expressed as clusters per 
cytospin spot). As shown in Figure 6.2C, there was a good correlation between both methods, which was expressed as a correlation coefficient of 0.83 .


Figure 6.1 Pair wise comparison between the different $C_{t}$ values for all samples $(n=45)$ that were found to be positive in all three real-time PCR assays. (A) Comparison of $C_{t}$ values from the RUNMC assay (y-axis) and the LUMC assay ( $x$-axis). (B) Comparison of the $C_{t}$ values from the MINC assay (y-axis) and the RUNMC assay (x-axis). (C) Comparison of the $C_{t}$ values from the LUMC assay ( $y$-axis)and the MINC assay ( $x$ axis).

\section{$P$. jirovecicarrier ship versus clinically relevant infection}

An important issue in the diagnosis of PCP is the distinction between apparent asymptomatic $P$. jiroveci-carriers and patients with clinically obvious PCP. In most studies, carriers have been defined as patients in which $P$. jiroveci DNA could be detected in the absence of clinical signs of $P$. jiroveci infection, and without microscopically detectable $P$. jirovecicysts in BALF samples. 
A

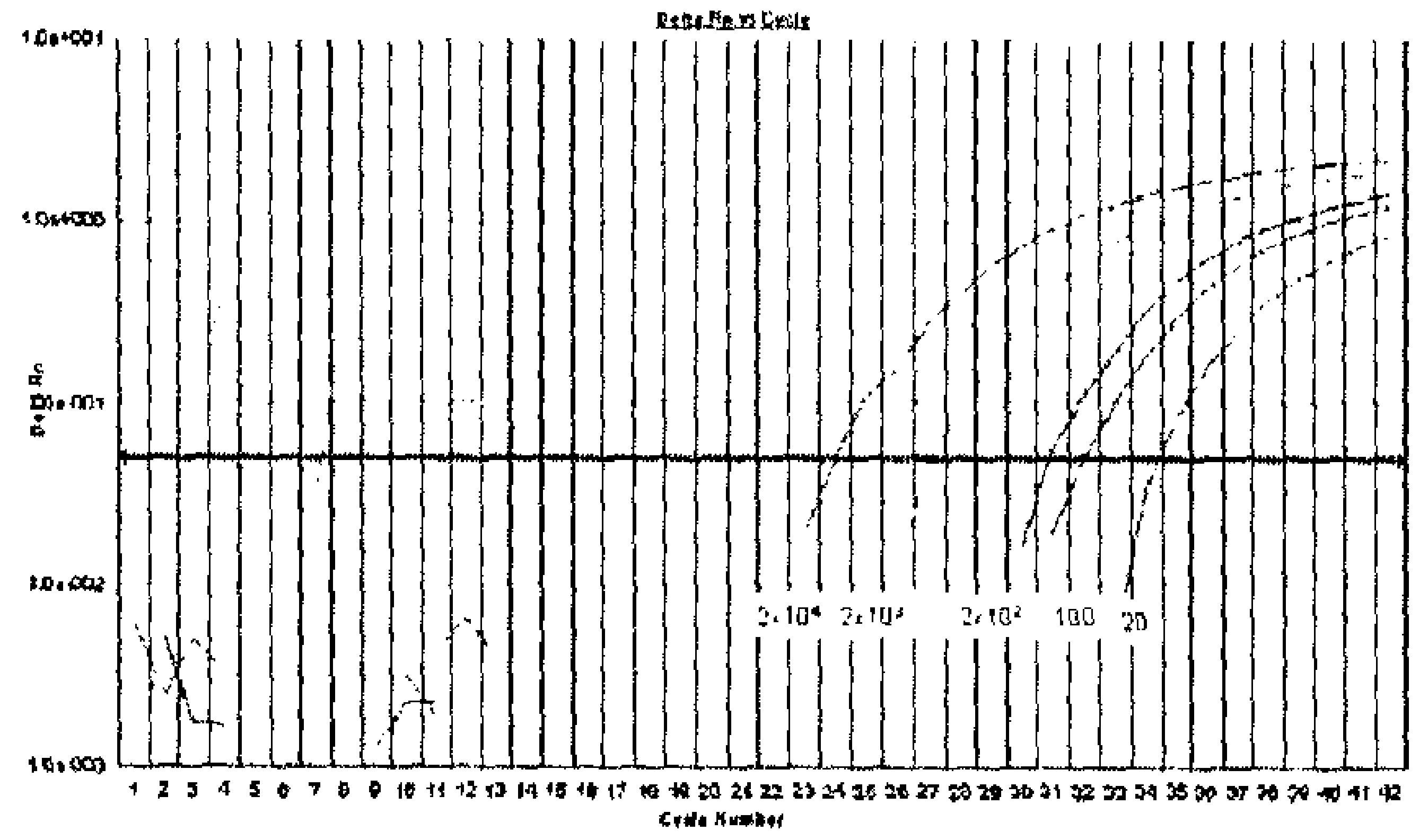

B

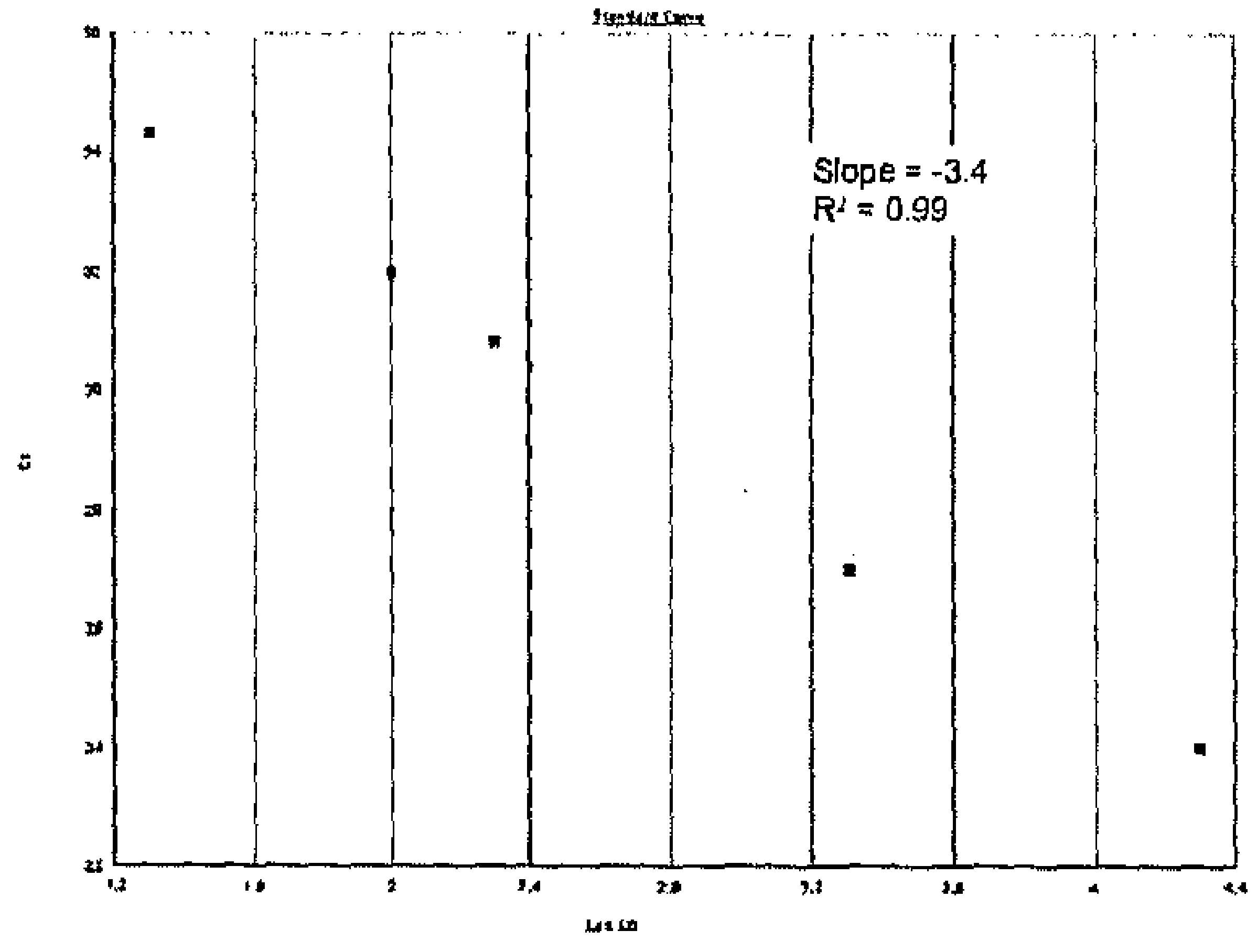

C

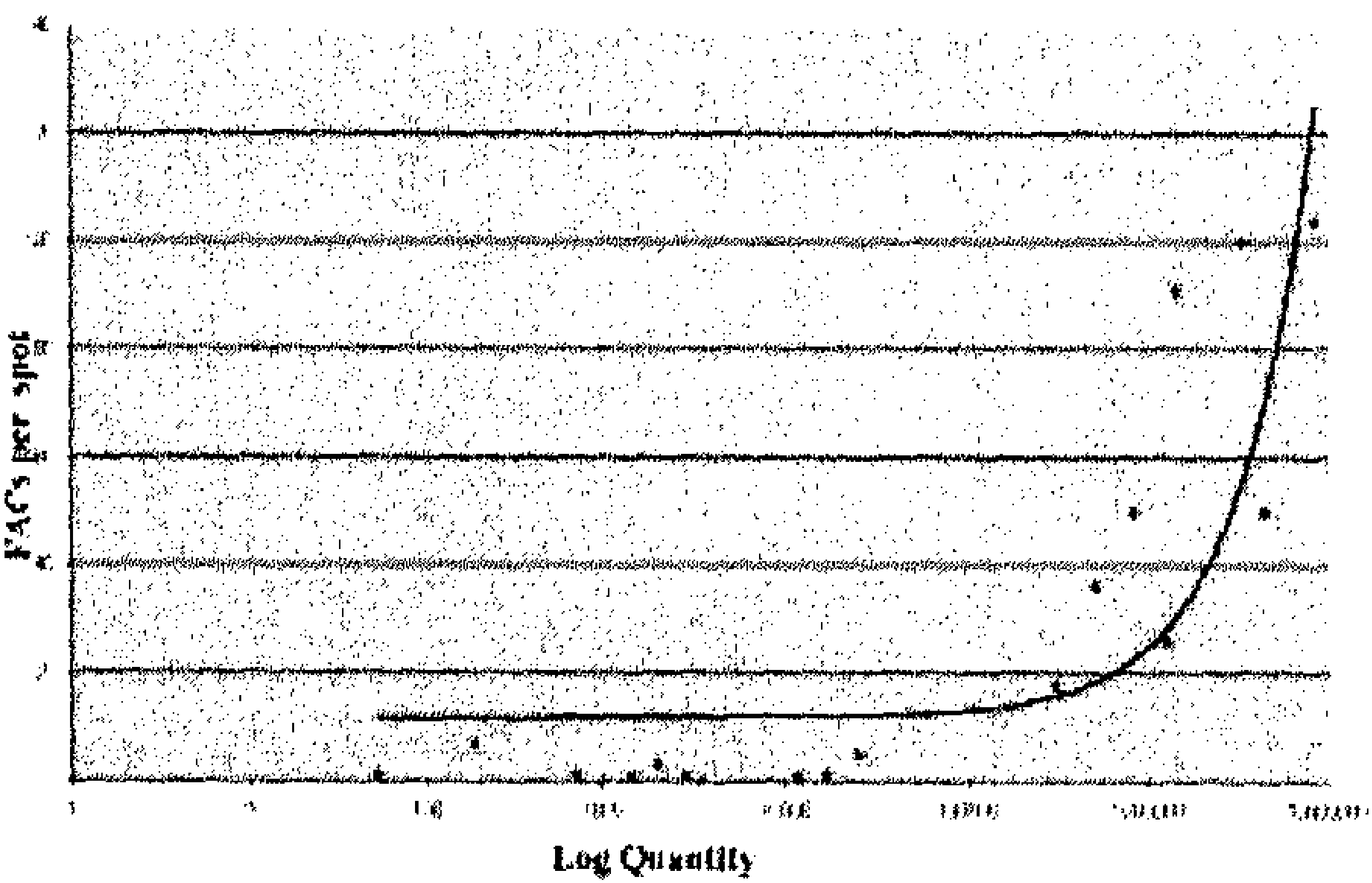

Figure 6.2 Correlation between microscopy and the MINC real-time PCR assay in quantification of $P$. jiroveci. (A) Amplification plot (Delta $R n$ versus cycle number) generated with dilutions of plasmid pPCP $\left(2 \times 10^{4}, 2 \times 10^{3}, 2 \times 10^{2}, 100\right.$, and 20 copies per reaction), which contains the $P$. jiroveci amplicon. (B) Standard curve $\left(C_{t}\right.$ versus log copy number [CO]) generated from the amplification plot shown in (A). (C) Correlation between the number of $P$. jiroveci clusters per cytospin spot (foamy alveolar casts (FACs) per spot) and the log of the $P$. jiroveci copy number (Log Quantity) for 26 PCRpositive BALF samples. 
Inter-laboratory comparison for the detection of P. jiroveci in BALF samples $\mid 99$

\section{Discussion}

In the present study, we found an overlap between $\mathrm{C}_{\mathrm{t}}$-values in samples obtained from potential carriers of $P$. jirovecion the one hand and some of the samples from patients with clinically and microscopically proven PCP on the other hand. This is in line with previous reports, in which a reliable cut-off value for the differentiation between disease and carrier state could not be firmly established ${ }^{18,19}$. Nevertheless, it is possible to divide patients into three categories. In the first category, patients are included with clinical symptoms suspect for PCP with a positive PCR result and/or a positive microscopy result; these patients are diagnosed with PCP. In the second category, patients are included who have no clinical symptoms and do not have any indication for infection with $P$. jiroveci, as indicated by negative results in both microscopy and PCR. The third group is more complex, and consists of patients who do not have typical clinical symptoms of PCP, but show a positive PCR result (usually with high $C_{t}$ values). We hypothesize that the patients without risk factors for PCP should be regarded as asymptomatic carriers and do not require treatment for PCP. In case of patients belonging to the at-risk group with negative microscopy results, the microscopy should be re-evaluated and the patient should be clinically followed and receive therapy with the appearance of any clinical symptoms suspect of PCP.

Previously, only immunocompromised patients, such as HIV-positive patients, were considered to be potential carriers of $P$. jirovec ${ }^{2,23}$. More recently, however, immunocompetent individuals were also found to be putative carriers $^{24,25}$. Miller and coworkers investigated health care workers who came into contact with patients with PCP and found among them a carrier rate of $30.5 \%{ }^{12}$. In particular, health care workers taking BALF or induced sputum samples were found to be at risk for developing a carrier status, which in one case even persisted for 27 months ${ }^{26}$. All $P$. jiroveciDNA positive patients from our study belonged to the group at risk, except for a single patient who was admitted to the intensive care unit and diagnosed with a community-acquired pneumonia caused by Streptococcus pneumoniae.

In conclusion, we have compared the performance of three different in-house developed real-time PCR assays for $P$. jiroveci. Interestingly, while these three assays employ different methods for nucleic acid isolation, amplification as well as detection, an excellent agreement in performance was found between the assays, both qualitatively (the diagnosis of $\mathrm{PCP}$ ) and quantitatively (the $P$. jiroveciburden). Likewise, a good correlation was found between the $P$. jiroveci quantity determined by real-time PCR and microscopic quantification. A cut-off value to discriminate between disease and carrier status for $P$. jiroveci could 
not be established in the present, retrospective study. A future prospective study is needed to investigate whether quantitative $P C R$ results can be employed to differentiate between PCP and carrier ship of $P$. jiroveci. Finally, in order to monitor the performance of the different in-house PCR assays currently used in microbiology laboratories, the availability of quality control panels is of utmost importance. The assays described here could serve as reference assays in the development and maintenance of such panels. 


\section{References}

1. Edman JC, Kovacs JA, Masur H, Santi DV, Elwood HJ, Sogin ML. Ribosomal RNA sequence shows Pneumocystis carinii to be a member of the fungi. Nature 1988;334:519-22.

2. Stringer JR, Cushion MT, Wakefield AE. New nomenclature for the genus Pneumocystis. J Eukaryot Microbiol. 2001; Suppl:184S-9S.

3. Kovacs JA, Gill VJ, Meshnick S, Masur H. New insights into transmission, diagnosis, and drug treatment of Pneumocystis carinii pneumonia. Jama. 2001;286:2450-60.

4. Sepkowitz KA. Opportunistic infections in patients with and patients without Acquired Immunodeficiency Syndrome. Clin Infect Dis. 2002;34:1098-107.

5. Yale $\mathrm{SH}$, Limper $\mathrm{AH}$. Pneumocystis carinii pneumonia in patients without acquired immunodeficiency syndrome: associated illness and prior corticosteroid therapy. Mayo Clin Proc. 1996;71:5-13.

6. Djamin RS, Drent M, Schreurs AJ, Groen EA, Wagenaar SS. Diagnosis of Pneumocystis carinii pneumonia in HIV-positive patients. Bronchoalveolar lavage vs. bronchial brushing. Acta Cytol. 1998;42:933-8.

7. Thomas CF, Jr., Limper AH. Pneumocystis pneumonia. N Engl J Med. 2004;350:2487-98.

8. Kovacs JA, Ng VL, Masur H, Leoung G, Hadley WK, Evans G, Lane HC, Ognibene FP, Shelhamer J, Parrillo JE., et al. Diagnosis of Pneumocystis carinii pneumonia: improved detection in sputum with use of monoclonal antibodies. N Engl J Med. 1988;318:589-93.

9. Elvin KM, Bjorkman A, Linder E, Heurlin N, Hjerpe A. Pneumocystis carinii pneumonia: detection of parasites in sputum and bronchoalveolar lavage fluid by monoclonal antibodies. BMJ. 1988;297:381-4.

10. Amin MB, Mezger E, Zarbo RJ. Detection of Pneumocystis carinii. Comparative study of monoclonal antibody and silver staining. Am J Clin Pathol. 1992;98:13-8.

11. Chandra P, Delaney MD, Tuazon CU. Role of special stains in the diagnosis of Pneumocystis carinii infection from bronchial washing specimens in patients with the acquired immune deficiency syndrome. Acta Cytol. 1988;32:105-8.

12. Miller RF. Pneumocystis carinii infection in non-AIDS patients. Curr Opin Infect Dis. 1999; $12: 371-7$.

13. Limper $A H$, Offord KP, Smith TF, Martin WJ, 2nd. Pneumocystis carinii pneumonia. Differences in lung parasite number and inflammation in patients with and without AIDS. Am Rev Respir Dis. 1989;140:1204-9.

14. Wakefield AE, Pixley FJ, Banerji S, Sinclair K, Miller RF, Moxon ER, Hopkin JM. Detection of Pneumocystis carinii with DNA amplification. Lancet. 1990;336:451-3.

15. Larsen HH, Masur H, Kovacs JA, Gill VJ, Silcott VA, Kogulan P, Maenza J, Smith M, Lucey $D R$, Fischer SH. Development and evaluation of a quantitative, touch-down, real-time PCR assay for diagnosing Pneumocystis carinii pneumonia. J Clin Microbiol. 2002;40:490-4.

16. Maskell NA, Waine DJ, Lindley A, Pepperell JC, Wakefield AE, Miller RF, Davies RJ. Asymptomatic carriage of Pneumocystis jiroveci in subjects undergoing bronchoscopy: a prospective study. Thorax. 2003;58:594-7.

17. Nevez G, Guyot K, Totet A, Raccurt C, Dei-Cas E. Pulmonary colonisation with Pneumocystis carinii in an immunosuppressed HiV-negative patient: detection and typing of the fungus by PCR. J Med Microbiol. 2001;50:198-200.

18. Flori $P$, Bellete $B$, Durand $F$, Raberin $H$, Cazorla $C$, Hafid J, Lucht F, Sung RT. Comparison between real-time PCR, conventional PCR and different staining techniques for diagnosing Pneumocystis jiroveci pneumonia from bronchoalveolar lavage specimens. J Med Microbiol. 2004;53:603-7.

19. Larsen $H H$, Huang L, Kovacs JA, Crothers $K$, Silcott VA, Morris A, Turner JR, Beard CB, Masur $\mathrm{H}$, Fischer $\mathrm{SH}$. A prospective, blinded study of quantitative touch-down polymerase chain reaction using oral-wash samples for diagnosis of Pneumocystis pneumonia in HIVinfected patients. J Infect Dis. 2004;189:1679-83. 
$102 \mid$ Chapter 6

20. Olsson $M$, Stralin $K$, Holmberg $H$. Clinical significance of nested polymerase chain reaction and immunofluorescence for detection of Pneumocystis carinii pneumonia. Clin Microbiol Infect. 2001;7:492-7.

21. Jacobs JA, Dieleman MM, Cornelissen El, Groen EA, Wagenaar SS, Drent $M$. Bronchoalveolar lavage fluid cytology in patients with Pneumocystis carinii pneumonia. Acta Cytol. 2001;45:317-26.

22. Weig $M$, Klinker $H$, Withelm $M$, Lemmer $K$, Gross U. Correlation of Pneumocystis carinii PCR with clinical diagnosis in immunocompromised patients. Lancet. 1996;347:1266.

23. Weig $M$, Klinker $H$, Bogner BH, Meier A, Gross $U$. Usefulness of PCR for diagnosis of Pneumocystis carinii pneumonia in different patient groups. J Clin Microbiol. 1997;35:1445-9.

24. Sing A, Roggenkamp A, Autenrieth IB, Heesemann J. Pneumocystis carinii carriage in immunocompetent patients with primary pulmonary disorders as detected by single or nested PCR. J Clin Microbiol. 1999;37:3409-10.

25. Visconti E, Marinaci S, Zolfo M, Mencarini P, Tamburrini E, Pagliari G, Ortona E, Siracusano A. Very low frequence of Pneumocystis carinii DNA detection by PCR in specimens from patients with lung damage. J Clin Microbiol. 2000;38:1307-8.

26. Miller RF, Ambrose HE, Wakefield AE. Pneumocystis carinii f. sp. hominis DNA in immunocompetent health care workers in contact with patients with P. carinii pneumonia. J Clin Microbiol. 2001;39:3877-82. 
Chapter

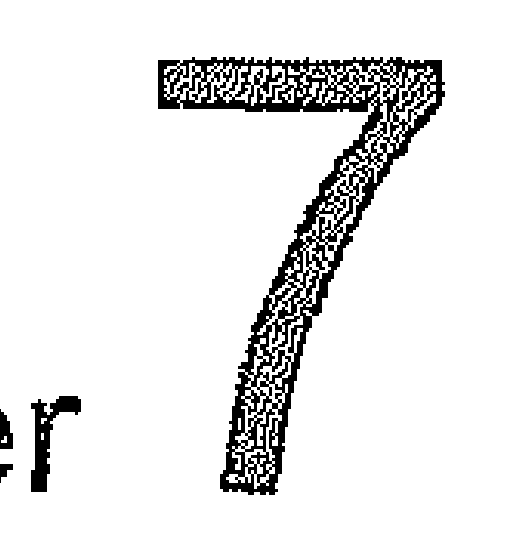

High herpes simplex virus load in bronchoalveolar lavage fluid is related to poor outcome in critically ill patients

CFM Linssen, JA Jacobs, FF Stelma, WNKA van Mook, P Terporten, C Vink, M Drent, CA Bruggeman, A Smismans

Submitted 
$104 \mid$ Chapter 7

\section{Abstract}

Objective

The clinical relevance of detecting HSV-1 and -2 in bronchoalveolar lavage fluid (BALF) is unclear. The aim of this study was to evaluate the relationship between the HSV-1 and -2 loads in BALF and clinical outcome.

Study design

A total of 521 BALF samples from 461 patients were included. Patients were divided in three groups; i) patients admitted to the hospital $<48$ hours before lavage (Community), ii) patients admitted to the ICU $>48$ hours before lavage (ICU) and ii) the remaining patients (non-ICU group). HSV-1 and HSV-2 loads were determined by real-time polymerase chain reaction (PCR).

Results

HSV-1 DNA was detected in 4.3\% (4/92) of the samples in the Community group, 15\% (18/121) in the non-ICU group and in $32 \%$ (99/308) of the ICU group. In the age group <50 years HSV-1 DNA was less frequently isolated compared to patients in the age group $\geq 50$ years $(17 / 145(12 \%)$ versus $104 / 376(28 \%)$ respectively, $O R=2.9 ; p<0.001)$. HSV-1 loads of $>10^{5}$ genome equivalents $(\mathrm{ge}) / \mathrm{ml}$ in BALF were associated with an increased 14 day in-hospital mortality compared to patients with a BALF HSV-1 load $\leq 10^{5} \mathrm{ge} / \mathrm{ml}$ in BALF (41\% versus $20 \%$ respectively, $\mathrm{p}$-value $=0.001) . \mathrm{HSV}-2$ was detected in low quantities in only two non-ICU patients and was neither associated with morbidity nor mortality. HSV-1 pneumonia was histologically proven, at postmortem examination, in two patients with a HSV-1 load exceeding $10^{5} \mathrm{ge} / \mathrm{ml}$.

\section{Conclusion}

HSV-1 occurs more in critically ill patients and high loads in BALF are associated with an increased mortality. The higher mortality observed in patients with HSV-1 load $>10^{5} \mathrm{ge} / \mathrm{ml}$ enforces its clinical relevance and the necessity to start randomized medical intervention studies. 


\section{Introduction}

Human herpes simplex virus (HSV) belongs to the family of Herpesviridae and encompasses two subtypes, HSV-1 and HSV-2, both of which are highly prevalent and ubiquitously distributed ${ }^{1,2}$. A primary HSV infection usually involves mucocutaneous surfaces, with HSV-1 more frequently isolated from oral-facial sites, whereas HSV-2 usually affects genital sites ${ }^{1}$. In the immunocompetent adult host HSV infection usually has a benign course. Nevertheless, it is the most commonly identified cause of acute sporadic encephalitis ${ }^{3}$.

As is the case with other herpesvirusses, the initial infection is followed by a lifelong latent infection, from which reactivation can occur. A variety of triggers for reactivation have been described such as injury to tissue innervated by the latently infected neurons, emotional or physical stress, hormonal imbalance, ultraviolet light, fever and immunosuppression ${ }^{1}$.

Occasionally, HSV may cause pneumonia as a result of immunosuppression ${ }^{4,5}$, with a high mortality. In earlier reports, HSV was isolated from respiratory secretions from patients with adult respiratory distress syndrome, burns and in other non-immunosuppressed patients without a history of lung disease ${ }^{6-8}$. Interestingly, Schuller et al. ${ }^{9}$ showed that immunocompetent patients from which HSV-1 was recovered from the respiratory tract were more severely ill and had a worse outcome compared to immunocompromised patients. In a study by Bruynseels et al..$^{10}$, HSV-1 was detected in $16 \%$ of lower respiratory tract samples of patients admitted to the intensive care unit (ICU) as determined by viral culture. Patients with severe disease were found to be the most susceptible to HSV-1 infection or disease. Since this virus can severely affect pulmonary function in a wide range of patients and effective treatment with aciclovir is available, it is of the utmost importance to detect the infection accurately and early. Nevertheless, it has been described that HSV can also be isolated from the respiratory tract of asymptomatic adults (up to $5 \%)^{1}$. As a consequence, it may be crucial to distinguish asymptomatic carrier ship of HSV from symptomatic infection. To investigate whether this distinction can be made by determination of the HSV load in bronchoalveolar lavage fluid (BALF), we subjected a series of BALF samples to HSV-1 and HSV-2 specific quantitative, real-time PCR assays. Subsequently, the viral loads were correlated with clinical parameters and outcome. 


\section{Materials and methods}

\section{Patients included}

This retrospective study was conducted at the University Hospital Maastricht. During a 72-month period (January 1999-December 2004) all consecutive BALF samples obtained from critically ill ICU patients clinically suspected of ventilator associated pneumonia (VAP) and all BALF samples from non-ICU patients, which were presented for viral culture were included. In the ICU patients clinical evolution was assessed by means of SOFA score (sequential organ failure assessment $)^{11}$. Patients were devided in three groups; i) patients admitted to the hospital $<48$ hours before lavage were classified as Community, ii) patients admitted to the ICU $>48$ hours before lavage as ICU and ii) the remaining patients were included in the non-ICU group.

\section{Clinical variables}

Clinical suspicion of VAP was defined as described by Bonten et al. ${ }^{12}$. Microbiologically confirmed VAP was defined as admission to the ICU $>48$ hours prior to BALF collection, a total quantitative culture result of $\geq 10^{4} \mathrm{cfu} / \mathrm{ml}$ and/or $\geq 2 \%$ infected cells $(I C)^{13,14}$. Mortality was measured as a dichotomous variable; death within 14 days after BAL-procedure (yes / no) in hospitalised patients.

Collected data included patients' demographic characteristics such as: age, gender and clinical data such as: admittance to ICU ward, smoking, length of ICU stay before the performance of BAL, total length of stay at ICU, total length of hospital stay, mortality, diagnosis at post-mortem examination and laboratory data concerning BALF: total cell count, differential cell count presence of ciliated epithelial cells, squamous epithelial cells, reactive pneumocytes type II $(\mathrm{RPII})^{15}$ and quantitative culture results.

\section{Sampling technique}

A fiberoptic bronchoscope (Pentax FB-15H/FB-15X, Pentax Medicals, Tokyo, Japan) was introduced and "wedged" into the affected segmental or subsegmental bronchus. Sterile saline $(0.9 \% \mathrm{NaCl}$, room temperature) was instilled in four aliquots of $50 \mathrm{ml}$ and immediately aspired and recovered. The samples were transported to the laboratory within 15 minutes after collection and processed immediately upon arrival at the microbiology laboratory. 


\section{Laboratory processing}

The first fraction of BALF represents the bronchial fraction and was not used in this study. The remaining three fractions (alveolar fractions) were pooled. A total cell count was performed using a Fuchs Rosenthal haemocytometer chamber. Quantitative bacterial culture was performed as previously described $^{16}$. Cytocentrifuged preparations ${ }^{17}$ were made and stained with MayGrünwald Giemsa stain and Gram-stain. Differential cell count ${ }^{18}$ was performed including infected cells $(I C)$ and $R P I I^{15}$. From each sample $6 \mathrm{ml}$ was centrifuged (250 g, 10 minutes), dividing the sample into cells and supernatant. The supernatant was stored in tubes of $1 \mathrm{ml}$ at $-80^{\circ} \mathrm{C}$. The cells were resuspended in a mixture of Eagle's Minimal Essential Medium (EMEM) with $2 \%$ Dimethyl Sulfoxide (DMSO) and also stored in tubes of $1 \mathrm{ml}$ at $-80^{\circ} \mathrm{C}$.

\section{Virological assessment:}

A total of $500 \mu \mathrm{l}$ of the stored cell fraction was used for DNA isolation using the Wizard $^{\circledR}$ Genomic DNA Purification Kit (Promega, Madison, USA). Purified DNA was resuspended in a final volume of $120 \mu \mathrm{l}$. Each sample was spiked with a control plasmid (murine cytomegalovirus glycoprotein B gene (MCMV gB) ${ }^{19}$ before DNA isolation as an isolation and amplification control. An in-house realtime PCR was performed using primers and probes which target the glycoprotein G-(gG) gene (HSV-1) and the glycoprotein $\mathrm{D}-(\mathrm{gD})$ gene $(\mathrm{HSV}-2)^{20}$. Assays (both HSV-1 and HSV-2) were performed in a 96-well Optical Reaction plate (Applied Biosystems, Foster City, California) in a total volume of $50 \mu \mathrm{l}$ which contained $0.2 \mu \mathrm{M}$ forward primer, $0.6 \mu \mathrm{M}$ reverse primer, $0.075 \mu \mathrm{M}$ probe, $1 \times$ Taqman $^{\circledR}$ Universal Master Mix (ABI) and $20 \mu$ purified DNA. The PCR reactions for the internal control (MCMV gB) were carried out as described previously ${ }^{19}$. The PCR thermal profile consisted of an initial incubation of two minutes at $50^{\circ} \mathrm{C}$, followed by activation of the AmpliTaq Gold ${ }^{\boxplus}$ Polymerase during 10 minutes at $95^{\circ} \mathrm{C}$. A total of 42 cycles of amplification were run consisting of 15 seconds at $95^{\circ} \mathrm{C}$ and 1 minute at $60^{\circ} \mathrm{C}$. Amplification was performed using the ABI PRISM 7000 Sequence Detection System (ABI) and data were interpreted using the $A B I$ Prism software. Quantification was done by extrapolation of data to standardcurves generated by amplification of quantified dilutions of plasmids containing the HSV-1gG gene and HSV-2 gDgene.

\section{Clinical chemistry}

Urea was measured in BALF (as a marker of dilution) and in serum using a commercially available kit (Urea, Beckman Coulter, Fullerton, California, USA). 


\section{Immunofluorescent staining of cytocentrifuged preparations}

From each BALF sample cytospin centrifuged preparations were stored at $-20^{\circ} \mathrm{C}$ until the PCR results were available. In case of a positive PCR result, the slides were thawed and an immunofluorescent staining technique was performed. First the cytospin preparations were fixated using acetone at $+4^{\circ} \mathrm{C}$ for 10 minutes. Hereafter a monoclonal antibody based test for the detection of and the differentiation between HSV-1 and HSV-2 (Pathfinder ${ }^{\left({ }^{(}\right)}$Herpes Simplex Virus Types 1 and 2, Bio-Rad laboratories, Hercules, California, USA). was performed on the cytospin preparations.

\section{Statistical analysis}

In order to compare the quantitative real-time $\mathrm{PCR}$ results between recovered BALF samples, the quantity was converted to those present in the epithelial lining fluid (ELF) using the formula described by Wiedermann et al. ${ }^{21}$, which is based upon urea concentrations in BALF and in serum:

$$
[\mathrm{X}] \mathrm{ELF}=([\mathrm{X}] \mathrm{BALF} \times \text { urea serum }) / \mathrm{urea} \text { BALF }
$$

Geometrical mean viral loads were calculated as log10 of HSV-positive BALF samples. Groups were compared by t-test statistics and Chi square statistics when appropriate. Risk factors for HSV-1 shedding (yes/no) were identified by univariate logistic regression analysis (Table 7.1). Clinical outcome measures were defined as in-hospital death within 14 days, presence of pneumonia and/or and presence of HSV-pneumonitis at post mortem examination.

\section{Results}

\section{Patient population}

In the period January 1999 until December 2004, 1033 BALF samples (from 866 patients) were eligible for inclusion in our study. This included 456 samples retrieved from ICU patients and 577 samples retrieved from non-ICU patients. Insufficient material for PCR was available for 148 and 55 BALF samples respectively, therefore these patients were excluded. Viral culture was requested on 132 out of the $522(25 \%)$ samples from non-ICU patients. This resulted in a total of 521 BALF samples from 461 patients to be included. The study population consisted of $92(18 \%)$ samples from 88 Community patients, $121(23 \%)$ samples from 113 non-ICU patients and 308 (59\%) samples from 260 ICU patients (Figure 7.1). 
Table 7.1 Clinical and demographic variables of patients with and without HSV-1 DNA in BALF

\begin{tabular}{|c|c|c|c|c|c|}
\hline & & $\begin{array}{c}\mathrm{HSV}+ \\
(n=121)\end{array}$ & $\begin{array}{l}\text { HSV - } \\
(n=400)\end{array}$ & Crude OR & p-value \\
\hline Gender & & & & & 0.354 \\
\hline Male & & $79(65 \%)$ & $279(70 \%)$ & & \\
\hline Female & & $42(35 \%)$ & $121(30 \%)$ & & \\
\hline \multicolumn{6}{|l|}{ VAP } \\
\hline No & & $77(20 \%)$ & $309(80 \%)$ & & \\
\hline Yes & & $44(33 \%)$ & $91(67 \%)$ & & \\
\hline Age & & & & 2.60 & $<0.001$ \\
\hline$<50$ years & 145 & $17(12 \%)$ & $128(88 \%)$ & & \\
\hline$>50$ years & 376 & $104(28 \%)$ & $272(72 \%)$ & & \\
\hline Patient group & & & & & $<0.001$ \\
\hline Community & 92 & $4(4.3 \%)$ & $88(95.7 \%)$ & 1.0 & \\
\hline Non-ICU & 103 & $18(15 \%)$ & $103(85 \%)$ & 3.7 & $<0.001$ \\
\hline ICU & 308 & $99(32 \%)$ & $209(68 \%)$ & 9.6 & $<0.001$ \\
\hline Smoking & & & & & 0.614 \\
\hline Non-smoker & 136 & $31(23 \%)$ & $105(77 \%)$ & & \\
\hline Not active smoker & 58 & $10(17 \%)$ & $48(83 \%)$ & & \\
\hline Active smoker & 115 & $26(23 \%)$ & $89(77 \%)$ & & \\
\hline SOFA score at admission & & & & & 0.101 \\
\hline$\leq 7$ & 93 & $22(24 \%)$ & $71(76 \%)$ & & \\
\hline$>7$ & 80 & $28(35 \%)$ & $52(65 \%)$ & & \\
\hline Length of hospitalisation & & 121 & 400 & & \\
\hline Mean days (SEM) & & $50.8(3.7)$ & $46.2(2.5)$ & & \\
\hline Length of stay at the ICU & & 121 & 400 & & \\
\hline Mean days (SEM) & & $32.5(2.8)$ & $27.9(2.1)$ & & \\
\hline
\end{tabular}

HSV: Herpes simplex virus, OR: odds ratio, BALF: bronchoalveolar lavage fluid, SOFA: sequential organ failure score, ICU: intensive care unit, SEM: standard error of the mean. VAP: ventilatorassociated pneumonia

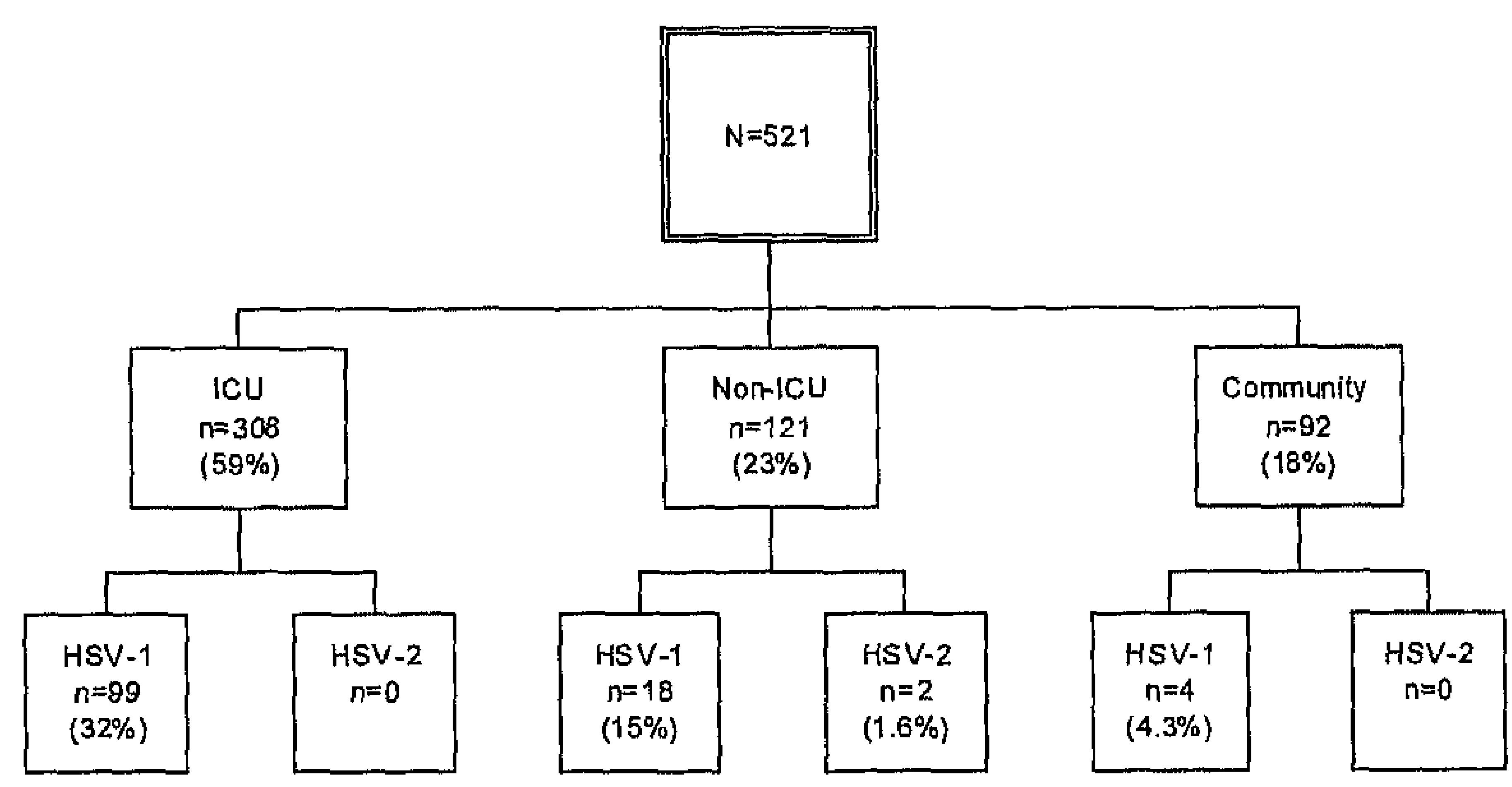

Figure 7.1 Prevalence of HSV-1 and HSV-2 in BALF samples.

HSV-1: Herpes simplex virus type 1, HSV-2: Herpes simplex virus type 2, ICU: intensive care unit, BALF: bronchoalveolar lavage fluid. 


\section{Factors associated with HSV-1 shedding in BALF}

Patient variables like gender and smoking were not associated with the presence of HSV-1 in BALF. However, patients over the age of 50 years did significantly shed HSV-1 more often in their BALF samples when compared to patients younger than 50 years $(28 \%$ versus $12 \%$; Table 7.1$)$. Among the clinical variables, including SOFA-score, length of hospitalisation, length of stay at the ICU, concomitant presence of a bacterial pneumonia and admittance to the ICU, only the latter was significantly associated with HSV-1 in BALF (Table 7.1). HSV-1 was found in $32 \%(99 / 308)$ of ICU samples, whereas it was only detected in 15\% (18/121) of the non ICU samples and $4.3 \%$ (4/92) of the Community samples (Figure 7.1). None of the cytological parameters of BALF, including total cell count, differential cell count including IC and RPII were found to be associated with the presence of HSV-1 in BALF. Multivariate analysis showed that hospital admittance and age over 50 years were independent predictors for the presence of HSV-1 in BALF with odds ratios of 3.7 (95\% confidence interval (CI): 1.2-11) for the non-ICU, 9.6 (95\% Cl: 3.4$27)$ for the ICU and $2.6(95 \% \mathrm{Cl}: 1.5-4.6)$ for age over 50.

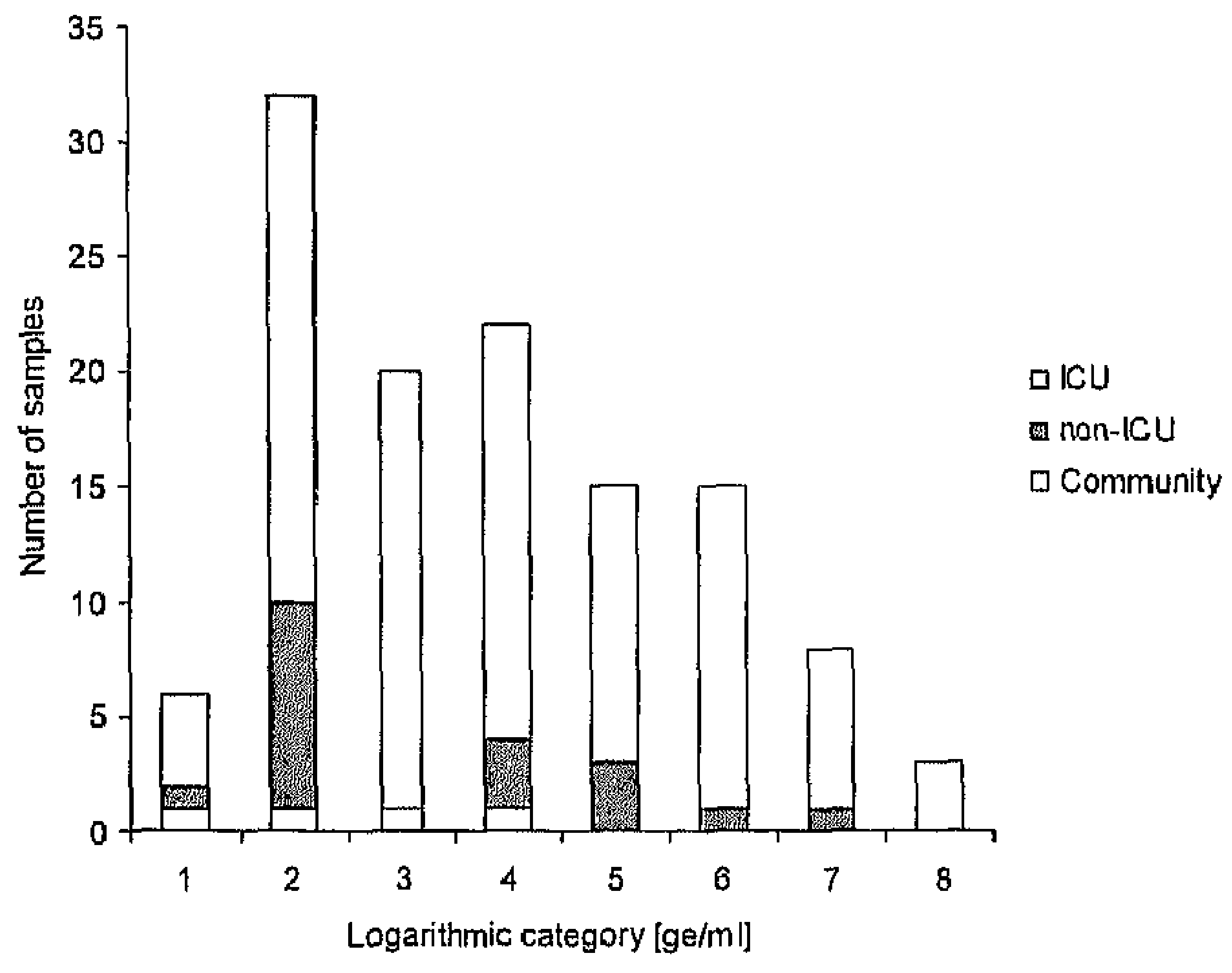

Figure 7.2 Distribution of quantitative HSV-1 loads in BALF. Each bar is divided into ICU, nonICU and Community patients. The y-axis represents the number of samples whereas the $x$-axis represents the HSV-1 load in logaritmic categories.

BALF: Bronchoalveolar lavage fluid, ICU: intensive care unit, HSV-1: herpes simplex virus type 1, PCR: polymerase chain reaction, ge/ml: genome equivalents per milliiter.

\section{Quantitative PCR results}

The BALF samples in which HSV-1 was identified, were divided into logarithmic categories, based upon quantitative PCR results $(10 \mathrm{ge} / \mathrm{ml}=\log 1,100 \mathrm{ge} / \mathrm{ml}=$ $\log 2$ and so forth). Figure 7.2 shows the number of BALF samples with HSV-1 
present divided into logarithmic categories. All patients in the Community group had a viral load in BALF of $10^{4} \mathrm{ge} / \mathrm{ml}$ or less. Among the ICU and non-ICU group $36 \%(36 / 99)$ and $28 \%(5 / 18)$ had a BALF viral load $\geq 10^{5} \mathrm{ge} / \mathrm{ml}$ respectively. In one patient, BAL was performed twice within a period of five days, the first BALF showed $10^{5} \mathrm{ge} / \mathrm{ml}$, the second BALF $10^{7} \mathrm{ge} / \mathrm{ml}$. The patient died four days after the second BAL. Post mortem examination revealed an extended pneumonia caused by HSV-1.

\section{Establishing a clinical relevant cut-off value for HSV-1 viral load}

To assess a cut-off value for the HSV-1 viral load, the in-hospital mortality within 14 days after collection of BALF was selected as relevant clinical parameter. At each possible cut-off value, the in-hospital mortality was compared to the in-hospital mortality of patients with a non-reactive HSV-1 PCR. Up to the cut-off value of $10^{5} \mathrm{ge} / \mathrm{ml} \mathrm{HSV}-1$ in BALF, the group above the cut-off value showed a significant higher mortality (Table 7.2). At higher cut-off values, the group above and below the cut-off value both showed significant differences. This indicated that the test was not differentiating anymore between the group below and above the cut-of value (Table 7.2). Therefore the cut-off value for HSV-1 load in BALF was set at $10^{5} \mathrm{ge} / \mathrm{ml}$. This resulted in an in- hospital death within 14 days of $20 \%$ below compared to $41 \%$ above the cut-off value.

Table 7.2 Odds ratios (OR) for different cut-off values as compared to 14 days in-hospital mortality for non-reactive HSV-1 PCR samples (reference).

\begin{tabular}{lcccc}
\hline Category & $N(\%)$ & OR & $95 \% \mathrm{Cl}$ & $\mathrm{p}$-value \\
\hline Reference & $62(17)$ & 1 & - & - \\
$\leq \log 3$ & $11(22)$ & 1.39 & $0.67-2.86$ & 0.37 \\
$>\log 3$ & $25(36)$ & 2.73 & $1.56-4.78$ & $<0.001^{\mathrm{a}}$ \\
$\leq \log 3.5$ & $13(22)$ & 1.42 & $0.72-2.79$ & 0.31 \\
$>\log 3.5$ & $23(37)$ & 2.90 & $1.62-5.20$ & $<0.001^{\mathrm{a}}$ \\
$\leq \log 4$ & $17(24)$ & 1.55 & $0.84-2.85$ & 0.16 \\
$>\log 4$ & $19(39)$ & 3.12 & $1.65-5.89$ & $<0.001^{\mathrm{a}}$ \\
$\leq \log 4.5$ & $20(25)$ & 1.67 & $0.94-2.97$ & 0.08 \\
$>\log 4.5$ & $16(39)$ & 3.15 & $1.59-6.24$ & $0.001^{\mathrm{a}}$ \\
$\log 5$ & $22(26)$ & 1.72 & $0.98-3.00$ & 0.057 \\
$\log 5$ & $14(41)$ & 3.28 & $1.58-6.80$ & $0.001^{\mathrm{a}}$ \\
$\leq \log 5.5$ & $26(28)$ & 1.88 & $1.11-3.19$ & $0.019^{\mathrm{a}}$ \\
$>\log 5.5$ & $10(39)$ & 3.08 & $1.33-7.09$ & $0.008^{\mathrm{a}}$ \\
$\leq \log 6$ & $29(29)$ & 2.01 & $1.21-3.35$ & $0.007^{\mathrm{a}}$ \\
$>\log 6$ & $7(35)$ & 2.65 & $1.02-6.91$ & $0.046^{\mathrm{a}}$ \\
\hline
\end{tabular}

a Statistically significant 
$112 \mid$ Chapter 7

Post-mortem examination results

A total of 152 patients died during hospitalisation. Out of these 152 patients 93 died within 14 days after BAL (Community: 6, non-ICU: 11 and ICU: 76). These 93 patients could be divided into patients from whom the BALF showed a HSV-1 load $\leq 10^{5} \mathrm{ge} / \mathrm{ml} \quad(n=79)$ and patients with a HSV-1 load in BALF exceeding $10^{5} \mathrm{ge} / \mathrm{ml}(\mathrm{n}=14)$. In 37 patients, post-mortem examination was performed (Community: 4 , non-ICU: $5, I C U: 28$ ). In the group patients with a HSV-1 load $\leq 10^{5} \mathrm{ge} / \mathrm{ml} 32(32 / 79,41 \%)$ post-mortem examinations were performed. In $70 \%(26 / 37)$ of these patients, the post-mortem examination revealed pneumonia as the cause of death. Out of the 14 patients with $>10^{5}$ $\mathrm{ge} / \mathrm{ml}$, post-mortem examination was available in five $(5 / 14,36 \%)$. All five postmortem examination reports stated pneumonia as the cause of death, including two patients $(2 / 5,40 \%)$ who were diagnosed with HSV-1 associated pneumonia, showing the presence of specific herpetic nuclear inclusions in the lungs at post-mortem examination which stained positive in the HSV-1 immunofluorescent stain. In the group of patients with a HSV-1 load in BALF $\leq 10^{5} \mathrm{ge} / \mathrm{ml}$ this diagnosis was never attributed.

\section{Concomitant presence of VAP}

Out of the 308 episodes of suspected VAP in 260 patients, 135 episodes $(44 \%)$ in 125 patients were microbiologically confirmed VAP. The causative organisms were: Pseudomonas aeruginosa $(\mathrm{n}=37)$, Staphylococcus aureus $(n=27)$, Enterobacteriaceae $(n=38)$, Haemophilus influenzae $(n=4)$, Streptococcus pneumoniae $(\mathrm{n}=3)$ and others (e.g. Stenotrophomonas maltophilia, Moraxella catarrhalis, $n=26)$. In $44(33 \%)$ episodes of VAP, the quantitative PCR for HSV-1 was positive. In $13(10 \%)$ cases the HSV-1 load in BALF exceeded $10^{5} \mathrm{ge} / \mathrm{ml}$. There were no significant differences in type of bacteria causing VAP between the HSV-1 positive and -negative group.

\section{Results of HSV-2 detection in BALF}

HSV-2 was detected in only 2 out of 520 examined BALF with viral loads of $253 \mathrm{ge} / \mathrm{ml}$ and $104 \mathrm{ge} / \mathrm{ml}$, respectively. Both BALF samples were from non-ICU patients who were admitted to the department of internal medicine (Figure 7.2). One patient was diagnosed with Morbus Wegener, the other with a bacterial pneumonia. In neither of the patients the recovery of HSV-2 was associated with morbidity or mortality. 


\section{Results of Direct Immunofluorescent staining of cytospin preparations}

Since a direct immunofluorescent HSV-1 staining of a cytospin preparation from a BALF would produce results more rapidly compared to the real-time $P C R$, we compared the performance of these assays on PCR positive samples. From 101 out of $120(84 \%)$ HSV-1 PCR positive samples, cytospin centrifuged preparations were available for HSV-1 immunofluorescent staining. This included samples with a viral load below $10^{5} \mathrm{ge} / \mathrm{ml}(\mathrm{n}=65)$, of $10^{5} \mathrm{ge} / \mathrm{ml}$ $(n=11), 10^{6} \mathrm{ge} / \mathrm{ml}(n=14)$ and $10^{7} \mathrm{ge} / \mathrm{ml}(n=11)$. None of the samples with a HSV-1 viral load below $10^{7} \mathrm{ge} / \mathrm{ml}$ stained positive, whilst $64 \%(7 / 11)$ samples exceeding $10^{7} \mathrm{ge} / \mathrm{ml}$ stained positive.

\section{Discussion}

In this study, HSV-1 DNA was detected in $32 \%$ of BALF samples from ICU patients compared to $4.3 \%$ BALF obtained from the open population and $15 \%$ obtained from non-ICU patients. From the clinical and demographic variables that we studied, including age, gender, smoking, ICU admittance, concomitant VAP and SOFA score, only age above 50 years and the patient group (ICU, non-ICU and community) of the patient appeared to be independent predictive factors for HSV-1 shedding. A significantly higher 14-day in-hospital mortality was observed in patients with HSV-1 loads $>10^{5} \mathrm{ge} / \mathrm{ml}$ compared to patients with HSV-1 loads $\leq 10^{5} \mathrm{ge} / \mathrm{ml}$ in BALF, $41 \%$ versus $20 \%$ respectively. HSV-1 viral loads in BALF exceeding $10^{5} \mathrm{ge} / \mathrm{ml}$ reflected serious disease and was associated with an increased mortality rate of $21 \%$ in this study.

Sero-epidemiological studies have shown a worldwide variation in HSV seroprevalence according to socio-economic status, geographical region and sexual activity with measured rates of $50-80 \%$ and of $13-41 \%$ for HSV-1 and HSV-2 respectively ${ }^{22}$. The most common manifestations are self-limited oral and genital lesions. Although rare, the most severe presentation of HSV infection is encephalitis in immunocompetent patients ${ }^{23}$. Visceral infections of oesophagus, liver and lung are considered to be extremely rare except in severely immunosuppressed patients ${ }^{24,25}$. However, animal models, case reports and pilot studies showed that a HSV-1 pneumonia is not exclusively linked to a state of immunosuppression ${ }^{5,26,27}$. Moreover, two recent reports, with a large number of patients included, detected HSV-1 in ICU patients that were not considered to be primarily immunocompromised ${ }^{10,28}$. In both studies a significant adverse effect of HSV-1 shedding in the respiratory tract on clinical outcome was established. In the first study, HSV-1 detection was performed with viral culture, a method that is not quantitative and has a sensitivity far 
below that of PCR. In the second study, a nested PCR assay was used. However this assay, which was HSV-1 specific, was not quantitative, and did not include controls for monitoring the process from nucleic acid extraction through amplification.

Since HSV can be detected in the pharynx of as much as $5 \%$ of adults in the general population ${ }^{1}$ we applied a quantitative real-time PCR on BALF in order to establish a cut-off value for the HSV-1 and -2 loads that may be predictive for a poor outcome. HSV-1 DNA was detected in $4.3 \%$ of BALF samples obtained from the open population, $15 \%$ of BALF samples obtained from nonICU patients and $32 \%$ of BALF samples from ICU patients. Overall detection rate in samples obtained from the hospital population was $27 \%$. The detection rate found in this study is similar to the $27 \%$ that has been reported in a pilot study using BALF and PCR in ICU patients ${ }^{28}$. In another study, a lower prevalence was found $(16 \%)$. This study, however used viral culture instead of the more sensitive PCR technique to detect $\mathrm{HSV}^{10}$. However, a third study showed a much higher prevalence of up to $64 \%{ }^{29}$, probably because their study population consisted only of severely ill ICU patients who were on ventilation for more than five days. From the clinical and demographic variables that we studied, including age, gender, smoking, ICU admittance, concomitant VAP and SOFA score, only age above 50 years and ICU admittance of the patient appeared to be independent predictive factors for HSV-1 shedding with odds ratios of 3.7 for non-ICU patients and 9.6 for ICU-patients as compared to Community patients.

In our studied group, an overall mortality of $35 \%$ was observed. The 14 day inhospital mortality in patients with a HSV-1 load in BALF $\leq 10^{5} \mathrm{ge} / \mathrm{ml}$ was $20 \%$ compared to $41 \%$ in patients with a load $>10^{5} \mathrm{ge} / \mathrm{ml}$. Thus, a HSV-1 viral load of $>10^{5} \mathrm{ge} / \mathrm{ml}$ was associated with $21 \%$ increase in mortality. A recent study by Luyt $e t a l^{29}$ showed the patients they classified as having bronchopneumonitis had BALF viral loads of $10^{2}$ to $10^{8}$ copies $/ 10^{6}$ cells present in BALF. In this study, only ICU patients with prolonged ventilation ( $>5$ days) were included. They classified their patients as having bronchopneumonitis by clinical suspicion of lower respiratory tract infection associated with the presence of HSV-1 in the lower respiratory tract and specific herpetic inclusions in BALF or bronchial biopsies. Using the HSV-1 viral load in BALF to predict the presence of HSV-1 bronchopneumonitis led to a sensitivity of $81 \%$ and a specificity of $83 \%$ at a cut-off value of $10^{4}$ copies $110^{6}$ cells present in BALF. The fact that they found a lower cut-off value may be due to the fact that they normalised the HSV-1 load in BALF by the number of cells in BALF, whilst we used the dilution factor of BALF compared to ELF. Since the number of cells present in BALF increase due inflammation ${ }^{30}$ and the total cell count of BALF depends upon technical variables ${ }^{31}$, the number of copies HSV per cells present in BALF may not be the most objective way of representing the HSV load in BALF. 
In a recent study, it was concluded that HSV-1 has a low pulmonary pathogenicity ${ }^{32}$. This notion was based on a normal capillary permeability measured in the lungs of only four critical ill patients without quantifying HSV-1 in the respiratory tract. Although the study was not designed to prove HSV-1 to be the absolute cause of mortality, in at least two of the four patients with a HSV-1 in BALF of $>10^{5} \mathrm{ge} / \mathrm{ml} \mathrm{HSV}-1$ pneumonia was determined as the cause of death at post-mortem examination. These results indicate that HSV-1 could play a causative role in the development of respiratory pathology, as was previously described for immunocompromised patients $s^{6,33,34}$. Apart from the more general causes of immunosuppression, such as immunosuppressive therapy, it has been shown that major surgery, trauma and excessive blood loss may also cause a dramatic decrease in cell-mediated immunity and hence induce the reactivation of HSV-1.

Besides the presence of HSV-1 in BALF, we also determined the presence of HSV-2. In only two out of 521 BALF samples HSV-2 was recovered, with relatively low loads of 253 and $104 \mathrm{ge} / \mathrm{ml}$. This finding corresponds with the notion that HSV-1 infections in our populatiol, are generally restricted to the oropharynx, whereas HSV-2 infections are usually limited to the genital mucosa.

Using HSV-1 immunofluorescent staining of the BALF cytospin-preparations we were able to identify $7 / 11$ (64\%) of samples with quantities of HSV-1 exceeding $10^{7} \mathrm{ge} / \mathrm{ml}$ including the two patients that died from a HSV-1 pneumonia. Since this technique could only detect 7 out of $36(19 \%)$ of the HSV-1 loads exceeding $10^{5} \mathrm{ge} / \mathrm{ml}$, and only approximately half of the samples exceeding $10^{7} \mathrm{ge} / \mathrm{ml}$, it was of no additional value in the diagnostic workup of BALF.

Although this study shows an increase in mortality in patients with a HSV-1 load in BALF exceeding $10^{5} \mathrm{ge} / \mathrm{ml}$, the design of this study was insufficient to prove HSV-1 to be the cause of death in all but 2 patients. Due to the retrospective nature of the study it was not possible to correlate HSV-1 load in BALF with adequate therapy (aciclovir) and clinical outcome. A large prospective, randomized medical intervention study in a wide range of critically ill patients is needed. Using the proposed cut-off level of $10^{5} \mathrm{ge} / \mathrm{ml} \mathrm{HSV}-1$ in BALF patients this may provide the opportunity to ultimately unravel the role of HSV-1 in pulmonary disease.

In conclusion, HSV-1 was present in approximately one third of all BALF samples acquired from ICU patients. Furthermore, our results indicated that a HSV-1 load in BALF of $>10^{5} \mathrm{ge} / \mathrm{ml}$ is an independent predictor for a poor outcome in critically ill patients, with an increase in mortality rate of $21 \%$. It remains to be determined whether HSV-1 is causally linked with a low survival or whether it is a marker of a severely disturbed immune system. Until additional data of a large prospective, randomised intervention study are 
116 Chapter 7

available, the administration of aciclovir in ICU patients with a HSV-1 load in BALF exceeding $10^{5} \mathrm{ge} / \mathrm{ml}$ should be considered. 


\section{References}

1. Cleator GM, Klapper PE. In principles and practice of clinical virology, 2005.

2. Whitley RJ, Roizman B. Herpes simplex virus infections. Lancet. 2001;357:1513-8.

3. Chaudhuri A, Kennedy PG. Diagnosis and treatment of viral encephalitis. Postgrad Med J. 2002;78:575-83.

4. Byers RJ, Hasleton PS, Quigley A, Dennett C, Klapper PE, Cleator GM, Faraher EB. Pulmonary herpes simplex in burns patients. Eur Respir J. 1996;9:2313-7.

5. Arata $K$, Sakata R, Iguro $Y$, Toda R, Watanabe $S$, Eitsuru $Y$. Herpes simplex viral pneumonia after coronary artery bypass grafting. Jpn J Thorac Cardiovasc Surg. 2003;51:158-9.

6. Wallace JM. Pulmonary infection in human immunodeficiency disease: viral pulmonary infections. Semin Respir Infect. 1989;4:147-54.

7. James $E$, Robinson L, Griffiths $P D$, Prentice $H G$. Acute myeloblastic leukaemia presenting with herpes simplex type-1 viraemia and pneumonia. Br J Haematol. 1996;93:401-2.

8. Prellner $T$, Flamholc $L$, Haidl $S$, Lindholm $K$, Widell A. Herpes simplex virus--the most frequently isolated pathogen in the lungs of patients with severe respiratory distress. Scand $J$ Infect Dis. 1992;24:283-92.

9. Schuller D. Lower respiratory tract reactivation of herpes simplex virus. Comparison of immunocompromised and immunocompetent hosts. Chest. 1994;106(1 Suppl):3S-7S; 34S-5S.

10. Bruynseels $P$, Jorens PG, Demey HE, Goossens H, Pattyn SR, Elseviers MM, Weyler J, Bossaert $L L$, Mentens $Y$, leven $M$. Herpes simplex virus in the respiratory tract of critical care patients: a prospective study. Lancet. 2003;362:1536-41.

11. Vincent JL, Moreno R, Takala J, Willatts, $S$, De Mendonca A, Bruining $H$, Reinhart $C K$, Suter $P M$, Thijs LG. The SOFA (Sepsis-related Organ Failure Assessment) score to describe organ dysfunction/failure. On behalf of the Working Group on Sepsis-Related Problems of the European Society of Intensive Care Medicine. Intensive Care Med. 1996;22:707-10.

12. Bonten MJ, Bergmans DC, Stobberingh EE, van der Geest S, de Leeuw PW, van Tiel FH, Gaillard CA. Implementation of bronchoscopic techniques in the diagnosis of ventilatorassociated pneumonia to reduce antibiotic use. Am J Respir Crit Care Med. 1997;156: $1820-4$.

13. Baselski V. Microbiologic diagnosis of ventilator-associated pneumonia. Infect Dis Clin North Am. 1993;7:331-57.

14. Allaouchiche $B$, Jaumain $H$, Dumontet $C$, Motin J. Early diagnosis of ventilator-associated pneumonia. Is it possible to define a cutoff value of infected cells in BAL fluid? Chest. 1996;110:1558-65.

15. Linssen KC, Jacobs JA, Poletti VE, van Mook W, Cornelissen El, Drent M. Reactive type II pneumocytes in bronchoalveolar lavage fluid. Acta Cytol. 2004;48:497-504.

16. Jacobs JA, De Brauwer El, Cornelissen El, Drent M. Accuracy and precision of quantitative calibrated loops in transfer of bronchoalveolar lavage fluid. J Clin Microbiol. 2000;38:2117-21.

17. De Brauwer $E l$, Jacobs JA, Nieman $F$, Bruggeman $C A$, Wagenaar SS, Drent $M$. Cytocentrifugation conditions affecting the differential cell count in bronchoalveolar lavage fluid. Anal Quant Cytol Histol. 2000;22:416-22.

18. De Brauwer El, Jacobs JA, Nieman F, Bruggeman CA, Drent M. Bronchoalveolar lavage fluid differential cell count. How many cells should be counted? Anal Quant Cytol Histol. $2002 ; 24: 337-41$.

19. Viegen I, Duijvestijn A, Stassen F, Bruggeman C. Murine cytomegalovirus infection directs macrophage differentiation into a pro-inflammatory immune phenotype: implications for atherogenesis. Microbes Infect. 2004;6:1056-62.

20. van Doornum GJ, Guldemeester J, Osterhaus AD, Niesters HG. Diagnosing herpesvirus infections by real-time amplification and rapid culture. J Clin Microbiol. 2003;41:576-80.

21. Wiedermann FJ, Mayr AJ, Kaneider NC, Fuchs D, Mutz NJ, Schobersberger W. Alveolar granulocyte colony-stimulating factor and alpha-chemokines in relation to serum levels, pulmonary neutrophilia, and severity of lung injury in ARDS. Chest. 2004;125:212-9. 
118 Chapter 7

22. Bunzli D, Wietlisbach V, Barazzoni F, Sahli R, Meylan PR. Seroepidemiology of Herpes Simplex virus type 1 and 2 in Western and Southern Switzerland in adults aged 25-74 in 1992-93: a population-based study. BMC Infect Dis. 2004;4:10.

23. Whitley RJ. Herpes simplex encephalitis: Adolescents and adults. Antiviral Res. 2006;25:25.

24. Tang IT, Shepp DH. Herpes simplex virus infection in cancer patients: prevention and treatment. Oncology (Williston Park). 1992;6:101-6.

25. Nichols WG, Boeckh M, Carter RA, Wald A, Corey L. Transferred herpes simplex virus immunity after stem-cell transplantation: clinical implications. J Infect Dis. 2003;187:801-8.

26. Miyazato $A$, Kishimoto $H$, Tamaki $K$, Nakama $K$, Saito $A$. Herpes simplex virus bronchopneumonia in a non-immunocompromized individual. Intern Med. 2001;40:836-40.

27. Cherr GS, Meredith JW, Chang M. Herpes simplex virus pneumonia in trauma patients. J Trauma. 2000;49:547-9.

28. Ong GM, Lowry K, Mahajan S, Wyatt DE, Simpson C, O'Neill HJ, Mc Caughey C, Coyle PV. Herpes simplex type 1 shedding is associated with reduced hospital survival in patients receiving assisted ventilation in a tertiary referral intensive care unit. $J$ Med Virology. 2004; $72: 121-5$.

29. Luyt $C E$, Combes $A$, Deback CA, A MH, Nieszkowska A, Trouillet JL, Capron F, Aqut $H$, Gilbert $C$, Chastre J.. Herpes simples cirus lung infection in patients undergoing prolonged mechanical ventilation. Am J Respir Crit Care Med. 2007;175:935-42.

30. Pugin J, Auckenthaler R, Mili N, Janssens JP, Lew PD, Suter PM. Diagnosis of ventilatorassociated pneumonia by bacteriologic analysis of bronchoscopic and nonbronchoscopic "blind" bronchoalveolar lavage fluid. Am Rev Respir Dis. 1991;143:1121-9.

31. Timsit JF, Misset B, Goldstein FW, Vaury P, Carlet J. Reappraisal of distal diagnostic testing in the diagnosis of ICU-acquired pneumonia. Chest. 1995;108:1632-9.

32. Verheij J, Groeneveld $A B$, Beishuizen A, van Lingen A, Simoons-Smit AM, van Schijndel RJ. Herpes simplex virus type 1 and normal protein permeability in the lungs of critically ill patients: a case for low pathogenicity? Crit Care. 2004;8:R139.

33. Graham BS, Snell JD, Jr. Herpes simplex virus infection of the adult lower respiratory tract. Medicine (Baltimore). 1983;62:384-93.

34. Kim E, Lee K, Primack S, Yoon HK, Byun HS, Kim TS, Suh OJ, Han J. Viral pneumonias in adults: radiologic and pathologic findings. Radiographics. 2002;22:\$137-49. 
Chapter

Summary and discussion 


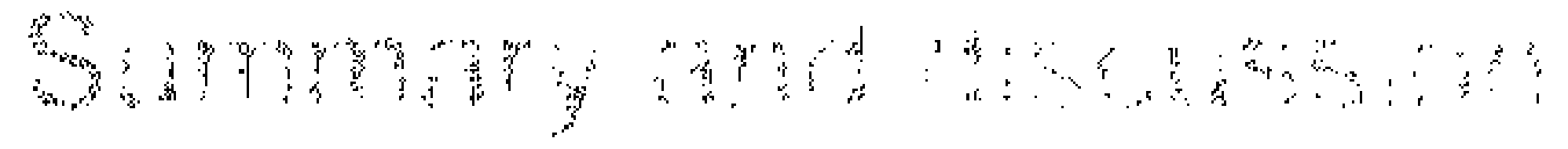

Pulmonary diseases can be of various aetiologies including infectious. irnmunologic, malignant, environmental or an occupational orgin Traditionally, these diseases are evaluated by laboratory tests, lung function tests. imaging procedures, bronchoalveolar lavage (BAL) and tissue biopsies

$B A L$ is a safe, limited invasive, and generally well-tolerated method for obtaining cellular and a-cellular components of the lower respiratory tract ${ }^{\prime 2}$. In the diagnostic work-up of pulmonary diseases BAL can be used as an additional tool. Careful analysis of the BAL fluid (BALF) cell profile and presence of a-cellular components in BALF can, combined with clinical and radiological features, help to ascertain a diagnosis. Application of BALF in the diagnosis of pulmonary infections has already proven to be very useful ${ }^{3}$. especially in case of ventilator-associated pneumonia (VAP) (1-6 $^{4}$ and opportunistic infections such as Pneumocystis pneumonia $(P C P)^{78}$. Figure 8.1 shows a flowchart of the BALF work-up as it is used in our laboratory used in immunocompetent intensive care patients on mechanical ventilation.

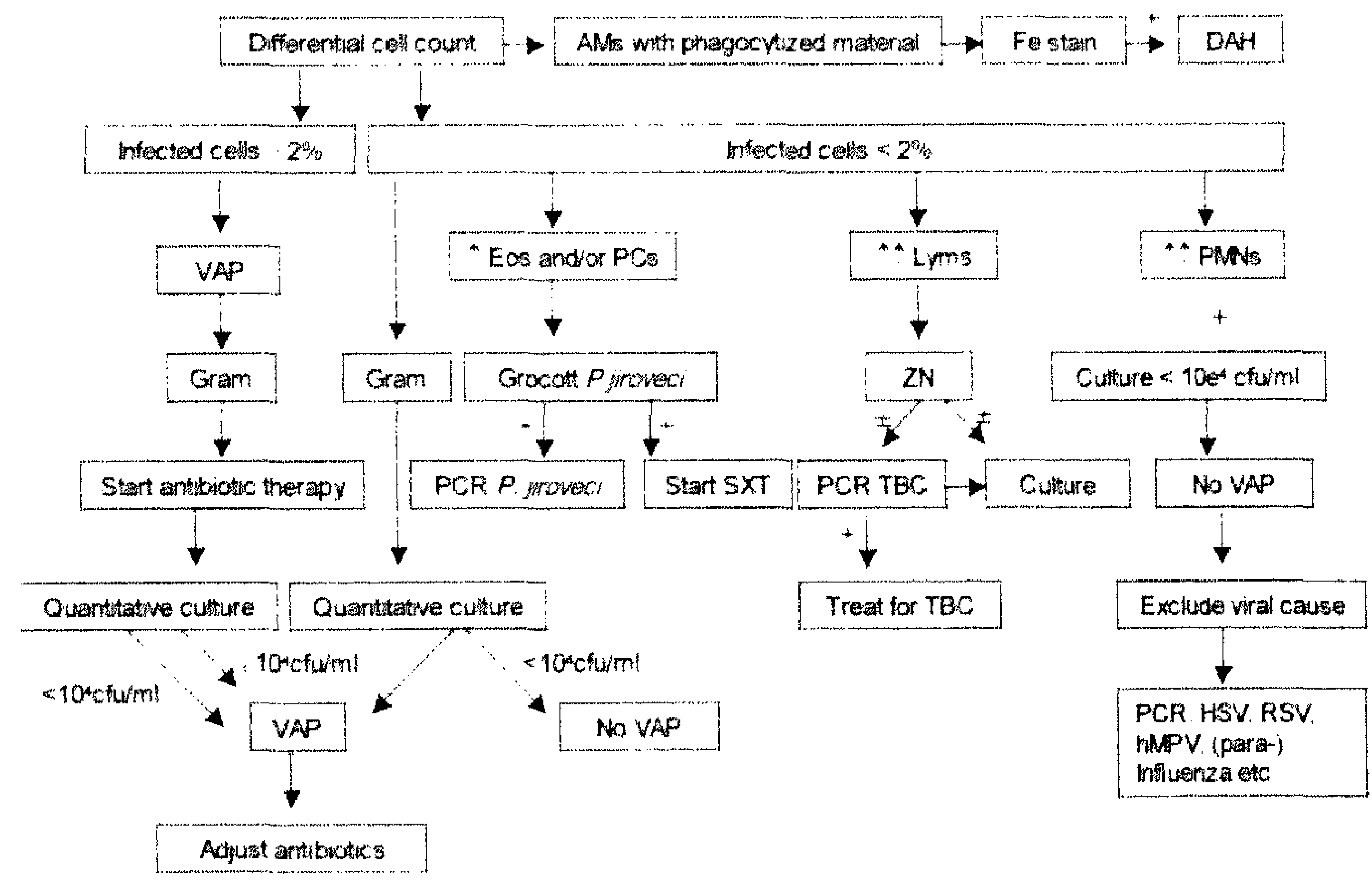

Figure 8.1 Flowchart showing the BALF work-up in immunocompetent intensive care patients on mechanical ventilation.

AMs: alveolar macrophages, cfu colony-forming units, DAH: diffuse alveolar haemorrhage, Eos: eosinophil, Fe: iron, hMPV: human metapneumovirus, HSV: herpes smplex virus, Lyms lymphocytes, PCs plasma cells, PCR polymerase chain reaction. PMNs: polymorphonuclear neutrophts, RSV: respiratory syncytial virus, SXT. trimethoprim + \$ulfamethoxazole, TBC tuberculosis, VAP ventilator-associated pnamonia, $Z N$ Ziehl-Neelsen (acid-fast stan) 
Figure 8.2 shows a flowchart of the BALF work-up as it is used in our laboratory in immunocompromised intensive care patients on mechanical ventilation.

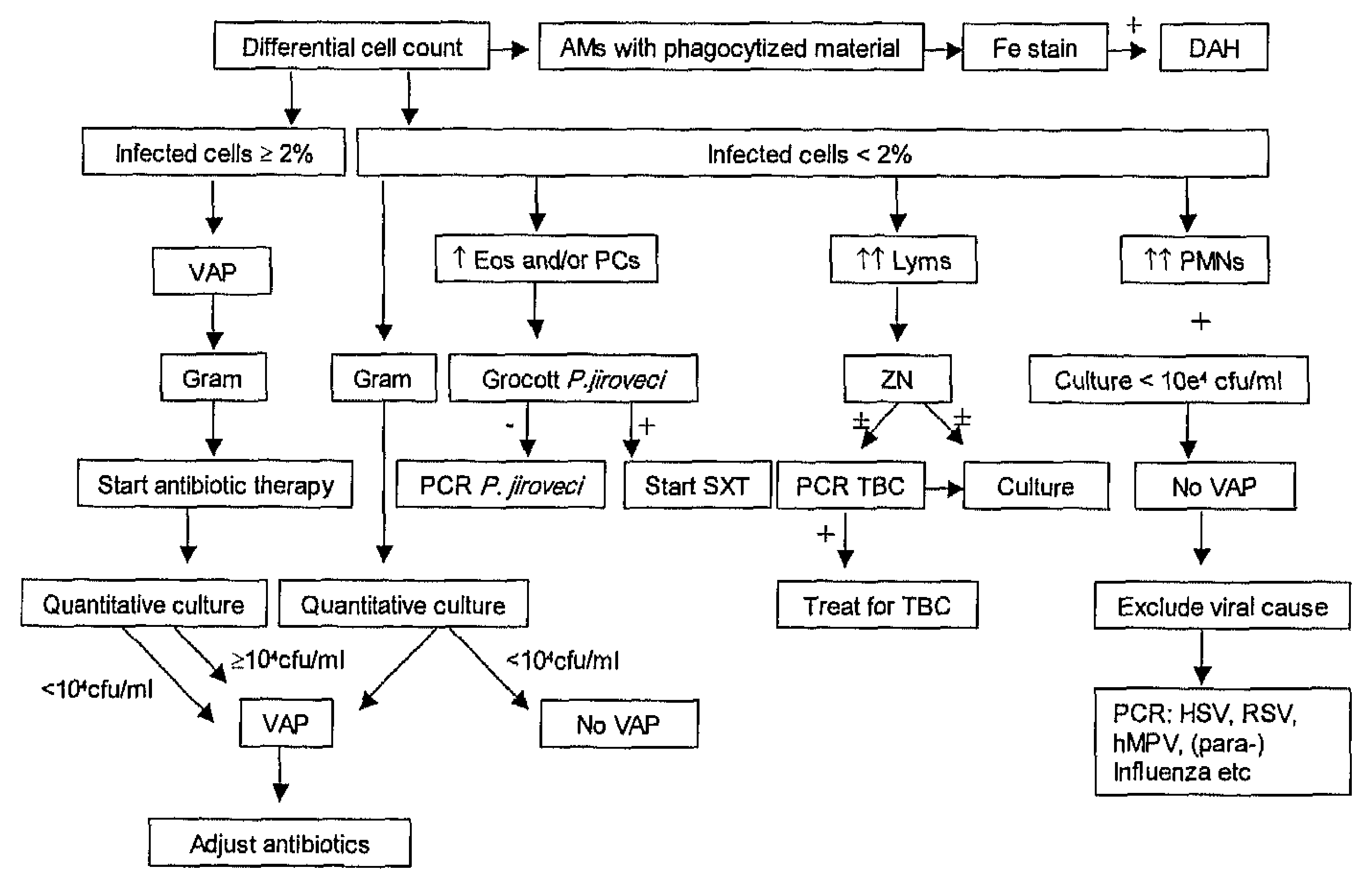

Figure 8.2 Flowchart showing the BALF work-up in immunocompromised intensive care patients on mechanical ventilation.

Cfu: colony-forming units, CMV: cytomegalovirus, hMPV: human metapneumovirus, HSV: herpes simplex virus, RSV: respiratory syncytial virus, SXT: trimethoprim + sulfamethoxazole, TBC: tuberculosis, VAP: ventilator-associated pneumonia, VOR: voriconazole, ZN: Ziehl-Neelsen (acid-fast stain).

\section{BALF versus induced sputum}

BALF as well as (induced) sputum samples have been used in the diagnostic work-up of pulmonary diseases. However, especially in infectious pulmonary diseases there is a difference in sensitivity between both types of samples. For example: the sensitivity of induced sputum for the microscopic diagnosis PCP varies between 50 and $90 \%$, depending on the experience with recovery and the laboratory work-up of the sample ${ }^{9,10}$. With the introduction of a PCR for the detection of $P$. jiroveci however, the sensitivity of induced sputum for the diagnosis PCP has greatly improved ${ }^{11}$. Unfortunately, this PCR is not yet available in every hospital. Another example is the quantitative culture of BALF for the diagnosis VAP, this has recently led to a lot of discussion whether or not BALF is still the material of choice for this diagnosis ${ }^{12,13}$. Even though, the advantage of using BALF over (induced) sputum is the fact that quality control 
is available for BALF (recovered volume, total cell count, presence of epithelial cells). This ensures that the sample used for further investigation originates from the alveolar space. Another advantage of BALF over (induced) sputum is the availability of a differential cell count. This makes it possible to explore noninfectious causes in the absence of an infectious cause ${ }^{14}$

\section{Aim of the study}

The aim of the studies presented in this thesis was attempting to improve the sensitivity of BAL as a diagnostic tool in pulmonary infectious diseases and to shorten the time to diagnosis.

BALF data obtained from patients during an eight year period from 1998 until 2005 were studied. In this thesis the use of BAL as a diagnostic tool for infectious diseases in patients suspected of a pulmonary infection is described. In chapter 1, the general introduction, the BAL procedure, laboratory work-up of $B A L F$ and the value of BAL in infectious and non-infectious diseases mimicking VAP are discussed. Furthermore, the use of nucleic acid amplification techniques in pulmonary infectious diseases in general, is briefly addressed.

\section{Microscopy of BALF}

In chapter 2 we evaluated the use of polylysine coated slides for the diagnostic work-up of clinical BALF samples. Since polylysine coating of microscopy slides has been indicated to provide superior cell adhesion, we compared polylysine coated (PLC) slides to conventional slides in cyto-centrifuged BALF samples. A total of 20 BALF samples with representative numbers of alveolar macrophages (Ams), lymphocytes (Lyms) and polymorphonuclear neutrophils (PMNs) were cytocentrentrifuged on both conventional glass slides and polylysine coated slides. Using a May-Grünwald Giemsa stain they were evaluated for total cell recovery, differential cell count and cytomorphology. Clinical significance of differences in differential cell counts was assessed using a validated computer program predicting the most probable diagnosis. Interestingly, cell recovery was lower on PLC slides compared to the conventional, uncoated, slides. The PLC slides showed significantly lower recovery of Lyms as compared to uncoated slides $(25.89 \% \pm 28.26$ versus $28.34 \pm 29.96$, respectively). The reliability of counts of Ams, Lyms and PMNs was excellent for both type of slides. No discrepancies in diagnoses were found between both type of slides. We therefore concluded the PLC slides not to be superior to conventional slides. Besides polylysine, a few other coatings have 
$124 \mid$ Chapter 8

been evaluated in various clinical samples ${ }^{15.16}$, often compared to the polylysine coated slides. In these studies polylysine coated slides demonstrated to be superior to albumin- and gelatine-coated slides. Since conventional uncoated glass slides are less expensive compared to coated slides and our study shows them to be non-inferior to the polylysine slides we opt the use of the uncoated slides in the diagnostic work-up of BALF in clinical laboratory practice.

\section{Reactive type II pneumocytes}

The aim of the study presented in chapter 3 was to evaluate the prevalence, the associated clinical conditions and the accompanying cytological findings of reactive type II pneumocytes (RPII) in a series of consecutive clinical BALF samples routinely submitted for analysis. All consecutive BALF samples obtained from patients in the period between 2000 and 2004 were included. The overall prevalence of RPII cells in our study population was $21.7 \%$. No differences were found between BALF samples with and without RPII cells, with respect to the differential cell count. However, in BALF samples with RPII, foamy Ams, activated Lyms and plasma cells were seen more frequently. RPII were observed in the samples of patients diagnosed with acute respiratory distress syndrome, diffuse alveolar damage, acute eosinophilic pneumonia, extrinsic allergic alveolitis or hypersensitivity pneumonitis, drug-induced pulmonary disorders, PCP and VAP. No RPII cells were found in BALF from patients diagnosed with pulmonary tuberculosis or sarcoidosis. Even though RPIl cells were found not to be pathognomonic for a specific disease, they are associated with severe pulmonary damage. Combined with the differential cell count and specific morphological findings such as foamy alveolar macrophages, activated Lyms and plasma cells, the presence of RPII may be of additional diagnostic value in the assessment of interstitial lung diseases and pulmonary infections.

\section{Influence of antibiotic therapy on prediction of VAP}

In intensive care patients on mechanical ventilation, VAP has a high prevalence ${ }^{17,18}$ and is associated with a high mortality ${ }^{17}$. BALF analysis including differential cell count and enumeration of infected cells (IC) have been used in the diagnosis of $V A P^{4,6}$. However, the influence of antibiotics on the differential cell count, including IC, remained unknown. Studies dealing with the subject showed conflicting results ${ }^{19-21}$. Therefore, in chapter 4 , the influence 
of antibiotics on the prediction of VAP was evaluated. The prospective study was conducted during a 61-month period (January 1999 until February 2004). All consecutive BALF samples of intensive care patients clinically suspected of VAP were included. Previous studies showed quantitative culture results to be influenced by antibiotic started up to 72 hours previous to the time of lavage. The main finding of this study was that, antibiotic therapy in 72 hours prior to performance of BAL, did not influence the reliability of the IC count in BALF in the prediction of VAP. The cytological parameter that most accurately predicted VAP was the percentage IC, using a cut-off value of $2 \%$. Combining the percentage $I C$ with cytological parameters did not result in a better prediction of VAP.

\section{Soluble factors in BALF in the prediction of VAP}

Even though routine application of BALF analysis is a valuable tool in the identification of infectious and non-infectious pulmonary diseases, it is limited by the fact that it is expensive, time-consuming, and relies upon specialised technicians. In most hospitals facilities for BALF cytology are not available on a 24-hour base, therefore we were interested in a fast method, present in most hospitals, to predict VAP. The use of acute phase proteins seemed promising ${ }^{22}$ and these tests are available in most hospitals on a 24 hour base. Chapter 5 describes the usefulness of $C$-reactive protein (CRP) and procalcitonin (PCT) in the prediction of VAP. Both CRP and PCT were determined in BALF and serum of patients with microbiologically proven VAP. Initially, the kits for highsensitive CRP (CRPH) and the kit for high-sensitive PCT (ProCa-S) were validated for BALF. Both tests performed well when assessed for matrix-effect, linearity and reproducibility, and, were therefore applicable for use on BALF. However, there was a large overlap in PCT and CRP concentrations in BALF samples between patients with and without VAP and both PCT and CRP concentrations in BALF resulted in a small area under the curve in the receiver operating characteristic curve. Therefore, the major conclusion from this study was that both parameters, in BALF as well as in serum, were not useful as a predictor for VAP.

However, other soluble factors have proven to be useful in the diagnosis of pulmonary diseases. The need for a rapid method for confirming or excluding VAP remains, especially a method that would be available in every hospital at any time of day. Other soluble factors are promising, for instance the soluble triggering receptor expressed on myeloid cells (TREM-1). STREM-1 is a member of the immunoglobulin superfamily which is a group of cell surface and soluble proteins involved in recognition, binding or adhesion of cells ${ }^{23}$. Expression of TREM-1 has been found on neutrophils and monocytes ${ }^{24}$, but 
also on alveolar macrophages ${ }^{25}$. The expression of this triggering receptor is up regulated by the presence of bacteria and fung $i^{26}$, thereby mediating the acute inflammatory response to these micro-organisms ${ }^{26}$. For the detection of STREM-1, in blood and sputum, an enzyme-linked immuno sorbent assay (ELISA) is currently on the market for research purposes (Human TREM-1 Quantikine kit, R\&D systems inc, Minneapolis, U.S.A.) taking approximately 4 hours to generate a result. Few studies have investigated the usefulness of sTREM-1 in the diagnosis pneumonia ${ }^{27,28}$. A multiple logistic-regression analysis conducted by Gibot et al. ${ }^{27}$ showed the presence of S-TREM-1 to be the strongest single predictor of pneumonia in a study with 148 patients, including 46 patients with VAP, undergoing mini-BAL ${ }^{27}$. They found a cut-off value of 5 $\mathrm{pg} / \mathrm{ml}$ to be the best predictor for the presence of pneumonia. Unfortunately, they did not take into account the dilution 10-100 times when BALF is compared to ELF. Richeldi and colleagues investigated STREM-1 as a potential marker in community-acquired pneumonia and tuberculosis ${ }^{28}$. Their study showed that STREM-1 was recovered in BALF of patients with communityacquired pneumonia, but not in patients with tuberculosis. Neither Gibot et $a l^{27}$ nor Richeldi et $a l^{28}$ used the above described ELISA. Until now, only one study used this kit in a small series of patients suspected of VAP $(n=28)^{29}$. They found STREM-1 to be an excellent predictor of VAP at a cut-off value of 200 $\mathrm{pg} / \mathrm{ml}$. Unfortunately, Determann et $\mathrm{al} .{ }^{29}$ did not validate the kit for use on BALF neither did they correct for the dilution factor. Therefore, the Human TREM-1 Quantikine kit should be validated for the use on BALF. Additionally, it should be tested in a prospective study of ICU patients suspected of VAP. The aim of this study could be determining the predictive value of STREM-1 in the diagnosis VAP and eventually defining a cut-off value to distinguish between VAP and non-VAP.

\section{Molecular techniques in the work-up of BALF}

In the past, the clinical standard for assessing many infectious agents was based on culture and serology. In recent years, detection of many microorganisms by means of nucleic acid amplification methods has been introduced as superior methods when compared to conventional methods in terms of sensitivity and specificity. Nucleic acid amplification techniques, such as polymerase chain reaction (PCR) can also contribute in the diagnostic work-up of BALF. Chapter 6 and 7 described two studies dealing with implementation and interpretation of PCR techniques in BALF work-up. 


\section{Detection of $P$. jiroveci in BALF}

The implementation of a new method as a diagnostic tool always requires extensive standardisation and validation before it can be used in daily practice. One additional measurement used to ensure good quality and to identify possible flaws in the used test is a quality control panel distributed by a coordinating organisation. However, these quality control panels are not available for all micro-organisms, one example of such a micro-organism is $P$. jiroveci. Real-time PCR methods for the diagnosis of $P$. jiroveci in pulmonary samples have recently made the switch from research tool to diagnostic tool ${ }^{30,31}$. However, since no quality control panels are available, validation, implementation and comparison of intra-laboratory results is difficult. Therefore, chapter 6 described a study which was initiated to compare the performance of three independently developed real-time PCR assays for the detection of $P$. jiroveci in three different tertiary care centres in The Netherlands. A cooperation was formed between the university hospitals of Nijmegen, Leiden and Maastricht. In the period August 1999 until April 2004 a total of 124 BALF samples were included. They were obtained from either HIV-positive or HIVnegative patients with a known risk factor for $\mathrm{PCP}$, such as a (hematological) malignancy, bone marrow or organ transplantation, Wegener's granulomatosis, and immunosuppressive or corticosteroid therapy $(n=84)$. Additionally a number of BALF samples obtained from patients with no known risk factor for $P C P$, but with either VAP or newly diagnosed sarcoidosis, were included $(n=40)$. From these 124 BALF samples 41 samples showed the presence of $P$. jiroveci by microscopy, the remaining 83 were microscopy negative. For 114 samples the PCR results from the three laboratories were conclusive. Forty out of 41 microscopy-positive samples were found positive in all three PCR assays. Out of the 83 microscopy-negative samples, 69 were also negative in all three $\mathrm{PCR}$ assays. From the remaining 14 microscopy-negative samples, five were positive in all three PCR assays. A high agreement between the three $P$. jiroveci real-time PCR assays was found, varying from $94.4 \%$ (Kappa value: 0.88 ) till $96.8 \%$ (Kappa value: 0.93 ) was found. Since $P$. jirovecican be present in low quantities in the pulmonary tract without causing disease (carriership). It is mandatory to distinguish between carriership and disease. It was hypothesized that, in case of PCP, P. jiroveci would be present in patients in higher quantities compared to carriers. Unfortunately, there was an overlap between patients with microscopically confirmed PCP and patients without (microscopically confirmed) PCP with regard to quantities of $P$. jiroveci present. In this retrospective study no absolute cut-off value to discriminate between disease and carrier status for $P$. jiroveci could be established. 


\section{$128 \mid$ Chapers}

\section{Improving the clinical relevance of a $P$. jiroveciPCR}

Different strategies could be investigated to eventually reduce the grey area. One strategy could be combining PCR results with serum indicators. Some indicators that may be helpful are: serum lactate dehydrogenase (LDH) and $\beta$-D-glucan. LDH in BALF has shown to be of use in differentiating between infectious and non-infectious pulmonary disease ${ }^{32}$. Especially in patients with PCP, LDH has shown to be elevated ${ }^{33-36}$. In a study by Zaman et al. ${ }^{35}$ they found a LDH serum concentration of 450 international units (IU) to predict the presence of PCP in their population. Quist et al. ${ }^{33}$ investigated 42 patients with PCP, 71 with disseminated tuberculosis, 40 with pulmonary tuberculosis and 37 with bacterial pneumonia. They found peak LDH levels to be significantly higher in patients with PCP compared with the other groups. Unfortunately, there was an overlap in measured serum LDH between patients with PCP and the other three groups, limiting its specificity ${ }^{33}$. A recent, retrospective, study by Tasaka et $a 1 .{ }^{36}$ included 295 patients who underwent BAL for the specific diagnosis of PCP. In 57 patients PCP was confirmed based upon microscopic findings of sedimented BALF. They showed serum levels of LDH to be significantly higher in patients with PCP compared with other pulmonary infections. The second serum marker which could be of interest is $\beta$-D-glucan, which is part of the cell wall of most fungi. It has already been used for the diagnosis of invasive mycosis such as candidiasis and invasive aspergillosis (IA). Tasaka et $a l^{36}$ evaluated the use of serum $\beta$-D-glucan in the diagnosis PCP. They showed that when using their cut-off value of $31.1 \mathrm{pg} / \mathrm{ml} \beta-D$-glucan in serum, led to a sensitivity of $92.3 \%$ with a specificity of $83.1 \%$. In their population this led to a positive predictive value (PPV) of 0.61 and a negative predictive value (NPV) of 0.98 . The relatively low NPV could be explained by other invasive fungi such as Candida species or Aspergillus species. A limitation of this study is the fact that they use a less sensitive method (microscopy of sedimentated BALF) as their gold standard. Especially the use of cytocentrifuged preparations can increase the sensitivity. They argue that microscopy has a PPV and NPV exceeding $90 \%$. However, in our experience this is only true in the hands of experiences technicians. Tasaka et $a / .{ }^{36}$ state they did not use PCR to diagnose PCP because of the possible detection of carriers. However, the combination of PCR and $\beta$-D-glucan may be very interesting. We hypothesize that since there is no pulmonary tissue damage in carriership, there may not be any (or only a low concentration of) $\beta$-D-glucan detectable in the peripheral blood. Therefore, a study determining the concentration $\beta$-D-glucan in serum (and BALF) of patients with proven PCP, carriers, patients with a PCR-result within the grey zone and patients without suspected PCP should be investigated and correlated with the PCR result. This 
Summary and discussion 129

may help to limit the grey zone of the PCR and confirm the usefulness of $\beta-D-$ glucan in the diagnosis PCP.

\section{Detection of HSV-1 in BALF}

Finally, in chapter 7, we tried to unravel the clinical relevance of a high herpes simplex virus load in BALF. The two subtypes of human herpes simplex virus, HSV-1 and HSV-2, are highly prevalent and ubiquitously distributed. HSV-1 has been described as an (unusual) cause of pneumonia in immune compromised patients ${ }^{37,38}$. However, the clinical relevance of detecting HSV-1 and -2 in BALF is unclear.

We aimed to evaluate the relationship between the HSV-1 and -2 loads in BALF and clinical outcome. Our data showed HSV-1 to be present in approximately one third of all BALF samples acquired from ICU patients. Furthermore, it indicates that a HSV-1 load in BALF of $>10^{5} \mathrm{ge} / \mathrm{ml}$ is an independent predictor for a poor outcome in critically ill patients, with an increase in mortality rate of $21 \%$. Even though, it remains to be determined whether HSV-1 is causally linked with a low survival or whether it is a marker of a severely disturbed immune system. Our study was limited by the fact that it was conducted retrospectively, therefore, the influence of aciclovir on the mortality and morbidity could not be evaluated. A prospective intervention study using the cut-off value of $10^{5} \mathrm{ge} / \mathrm{ml} \mathrm{BALF}$ may generate the data needed. If HSV-1 is the cause of an increased mortality of ICU patients, with a HSV-1 load exceeding $10^{5}$, treatment with aciclovir should at least decrease the mortality rate in these patients Of course HSV is not the only virus that could cause pneumonia. Other viruses that cause pneumonia ${ }^{3,39}$ include influenza virus $A$, $B$, para-influenza virus $1,2,3,4$, cytomegalovirus, varicella zoster virus, coronavirus, human respiratory syncytial virus (RSV) and rhinovirus. In recent years, attention has been drawn towards human metapneumovirus (hMPV) as a cause of pneumonia. HMPV is an paramyxovirus identified in 2001 in the Netherlands ${ }^{40}$. The study by van den Hoogen et $a / .{ }^{40}$ included nasopharyngeal aspirate samples collected, over a period of 20 years, from 28 young children ( $<5$ years) with symptoms of respiratory tract infections similar to those caused by RSV. Epidemiologically, the children were unrelated ${ }^{40}$. The infection seems to have a seasonal cycle with most infections occurring in the winter months (resembling infection caused by $\mathrm{RSV}^{41}$ ). Most studies use reverse transcriptase PCR (RT-PCR) for the detection of hMPV RNA in respiratory samples ${ }^{42-45}$. It is possible to culture the virus, it grows slowly on tertiary monkey kidney cells ${ }^{40,43}$ and shows poor growth in Vero cells and A549 cells with a cytopathogenic effect strongly resembling that initiated by $\mathrm{RSV}^{40}$. Since its discovery, data have been published about its role in pneumonia in young children ${ }^{39,40,44,46}$, the 
elderly ${ }^{42}$ and immunocompromised patients ${ }^{42,45}$. The virus has been described in a variety of patients. Accordingly, it may also play a role in intubated patients at the ICU. Until now, only one study has been published including adult intensive care patients in the study population ${ }^{43}$. The study by Gray et $a l^{43}$ included 1500 respiratory samples $(75 \%$ collected by nasal wash, only $10 \%$ BALF) from 1294 patients. By using RT-PCR they found 34 patients to be hMPV positive. These 34 patients included 9 adult patients with various underlying disorders such as malignancy $(n=2)$, obstructive bronchitis $(n=2)$, bacterial pneumonia $(n=1)$, influenza $(n=1)$ and respiratory failure of unknown origin ( $n=3$ ). A number of patients admitted to our ICU develop additional respiratory problems during ventilation. Since only approximately $25-33 \%$ can be explained by bacterial infection, we hypothesize that some may be associated with a viral infection Therefore, a respiratory multiplex PCR (including hMPV) may discover additional viral causes for the respiratory deterioration of the patients admitted to our ICU.

\section{BAL in immunosuppressed patients}

The same may be applicable to patients admitted to the hematology-oncology ward with signs of pulmonary infection. Often analysis of BALF samples obtained from these patients do not result in the identification of a causative organism. Due to their underlying disease and subsequent therapy (chemotherapy) these patients often have no (functional) granulocytes. Therefore, they are vulnerable for all kinds of (pulmonary) infections. Besides bacterial, viral, and fungal infections in parasitic causes should be considered ${ }^{3}$. The advantage of a sensitive and fast method for detection of these organisms are mainly clear when there is therapy available directed against the suspected micro-organism. For instance Aspergillus fumigatus, this fungus is notorious for causing life-threatening pulmonary infections in immunocompromised patients ${ }^{47}$ and seldom in immunocompetent patients ${ }^{48}$. Invasive Aspergillosis $(\mathrm{IA})$ is associated with a high mortality varying from $30-80 \%{ }^{49,50}$ depending on the time of diagnosis and the initiation of therapy. The diagnosis IA is difficult since clinical symptoms and radiological features are often non-specific. Cultures of BALF or biopsies are very specific, however the sensitivity is low $(30-50 \%)^{51}$. In recent years, the detection of galactomannan, a part of the cell wall of $A$. fumigatus, in BALF and serum has contributed to an earlier diagnosis of $I A^{52}$. PCR methods for the detection of $A$. fumigatus in respiratory samples have been described in literature ${ }^{53,54}$. However, studies evaluating the value of an $A$. fumigatus specific PCR compared to the detection of galactomannan, in the diagnosis $\mid \mathrm{A}$ has led to conflicting results. Becker et $a / .^{55}$ using an animal model to study IA found the quantitative galactomannan detection to be 
superior over the PCR in both serum as BALF. A study by Costa et al. ${ }^{56}$ comparing galactomannan detection with $P C R$ in serum from patients suspected of IA, showed comparable results. A study conducted by Kami et $a / .^{57}$ showed a higher sensitivity and specificity for the PCR compared to the detection of galactomannan in serum from patients suspected of IA. All three described studies used the same ELISA for the detection of galactomannan in their samples; however the molecular methods they used differed significantly. One use a conventional $P C R^{55}$, whilst the others used a real-time $P C R^{56,57}$. The isolation of DNA, the target and the platform used to run the PCR differed in all three studies. This could, in part explain the differences found. Combining a real-time PCR assay with the ELISA may increase the diagnostic yield in the diagnosis IA.

As stated earlier, even parasitic pulmonary infection should be considered in immunocompromised patients suspected of pulmonary infection. One of the possibilities is Toxoplasma gondii. T. gondii is an obligate intracellular parasite with a ubiquitous distribution. After the acute, in immunocompetent hosts often asymptomatic phase of infection, bradyzoites remain within the human body. In immunocompromised hosts it is known for its tendency to reactivate and to cause disseminated disease ${ }^{58,59}$. Pulmonary infection with $T$. gondii is associated with a mortality exceeding $50 \%{ }^{60}$. The diagnosis pulmonary infection by $T$. gondii can be ascertained in a way comparable to $P$. jiroveci, by microscopic examination of BALF ${ }^{61}$. However, patients at risk for $T$. gondii pulmonary infections are identical to patients at risk for PCP, therefore they may already be receiving PCP prophylaxis (co-trimoxazole). Co-trimoxazole also has an effect on $T$. gondii, which may influence the load of $T$. gondii present in BALF, just as it does influence the load of $P$. jiroveci in BALF. This may be enough to make it undetectable in microscopic preparations, but not enough to fully protect against disseminated $T$. gondii infection ${ }^{62}$. To increase the detection rate of $T$. gondii in BALF, PCR may be useful ${ }^{63}$. Petersen et al. ${ }^{62}$ examined 332 BALF samples of 290 HIV positive patients by means of realtime PCR. They found T. gondii DNA in 7 patients, resulting in a prevalence of $2 \%$. Since pulmonary toxoplasmosis has not only been described in patients with HIV, but also in otherwise immunocompromised patients ${ }^{64}$, the addition of a PCR for T. gondii to the diagnostic work-up of BALF could be beneficial. To evaluate this, BALF samples from immunocompetent and immunocompromised patients (both HIV-positive and -negative) should be evaluated for the presence of $T$. gondii DNA by means of real-time PCR. This could eventually lead to an increase of diagnosed $T$. gondii pulmonary infections and subsequent treatment with high dose co-trimoxazole. 
132 Chapter 8

\section{In summary}

- polylysine coated slides are not superior over conventional uncoated glass slides in the work-up of clinical bronchoalveolar lavage fluid samples

- Normally, reactive pneumocytes type $\mathrm{Il}$ are not present in bronchoalveolar lavage fluid

- The presence of reactive pneumocytes type II is associated with conditions of acute lung injury such as alveolar damage as extrinsic allergic alveolitis and drug-induces pulmonary disorders, pneumocystis pneumonia and ventilator-associated pneumonia

- Antibiotic therapy in the 72 hours preceding the bronchoalveolar lavage does not influence the predictive value of cytological bronchoalveolar lavage fluid parameters in the microscopic diagnosis ventilator-associated pneumonia.

- Amongst the cells present in bronchoalveolar lavage fluid, the percentage of infected cells is the most important parameter for distinguishing ventilator-associated pneumonia from a non-ventilator-associated pneumonia condition.

- Using a standardised method, the best cut-off value for the percentage infected cells was set at $2 \%$. Combining the percentage infected cells with any other cytological parameter did not reveal better predictive values.

- The three different in-house real-time polymerase chain reaction assays for $P$. jiroveci developed in the university hospitals of Leiden, Nijmegen and Maastricht show an excellent agreement in performance.

- $P$. jiroveci quantity determined by real-time polymerase chain reaction and microscopic quantification are comparable.

- At this moment an absolute cut-off value discriminating disease and carrier status for $P$. jiroveci can not be established due to the presence of a grey zone.

- In $32 \%$ of all bronchoalveolar lavage fluid samples acquired from intensive care patients, a herpes simplex type 1 load can be detected

- A herpes simplex type 1 load in bronchoalveolar lavage fluid of $>10^{5} \mathrm{ge} / \mathrm{ml}$ is an independent predictor for a poor outcome in critically ill patients, with an increase in mortality rate of $21 \%$. 


\section{Directions for future research:}

This thesis underlines the value of BALF in the diagnostic work-up of infectious pulmonary diseases. Especially the incorporation of molecular methods will increase the diagnostic yield and sensitivity of BAL in infectious diseases. However, future studies are needed to:

1. Validate the usefulness of the Human TREM-1 Quantikine kit on bronchoalveolar lavage fluid

2. Evaluation of the Human TREM-1 Quantikine kit in the prediction of ventilator-associated pneumonia

3. Refine the value of new techniques such as the limitation of the grey zone in the P. jiroveci PCR because this will result in an increase of clinical applicability. Two possible strategies could be:

a. The detection of LDH in both bronchoalveolar lavage fluid and serum.

b. The detection of $\beta-D$-glucan in both bronchoalveolar lavage fluid and serum

4. Evaluate the herpes simplex type 1 polymerase chain reaction cut-off value of $10^{5} \mathrm{ge} / \mathrm{ml}$ in a prospective intervention study.

5. Evaluate the clinical value of a respiratory multiplex (including human metapneumovirus) for patients with respiratory deterioration whilst on mechanical ventilation at the ICU.

6. Evaluate the clinical value of a respiratory multiplex polymerase chain reaction (including human metapneumovirus) for patients admitted to the hematology-oncology ward with signs of pulmonary infection.

7. Evaluate the combination of an Aspergillus fumigatus specific real-time polymerase chain reaction assay and the enzyme-linked immuno sorbent assay for the detection of circulating galactomannan in both serum and blood of patients suspected of invasive Aspergillosis.

8. Evaluate the clinical value of a $T$. gondii real-time polymerase chain reaction on bronchoalveolar lavage fluid samples of immunocompromised patients suspected of a pulmonary infection.

in conclusion, BALF work-up is of great value in the diagnosis of pulmonary infections. Especially the incorporation of molecular techniques for viral pathogens, fungi and parasites will increase the number of confirmed infections which in turn will lead to an improvement of patient care because of a targeted therapy. 
$134 \mid$ Chapter 8

\section{References}

1. Klech H, Hutter C. Side-effects and safety of BAL. Eur Respir J. 1990:939-40; 961-9.

2. Goldstein RA, Rohatgi PK, Bergofsky EH, Block ER, Daniele RP, Dantzker DR, Davis GS, Hunninghake GW, King TE, Metzger WJ. Clinical role of bronchoalveolar lavage in adults with pulmonary disease. Am Rev Respir Dis. 1990;142:481-6.

3. Joos L, Chhajed PN, Wallner J, Battegay M, Steiger J, Gratwohl A, Tamm M. Pulmonary infections diagnosed by BAL: A 12-year experience in 1066 immunocompromised patients. Respiratory medicine. 2007;101:93-7.

4. Allaouchiche B, Jaumain H, Dumontet $\mathrm{C}$, Motin J. Early diagnosis of ventilator-associated pneumonia. Is it possible to define a cutoff value of infected cells in BAL fluid? Chest. 1996;110:1558-65.

5. Baselski V. Microbiologic diagnosis of ventilator-associated pneumonia. Infect Dis Clin North Am. 1993; 7:331-57.

6. Kirtland SH, Corley DE, Winterbauer RH, Springmeyer SC, Casey KR, Hampson NB, Dreis DF. The diagnosis of ventilator-associated pneumonia: a comparison of histologic, microbiologic, and clinical criteria. Chest. 1997;112:445-57.

7. Armbruster C, Pokieser L, Hassl A. Diagnosis of Pneumocystis carinii pneumonia by bronchoalveolar lavage in AIDS patients. Comparison of Diff-Quik, fungifluor stain, direct immunofluorescence test and polymerase chain reaction. Acta Cytol. 1995;39:1089-93.

8. Baughman RP. Current Methods of Diagnosis. In: Walzer PD, editor. Pneumocystis carinii pneumonia. New York: Marcel Dekker, Inc. 1994:381-401.

9. Bigby TD, Margolskee D, Curtis JL, Michael PF, Sheppard D, Hadley WK, Hopewell PC. The usefulness of induced sputum in the diagnosis of Pneumocystis carinii pneumonia in patients with the acquired immunodeficiency syndrome. Am Rev Respir Dis. 1986;133:515-8.

10. Kovacs JA, Ng VL, Masur H, Leoung G, Hadley WK, Evans G, Lane HC, Ognibene FP, Shelhamer J, Parrillo JE. Diagnosis of Pneumocystis carinii pneumonia: improved detection in sputum with use of monoclonal antibodies. N Engl J Med. 1988;318:589-93.

11. Turner $D$, Schwartz $Y$, Yust $I$. Induced sputum for diagnosing Pneumocystis carinii pneumonia in HIV patients: new data, new issues. Eur Respir J. 2003;21:204-8.

12. Fagon JY, Chastre J, Rouby JJ. Is bronchoalveolar lavage with quantitative cultures a useful tool for diagnosing ventilator-associated pneumonia? Crit Care. 2007;11:123.

13. A randomized trial of diagnostic techniques for ventilator-associated pneumonia. $\mathrm{N}$ Engl $\mathrm{J}$ Med. 2006;355:2619-30.

14. Jacobs JA, De Brauwer El, Ramsay G, Cobben NA, Wagenaar SS, van der Ven AJ, Drent M. Detection of non-infectious conditions mimicking pneumonia in the intensive care setting: usefulness of bronchoalveolar fluid cytology. Respir Med. 1999;93:571-8.

15. van Oostenbrugge RJ, Arends JW, Buchholtz R, Twijnstra A. Cytology of cerebrospinal fluid. Are polylysine-coated slides useful? Acta Cytol. 1997;41:1510-2.

16. Husain OA, Millett JA, Grainger JM. Use of polylysine-coated slides in preparation of cell samples for diagnostic cytology with special reference to urine sample. $J$ Clin Pathol. 1980;33:309-11.

17. Chastre J, Fagon JY. Ventilator-associated pneumonia. Am J Respir Crit Care Med. 2002;165:867-903.

18. Rello J, Ollendorf DA, Oster G, Vera-Llonch M, Bellm L, Redman R, Kollef MH. Epidemiology and outcomes of ventilator-associated pneumonia in a large US database. Chest. 2002; 122:2115-21.

19. Timsit JF, Misset B, Goldstein FW, Vaury P, Carlet J. Reappraisal of distal diagnostic testing in the diagnosis of ICU-acquired pneumonia. Chest. 1995;108:1632-9.

20. Sirvent JM, Vidaur L, Gonzalez S, Castro P, de Batlle J, Castro A, Bonet A. Microscopic examination of intracellular organisms in protected bronchoalveolar mini-lavage fluid for the diagnosis of ventilator-associated pneumonia. Chest. 2003;123:518-23. 
21. Dotson RG, Pingleton SK. The effect of antibiotic therapy on recovery of intracellular bacteria from bronchoalveolar lavage in suspected ventilator-associated nosocomial pneumonia. Chest. 1993;103:541-6.

22. Duflo $F$, Debon $R$, Goudable J, Chassard D, Allaouchiche B. Alveolar and serum oxidative stress in ventilator-associated pneumonia. $\mathrm{Br} J$ Anaesth. 2002;89:231-6.

23. Bouchon $A$, Dietrich J, Colonna M. Inflammatory responses can be triggered by TREM-1, a novel receptor expressed on neutrophils and monocytes. J Immunol. 2000;164:4991-5.

24. Gingras MC, Lapillonne $H$, Margolin JF. TREM-1, MDL-1, and DAP12 expression is associated with a mature stage of myeloid development. Mol Immunol. 2002;38:817-24.

25. Colonna M, Facchetti F. Triggering receptor expressed on myeloid cells: role in the diagnosis of lung infections. Eur Respir J. 2004;24:247-50.

26. Bouchon $A$, Facchetti $F$, Weigand MA, Colonna M. TREM-1 amplifies inflammation and is a crucial mediator of septic shock. Nature. 2001;410:1103-7.

27. Gibot $S$, Cravoisy A, Levy $B$, Bene MC, Faure G, Bollaert PE. Soluble triggering receptor expressed on myeloid cells and the diagnosis of pneumonia. N Engl J Med. 2004;350:451-8.

28. Richeldi L, Mariani M, Losi M, Maselli $F$, Corbetta L, Buonsanti $C$, Colonna $M$, Sinigaglia $F$, Panina-Bordignon P, Fabbri LM. Triggering receptor expressed on meloid cells: role in the diagnosis of lung infections. Eur Respir J. 2004;24:247-50.

29. Determann RM, Millo JL, Gibot S, Korevaar JC, Vroom MB, van der Poll T, Garrard CS, Schultz MJ. Serial changes in soluble triggering receptor expressed on myeloid cells in the lung during development of ventilator-associated pneumonia. Intensive Care Med. 2005; 31:1495-500.

30. Flori P, Bellete B, Durand F, Raberin H, Cazorla C, Hafid J, Lucht F, Sung RT. Comparison between real-time PCR, conventional PCR and different staining techniques for diagnosing Pneumocystis jiroveci pneumonia from bronchoalveolar lavage specimens. J Med Microbiol. 2004;53:603-7.

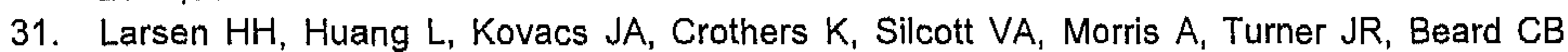
Masur $\mathrm{H}$, Fischer SH. A prospective, blinded study of quantitative touch-down polymerase chain reaction using oral-wash samples for diagnosis of Pneumocystis pneumonia in HIVinfected patients. J Infect Dis. 2004;189:1679-83.

32. Cobben NA, Jacobs JA, van Dieijen-Visser MP, Mulder PG, Wouters EF, Drent M. Diagnostic value of BAL fluid cellular profile and enzymes in infectious pulmonary disorders. Eur Respir J. 1999;14:496-502.

33. Quist J, Hill AR. Serum lactate dehydrogenase (LDH) in Pneumocystis carinil pneumonia, tuberculosis and bacterial pneumonia. Chest. 1995;108:415-8.

34. Silverman BA, Rubinstein A. Serum lactate dehydrogenase leels in adults and children with acquired immune deficiency syndrome (AIDS) and AIDS-related complex: possible indicator of B cell lymphoproliferation and disease activity. Am J Med. 1985;78:728-36.

35. Zaman MK, White DA. Serum lactate dehydrogenase levels and Pneumocystis carinii pneumonia. Diagnostic and prognostic significance. Am Rev Respir Dis. 1988;137:796-800.

36. Tasaka S, Hasegawa N, Kobayashi S, Yamada W, Nishimura T, Takeuchi T, Ischizaka A. Serum indicators for the diagnosis of Pneumocystis pneumonia. Chest. 2007;131:1173-80.

37. Byers RJ, Hasleton PS, Quigley A, Dennett C, Klapper PE, Cleator GM, Faragher EB. Pulmonary herpes simplex in burns patients. Eur Respir J. 1996;9:2313-7.

38. Arata K, Sakata R, Iguro $Y$, Toda R, Watanabe S, Eitsuru Y. Herpes simpiex viral pneumonia after coronary artery bypass grafting. Jpn $J$ Thorac Cardiovasc Surg. 2003;51:158-9.

39. Pierangeli $A$, Gentile $M$, Di Marco $P$, Pagnotti $P$, Scagnolari $C$, Trombetti $S$, Lo Russo L Tromba V, Moretti $C$, Midulla F, Antonelli $G$. Detection and typing by molecular techniques of respiratory viruses in children hospitalized for acute respiratory infection in Rome, italy. j Med Virol. 2007;79:463-8.

40. van den Hoogen BG, de Jong JC, Groen J, Kuiken T, de Groot R, Fouchier RAM, Osterhaus ADME. A newly discovered human pneumovirus isolated from young children with respiratory tract disease. Nature Medicine. 2001;7:719-24. 
$136 \mid$ Chapter 8

41. Wilkesmann A, Schildgen O, Eis-Hubinger AM, Geikowski T, Glatzel T, Lentze MJ, Bode U, Simon A. Human metapneumovirus infections cause similar symptoms and clinical severity as respiratory syncytial virus infections. Eur J Pediatr. 2006;165:467-75.

42. Carr MJ, McCormack GP, Crowley B. Human metapneumovirus-associated respiratory tract infections in the Republic of Ireland during the influenza season of 2003-2004. Clin Microbiol Infect. 2005;11:366-71.

43. Gray GC, Capuano AW, Setterquist SF, Erdman DD, Nobbs ND, Abed Y, Doern GV, Starks SE, Boivin $G$. Multi-year study of human metapneumovirus infection at a large US midwestern medical referral center. J Clin Virol. 2006;37:269-76.

44. Esper F, Martinello A, Boucher BA, Weibel C, Ferguson D, Landry ML. A 1-year experience with human metapneumovirus in children aged $<5$ years. J Infect Dis. 2004;189:1388-96.

45. Englund JA, Broeckh $M$, Kuypers J, Nichols WG, Hackman RC, Morrow RA, Fredricks SDN, Corey L. Brief communication: fatal human metapneumovirus infection in stem-cell transplant recipients. Ann Intern Med, 2006;144:344-9.

46. Esper F, Boucher BA, Weibel C, Martinello RA, Kahn JS. Human metapneumovirus infection in the United State: clinical manifestations associated with a newly emerging respiratory infection in children. Pediatrics. 2003;111:1407-9.

47. Soubani $A O$, Chandrasekar PH. The clinical spectrum of pulmonary Aspergillosis. Chest. 2002;121:1988-99.

48. Dijkman WM, Postma BH. Fatal invasive Aspergillosis in an apparently immunocompetent host. Netherlands Jounal of critical care. 2006;10:536-7.

49. Wald A, Leisenring W, van Burik JA, Bowden RA. Epidemiology of Aspergillus infections in a large cohort of patients undergoing bone marrow transplantation. J Infect Dis. 1997;175: 1459-66.

50. McWinney PH, Kibbler CC, Hamon MD, Smith OP, Gandhi L, Berger LA, Walesby RK, Hoffbrand AV, Prentice HG. Progress in the diagnosis and management of aspergillosis in bone marrow transplantation: 13 years' experience. Clin Infect Dis. 1993;17:397-404.

51. Kahn FW, Jones JM, England DM. The role of bronchoalveolar lavage in the diagnosis of invasive pulmonary aspergillosis. Am J Clin Pathol. 1986;84:518-23.

52. Verweij PE, Stynen D, Rijs AJ, de Pauw BE, Hoogkamp-Korstanje JA, Meis JF. Sandwich enzyme-linked immunosorbent assay compared with Pastorex latex agglutination test for diagnosing invasive aspergillosis in immunocompromised patients. $J$ Clin Microbiol. 1995;33:1912-4.

53. Rantakokko-Jalava K, Laaksonen S, Issakainen J, Vauras J, Nikoskelainen J, Viljanen MK, Salonen J. Semiquantitative detection by real-time PCR of Aspergillus fumigatus in bronchoalveolar lavage fluids and tissue biopsy specimens from patients with invasive aspergillosis. J Clin Microbiol. 2003;41:4304-11.

54. Spiess B, Buchheidt D, Baust C, Skladny H, Seifarth W, Zeilfelder U, Leib-Mosch C, Morz $H$, Hehlmann R. Development of a LightCycler PCR assay for detection and quantification of Aspergillus fumigatus DNA in clinical samples from neutropenic patients. J Clin Microbiol. 2003;41:1811-8.

55. Becker MJ, de Marie S, Willemse D, Verbrugh HA, Bakker-Woudenberg IA. Quantitative galactomannan detection is superior to $P C R$ in diagnosing and monitoring invasive pulmonary aspergillosis in an experimental rat model. J Clin Microbiol. 2000;38:1434-8.

56. Costa C, Costa JM, Desterke C, Botterel F, Cordonnier C, Bretagne S. Real-time PCR coupled with automated DNA extraction and detection of galactomannan antigen in serum by enzyme-linked immunosorbent assay for the diagnosis of invasive aspergillosis. $J$ Clin Microbiol. 2002;40:2224-7.

57. Kami M, Fukui T, Ogawa S, Kazuyama Y, Machida U, Tanaka Y, Kanda $Y$, Kashima, T, Yamazaki $Y$, Hamaki T, Mori Al, Akiyama H, Mutou Y, Sakamaki H, Osumi K, Kimura S, Hirai $H$. Use of real-time PCR on blood samples for the diagnosis of invasive aspergillosis. Clin Infect Dis. 2001;33:1504-12.

58. Montoya JM, Liesenfeld O. Toxoplasmosis. Lancet. 2004;363:1965-76.

59. Davis MA, Bottone EJ, Vlachos A, Burroughs $M H$. Unsuspected Toxoplasma gondii empyema in a bone marrow transplant reciepient. Clin Infect Dis. 2002;34:e37-9. 
60. Pomeroy C, Fillice GA. Pulmonary Toxoplasmosis: a review. Clin Infect Dis. 1992;14:863-70.

61. Bonilla CA, Rosa UW. Toxoplasma gondii pneumonia in patients with the acquired immunodeficiency syndrome: diagnosis by bronchoalveolar lavage. Southern Medical Journal. 1994;87:659-63.

62. Petersen $E$, Edvinsson $B$, Lundgren $B$, Benfeld $T$, Evengard $B$. Diagnosis of pulmonary infection with Toxoplasma gondii in immunocompromised HIV-positive patients by real-time PCR. Eur J Clin Microbiol Infect Dis. 2006;25:401-4.

63. Aubert $D$, Foudrinier F, Villena I, Pinon JM. Biava MF, Renoult E. PCR for diagnosis and follow-up of two cases of disseminated toxoplasmosis after kidney grafting. J Clin Microbiol. 1996;34:1347.

64. Sing $A$, Leitritz $L$, Roggenkamp $A$, Kolb $H J$, Szabados $A$, Fingerle $V$, Auterrieth $I B$, Heesemann J. Pulmonary Toxoplasmosis in bone marrow transplant recipients: report of two cases and review. Clin Infect Dis. 1999;29:429-33. 
Samenvatting 


\section{Samenvatting}

Longaandoeningen kunnen verschillende onderliggende oorzaken hebben. Hierbij kunnen infecties, immunologische processen, maligniteiten, omgevingsen werkgerelateerde factoren een rol spelen. Traditioneel worden deze ziektes gediagnosticeerd met behulp van laboratoriumtesten, longfunctietesten en radiologisch onderzoek eventueel met afname van een bronchoalveolaire lavage (BAL). In sommige gevallen zal getracht worden een histologische bevestiging te verkrijgen door middel van een longbiopt.

BAL is een veilige, beperkt invasieve en over het algemeen goed getolereerde methode voor het verkrijgen van cellulair en a-cellulair materiaal uit de onderste luchtwegen ${ }^{1,2}$.

In het diagnostisch traject van longziektes kan BAL dus gezien worden als een waardevolle aanvulling. Een zorgvuldige analyse van de in BAL-vloeistof aanwezige cellen plus de eventueel aanwezige a-cellulaire componenten kunnen, in combinatie met klinische en radiologische bevindingen, helpen om tot een diagnose te komen. De toepassing van BAL-vloeistof in het diagnostisch traject van longinfecties heeft zijn waarde inmiddels al bewezen ${ }^{3}$, met name bij verdenking op een beademingspneumonie $(V A P)^{4-6}$ en opportunistische infecties zoals Pneumocystis pneumonie $(P C P)^{7,8}$.

\section{BAL versus geïnduceerd sputum}

Zowel BAL-vloeistof als (geïnduceerd) sputum kunnen gebruikt worden in het diagnostisch traject van longziekten. Echter, met name bij infectieuze aandoeningen, bestaan er verschillen in gevoeligheid tussen de twee methodes. In het geval van PCP bijvoorbeeld, varieert de sensitiviteit van geïnduceerd sputum voor de microscopische diagnose PCP tussen 50 and $90 \%$, afhankelijk van de ervaring met de materiaalafname en de verwerking van het monster ${ }^{9,10}$. Door introductie van een polymerase ketting- reactie (PCR) voor de detectie van Pneumocystis jiroveci is de sensitiviteit van geïnduceerd sputum voor de diagnose PCP toegenomen ${ }^{11}$. Helaas is deze methode nog niet operationeel in alle Nederlandse ziekenhuizen. Een ander voorbeeld is de kwantitatieve kweek van BAL-vloeistof voor de diagnose VAP. Recent is er veel discussie ontstaan over de waarde hiervan. Met name de vraag of BAL-vloeistof nog steeds het materiaal van keuze is voor deze diagnose ${ }^{12,13}$. Desondanks heeft het gebruik van BAL-vloeistof in plaats van (geïnduceerd) sputum als voordeel dat er een kwaliteitscontrole beschikbaar is voor BAL-vloeistof (verkregen volume, totale celtelling, aanwezigheid van epitheel). Dit geeft de bevestiging dat het materiaal dat verwerkt wordt ook daadwerkelijk uit de lagere luchtwegen afkomstig is. Een ander voordeel is dat 
bij gebruik van BAL-vloeistof een differentiële celtelling voorhanden is. Dit biedt de mogelijkheid ook niet-infectieuze aandoeningen op te sporen ${ }^{14}$.

\section{Doel van de studie}

In dit proefschrift wordt het gebruik van BAL als een diagnosticum bij infectieuze longaandoeningen bij patiënten verdacht van een longinfectie beschreven. Het doel van de studies gepresenteerd in dit proefschrift was om te trachten de sensitiviteit van BAL-vloeistof als diagnosticum bij longinfecties te verbeteren en de tijd waarin dit gebeurt te verkorten. Hiertoe werden BALvloeistof gegevens verkregen van patiënten gedurende een periode vanaf 1998 tot 2005 bekeken.

In hoofdstuk 1 de algemene introductie, wordt de BAL procedure, verwerking van BAL-vloeistof in het laboratorium en de waarde van BAL bij infectieuze en niet-infectieuze aandoeningen die op VAP kunnen lijken beschreven. Verder wordt het gebruik van nucleïnezuur amplificatie technieken bij longinfecties in het algemeen kort besproken.

\section{Microscopie van BAL-vloeistof}

In hoofdstuk 2 werd het gebruik van polylysine gecoate glaasjes in de BAL diagnostiek geëvalueerd. Het gebruik van gecoate objectglaasjes zou zorgen voor een betere hechting van cellen aan het oppervlakte van de objectglaasjes. Om dit te testen voor BAL-vloeistof vergeleken we polylysine gecoate (PLC) glaasjes met conventionele objectglaasjes. In totaal werden twintig BALvloeistof monsters met een representatief aantal alveolaire macrofagen (Ams), lymfocyten (Lyms) en polymorfonucleaire neutrofiele granulocyten (PMNs) genomen. Van deze BAL-vloeistoffen werden cytospinpreparaten gemaakt op zowel conventionele als gecoate glaasjes. Met behulp van een May-Grünwald Giemsa kleuring werd gekeken naar de totale celopbrengst, de differentiële celtelling en de morfologie van de cellen. Klinische significantie van de eventueel aanwezige verschillen werden geëvalueerd door middel van een computerprogramma. Hieruit bleek dat de celopbrengst lager was indien gebruik werd gemaakt van de PLC glaasjes in vergelijking met de conventionele niet gecoate objectglaasjes. De opbrengst van Lyms was significant lager op de PLC glaasjes in vergelijking met de conventionele glaasjes $(25.89 \% \pm 28.26$ versus $28.34 \pm 29.96)$. De betrouwbaarheid van de telling van alveolar AMs, Lyms en PMNs was uitstekend voor beide type glaasjes. Er werden geen discrepanties gevonden in diagnose verkregen met 
beide type glaasjes. Wij concludeerden daarom dat PLC glaasjes niet superieur waren in vergelijking met conventionele glaasjes. Behalve een polylysine coating zijn nog enkele andere coatings beschreven in de literatuur ${ }^{15,16}$, vaak werden deze vergeleken met polylysine gecoate glaasjes. Polylysine gecoate glaasjes bleken in deze studies superieur te zijn in vergelijking met albumine- en gelatine-gecoate glaasjes. Aangezien uit onze studie echter bleek dat conventionele glaasjes zonder coating niet inferieur waren in vergelijking met polylysine gecoate glaasjes, en conventionele glaasjes bovendien goedkoper zijn, gaat onze voorkeur uit naar het gebruik van ongecoate glaasjes bij de opwerking van BAL-vloeistof in de dagelijkse praktijk.

\section{Reactieve pneumocyten type II}

Het doel van de studie, beschreven in hoofdstuk 3, was om het voorkomen van reactieve pneumocyten type II (RPII) in BAL-vloeistof vast te stellen. Daarnaast werd de associatie van deze cellen met klinische aandoeningen en de bijkomende cytologische bevindingen geëvalueerd. Alle opeenvolgende BALvloeistof monsters verkregen van patiënten in de periode tussen 2000 en 2004 werden geïncludeerd. De algemene prevalentie van RPII cellen binnen onze studiepopulatie was $21.7 \%$. Met betrekking tot de differentiële celtelling werden er geen verschillen gevonden tussen BAL-vloeistof monsters met en zonder RPII cellen. Echter, in BAL-vloeistof met RPII, werd vaker de aanwezigheid van schuimmacrofagen, geactiveerde lymfocyten en plasmacellen gezien. RPII werden geobserveerd in monsters van patiënten gediagnosticeerd met het ARDS, diffuse alveolaire beschadiging, acute eosinofiele pneumonie, extrinsiek allergische alveolitis of hypersensitiviteits pneumonitis, medicijn geassocieerde longafwijkingen, PCP en VAP. Er werden geen RPII cellen gevonden in BALvloeistof van patiënten met longtuberculose of sarcoïdose. Ondanks het feit dat RPII cellen niet pathognomonisch werden bevonden voor een specifieke ziekte, werden ze geassocieerd met ernstige longbeschadiging. In combinatie met de differentiële celtelling en specifieke morfologische bevindingen, zoals schuimmacrofagen, geactiveerde lymfocyten en plasmacellen zou de aanwezigheid van RPII cellen van toegevoegde waarde kunnen zijn in de differentiatie tussen interstitiële longziekten en longinfecties. 


\section{Beademingspneumonie}

Bij intensive care patiënten die beademd worden heeft VAP een hoge prevalentie $e^{17,18}$ en wordt geassocieerd met een hoge mortaliteit ${ }^{17}$. BAL-vloeistof analyse, inclusief differentiële celtelling en tellen van het percentage geïnfecteerde cellen (IC) wordt gebruikt in de diagnostiek naar VAP ${ }^{4,6}$. Echter, de invloed van antibiotica op de differentiële celtelling, inclusief IC, is nog onbekend. Studies die gekeken hebben naar dit onderwerp leverden verschillende resultaten op ${ }^{19-21}$. In hoofdstuk 4 werd daarom gekeken naar de invloed van antibiotica op het voorspellen van de aanwezigheid van een VAP. Deze prospectieve studie werd gedurende een periode van 61 maanden uitgevoerd (januari 1999 tot februari 2004). Alle opeenvolgend afgenomen BAL-vloeistof monsters van intensive care patiënten, klinische verdacht van VAP, werden geïncludeerd. Eerdere studies lieten zien dat de kwantitatieve kweek beïnvloed werd door antibiotische therapie gestart binnen 72 uur voordat de BAL werd uitgevoerd. De voornaamste conclusie uit onze studie was dat antibiotische therapie, gestart binnen 72 uur voor uitvoering van de $B A L$, de betrouwbaarheid van de telling van de $I C$ als voorspeller voor VAP niet beïnvloed. De cytologische parameter die de aanwezigheid van VAP het best voorspelde bleek het percentage IC te zijn indien een afkappunt van $2 \%$ werd gehanteerd. Het combineren van het percentage IC met andere cytologische parameters resulteerde niet in een betere voorspelling van VAP.

\section{A-cellulaire factoren in BAL}

Ondanks het feit dat de routinematige toepassing van BAL-vloeistof onderzoek een waardevol instrument in de identificatie van infectieuze en niet-infectieuze longaandoeningen is, wordt het toepassen ervan gelimiteerd. Het is namelijk een relatief dure en arbeidsintensieve methode en afhankelijk van gespecialiseerd personeel. In de meeste ziekenhuizen zijn faciliteiten voor cytologische bepalingen in BAL-vloeistof niet 24 uur per dag beschikbaar. Uit praktische overwegingen zijn we op zoek gegaan naar een snellere en meer betrouwbare methode om de aanwezigheid van een VAP te voorspellen die in de meeste ziekenhuizen uitvoerbaar is. Het gebruik van acute fase eiwitten leek veelbelovend ${ }^{22}$; bovendien kunnen deze testen 24 -uur per dag worden uitgevoerd in de meeste ziekenhuizen. Hoofdstuk 5 beschrijft de toepasbaarheid van C-reactief proteine (CRP) en procalcitonine (PCT) in het voorspellen van VAP. Zowel CRP als PCT werden bepaald in BAL-vloeistof en serum van patiënten met microbiologisch bewezen VAP. Als eerste werden de testen voor hoog gevoelige CRP (CRPH) en hoog gevoelige PCT (ProCa-S) gevalideerd voor gebruik op BAL-vloeistof, aangezien beide testen ontworpen 
werden voor gebruik op serum. Beide testen presteerden goed met betrekking tot matrix-effect, lineariteit en reproduceerbaarheid en werden toepasbaar geacht voor gebruik op BAL-vioeistof. Helaas was er een grote overlap tussen ProCa-S and CRPH concentraties in BAL-vbesstof monsters, maar ook in serum, van patiènten met en zonder VAP. Dit resulteerde in een klein gebied onder de curve bij de ROC curve. De voornaamste conclusie uit dit onderzoek was dan ook dat beide parameters, zowel in BAL-vbeistof als in serum, niet geschikt waren als voorspeller voor VAP. Echter, andere a-cellulaire parameters zijn wel nuttig gebleken in de diagnostiek van longziekten. Een snelle methode ter bevestiging of uitsluiting van VAP blijt noodzakelijk, deze dient beschikbaar te zijn in de meeste ziekenhuizen op elk moment van de dag. Een van de acellulaire parameters die in recente studies waardevol bleken is TREM-1. TREM-1 behoort tot de groep immunoglobuline superfamilie, een groep van celoppervlakte- en oplosbare eiwitten die betrokken zijn bij herkenning, binding of aanhechting van cellen ${ }^{23}$. Expressie van TREM-1 is aanwezig op neutrofielen en monocyten ${ }^{24}$, maar ook op alveolaire macrofagen ${ }^{25}$. De expressie van deze receptor wordt verhoogd in aanwezigheid van bacterièn en schimmels ${ }^{26}$, waardoor de acute inflammatoire respons op deze organismen in gang wordt gezet ${ }^{26}$. Voor de detectie van de oplosbare variant van dit eiwit, STREM-1, in bloed en sputum is er een enzyme-linked immuno sorbent assay (ELISA) op de markt, strikt voor onderzoeksdoeleinden (Human TREM-1 Quantikine kit, R\&D systems inc, Minneapolis, U.S.A.). Met behulp van deze kit kan in ongeveer 4 uur een resultaat gegenereerd worden. Enkele studies hebben gekeken naar de bruikbaarheid van STREM-1 bij de diagnostiek naar pneumonieën ${ }^{27.28}$. Onderzoek uitgevoerd door Gibot et $a{ }^{27}$ liet zien dat de aanwezigheid van sTREM-1 de beste voorspeller van pneumonie was in een groep van 148 patiënten. In deze studie waren 46 patiënten met een VAP geïncludeerd die een mini-BAL hadden ondergaan ${ }^{27}$. Zij vonden dat een afkappunt van $5 \mathrm{pg} / \mathrm{ml}$ de beste voorspeller was voor de aanwezigheid van een pneumonie. Helaas hielden zij er geen rekening mee dat BAL-vloeistof 10-100 keer verdund is ten opzichte van de situatie in de alveoli. Richeldi et al. onderzochten de bruikbaarheid van STREM-1 als een mogelijke marker voor communityacquired pneumonie en tuberculose ${ }^{28}$. Deze laatste studie liet zien dat sTREM-1 werd teruggevonden in BAL-vloeistof van patiënten met communityacquired pneumonie, maar niet bij patiënten met tuberculose. Zowel Gibot $e t$ $a .^{27}$ als Richeldi et al. ${ }^{28}$ gebruikten een andere methode dan de boven beschreven ELISA. Tot nu toe is deze ELISA slechts in een studie gebruikt met een gering aantal patienten verdacht van VAP $(n=28)^{29}$. Uit deze studie bleek sTREM-1 een uitstekende voorspeller van VAP te zijn, indien een afkappunt van $200 \mathrm{pg} / \mathrm{ml}$ werd gebruikt. Helaas hebben Determann et al. ${ }^{29}$ de kit niet gevalideerd voor gebruik op BAL-vloeistof en hebben ook zij geen rekening 
gehouden met de verdunningsfactor. Een validatie van de Humane TREM-1 Quantikine kit op BAL-vloeistof zou moeten gebeuren. Hierna zou de kit dan gebruikt kunnen worden in een prospectieve studie van intensive care patiënten verdacht van VAP. Het doel van deze nieuw op te zetten studie zou kunnen zijn de voorspellende waarde van STREM-1 bij het diagnosticeren van VAP te evalueren en uiteindelijk een afkappunt te definiëren dat een onderscheid maakt tussen VAP en non-VAP.

\section{Moleculaire technieken toegepast op BAL-vloeistof}

In het verleden was de standaard methode voor het aantonen van infectieuze oorzaken gebaseerd op kweek en serologie. Tegenwoordig wordt de detectie van veel micro-organismen gedaan met behulp van nucleïnezuur amplificatie methodes. Deze methodes zijn vaak superieur in vergelijking met conventionele methodes op het gebied van sensitiviteit en specificiteit. Deze moleculaire methodes, zoals de polymerase ketting reactie (PCR) kan ook een bijdrage leveren aan de opwerking van BAL bij verdenking op een infectieuze longaandoening. Hoofdstuk 6 en 7 beschrijven twee studies die betrekking hebben op de implementatie en interpretatie van PCR technieken op BALvloeistof.

\section{Detectie van $P$. jirovecidoor middel van real-time PCR}

De implementatie van een nieuwe diagnostische methode vergt altijd uitgebreide standaardisatie en validatie voordat een test in de dagelijkse praktijk kan worden geïntroduceerd. Een additioneel instrument dat gebruikt kan worden om een goede kwaliteit te waarborgen en dat bovendien eventuele gebreken van een test aan het licht kan brengen is een kwaliteitscontrole panel gedistribueerd door een coördinerende organisatie. Deze kwaliteitscontroles zijn echter niet voor alle micro-organismen voorradig, een voorbeeld is $P$. jiroveci. Real-time PCR methodes voor de detectie van $P$. jiroveci in respiratoire monsters zijn recent verschoven van onderzoeksdoeleinden naar de dagelijkse diagnostiek ${ }^{30,31}$. Aangezien een kwaliteitscontrole (nog) niet bestaat is de validatie, implementatie en vergelijking van resultaten tussen de laboratoria moeilijk. In hoofdstuk 6 wordt derhalve een studie beschreven die geïnitieerd werd om drie onafhankelijke in-huis ontwikkelde PCR testen voor de detectie van $P$. jiroveci vanuit drie verschillende academische ziekenhuizen in Nederland te vergelijken. Hiertoe werd een samenwerkingsverband opgezet tussen de academische ziekenhuizen van Nijmegen, Leiden en Maastricht. In 
de periode augustus 1999 tot april 2004 werden in totaal 124 BAL-vloeistof monsters geïncludeerd. Dit waren monsters verkregen van HIV-positieve of HIV-negatieve patiënten met een bekende risicofactor voor PCP, zoals een onderliggende (hematologische) maligniteit, status na beenmerg- of orgaan transplantatie, ziekte van Wegener, en immunosuppressieve en/of corticosteroïden therapie $(n=84)$. Daarnaast werden een aantal BAL-vloeistof monsters van patiënten zonder bekende risicofactoren voor PCP, maar met of een VAP of een recent gediagnosticeerde sarcoïdose geïncludeerd $(n=40)$. In 41 van de 124 BAL-vloeistof monsters waren $P$. jiroveci cysten en trophozoïten microscopisch zichtbaar. Van 114 monsters kwamen de PCR resultaten vanuit de drie verschillende laboratoria overeen. Veertig van de 41 microscopiepositieve monsters werden door de drie verschillende laboratoria met behulp van PCR positief bevonden. Van de 83 microscopie-negatieve monsters waren er 69 ook negatief met behulp van de PCRs. Van de andere 14 microscopienegatieve monsters, waren vijf positief in de drie ziekenhuizen. Er werd een hoge overeenkomst gevonden tussen de drie real-time PCR methodes voor $P$. jiroveci variërend van $94.4 \%$ (Kappa value: 0.88 ) tot $96.8 \%$ (Kappa value: 0.93). Aangezien $P$. jiroveci in lage hoeveelheden aanwezig kan zijn in de luchtwegen zonder dat er sprake is van ziekte (dragerschap) is het essentieel om onderscheid te maken tussen dragerschap en ziekte. De verwachting was dat bij een klinische PCP $P$. jiroveci in veel hogere hoeveelheden aanwezig zou zijn dan bij dragers. Helaas bleek er een overlap te bestaan tussen patiënten met microscopisch bevestigde $P C P$ en patiënten zonder (microscopisch bevestigde) PCP in termen van gevonden hoeveelheid $P$. jiroveci per ml BAL-vloeistof. Het was niet mogelijk om met behulp van deze retrospectieve studie een absoluut afkappunt te bepalen tussen ziekte en dragerschap.

\section{Verbetering klinische toepasbaarheid $P$. jiroveciPCR op BAL}

Verschillende strategieën zouden gebruikt kunnen worden om dit zogenaamde grijze gebied in de PCR te verkleinen. Een mogelijke strategie is het combineren van PCR resultaten met serologische indicatoren. Een tweetal bruikbare indicatoren zijn: serum lactate dehydrogenase (LDH) en $\beta$-D-glucan. $\mathrm{LDH}$ in BAL-vloeistof is zinvol gebleken in de differentiatie tussen infectieuze en niet-infectieuze aandoeningen ${ }^{32}$. Met name bij patiënten met PCP is LDH vaak verhoogd ${ }^{33-36}$. De studie van Zaman et $a l^{35}$ liet zien dat een serum LDH concentratie van 450 international units (IU) de aanwezigheid van PCP voorspelde in hun populatie. Quist et $a l^{33}$ onderzocht 42 patiënten met PCP, 71 met gedissemineerde tuberculose, 40 met longtuberculose en 37 met een 
bacteriële pneumonie. De LDH concentraties waren significant hoger bij patiënten met PCP vergeleken met andere groepen. Helaas bleek er een overlap te zijn in het gemeten LDH bij patiënten met PCP en de andere drie groepen, waardoor de specificiteit gelimiteerd werd $^{33}$. Een recente retrospectieve studie uitgevoerd door Tasaka et al. ${ }^{36}$ betrof 295 patiënten die een BAL ondergingen specifiek voor de diagnose PCP. Bij 57 patiënten werd $P C P$ bevestigd op basis van microscopische bevindingen van gesedimenteerde BAL-vloeistof. Zij vonden dat serum LDH concentraties significant hoger waren bij patiënten met PCP in vergelijking met patiënten met andere longaandoeningen. Een tweede serologische marker die interessant zou kunnen zijn is $\beta$-D-glucan, een onderdeel van de celwand van schimmels. Deze marker wordt al gebruikt in de diagnostiek naar invasieve schimmelinfectie zoals candidemie en invasieve aspergillose (IA). Tasaka et $a{ }^{36}$ evalueerde het gebruik van $\beta$-D-glucan in serum in de diagnostiek naar PCP. Zij vonden dat bij gebruik van een afkappunt van $31.1 \mathrm{pg} / \mathrm{ml} \beta$-D-glucan in serum, deze bepaling een sensitiviteit van $92.3 \%$ had met een specificiteit van $83.1 \%$. In die populatie leidde dit tot een positief voorspellende waarde (PPV) van 0.61 en een negatief voorspellende (NPV) waarde van 0.98 voor de diagnose PCP. De relatief lage NPV zou verklaard kunnen worden door andere invasieve schimmels zoals Candida species of Aspergillus species. Een tekortkoming van deze studie is het feit dat ze een minder gevoelige methode (microscopie van gesedimenteerde BAL-vloeistof) als gouden standaard gebruiken. Vooral het gebruik van cytospin preparaten kan de gevoeligheid verbeteren. Zij gebruiken als argument dat microscopie een PPV en een NPV boven de $90 \%$ heeft. Echter, onze ervaring leert dat dit alleen bereikt kan worden door ervaren laboratoriummedewerkers. Tasaka et $a l^{36}$ geven aan dat ze geen PCR gebruiken om PCP te diagnosticeren in verband met het mogelijk detecteren van dragers. De combinatie van PCR en $\beta$-D-glucan zou juist erg interessant kunnen zijn. Onze hypothese is dat, aangezien er geen weefselschade is bij dragerschap, er waarschijnlijk geen (of slechts een lage concentratie) $\beta$-D-glucan aantoonbaar is in het perifere bloed. Een studie die kijkt naar de combinatie van $\beta$-D-glucan in serum (and BAL-vloeistof) en de $P C R$ in BAL van patiënten met bewezen PCP, dragers en patiënten met een $P C R$ resultaat binnen de grijze zone en patiënten zonder klachten is wenselijk. Deze studie zou bij kunnen dragen aan het verkleinen van de grijze zone van de PCR en de waarde van $\beta$-D-glucan binnen de diagnostiek naar PCP bevestigen. 


\section{Detectie van HSV-1 in BAL-Vloeistof}

In hoofdstuk 7 hebben we de klinische relevantie van een hoge herpes simplex virus lading proberen te ontrafelen. De twee subtypes van humaan herpes simplex virus, HSV-1 en HSV-2, hebben een hoge prevalentie en zijn alomtegenwoordig. HSV-1 is beschreven als een (zeldzame) oorzaak van een pneumonie bij immunogecompromitteerde patiënten ${ }^{37,}{ }^{38}$. Echter, de klinische relevantie van HSV-1 en -2 detectie in BAL-vloeistof is tot op heden onduidelijk. Een mogelijke relatie tussen de HSV-1 and -2 hoeveelheid in BAL-vloeistof en de klinische uitkomst is onderzocht. Onze data laten zien dat HSV-1 in ongeveer een derde van alle BAL-vloeistof monsters afgenomen bij intensive care patiënten aanwezig is. Bovendien laat onze studie zien dat een hoeveelheid HSV-1 in BAL-vloeistof $>10^{5} \mathrm{ge} / \mathrm{ml}$ een onafhankelijke voorspeller is van een slechte prognose bij intensive care patiënten, weergegeven in een toegenomen mortaliteit met $21 \%$. De vraag is of hier een causaal verband is of dat er slechts sprake is van een marker van een ernstig verstoord immuunsysteem. Doordat de studie retrospectief werd uitgevoerd was het niet mogelijk om de invloed van aciclovir op de mortaliteit en morbiditeit te evalueren. De benodigde data voor het aantonen van een causaal verband zouden eventueel gegenereerd kunnen worden door middel van een prospectieve interventie studie die gebruik maakt van het afkappunt van $10^{5} \mathrm{ge} / \mathrm{ml}$ BAL-vloeistof. Als er werkelijk een causaal verband is tussen de hoeveelheid HSV-1 en de prognose van de patiënt, is het de verwachting dat behandeling met aciclovir van patiënten met een hoeveelheid HSV-1 boven de $10^{5}$ op zijn minst een reductie van de mortaliteit tot gevolg zou hebben.

\section{Virale pneumonie}

Natuurlijk is HSV niet het enige virus dat een pneumonie kan veroorzaken. Andere virussen die eenzelfde ziektebeeld kunnen veroorzaken ${ }^{3,39}$ zijn onder andere influenza virus $A, B$, para-influenza virus $1,2,3,4$, cytomegalovirus, varicella zoster virus, coronavirus, human respiratory syncytial virus (RSV) en rhinovirus. De laatste jaren is er met name veel aandacht geweest voor het humaan metapneumovirus (hMPV) als oorzaak voor een pneumonie. hMPV is een paramyxovirus dat in 2001 werd ontdekt in Nederland ${ }^{40}$. Een studie uitgevoerd door van den Hoogen et al. ${ }^{40}$ omvatte monsters afgenomen via nasopharyngeale aspiratie bij 28 jonge kinderen $(<5$ jaar). Deze kinderen hadden allemaal symptomen van luchtweginfecties die sterk leken op de symptomen veroorzaakt door RSV. Epidemiologisch gezien was er geen verband tussen deze kinderen ${ }^{40}$. De infectie lijkt een seizoensgebonden cyclus te volgen waarbij de meeste infecties gedurende de wintermaanden optreden 
(vergelijkbaar met infecties veroorzaakt door $\mathrm{RSV}^{41}$ ). In de meeste studies wordt gebruik gemaakt van een reverse transcriptase PCR (RT-PCR) voor de detectie van hMPV RNA in respiratoire monsters ${ }^{42-45}$. Het is mogelijk om het virus te kweken, het groeit langzaam op tertiaire apeniercelle ${ }^{40,43}$ en laat een slechte groei zien in Vero cellen en A549 cellen waarbij het cytopathogeen effect sterk lijkt op dat van $\mathrm{RSV}^{40}$. Sinds de ontdekking van het virus zijn er verschillende publicaties verschenen betreffende zijn rol in luchtweginfecties bij jonge kinderen ${ }^{39,40,44,46}$, ouderen $n^{42}$ en immuungecompromitteerde patiënten ${ }^{42,45}$. Aangezien het virus in verschillende patiëntengroepen beschreven is, speelt het mogelijk ook een rol bij geïntubeerde patiënten op de intensive care. Tot nu toe is er slechts een studie gepubliceerd waarbij volwassen intensive care patiënten tot de studiepopulatie behoorden ${ }^{43}$. De studie van Gray et $a l^{43}$ omvatte 1500 respiratoire monsters $(75 \%$ afgenomen door middel van nasale lavage, slechts $10 \%$ was BAL-vloeistof) van 1294 patiënten. Met behulp van RT-PCR vonden ze $34 \mathrm{hMPV}$ positieve patiënten. Tussen deze 34 patiënten waren ook 9 volwassen patiënten met verschillende onderliggende aandoeningen zoals maligniteiten $(n=2)$, obstructieve bronchitis $(n=2)$, bacteriële pneumonie $(n=1)$, influenza $(n=1)$ en respiratoir falen van onbekende origine $(n=3)$. Een aantal patiënten opgenomen op onze intensive care afdeling ontwikkelden bijkomende respiratoire problemen tijdens beademing. Aangezien slechts $25-33 \%$ verklaard kon worden door een bacteriële infectie was onze hypothese dat een aantal gevallen geassocieerd zijn met een virale infectie. Om deze hypothese te toetsen zou gebruik gemaakt kunnen worden van een respiratoire multiplex PCR (inclusief hMPV) voor de opsporing van bijkomende virale oorzaken van de verslechtering van patiënten tijdens intensive care opname. Bovenstaande zou ook van toepassing kunnen zijn voor patiënten opgenomen op de hematologie-oncologie afdeling met tekenen van een luchtweginfectie. De analyse van BAL-vloeistof monsters afgenomen bij deze patiënten leidt vaak niet tot de identificatie van een oorzakelijk microorganisme. Door hun onderliggende aandoening en bijbehorende therapie (chemotherapie) hebben deze patiënten vaak geen (functionele) granulocyten. Dit maakt ze extra vatbaar voor allerlei (long) infecties. Naast bacteriële en virale verwekkers en schimmels moet bij deze patiënten ook gedacht worden aan parasitaire infecties ${ }^{3}$. Het voordeel van een snelle en gevoelige methode voor de opsporing van deze micro-organismen is vooral duidelijk indien een behandeling voorhanden is. Een voorbeeld is Aspergillus fumigatus, deze schimmel is berucht vanwege het veroorzaken van levensbedreigende longinfecties bij immuungecompromitteerde patiënten ${ }^{47}$ en zeldzaam ook in immuuncompetente patiënten ${ }^{48}$. Invasieve aspergillose (IA) wordt geassocieerd met een hoge mortaliteit die varieert van $30-80 \%{ }^{49,50}$. Dit is afhankelijk van de snelheid waarmee de diagnose gesteld wordt en de start van therapie. De diagnose IA is moeilijk aangezien klinische symptomen en radiologische 
beelden vaak aspecifiek zijn. Tot op heden wordt de uiteindelijke diagnose histologisch gesteld ${ }^{51}$. Kweek van BAL-vloeistof of longbiopten is erg specifiek voor het aantonen van Aspergillus in de long, echter de gevoeligheid is erg laag $(30-50 \%)^{52}$. De laatste jaren heeft de detectie van galactomannan, een onderdeel van de celwand van $A$. fumigatus, in BAL-vloeistof en serum een bijdrage geleverd aan een vroege diagnose van $I^{53}$. PCR methodes voor de detectie van $A$. fumigatus in respiratoire monsters zijn ook beschreven in de literatuur $^{54,55}$. Tot op heden hebben studies die de $A$. fumigatus PCR vergelijken met de bepaling van galactomannan geleid tot tegenstrijdige resultaten. Becker et al. ${ }^{56}$ maakte gebruik van een diermodel om IA te bestuderen. In hun studie bleek de kwantitatieve galactomannan superieur boven de PCR in zowel serum als BAL-vloeistof. Een studie uitgevoerd door Costa et al. ${ }^{57}$ waarin de detectie van galactomannan vergeleken werd met de $P C R$ in serum van patiënten liet vergelijkbare resultaten zien. De studie van Kami et al. ${ }^{58}$ liet een hogere sensitiviteit en specificiteit zien voor de PCR in vergelijking met de galactomannan in serum van patiënten met IA. Elk van deze drie studies gebruikte dezelfde ELISA voor de detectie van galactomannan in hun monsters. De PCR methodes waren echter zeer verschillend. In een studie werd een conventionele PCR gebruikt ${ }^{56}$, terwijl in de anderen gebruik werd gemaakt van een real-time $P C R^{57,58}$. De DNA isolatie, het target en de gebruikte apparatuur verschilden tussen de drie studies. Voor een deel zou dit de verschillende uitkomsten kunnen verklaren. De combinatie van een real-time PCR en de ELISA voor de detectie van galactomannan zou een toegevoegde waarde kunnen hebben in de IA diagnostiek.

\section{BAL diagnostiek bij immuungecompromitteerde patiënten}

Zoals eerder al gesteld werd, horen ook parasitaire aandoeningen van de luchtwegen in de differentiaal diagnose van luchtweginfecties bij immuungecompromitteerde patiënten. Een van de mogelijke verwekkers is Toxoplasma gondii. T. gondii is een intracellulaire parasiet die alomtegenwoordig is. $\mathrm{Na}$ de acute, bij immuuncompetente gastheren vaak asymptomatische, fase van infectie, blijven bradyzoïten aanwezig in het menselijk lichaam. Bij immuungecompromitteerde patiënten heeft de parasiet de neiging om te reactiveren en een gedissemineerde ziekte te veroorzaken ${ }^{59}$, ${ }^{60}$. Een longinfectie met $T$. gondii wordt geassocieerd met een mortaliteit boven de $50 \%{ }^{61}$. De diagnose kan worden gesteld op een manier die vergelijkbaar is met de diagnostiek van $P$. jiroveci, namelijk door microscopische analyse van BAL-vloeistof ${ }^{62}$. Echter, aangezien de patiënten die risico lopen op een $T$. gondii infectie dezelfde zijn als de patiënten die tot de risicogroep voor PCP 
behoren, hebben deze patiënten vaak al PCP profylaxe (co-trimoxazol). Cotrimoxazol is ook effectief tegen $T$. gondii, waardoor de hoeveelheid $T$. gondii aanwezig in BAL-vloeistof beïnvloed kan worden, net zoals de hoeveelheid $P$. jiroveci in BAL-vloeistof beïnvloed wordt. Deze invloed zou net voldoende kunnen zijn om de parasiet niet te kunnen detecteren door middel van microscopie, maar net onvoldoende om te beschermen tegen een gedissemineerde $T$. gondii infectie ${ }^{63}$. Om de detectie van $T$. gondii in BALvloeistof te verbeteren zou het gebruik van een PCR nuttig kunnen zijn ${ }^{64}$. Petersen et al. ${ }^{63}$ bestudeerden 332 BAL-vloeistof monsters van 290 HIV positieve patiënten door middel van een real-time PCR. Zij vonden $T$. gondii DNA bij 7 patiënten, resulterend in een prevalentie van $2 \%$. Aangezien toxoplasmosis niet alleen geschreven wordt bij HIV positieve patiënten, maar ook bij andere immuungecompromitteerde patiënten ${ }^{65}$, zou de toevoeging van een T. gondii PCR in het diagnostische traject van BAL-vloeistof zinvol kunnen zijn. Om dit te evalueren zouden BAL-vloeistof monsters van immuuncompetente en immuungecompromitteerde patiënten (zowel HIV-positief als negatief) onderzocht moeten worden op de aanwezigheid van $T$. gondii DNA door middel van een real-time PCR. Dit zou kunnen leiden tot een toename van gediagnosticeerde $T$. gondii longinfecties en daaropvolgende behandeling met hoge dosis co-trimoxazol. 


\section{Samenvattend}

1. Object glaasjes gecoat met polylysine zijn niet superieur in vergelijking met conventionele niet-gecoate glaasjes in de opwerking van bronchoalveolaire lavage vloeistof.

2. Onder normale omstandigheden zijn reactieve pneumocyten type II niet aanwezig in bronchoalveolaire lavage vloeistof.

3. De aanwezigheid van reactieve pneumocyten type II is geassocieerd met aandoeningen waarbij er sprake is van een acute alveolaire schade zoals bij extrinsiek allergische alveolitis en drug-induced longaandoeningen, pneumocysten pneumonie en beademingspneumonie.

4. Antibioticatherapie gedurende de 72 uur voor afname van bronchoalveolaire lavage vloeistof beïnvloedt de voorspellende waarde van de cytologische parameters voor de microscopisch gestelde diagnose beademingspneumonie niet.

5. Van de cellen aanwezig in bronchoalveolaire lavage vloeistof is het percentage geïnfecteerde cellen de belangrijkste parameter voor de differentiatie tussen de aan- en afwezigheid van een beademingspneumonie.

6. Het beste afkappunt voor het percentage geïnfecteerde cellen is $2 \%$ indien gebruik wordt gemaakt van een gestandaardiseerde methode. Het combineren van het percentage geïnfecteerde cellen met andere parameters leverde geen verbetering op van de voorspellende waarden.

7. De drie verschillende in-house real-time polymerase ketting reactie testen voor de detectie van P. jiroveci ontwikkeld in de academische ziekenhuizen van Leiden, Nijmegen en Maastricht laten een uitstekende overeenkomst zien.

8. P. jiroveci kwantitatief bepaald door middel van real-time polymerase ketting reactie en microscopische kwantificatie leveren vergelijkbare resultaten op.

9. Op dit moment is een absoluut afkappunt voor differentiatie tussen ziekte en dragerschap van P. jiroveci niet te geven door aanwezigheid van een grijs gebied.

10. In $32 \%$ van alle bronchoalveolaire lavage vloeistof monsters afgenomen bij intensive care patiënten, wordt herpes simplex type 1 teruggevonden in de bronchoalveolaire lavage vloeistof met behulp van polymerase ketting reactie.

11. Een hoeveelheid herpes simplex type 1 in bronchoalveolaire lavage vloeistof boven $10^{5} \mathrm{ge} / \mathrm{ml}$ is een onafhankelijke voorspeller voor een slechte prognose bij intensive care patiënten. 


\section{Voorstellen voor toekomstig onderzoek:}

Dit proefschrift onderstreept de waarde van BAL-vloeistof in het diagnostisch traject van infectieuze longinfecties. Vooral de toevoeging van moleculaire methoden zal de diagnostische mogelijkheden en de sensitiviteit van BAL in de diagnostiek naar infectieziektes doen toenemen. Toekomstige studies zijn nodig om:

1. de bruikbaarheid van de humane TREM-1 Quantikine kit op bronchoalveolaire lavage vloeistof te valideren

2. de bruikbaarheid van de humane TREM-1 Quantikine kit te evalueren als voorspeller voor aan- of afwezigheid van een beademingspneumonie.

3. nieuw geïntroduceerde technieken te verfijnen zoals de $P$. jiroveci $P C R$, door het grijze gebied te verkleinen. Dit zou namelijk een verbetering van de klinische toepasbaarheid betekenen. Twee mogelijke strategieën zouden kunnen zijn:

a. de detectie van LDH in zowel bronchoalveolaire lavage vloeistof en serum.

b. de detectie van $\beta$-D-glucan in zowel bronchoalveolaire lavage vloeistof en serum

4. evaluatie van het herpes simplex type 1 polymerase ketting reactie afkappunt van $10^{5} \mathrm{ge} / \mathrm{ml}$ in een prospectieve interventie studie.

5. evaluatie van de klinische toepasbaarheid van een respiratoire multiplex PCR (inclusief humaan metapneumovirus) bij patiënten met een respiratoire achteruitgang terwijl ze beademd worden op de intensive care.

6. evaluatie van de klinische toepasbaarheid van een respiratoire multiplex PCR (inclusief humaan metapneumovirus) bij patiënten opgenomen op de hematologie/oncologie afdeling met tekenen van een luchtweginfectie.

7. evaluatie van de combinatie van een Aspergillus fumigatus specifieke realtime polymerase ketting reactie en de enzyme-linked immuno sorbent assay voor de detectie van circulerende galactomannan in zowel BALvloeistof en serum van patiënten verdacht van een invasieve Aspergillose.

8. evaluatie van de klinische waarde van een $T$. gondii real-time polymerase ketting reactie op bronchoalveolaire lavage vloeistof van immuungecompromitteerde patiënten verdacht van een luchtweginfectie.

Concluderend, onderzoek van BAL-vloeistof is zeer waardevol in het diagnostisch traject van luchtweginfecties. Met name de toevoeging van moleculaire technieken voor virale pathogenen, schimmels en parasieten zal een toename opleveren van aangetoonde infecties. Dit zal vervolgens leiden een toename van de kosteneffectiviteit en een verbetering van de patiëntenzorg door gerichte therapie. 


\section{Referenties}

1. Klech H, Hutter C. Side-effects and safety of BAL. Eur Respir J. 1990;3:939-40, 961-9.

2. Goldstein RA, Rohatgi PK, Bergofsky EH, Block ER, Daniele RP, Dantzker DR, Davis GS, Hunninghake GW, King TE, Metzger WJ. Clinical role of bronchoalveolar lavage in adults with pulmonary disease. Am Rev Respir Dis. 1990;142:481-6.

3. Joos L, Chhajed PN, Wallner J, Battegay M, Steiger J, Gratwohl A, Tamm M. Pulmonary infections diagnosed by BAL: A 12-year experience in 1066 immunocompromised patients. Respiratory medicine. 2007;101:93-7.

4. Allaouchiche $B$, Jaumain $H$, Dumontet $C$, Motin J. Early diagnosis of ventilator-associated pneumonia. Is it possible to define a cutoff value of infected cells in BAL fluid? Chest. 1996;110:1558-65.

5. Baselski V. Microbiologic diagnosis of ventilator-associated pneumonia. Infect Dis Clin North Am. 1993;7:331-57.

6. Kirtland SH, Corley DE, Winterbauer RH, Springmeyer SC, Casey KR, Hampson NB, Dreis DF. The diagnosis of ventilator-associated pneumonia: a comparison of histologic, microbiologic, and clinical criteria. Chest. 1997;112:445-57.

7. Armbruster C, Pokieser L, Hassl A. Diagnosis of Pneumocystis carinii pneumonia by bronchoalveolar lavage in AIDS patients. Comparison of Diff-Quik, fungifluor stain, direct immunofluorescence test and polymerase chain reaction. Acta Cytol. 1995;39:1089-93.

8. Baughman RP. Current Methods of Diagnosis. In: Walzer PD, editor. Pneumocystis carinii pneumonia. New York: Marcel Dekker, Inc. 1994:381-401.

9. Bigby TD, Margolskee D, Curtis JL, Michael PF, Sheppard D, Hadley WK, Hopewell PC. The usefulness of induced sputum in the diagnosis of Pneumocystis carinii pneumonia in patients with the acquired immunodeficiency syndrome. Am Rev Respir Dis. 1986;133:515-8.

10. Kovacs JA, Ng VL, Masur H, Leoung G, Hadley WK, Evans G, Lane HC, Ognibene FP, Shelhamer J, Parrillo JE. Diagnosis of Pneumocystis carinii pneumonia: improved detection in sputum with use of monoclonal antibodies. N Engl J Med. 1988;318:589-93.

11. Turner D, Schwartz $Y$, Yust I. Induced sputum for diagnosing Pneumocystis carinii pneumonia in HIV patients: new data, new issues. Eur Respir J. 2003;21:204-8.

12. Fagon $J Y$, Chastre $J$, Rouby $J J$. Is bronchoalveolar lavage with quantitative cultures a useful tool for diagnosing ventilator-associated pneumonia? Crit Care. 2007;11:123.

13. A randomized trial of diagnostic techniques for ventilator-associated pneumonia. $N$ Engl $J$ Med. 2006;355:2619-30.

14. Jacobs JA, De Brauwer El, Ramsay G, Cobben NA, Wagenaar SS, van der Ven AJ, Bruggeman $C A$, Drent $M$. Detection of non-infectious conditions mimicking pneumonia in the intensive care setting: usefulness of bronchoalveolar fluid cytology. Respir Med. 1999;93:571 8.

15. van Oostenbrugge RJ, Arends JW, Buchholtz R, Twijnstra A. Cytology of cerebrospinal fluid. Are polylysine-coated slides useful? Acta Cytol. 1997;41:1510-2.

16. Husain OA, Millett JA, Grainger JM. Use of polylysine-coated slides in preparation of cell samples for diagnostic cytology with special reference to urine sample. J Clin Pathol. 1980;33:309-11.

17. Chastre J, Fagon JY. Ventilator-associated pneumonia. Am J Respir Crit Care Med. 2002;165:867-903.

18. Rello J, Ollendorf DA, Oster G, Vera-Llonch M, Bellm L, Redman R, Kollef MH. Epidemiology and outcomes of ventilator-associated pneumonia in a large US database. Chest. 2002;122:2115-21.

19. Timsit JF, Misset B, Goldstein FW, Vaury P, Carlet J. Reappraisal of distal diagnostic testing in the diagnosis of ICU-acquired pneumonia. Chest. 1995;108:1632-9.

20. Sirvent JM, Vidaur L, Gonzalez S, Castro P, de Batlle J, Castro A, Bonet A. Microscopic examination of intracellular organisms in protected bronchoalveolar mini-lavage fluid for the diagnosis of ventilator-associated pneumonia. Chest. 2003;123:518-23. 
21. Dotson RG, Pingleton SK. The effect of antibiotic therapy on recovery of intracellular bacteria from bronchoalveolar lavage in suspected ventilator-associated nosocomial pneumonia. Chest. 1993;103:541-6.

22. Duflo F, Debon R, Goudable J, Chassard D, Allaouchiche B. Alveolar and serum oxidative stress in ventilator-associated pneumonia. Br J Anaesth. 2002;89:231-6.

23. Bouchon A, Dietrich $J$, Colonna $M$. Inflammatory responses can be triggered by TREM-1, a novel receptor expressed on neutrophils and monocytes. J Immunol. 2000;164:4991-5.

24. Gingras MC, Lapillonne $H$, Margolin JF. TREM-1, MDL-1, and DAP12 expression is associated with a mature stage of myeloid development. Mol immunol. 2002;38:817-24.

25. Colonna M, Facchetti $F$. Triggering receptor expressed on myeloid cells: role in the diagnosis of lung infections. Eur Respir J. 2004:24:247-50.

26. Bouchon A, Facchetti $F$, Weigand MA, Colonna M. TREM-1 amplifies inflammation and is a crucial mediator of septic shock. Nature. 2001:410:1103-7.

27. Gibot S, Cravoisy A, Levy B, Bene MC, Faure G, Bollaert PE. Soluble triggering receptor expressed on myeloid cells and the diagnosis of pneumonia. N Engl J Med. 2004;350:451-8.

28. Richeldi L, Mariani M, Losi M, Maselli F, Corbetta L, Buonsanti $C$, Colonna M, Sinigaglia F, Panina-Bordignon P, Fabbri LM. Triggering receptor expressed on meloid cells: role in the diagnosis of lung infections. Eur Respir J. 2004;24:247-50.

29. Determann RM, Millo JL, Gibot S, Korevaar JC, Vroom MB, van der Poll T, Garrard CS, Schultz MJ. Serial changes in soluble triggering receptor expressed on myeloid cells in the lung during development of ventilator-associated pneumonia. intensive Care Med. 2005;31:1495-1500

30. Flori P, Bellete B, Durand F, Raberin H, Cazorla $C$, Hafid J, Lucht F, Sung RT. Comparison between real-time PCR, conventional PCR and different staining techniques for diagnosing Pneumocystis jiroveci pneumonia from bronchoalveolar lavage specimens. J Med Microbiol. 2004;53:603-7.

31. Larsen $H H$, Huang $L$, Kovacs JA, Crothers $K$, Silcott VA, Morris A, Turner JR, Beard CB, Masur $\mathrm{H}$. Fischer $\mathrm{SH}$. A prospective, blinded study of quantitative touch-down polymerase chain reaction using oral-wash samples for diagnosis of Pneumocystis pneumonia in HIVinfected patients. J Infect Dis. 2004;189:1679-83.

32. Cobben NA, Jacobs JA, van Dieijen-Visser MP, Mulder PG, Wouters EF, Drent M. Diagnostic value of BAL fluid cellular profile and enzymes in infectious pulmonary disorders. Eur Respir J. 1999;14:496-502.

33. Quist J, Hill AR. Serum lactate dehydrogenase (LDH) in Pneumocystis carinii pneumonia, tuberculosis and bacterial pneumonia. Chest. 1995;108:415-8.

34. Silverman BA, Rubinstein A. Serum lactate dehydrogenase leels in adults and children with acquired immune deficiency syndrome (AIDS) and AIDS-related complex: possible indicator of B cell lymphoproliferation and disease activity. Am J Med. 1985;78:728-36.

35. Zaman MK, White DA. Serum lactate dehydrogenase levels and Pneumocystis carinil pneumonia. Diagnostic and prognostic significance. Am Rev Respir Dis. 1988;137:796-800.

36. Tasaka $S$, Hasegawa $N$, Kobayashi $S$, Yamada $W$, Nishimura $T$, Takeuchi $T$, Ischizaka $A$. Serum indicators for the diagnosis of Pneumocystis pneumonia. Chest. 2007;131:1173-80.

37. Byers RJ, Hasleton PS, Quigley A, Dennett C, Klapper PE, Cleator GM, Faragher EB. Pulmonary herpes simplex in burns patients. Eur Respir J. 1996;9:2313-7.

38. Arata $K$, Sakata $R$, Iguro $Y$, Toda $R$, Watanabe $S$, Eitsuru $Y$. Herpes simplex viral pneumonia after coronary artery bypass grafting. Jpn J Thorac Cardiovasc Surg. 2003;51:158-9.

39. Pierangeli A, Gentile M, Di Marco P. Pagnotti P, Scagnolari C, Trombetti S, Lo Russo L, Tromba V, Moretti $C$, Midulla F, Antonelli $G$. Detection and typing by molecular techniques of respiratory viruses in children hospitalized for acute respiratory infection in Rome, Italy. j Med Virol. 2007;79:463-8.

40. van den Hoogen BG, de Jong JC, Groen J, Kuiken T, de Groot R, Fouchier RAM, Osterhaus $A D M E$. A newly discovered human pneumovirus isolated from young children with respiratory tract disease. Nature Medicine. 2001;7:719-24. 
41. Wilkesmann $A$, Schildgen $O$, Eis-Hubinger AM, Geikowski T, Glatzel $T$, Lentze MJ, Bode U, Simon A. Human metapneumovirus infections cause similar symptoms and clinical severity as respiratory syncytial virus infections. Eur J Pediatr. 2006;165:467-75.

42. Carr MJ, McCormack GP, Crowley $B$. Human metapneumovirus-associated respiratory tract infections in the Republic of Ireland during the influenza season of 2003-2004. Clin Microbiol Infect. 2005;11:366-71.

43. Gray GC, Capuano AW, Setterquist SF, Erdman DD, Nobbs ND, Abed Y, Doern GV, Starks $S E$, Boivin G. Multi-year study of human metapneumovirus infection at a large US midwestern medical referral center. J Clin Virol. 2006;37:269-76.

44. Esper F, Martinello A, Boucher BA, Weibel C, Ferguson D, Landry ML. A 1-year experience with human metapneumovirus in children aged $<5$ years. J Infect Dis. 2004;189:1388-96.

45. Englund JA, Broeckh M, Kuypers J, Nichols WG, Hackman RC, Morrow RA, Fredricks SDN, Corey L. Brief communication: fatal human metapneumovirus infection in stem-cell transplant recipients. Ann Intern Med. 2006;144:344-9.

46. Esper F, Boucher BA, Weibel C, Martinello RA, Kahn JS. Human metapneumovirus infection in the United State: clinical manifestations associated with a newly emerging respiratory infection in children. Pediatrics. 2003;111:1407-9.

47. Soubani AO, Chandrasekar PH. The clinical spectrum of pulmonary Aspergillosis. Chest. 2002;121:1988-99.

48. Dijkman WM, Postma BH. Fatal invasive Aspergillosis in an apparently immunocompetent host. Netherlands Jounal of Critical Care. 2006;10:536-7.

49. Wald A, Leisenring W, van Burik JA, Bowden RA. Epidemiology of Aspergillus infections in a large cohort of patients undergoing bone marrow transplantation. J Infect Dis. 1997;175: 1459-66.

50. McWinney PH, Kibbler CC, Hamon MD, Smith OP, Gandhi L, Berger LA, Walesby RK, Hoffbrand AV, Prentice HG. Progress in the diagnosis and management of aspergillosis in bone marrow transplantation: 13 years' experience. Clin Infect Dis. 1993;17:397-404.

51. Ruhnke M, Bohme A, Buchheidt D, Donhuijsen $K$, Einsele $H$, Enzensberger R. Diagnosis of invasive fungal infections in hematology and oncology--guidelines of the Infectious Diseases Working Party (AGIHO) of the German Society of Hematology and Oncology (DGHO). Ann Hematol. 2003;82(Suppl 2):S141-8.

52. Kahn FW, Jones JM, England DM. The role of bronchoalveolar lavage in the diagnosis of invasive pulmonary aspergillosis. Am J Clin Pathol. 1986;84:518-23.

53. Verweij PE, Stynen D, Rijs AJ, de Pauw BE, Hoogkamp-Korstanje JA, Meis JF. Sandwich enzyme-linked immunosorbent assay compared with Pastorex latex agglutination test for diagnosing invasive aspergillosis in immunocompromised patients. J Clin Microbiol. 1995;33:1912-4.

54. Rantakokko-Jalava K, Laaksonen S, Issakainen J, Vauras J, Nikoskelainen J, Viljanen MK, Salonen J. Semiquantitative detection by real-time PCR of Aspergillus fumigatus in bronchoalveolar lavage fluids and tissue biopsy specimens from patients with invasive aspergillosis. J Clin Microbiol. 2003;41:4304-11.

55. Spiess B, Buchheidt D, Baust C, Skladny H, Seifarth W, Zeilfelder U, Leib-Mosch C, Morz $H$, Hehlmann R. Development of a LightCycler PCR assay for detection and quantification of Aspergillus fumigatus DNA in clinical samples from neutropenic patients. J Clin Microbiol. 2003;41:1811-8.

56. Becker MJ, de Marie S, Willemse D, Verbrugh HA, Bakker-Woudenberg IA. Quantitative galactomannan detection is superior to $P C R$ in diagnosing and monitoring invasive pulmonary aspergillosis in an experimental rat model. J Clin Microbiol 2000;38:1434-8.

57. Costa C, Costa JM, Desterke C, Botterel F, Cordonnier C, Bretagne S. Real-time PCR coupled with automated DNA extraction and detection of galactomannan antigen in serum by enzyme-linked immunosorbent assay for the diagnosis of invasive aspergillosis. $\mathrm{J}$ Clin Microbiol 2002;40:2224-7. 
58. Kami M, Fukui $T$, Ogawa $S$, Kazuyama $Y$, Machida U, Tanaka $Y$, Kanda $Y$, Kashima, $T$, Yamazaki $Y$, Hamaki T, Mori Al, Akiyama $H$, Mutou Y, Sakamaki H, Osumi K, Kimura S, Hirai $\mathrm{H}$.et al. Use of real-time PCR on blood samples for the diagnosis of invasive aspergillosis. Clin Infect Dis. 2001;33:1504-12.

59. Montoya JM, Liesenfeld $O$. Toxoplasmosis. Lancet. 2004;363:1965-76.

60. Davis MA, Bottone EJ, Vlachos A, Burroughs MH. Unsuspected Toxoplasma gondii empyema in a bone marrow transplant reciepient. Clin Infect Dis. 2002;34:e37-9.

61. Pomeroy C, Fillice GA. Pulmonary Toxoplasmosis: a review. Clin Infect Dis. 1992;14:863-70.

62. Bonilla CA, Rosa UW. Toxoplasma gondii pneumonia in patients with the acquired immunodeficiency syndrome: diagnosis by bronchoalveolar lavage. Southern Medical Journal. 1994;87:659-63.

63. Petersen $E$, Edvinsson $B$, Lundgren $B$, Benfeld $T$, Evengard $B$. Diagnosis of pulmonary infection with Toxoplasma gondii in immunocompromised HIV-positive patients by real-time PCR. Eur J Clin Microbiol Infect Dis. 2006;25:401-4.

64. Aubert D, Foudrinier F, Villena I, Pinon JM, Biava MF, Renoult E. PCR for diagnosis and follow-up of two cases of disseminated toxoplasmosis after kidney grafting. $\mathrm{J}$ Clin Microbiol. 1996;34:1347.

65. Sing A, Leitritz $L$, Roggenkamp $A$, Kolb $H J$, Szabados A, Fingerle $V$, Auterrieth $B$, Heesemann J. Pulmonary Toxoplasmosis in bone marrow transplant recipients: report of two cases and review. Clin Infect Dis. 1999;29:429-33. 


\section{List of abbreviations}




\section{List of abbreviations}

$\begin{array}{ll}\text { AIDS } & \text { Acquired immunodeficiency syndrome } \\ \text { AMs } & \text { Alveolar macrophage } \\ \text { ARDS } & \text { Acute respiratory distress syndrome } \\ \text { AUC } & \text { Area under the curve } \\ \text { BAL } & \text { Bronchoalveolar lavage } \\ \text { BALF } & \text { Bronchoalveolar lavage fluid } \\ \text { BOOP } & \text { Bronchitis obliterans with organizing pneumonia } \\ \text { CFU } & \text { Colony Forming Units } \\ \text { CI } & \text { Confidence interval } \\ \text { CRP } & \text { C-reactive protein } \\ \text { CRPH } & \text { High sensitive C-reactive protein } \\ \text { C } & \text { Threshold cycle } \\ \text { DNA } & \text { Desoxyribo nucleic acid } \\ \text { DHPS } & \text { Diphydroperoate synthase gene } \\ \text { ELF } & \text { Epithelial lining fluid } \\ \text { ELISA } & \text { Enzyme linked immuno sorbent assay } \\ \text { EOS } & \text { Eosinophil } \\ \text { ERS } & \text { European Respiratory Society } \\ \text { FACs } & \text { Foamy alveolar casts } \\ \text { HAART } & \text { Highly active antiretroviral therapy } \\ \text { HIV } & \text { Human immunodeficiency virus } \\ \text { HMPV } & \text { Human metapneumovirus } \\ \text { HSV } & \text { Herpes simplex virus } \\ \text { HSV-1 } & \text { Herpes simplex virus type 1 } \\ \text { HSV-2 } & \text { Herpes simplex virus type 2 } \\ \text { IA } & \text { Invasive Aspergillosis } \\ \text { IC } & \text { Infected cells } \\ \text { ICU } & \text { Intensive Care Unit } \\ \text { ILD } & \text { Interstitial lung disease } \\ \text { IU } & \text { International units } \\ \text { LDH } & \text { Lactate dehydrogenase } \\ \text { LPS } & \text { Lipopolysaccheride } \\ \text { Lyms } & \text { Lymphocyte } \\ \text { LUMC } & \text { Leids university medical center } \\ \text { MCs } & \text { Mast cell } \\ \text { MGG } & \text { May-Grünwald Giemsa } \\ \text { MINC } & \text { Maastricht infection center } \\ \text { MSG } & \text { Major Surface Glycoprotein } \\ \text { OR } & \text { Odds ratio } \\ \text { PCs } & \text { Plasma cell } \\ & \end{array}$




$\begin{array}{ll}\text { PCP } & \text { Pneumocystis pneumonia } \\ \text { PCR } & \text { Polymerase chain reaction } \\ \text { PCT } & \text { Procalcitonin } \\ \text { PMNs } & \text { Polymorphonuclear neutrophil } \\ \text { ProCaS } & \text { High sensitive procalcitonin } \\ \text { RNA } & \text { Ribo nucleic acid } \\ \text { ROC } & \text { Receiver operating characteristic } \\ \text { RPII } & \text { Reactive type II pneumocyte } \\ \text { RPM } & \text { Revolutions per minute } \\ \text { RSV } & \text { Respiratory syncytial virus } \\ \text { RT-PCR } & \text { Reverse transcriptase polymerase chain reaction } \\ \text { RUNMC } & \text { Radboud university Nijmegen medical center } \\ \text { SD } & \text { Standard deviation } \\ \text { SEM } & \text { Standard error of the mean } \\ \text { SIRS } & \text { Systemic inflammatory response syndrome } \\ \text { SOFA } & \text { Sequential organ failure assessment } \\ \text { S-TREM-1 } & \text { Soluble triggering receptor expressed on myeloid cells type 1 } \\ \text { TCC } & \text { Total cell count } \\ \text { VAP } & \text { Ventilator-associated pneumonia }\end{array}$


List of publications 


\section{List of publications}

1. Linssen CFM, Jacobs JA, Nieman FH, Cornelissen El, Drent M. Use of poly-l-lysine-coated slides in clinical bronchoalveolar lavage fluid samples. Anal Quant Cytol Histol. 2003;25:281-4.

2. Linssen CFM, Jacobs JA, Poletti VE, van Mook WNAK, Cornelissen El, Drent M. Reactive type II pneumocytes in bronchoalveolar lavage fluid. Acta Cytol 2004;48:497-504

3. Linssen CFM, Stappers J, Mochtar B, Jacobs JA. Recurrent endocarditis caused by Streptococcus oralis, Streptococcus bovis, and Enterococcus faecalis Clinical Microbiology Newsletter 2005;27: 96-98

4. Linssen CFM, Jacobs JA, Beckers $P$, Templeton KE, Bakkers J, Kuijper EJ, Melchers WJG, Drent M, Vink C. Inter-laboratory agreement of three real-time PCR assays for the detection of Pneumocystis jiroveci in bronchoalveolar lavage fluid samples. J Med Microbiol 2006;55:1229-1235

5. Linssen CFM, Cornelissen EIM, Jacobs JA. Bronchoalveolaire lavage diagnostiek vanuit microbiologische hoek. VAP Visie 2006;8:11-22

6. Linssen CFM, Cornelissen EIM, Jacobs JA. Laboratoriumdiagnostiek van Pneumocystis jiroveci: mogelijkheden en beperkingen. HIV AIDS nieuwsbulletin 2007;1:13-16

7. Linssen CFM, Vink C, Cornelissen El, Jacobs JA. Pneumocystis jiroveci. van microscopie tot PCR. Ned Tijdschr Med Microbiol 2007:15;62-65

8. Been JV, Linssen CFM, van Iwaarden JF, Zimmermann LJ. Massive bacterial cell invasion and reactive type II pneumocytes in bronchoalveolar lavage fluid from a preterm neonate. Arch Dis Child Fetal Neonatal Ed 2007;92:F319

9. Linmans JJ, Linssen CFM, Stokroos RJ. Mycobacterium abcessus, an uncommon cause of chronic otitis media. Archives of Otolaryngology, Head $\&$ Neck Surgery 
Dankwoord 


\section{Dankwoord}

Op het moment van goedkeuring van dit proefschrift dacht ik dat alle hobbels genomen waren. Echter het dankwoord moest nog geschreven worden. Mijn grootste angst is dat ik op het moment dat dit boekje van de drukker komt erachter kom dat ik iemand vergeten heb te vermelden in mijn dankwoord. Bij deze; mocht ik iemand vergeten zijn te noemen, alsnog bedankt!

Als eerste wil ik mijn promotie team bedanken.

Prof. Dr. C.A. Bruggeman, Cathrien, bij deze wil ik je bedanken dat je me de mogelijkheid hebt gegeven om te promoveren binnen de afdeling medische microbiologie. Bedankt voor het vertrouwen en de stimulerende gesprekken die we de afgelopen jaren gevoerd hebben.

Prof. Dr. M. Drent. Beste Marjolein, ik heb grote bewondering voor de manier waarop jij de zaken regelt. Vooral in het laatste half jaar voor de promotie heb jij mijn directe begeleiding op je genomen om me klaar te stomen voor de verdediging. Ik wil je hartelijk bedanken voor je inzet.

Mijn co-promotor, Prof. Dr. J.A. Jacobs. Beste Jan, als initiatiefnemer van het BAL-onderzoek in Maastricht heb jij altijd een grote rol gespeeld in mijn begeleiding. Ik wil je bedanken voor je steun en de motiverende gesprekken. Jouw enorme vakkennis en kundigheid, niet alleen op gebied van BAL, maakt je tot een groot voorbeeld. I hoop dat ik in de toekomst nog af en toe jouw expertise mag raadplegen.

Behalve mijn promotieteam waren nog een aantal mensen direct betrokken bij de totstandkoming van dit proefschrift. Als eerste Walther van Mook, ondanks dat het mij soms een onbegonnen zaak, leek bleef jij optimistisch over een manuscript. Bedankt voor je suggesties en je inzet! Prof. Dr. V. Poletti, thank you for your participation in my thesis and your suggestions for improvement. Prof. Dr. G. Ramsay, thank you for your contributions to chapter four of my thesis. Jan Schouten, beste Jan, ik wil je bedanken voor al je inzet betreffende hoofdstuk 4 van mijn proefschrift. lk weet dat je er veel werk aan gehad hebt en ik waardeer je inzet enorm. Voor het includeren van patiënten voor hoofdstuk 4 kreeg ik ondersteuning van Miranda. Miranda, bedankt voor je onophoudelijke enthousiasme bij je werk en alle extra taken die je, ook nadat je voor iemand anders werkte, voor mij uitvoerde!

Otto Bekers. Beste Otto, ondanks het feit dat mijn kennis betreffende klinische chemie en het valideren van testen in het begin erg minimaal was, wist jij mij steeds de goede kant op te sturen. Jouw inzet om ons gezamenlijke manuscript gepubliceerd te krijgen heb ik enorm gewaardeerd. Mijn dank! 
Hoofdstuk 6 was niet tot stand gekomen zonder onze samenwerking met de afdeling medische microbiologie van Leiden en Nijmegen. Pieter, Kate, Judith, Ed en Willem; bedankt voor de plezierige samenwerking!

Plezier hebben in je werk is gedeeltelijk afhankelijk van je werkomgeving. Een goede sfeer op een afdeling is essentieel, zeker als je met een aantal mensen op een kamer zit. Wat dat betreft heb ik het altijd getroffen met mijn kamergenoten. Foekje, van mijn huidige kamergenoten was jij er het eerst. lk wil je bedanken voor al je statistische hulp en je stimulerende woorden als ik weer eens zat te mopperen. Steve, ik heb bewondering voor jou vanwege de rust die je uitstraalt en de positieve insteek die je in het leven hebt. Niets lijkt je van je stuk te brengen, ook al moet je 10 keer op een dag je excuses aanbieden! Guy, helaas was het samenleven maar kort, echter jouw gevoel voor humor is niet te evenaren. Bedankt dat je wat leven in de kamer bracht en af en toe voor wat afleiding zorgde! Yvonne, als infectioloog i.o. is misschien niet de meest voor de hand liggende plek voor jou een kamer vol artsmicrobiologen i.o.. Je weet je echter goed staande te houden! Ik heb genoten van onze diepgaande gesprekken die mij altijd weer stimuleerden een nieuw artikel over PCP (of zoals jij altijd zegt: PJP) te schrijven waarvan ik weet dat jou de diepere betekenis niet ontgaat! Bedankt dat je me altijd in mijn visie steunde, ook al werd mijn arm blauw!

En dan tenslotte mijn twee paranymfen: lieve Laura, jouw optimisme heeft menige dag gered. Ik wil je bedanken voor al je steunende woorden en ik ben blij dat jij straks naast me staat! Schattige Suzanne, jij weet altijd precies die (foute) grap te maken om me op te fleuren. In het jaar dat $\mathrm{jij}$ nu in opleiding bent heb je me al veelvuldig geholpen als ik weer eens een vreemd probleem had, waarvoor mijn dank. Ik reken op een paar extra foute grappen in het kamertje!

Toen ik klaar was met mijn opleiding tot arts-microbioloog was er tot mijn vreugde een plekje vrij in Maastricht. Aangezien ik nog zaken af moest maken voor mijn proefschrift kwam het wel eens voor dat collega's zaken van me over namen, zeker toen ik ook nog eens heel handig mijn pols brak! Bij deze wil ik jullie hiervoor bedanken; Ellen, Frank, Helke en Peter, mijn dank! Natuurlijk ook dank aan de virologen, Valère en Inge, en de infectiologen, Annelies, Astrid en Selwyn, voor de motiverende gesprekken en goede werksfeer.

De mensen die zeker niet mogen ontbreken zijn de mensen van het BALgroepje. Met name Lisette. Je leerde me de differentiële celtelling van BAL en alle bijzondere cellen die er in voor kunnen komen herkennen. De tijd die wij samen achter de microscoop hebben doorgebracht was leerzaam en plezierig. Bovendien zijn mijn Nederlandse artikelen door jou leesbaar en (bijna) foutloos 
geworden. Ik hoop dat je niet te veel taalfouten hebt ontdekt in dit dankwoord en wil je bij deze van harte danken voor al je inzet. Ook de andere leden van het BAL-groepje wil ik bedanken voor hun inzet; Yvonne, Nicole en Beth, jullie hulp bij het invriezen en verwerken van de BAL was van essentieel belang. Bovendien heb ik de samenwerking met jullie als groep, zowel in het lab als tijdens werkoverleggen, altijd als erg plezierig ervaren. Mijn dank hiervoor! Ik hoop nog lang met jullie op deze manier samen te kunnen werken.

Behalve bovenstaande mensen van het BAL groepje wil ik de andere medewerkers van de bacteriologie en virologie diagnostiek bedanken voor het interesse dat ze altijd toonden in mijn onderzoek en de stimulerende woorden om me een hart onder de riem te steken! Bovendien wil ik enkele groepsleden bedanken voor het verzinnen van titels en hoop dat het aanbod voor het schillen van aardappelen niet alleen geldt voor een bruiloft maar ook voor het promotiefeestje?! Dus bij deze, in alfabetische volgorde: Anita, Ans D, Ans V, Chantal, Desire, Doré, Ilse, Ineke, Frank C., Frank H., John, Jos, Judith, Kevin, Lucy, Magdalena, Margot, Marielle, Marie-Louise, Myriam Ts, Myriam Tss, Nicole L., Nicole M., Nicole P., Peter, Resi, Robje, Ron, Rosalie, Sabine, Sarah, Veronique en Wanda.

In een deel van mijn proefschrift heb ik gebruik gemaakt van moleculaire technieken, hierin ben ik altijd ondersteund door de mensen van de moleculaire diagnostiek. Eerst onder leiding van Kees Vink, later werd dit overgenomen door Petra Wolfs. Beste Kees, bedankt voor de leuke gesprekken, ze waren misschien niet altijd even klinisch relevant, maar zeker leerzaam! Petra, onze samenwerking zal de komende jaren alleen maar uitgebreider worden. Ik heb bewondering voor de efficiënte manier waarop jij met tijd en personeel om gaat en hoop nog veel (moleculaire) dingen van je te kunnen leren! Ook de analisten moleculaire diagnostiek mogen in dit dankwoord natuurlijk niet ontbreken; Bart, Eric, Hanne, Judith, Lieve en Selma. Bedankt voor het wegwijs maken in de moleculaire technieken en de vele tips waar jullie me van voorzien hebben! Ik wilde deze gelegenheid ook aangrijpen om Moniek te bedanken die een klein jaartje ons team heeft versterkt.

In een dankwoord mogen de mensen die het leven aangenaam maken niet ontbreken; familie en vrienden.

Allereerst mam, ik heb grote bewondering voor $u$ en de manier waarop $u$ uw leven weer heeft opgepakt na het overlijden van pap. Alhoewel mijn leven voor $u$ vaak onbegrijpelijk is heeft $u$ me altijd gesteund in mijn keuzes en stond $u$ altijd voor me klaar. Bedankt voor uw steun en medeleven.

Dan, mijn grote (schoon) broers en (schoon) zussen! Dankzij jullie werd ik al snel ingewijd in het drinken van koffie, kijken naar films ongeschikt voor mijn 
leeftijd en brommer rijden. Ondanks het kleine leeftijdsverschil zijn jullie altijd echte broers en zussen voor me geweest. Ik wil jullie bedanken voor alle steun die ik van jullie ontvangen heb de afgelopen jaren. Ook mijn neefjes en nichtjes, Marc en Vera, Tim en Inge, Patrick en Manon wil ik bij deze bedanken voor de afleidingsmanouvres in het weekend!

Kim, Ritch, Femke, Joost, Kyo en Luna; in de weekends en vakanties hielpen jullie me altijd tijdelijk mijn promoveer stress te vergeten. Van barbecuen op (te) kleine balkons via snowboarden in de woonkamer tot interessante gesprekken met mannen in gele Alfa Romeo jassen, jullie wisten precies die ingrediënten te vinden om me af te leiden van mijn werk.

Soms leer je via je werk mensen kennen waar je zo'n klik mee hebt dat het vrienden worden en blijven nadat ze een andere baan hebben gevonden. Maddy, sinds de dag dat je bij de virologie kwam werken klikte het tussen ons. Ik waardeer je om je directheid en hoop nog vaak samen (met Randy natuurlijk) af te spreken! Eventueel toch maar een tentje en graspop? Laat ik de föhn thuis.

Jeroen, jarenlang hebben we samen op een kamer gebivakkeerd. Ondanks het feit dat onze muziekkeuze niet altijd overeen komt en dat mensen soms denken dat we elkaar (verbaal) aan het afslachten zijn vond ik onze samenwerking altijd heel plezierig en heb ik veel steun gehad aan onze gesprekken over promoveren. Mijn dank!

Annick, natuurlijk hebben we samengewerkt aan het laatste experimentele hoofdstuk van mijn proefschrift en was je daarin een grote steun. Echter ook op persoonlijk vlak heb ik veel aan jou gehad. Ik hoop dat je leven nu in een rustiger vaarwater zal komen en dat ik je nog regelmatig zie!

En dan last, but certainly not least: Ron! Toen ik begon aan dit dankwoord merkte ik dat het niet zo makkelijk was als ik gedacht had. Zoals altijd was jij er om me te steunen en ik weet dat je het liefst het schrijven hiervan van me over had genomen. Maar zie hier; het is me toch gelukt! $\mathrm{lk}$ denk dat ik in alle eerlijkheid kan zeggen dat dit proefschrift er niet had gelegen als jij er niet was geweest. Jij weet als geen ander hoe je me moet stimuleren datgene te doen wat gedaan moet worden, hoe hard ik me er ook tegen verzet! Ik wil jou dan ook bedanken voor je onvoorwaardelijke steun, liefde en vertrouwen in mij. Het laatste wat ik dan ook wil zeggen in dit dankwoord is; mijn vader had absoluut gelijk wat jou betreft! 


\section{Curriculum vitae}




\section{Curriculum Vitae}

Catharina (Kitty) Linssen was born on May 19th 1974 in Roermond, the Netherlands. She graduated from the Atheneum of the Sint Ursula College (Horn) in 1994. Thereafter she studied Medicine at the University of Maastricht where she obtained her medical degree in August 2000. In the same year she started work as a "AGNIO" at the department of Medical Microbiology of the University hospital Maastricht. A year later she began her training as a Medical Microbiologist at the same department. On December $1^{\text {st }} 2006$ she was registered as a Medical Microbiologist. She now works as a staff member at the department of Medical Microbiology of the University hospital Maastricht. The experimental chapters described in this thesis were conducted during the traineeship. She is planning to continue her research towards improving bronchoalveolar lavage fluid as a diagnostic tool in pulmonary infectious diseases. 